\title{
Optimization of Small Molecules that Sensitize HIV-1 Infected Cells to Antibody Dependent Cellular Cytotoxicity
}

Melissa C. Grenier ${ }^{1, \#}$, Shilei Ding, ${ }^{2,3, \#}$, Dani Vézina ${ }^{2,3}$, Jean-Philippe Chapleau ${ }^{2,3}$, William D. Tolbert $^{4}$, Rebekah Sherburn ${ }^{4}$, Arne Schön ${ }^{5}$, Sambasivarao Somisetti ${ }^{6}$, Cameron F. Abrams ${ }^{6}$, Marzena Pazgier ${ }^{4}$, Andrés Finzi ${ }^{2,3, *}$, Amos B. Smith, III ${ }^{1, *}$

\#Equal contribution

${ }^{1}$ Department of Chemistry, University of Pennsylvania, Philadelphia, Pennsylvania, United States

${ }^{2}$ Centre de Recherche du CHUM, Montreal, Quebec, Canada

${ }^{3}$ Département de Microbiologie, Infectiologie et Immunologie, Université de Montréal, Montreal Quebec, Canada

${ }^{4}$ Infections Diseases Division, Uniformed Services University of the Health Sciences, Bethesda, MD, United States

${ }^{5}$ Department of Biology, The Johns Hopkins University, Baltimore, Maryland, United States

${ }^{6}$ Department of Chemical and Biological Engineering, Drexel University, Philadelphia, PA, United States

\section{Corresponding Author}

*ABS, e-mail: smithab@sas.upenn.edu, phone: 215-898-4860

*AF, e-mail: andres.finzi@umontreal.ca

\section{Supporting Information}

\section{Table of Contents}

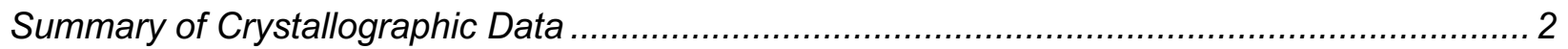

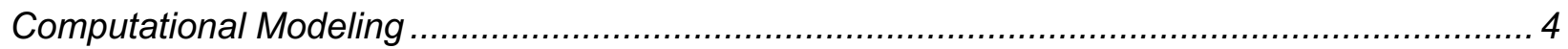

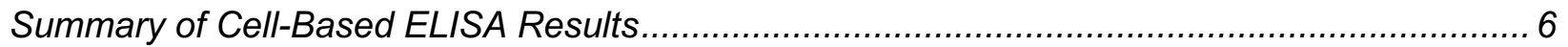

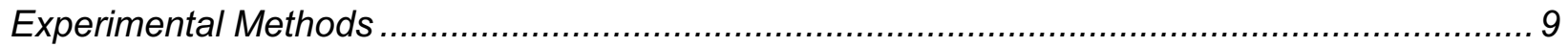

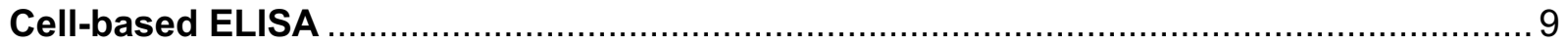

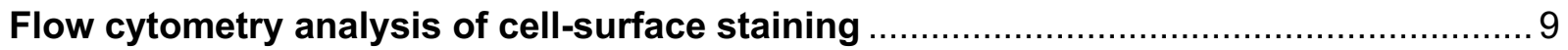

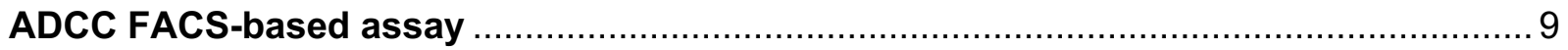

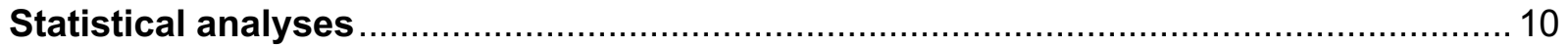

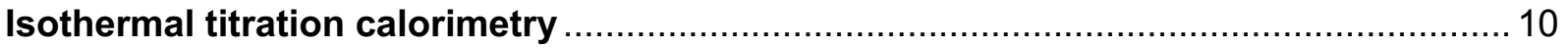

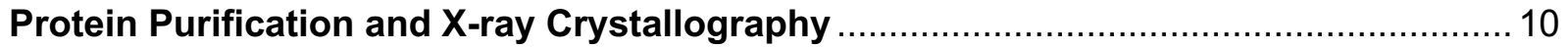

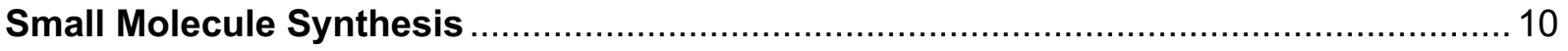




\section{Summary of Crystallographic Data}

Table S1. Data collection and refinement statistics

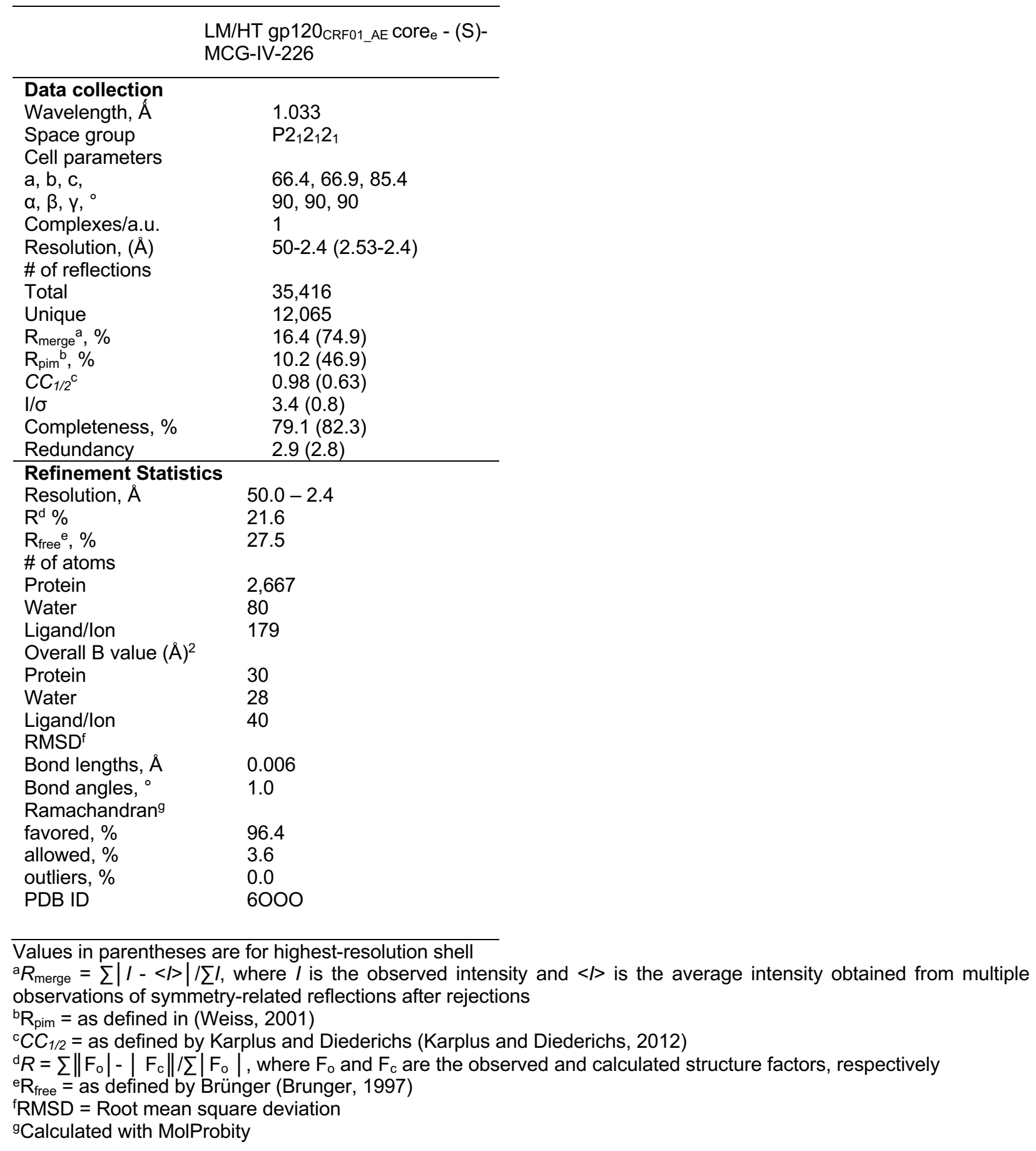



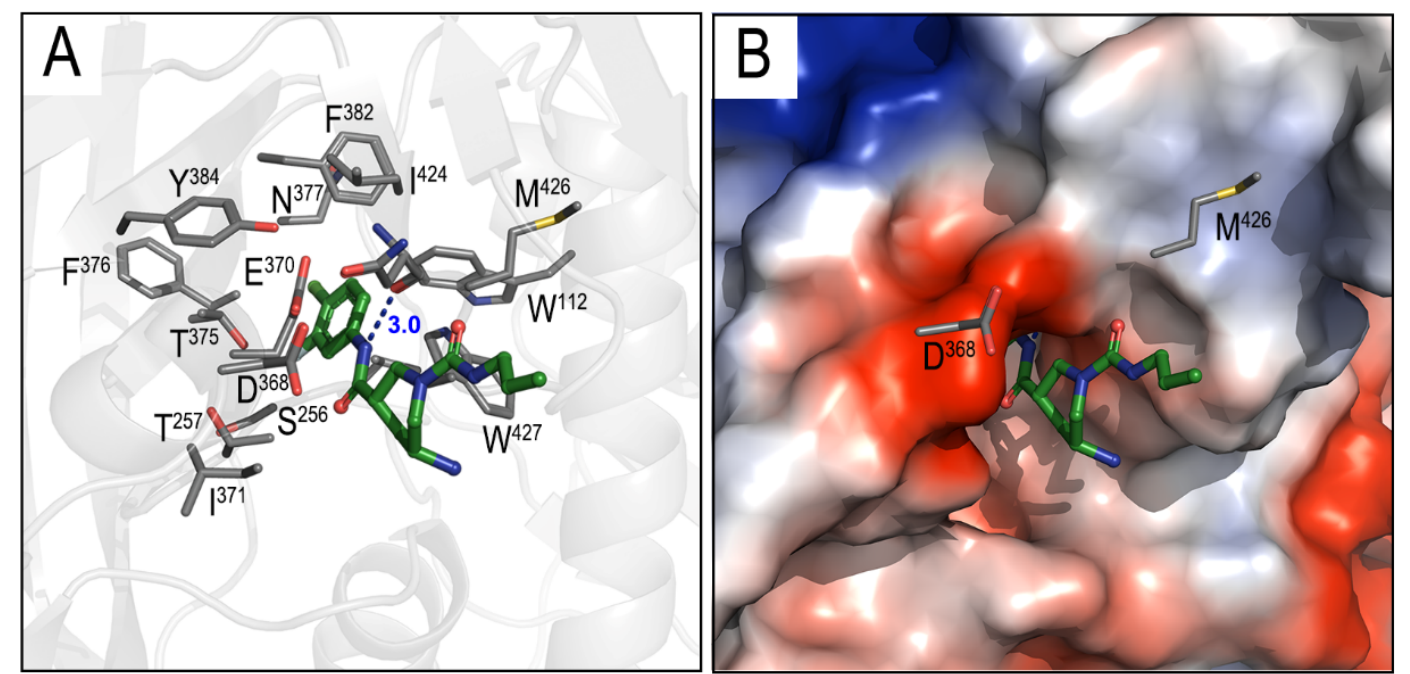

Figure S1. Crystal structure of 21a in complex with LM/HT gp120

(A) Details of 21a interaction with gp120 core. 21a is shown as ribbon-ball-stick and side chains of gp120 residues (as determined by PISA software) contributing to 21a binding are shown as sticks. The $\mathrm{H}$-bond is shown as blue dashes.

(B) Blow-up view into 21a binding pocket. The electrostatic potential is displayed over the molecular surface of gp120 colored red for negative, blue for positive and white for apolar. 21a is shown in a ribbon and stick and $\mathrm{Asp}^{368}$, Gly ${ }^{472}$ and $\mathrm{Met}^{426}$ are shown as sticks. 


\section{Computational Modeling}

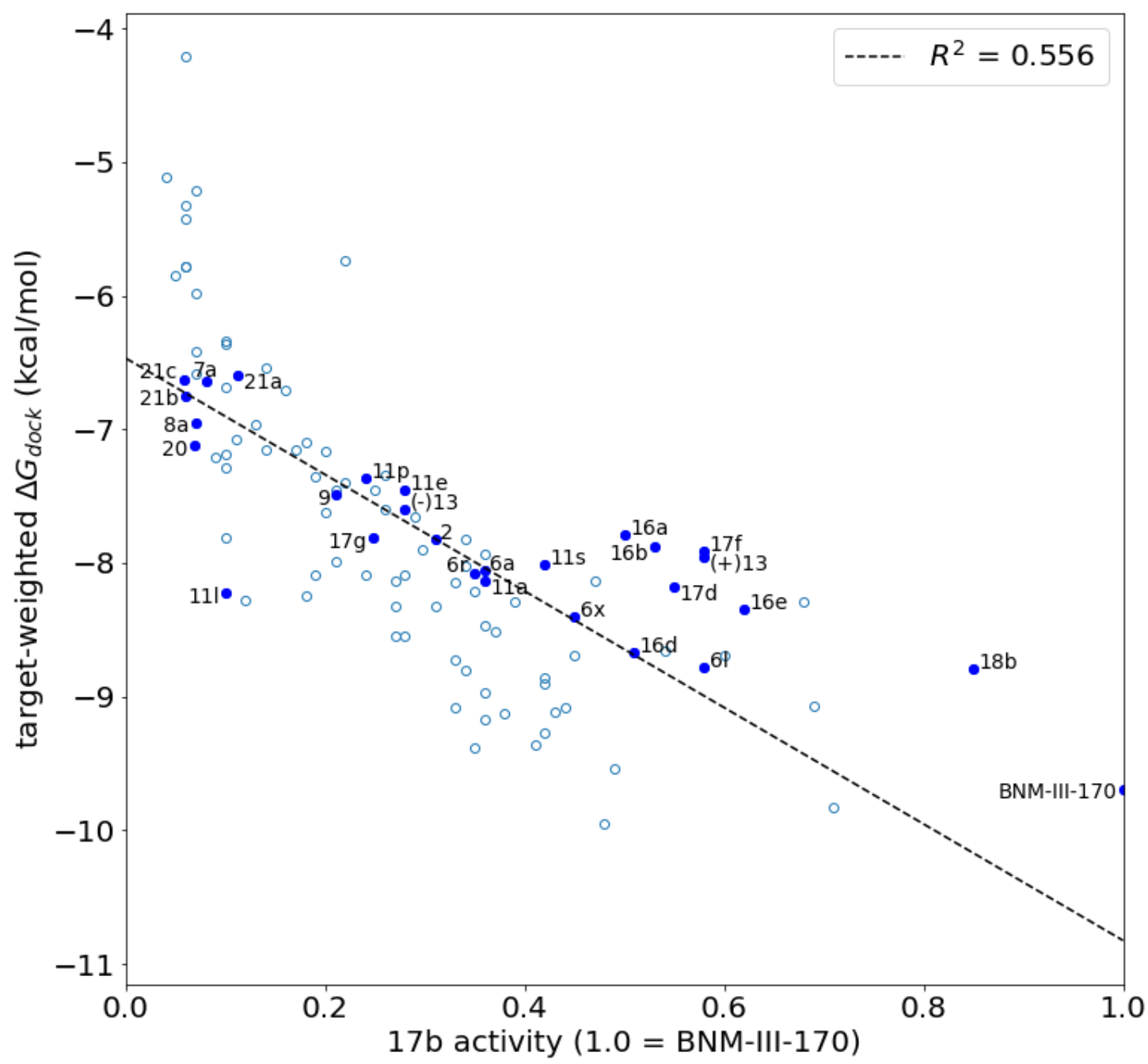

Figure S2. Correlation between 17b binding activity and target-weighted docking scores for all compounds. Solid symbols highlight compounds explicitly presented in the main text, and each is labeled with its unique code. Each target-weighted $\Delta \mathrm{G}$ is a linear combination of scores across seven crystallographic targets, with weights computed such that $\left(R^{2}-1\right)^{2}$ is minimal for a linear fit over all compounds. Schrodinger Suite ${ }^{4}$ and AutoDock ${ }^{5}$ were used docking simulations.

A relationship between $17 \mathrm{~b} \mathrm{CBE}$ and predicted binding affinities $\Delta \mathrm{G}$ of best-aligned conformations with crystallographic ligands is presented in Figure S2. Generally, the better a compound is predicted to bind computationally, the more active it is in the $17 \mathrm{~b}$ assay $\left(R^{2}=0.556\right.$ overall). The compounds that contribute the most to the lower correlation include those with amides and ester linkages, the 4-position regioisomer, and the pyrrolidine, morpholine and piperazine analogs. In particular, docking predictions for compounds 7-11 (Table 1) have favorable binding affinities despite the fact that they have low $17 \mathrm{~b}$ activities. However, compounds 16-18, specifically with carbamate, urea, and guanidine moieties, are predicted to have good binding affinities and high $17 \mathrm{~b}$ activity. Compound $\mathbf{1 8 b}$ is the furthest right point in Figure $\mathrm{S} 2$ and appears to be the most active in the $17 \mathrm{~b}$ assay, and it has a very favorable score. In line with experimental observations, 
our calculations predicted that 3-amino substitutions (compounds 20-21) do not directly $\mathrm{H}$-bond with Asp368 and have very low predicted binding affinities.

Docking scores were computed for all compounds across seven crystallographic targets. Five of these targets are derived from co-crystals with a selection of compounds in this publication and are pending publication (Ding and Grenier et $a l^{6}{ }^{6}$ ), one is unpublished with BNM-III-170 bound (Pazgier, private communication), and one exists in the PDB (5F4P). Protein preparation was carried using Maestro. Bound crystallographic ligands and waters were removed. Missing loops and residues are constructed with Prime module of the Schrodinger Suite, with capped terminal residues. A restrained minimization step was performed using the OPLS_2005 force fields. De novo docking calculations are performed with Autodock software. The structure preparation, run, and analysis of docking simulations are carried out using AutoDock Tools (ADT). The rigid and flexible roots of each ligand were defined in a manner that amide bonds were made nonrotatable. Polar hydrogens and Gasteiger charges were added and subsequently nonpolar hydrogens were merged onto their respective heavy atoms for docking energy evaluations. A grid was placed on the active site region to encompass all amino acid residues surrounding the ligand to be docked in the Phe 43 cavity with a box size at $40 \times 40 \times 44 \AA^{3}$. Autogrid 4 was used to make grid maps with a grid spacing of $0.375 \AA$. Autodock 4 was used to dock the 100 conformers for each ligand using the Lamarckian Genetic Algorithm (LGA) to search for the best conformers. The population size was set to 150 and the energy evaluation was set to 2500000 with default docking parameters were used.

Each target was assigned a weight factor $w_{j}$ such that $\Sigma w_{j}=1$ and the quantity $\left(R^{2}-1\right)^{2}$ is minimized, where $R^{2}$ refers to a linear fit of weighted score $\Sigma w_{j} s_{i j}$ vs. normalized $17 \mathrm{~b}$ activity, where $s_{i j}$ is the docking score of compound $i$ on target $j$. The optimal $R^{2}$ was 0.556 , while the $R^{2}$ for a straight average was 0.49 , and the $R^{2}$ on the single best target was 0.516 . 


\section{Summary of Cell-Based ELISA Results}

Table S2. Cell-Based ELISA Results
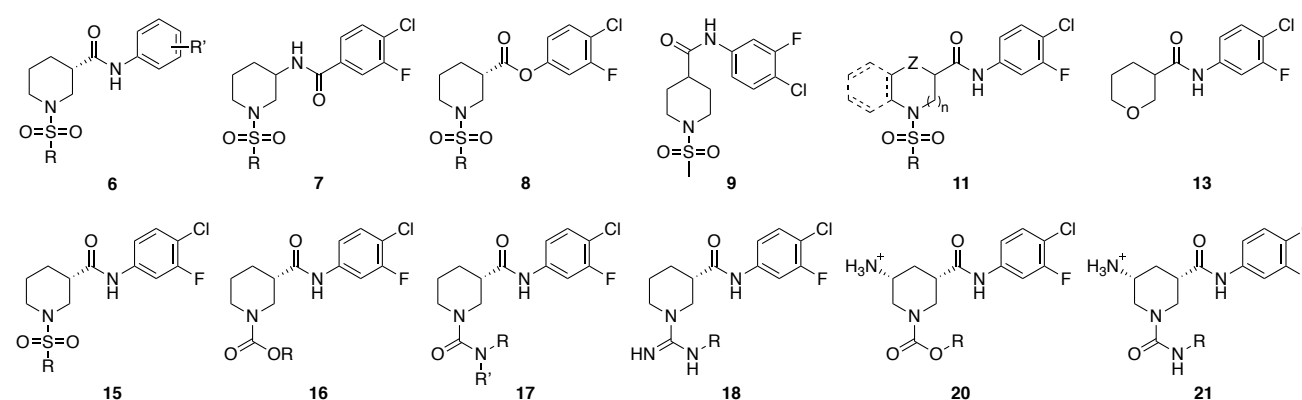

Compound Name

16

(S)-MCG-II-153 2

(R)-MCG-II-156

(S)-MCG-III-027-A02

$6 a$

(S)-MCG-III-027-A03

(S)-MCG-III-027-A04

(S)-MCG-III-027-B01

(S)-MCG-III-027-B02

(S)-MCG-III-027-B03

(S)-MCG-III-027-B04

(S)-MCG-III-027-B05

(S)-MCG-III-027-C01 6

(S)-MCG-III-027-C02 6j

(S)-MCG-III-027-D04 6k

(S)-MCG-III-027-D05 6

(S)-MCG-III-085-A02 6m

$\mathrm{R}$

(S)-MCG-III-085-A03

(S)-MCG-III-085-A04

(S)-MCG-III-085-A05

(S)-MCG-III-085-A06

(S)-MCG-III-085-C01

(S)-MCG-III-085-C02

(S)-MCG-III-085-C03

(S)-MCG-III-085-C04 6u Et

(S)-MCG-III-085-C05 6v Et

(S)-MCG-III-085-C06 6w Et

(S)-MCG-III-085-D01 6x Ph

(S)-MCG-III-085-D02 6y $\quad \mathrm{Ph}$

(S)-MCG-III-085-D03 6z Ph

(S)-MCG-III-085-D04 6aa Ph

(S)-MCG-III-085-D05 6ab $\quad P h$

(S)-MCG-III-085-D06 6ac Ph

(S)-MCG-III-116-A01

$15 a$

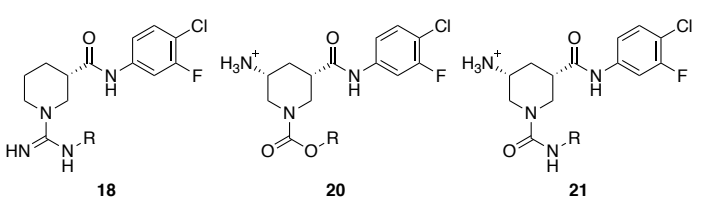

${ }^{18} \mathrm{R}^{\prime}$

4-Cl

4-Cl

4-Br

4-F

4-CF 3

3-Cl

$3-\mathrm{Br}$

3-F

$3-\mathrm{CF}_{3}$

3-OMe

2-Cl

2-OMe

2,4-diF

4-Cl-3-F

$3-\mathrm{Cl}-4-\mathrm{F}$

3,4-diCl

3,4-diF

3-Br-4-Cl

$4-\mathrm{Br}-3-\mathrm{Cl}$

4-Cl-3-F

3-Cl-4-F

3,4-diCl

3,4-diF

3-Br-4-Cl

4-Br-3-Cl

4-Cl-3-F

Z

n Fused Ring

$17 \mathrm{~b}$ binding ${ }^{a}$

$0.20 / 0.31$

0.08

0.36

0.12

0.17

0.10

0.10

0.13

0.07

0.06

0.06

0.14

0.07

$0.46 / 0.58$

0.22

0.19

0.10

0.16

0.14

0.35

0.20

0.25

0.26

0.26

0.34

0.45

0.18

0.20

3,4-diCl

0.28

3,4-diF

0.10

0.19

4-Br-3-Cl

0.41 


\begin{tabular}{|c|c|c|c|c|c|c|c|}
\hline (S)-MCG-III-116-A02 & $15 b$ & N-Me Imidazole & $4-\mathrm{Cl}-3-\mathrm{F}$ & - & - & - & 0.24 \\
\hline (S)-MCG-III-116-A03 & $15 c$ & Cyclohexyl & $4-\mathrm{Cl}-3-\mathrm{F}$ & - & - & - & 0.36 \\
\hline (S)-MCG-III-116-A05 & $15 d$ & 4-OMe-Ph & $4-\mathrm{Cl}-3-\mathrm{F}$ & - & - & - & 0.29 \\
\hline (S)-MCG-III-116-A06 & $15 \mathrm{e}$ & $4-\mathrm{CN}-\mathrm{Ph}$ & $4-\mathrm{Cl}-3-\mathrm{F}$ & - & - & - & 0.31 \\
\hline (S)-MCG-III-117 & $15 f$ & 4-(NHC(O)Me)-Ph & $4-\mathrm{Cl}-3-\mathrm{F}$ & - & - & - & 0.21 \\
\hline (S)-MCG-III-132 & $15 g$ & $\mathrm{CF}_{3}$ & $4-\mathrm{Cl}-3-\mathrm{F}$ & - & - & - & 0.27 \\
\hline (S)-MCG-III-128 & $15 \mathrm{~h}$ & 4-Br-Ph & $4-\mathrm{Cl}-3-\mathrm{F}$ & - & - & - & 0.21 \\
\hline (士)-MCG-III-157-C01 & $7 a$ & $\mathrm{Me}$ & - & - & - & No & 0.08 \\
\hline (士)-MCG-III-157-C02 & $7 b$ & Et & - & - & - & No & 0.07 \\
\hline (士)-MCG-III-157-C04 & 7c & N-Me Imidazole & - & - & - & No & 0.04 \\
\hline (S)-MCG-III-213-A01 & $8 a$ & $\mathrm{Me}$ & - & - & - & No & 0.07 \\
\hline (S)-MCG-III-213-A02 & $8 b$ & Et & - & - & - & No & 0.07 \\
\hline (S)-MCG-III-213-A03 & $8 c$ & $\mathrm{Ph}$ & - & - & - & No & 0.05 \\
\hline (S)-MCG-III-213-A04 & $8 d$ & N-Me Imidazole & - & - & - & No & 0.10 \\
\hline MCG-III-101 & 9 & - & - & - & - & No & 0.21 \\
\hline (士)-MCG-III-196 & $10 a$ & - & - & $\mathrm{O}$ & 1 & No & 0.34 \\
\hline (士)-MCG-III-210 & $10 \mathrm{~b}$ & - & - & NBoc & 1 & No & 0.22 \\
\hline (士)-MCG-III-216-A01 & $10 c$ & - & - & $\mathrm{NH}$ & 1 & No & 0.21 \\
\hline (士)-MCG-III-209 & $10 \mathrm{~d}$ & - & - & - & - & Yes & 0.42 \\
\hline (士)-MCG-III-157-A01 & $11 a$ & $\mathrm{Me}$ & - & $\mathrm{CH}_{2}$ & 0 & No & 0.36 \\
\hline (士)-MCG-III-157-A02 & $11 b$ & Et & - & $\mathrm{CH}_{2}$ & 0 & No & 0.27 \\
\hline (士)-MCG-III-157-A03 & $11 \mathrm{c}$ & $\mathrm{Ph}$ & - & $\mathrm{CH}_{2}$ & 0 & No & 0.33 \\
\hline (士)-MCG-III-157-A04 & $11 d$ & N-Me Imidazole & - & $\mathrm{CH}_{2}$ & 0 & No & 0.34 \\
\hline (士)-MCG-III-211-A01 & $11 \mathrm{e}$ & $\mathrm{Me}$ & - & $\mathrm{O}$ & 1 & No & 0.28 \\
\hline (士)-MCG-III-211-A02 & $11 f$ & Et & - & $\mathrm{O}$ & 1 & No & 0.33 \\
\hline (士)-MCG-III-211-A03 & $11 \mathrm{~g}$ & $\mathrm{Ph}$ & - & $\mathrm{O}$ & 1 & No & 0.28 \\
\hline (士)-MCG-III-211-A04 & $11 \mathrm{~h}$ & N-Me Imidazole & - & $\mathrm{O}$ & 1 & No & 0.35 \\
\hline (士)-MCG-III-212-A01 & $11 i$ & $\mathrm{Me}$ & - & NBoc & 1 & No & 0.06 \\
\hline (士)-MCG-III-212-A03 & $11 \mathrm{j}$ & $\mathrm{Ph}$ & - & NBoc & 1 & No & 0.06 \\
\hline (士)-MCG-III-212-A04 & $11 \mathrm{k}$ & N-Me Imidazole & - & NBoc & 1 & No & 0.06 \\
\hline (士)-MCG-III-216-A02 & 111 & $\mathrm{Me}$ & - & $\mathrm{NH}$ & 1 & No & 0.10 \\
\hline (士)-MCG-III-212-A02 & $11 \mathrm{~m}$ & Et & - & $\mathrm{NH}$ & 1 & No & 0.36 \\
\hline (士)-MCG-III-216-A03 & $11 n$ & $\mathrm{Ph}$ & - & $\mathrm{NH}$ & 1 & No & 0.11 \\
\hline (士)-MCG-III-216-A04 & 110 & N-Me Imidazole & - & $\mathrm{NH}$ & 1 & No & 0.10 \\
\hline (士)-MCG-III-214-A01 & $11 p$ & $\mathrm{Me}$ & - & $\mathrm{CH}_{2}$ & 1 & Yes & 0.24 \\
\hline (士)-MCG-III-214-A03 & $11 q$ & $\mathrm{Ph}$ & - & $\mathrm{CH}_{2}$ & 1 & Yes & 0.09 \\
\hline (士)-MCG-III-214-A04 & $11 r$ & N-Me Imidazole & - & $\mathrm{CH}_{2}$ & 1 & Yes & 0.18 \\
\hline (士)-MCG-III-157-B01 & $11 \mathrm{~s}$ & $\mathrm{Me}$ & - & $\mathrm{CH}_{2}$ & 1 & No & 0.42 \\
\hline (士)-MCG-III-157-B02 & $11 t$ & Et & - & $\mathrm{CH}_{2}$ & 1 & No & 0.68 \\
\hline (士)-MCG-III-157-B03 & $11 u$ & $\mathrm{Ph}$ & - & $\mathrm{CH}_{2}$ & 1 & No & 0.43 \\
\hline (士)-MCG-III-157-B04 & $11 v$ & N-Me Imidazole & - & $\mathrm{CH}_{2}$ & 1 & No & 0.69 \\
\hline (士)-MCG-III-207 & 13 & - & - & - & - & - & 0.48 \\
\hline (+)-MCG-III-207 & $(+)-13$ & - & - & - & - & - & 0.58 \\
\hline (-)-MCG-III-207 & $(-)-13$ & - & - & - & - & - & 0.28 \\
\hline
\end{tabular}




\begin{tabular}{|c|c|c|c|c|c|c|c|}
\hline (S)-MCG-III-115 & 14 & - & - & - & - & - & 0.39 \\
\hline (S)-MCG-III-188-A01 & $16 a$ & $\mathrm{Me}$ & - & - & - & - & 0.50 \\
\hline (S)-MCG-III-188-A02 & $16 \mathrm{~b}$ & $\mathrm{Et}$ & - & - & - & - & 0.53 \\
\hline (S)-MCG-III-188-A03 & $16 \mathrm{c}$ & $\mathrm{Ph}$ & - & - & - & - & 0.47 \\
\hline (S)-MCG-IV-058 & $16 d$ & $n-\operatorname{Pr}$ & - & - & - & - & 0.51 \\
\hline (S)-MCG-IV-061 & $16 e$ & $i$-Bu & - & - & - & - & 0.62 \\
\hline (S)-MCG-IV-267 & $16 f$ & $\left(\mathrm{CH}_{2}\right)_{2} \mathrm{NH}_{3}{ }^{+}$ & - & - & - & - & 0.30 \\
\hline (S)-MCG-IV-031-A02 & $17 a$ & Et & $\mathrm{H}$ & - & - & - & 0.37 \\
\hline (S)-MCG-IV-031-A03 & $17 \mathrm{~b}$ & $\mathrm{Me}$ & $\mathrm{Me}$ & - & - & - & 0.71 \\
\hline (S)-MCG-IV-031-A04 & $17 \mathrm{c}$ & Et & $\mathrm{Me}$ & - & - & - & 0.54 \\
\hline (S)-MCG-IV-031-A05 & $17 \mathrm{~d}$ & $n-\operatorname{Pr}$ & $\mathrm{H}$ & - & - & - & 0.55 \\
\hline (S)-MCG-IV-031-A06 & $17 \mathrm{e}$ & $i$-Bu & $\mathrm{H}$ & - & - & - & 0.42 \\
\hline (S)-MCG-IV-210 & $17 f$ & $\left(\mathrm{CH}_{2}\right)_{2} \mathrm{NH}_{3}{ }^{+}$ & - & - & - & - & 0.58 \\
\hline (S)-MCG-IV-211 & $17 \mathrm{~g}$ & $\left(\mathrm{CH}_{2}\right)_{3} \mathrm{NH}_{3}{ }^{+}$ & & & & & 0.25 \\
\hline (S)-MCG-IV-053-A01 & $18 a$ & $\mathrm{Me}$ & - & - & - & - & 0.42 \\
\hline (S)-MCG-IV-053-A05 & $18 \mathrm{~b}$ & $n-\operatorname{Pr}$ & - & - & - & - & 0.85 \\
\hline (S)-MCG-IV-053-A06 & $18 \mathrm{c}$ & $i$-Bu & - & - & - & - & 0.60 \\
\hline (3R,5S)-MCG-IV-272 & 20 & $\left(\mathrm{CH}_{2}\right)_{2} \mathrm{NH}_{3}^{+}$ & - & - & - & - & 0.07 \\
\hline (3R,5S)-MCG-IV-226 & $21 a$ & $n-\operatorname{Pr}$ & - & - & - & - & 0.11 \\
\hline (3R,5S)-MCG-IV-273 & 21b & $\left(\mathrm{CH}_{2}\right)_{2} \mathrm{NH}_{3}^{+}$ & - & - & - & - & 0.06 \\
\hline (3R,5S)-MCG-IV-274 & $21 \mathrm{c}$ & $\left(\mathrm{CH}_{2}\right)_{3} \mathrm{NH}_{3}^{+}$ & - & - & - & - & 0.06 \\
\hline (S)-MCG-IV-024-A02 & S30a & $\mathrm{Me}$ & - & - & - & - & 0.38 \\
\hline (S)-MCG-IV-024-B02 & S30b & Et & - & - & - & - & 0.36 \\
\hline (S)-MCG-IV-050-A01 & S32a & $\mathrm{Me}$ & - & - & - & - & 0.44 \\
\hline (S)-MCG-IV-050-A02 & S32b & Et & - & - & - & - & 0.49 \\
\hline (S)-MCG-IV-063-A01 & S33a & $\mathrm{Me}$ & $\mathrm{H}$ & - & - & - & 0.33 \\
\hline (S)-MCG-IV-063-A02 & S33b & Et & $\mathrm{H}$ & - & - & - & 0.35 \\
\hline (S)-MCG-IV-063-A03 & S33c & $\mathrm{Me}$ & $\mathrm{Me}$ & - & - & - & 0.48 \\
\hline (S)-MCG-IV-063-A05 & S33e & $n \mathrm{Pr}$ & $\mathrm{H}$ & - & - & - & 0.45 \\
\hline (S)-MCG-IV-063-A06 & S33f & $i \mathrm{Bu}$ & $\mathrm{H}$ & - & - & - & 0.36 \\
\hline
\end{tabular}

aThe fold over BNM-III-170 (5 $\mu \mathrm{M})$ of Cell-Based ELISA with MCG Analogs (50 $\mu \mathrm{M})$ - 17b readout, $2 \mathrm{G} 12$ and DMSO normalized ( $17 \mathrm{~b}$ binding in presence of BNM-III-170 $=1$ and in the absence of CD4mc is <0.05). Values reported represent the average of experiments performed in quadruplicate.

\section{Experimental Methods}

\section{Cell-based ELISA}

Detection of trimeric HIV-1 JRFLEnv $\triangle \mathrm{CT}$ at the surface of HOS cells was performed by cell-based ELISA, as previously described. ${ }^{7}$ Briefly, HOS cells were seeded in T-75 flasks $\left(3 \times 10^{6}\right.$ cells per flask) and transfected the next day with $22.5 \mu \mathrm{g}$ of Env-expressing plasmids using the standard polyethylenimine (PEI, Polyscience Inc, PA, USA) transfection method. Twenty-four hours after transfection, cells were plated in 384 -wells plates ( $2 \times 10^{4}$ cells per well). One day later, cells were incubated in blocking buffer (washing buffer [25 mM Tris, ph 7.5, $1.8 \mathrm{mM} \mathrm{CaCl} 2,1.0 \mathrm{mM} \mathrm{MgCl}$, $\mathrm{pH} 7.5$ and $140 \mathrm{mM} \mathrm{NaCl}$ ] supplemented with $10 \mathrm{mg} / \mathrm{ml}$ non-fat dry milk and $5 \mathrm{mM}$ Tris $\mathrm{pH}$ 8.0) for 30 minutes and then co-incubated for $1 \mathrm{~h}$ at room temperature with either the anti-CoRBS $17 \mathrm{~b}$ $\mathrm{Ab}$ or the bNAb $2 \mathrm{G} 12(1 \mu \mathrm{g} / \mathrm{ml})$ and with the compounds $(50 \mu \mathrm{M})$, sCD4 $(10 \mu \mathrm{g} / \mathrm{ml})$ or the 
compounds' vehicle (DMSO) diluted in blocking buffer. A horseradish peroxidase-conjugated antibody specific for the Fc region of human IgG (Pierce) was then incubated with the samples for 45 minutes at room temperature. For all conditions, cells were washed 5 times with blocking buffer and 5 times with washing buffer. HRP enzyme activity was determined after the addition of $20 \mu \mathrm{l}$ per well of a 1:1 mix of Western Lightning oxidizing and luminol reagents (Perkin Elmer Life Sciences). Light emission was measured with an LB 941 TriStar luminometer (Berthold Technologies). 17b binding results presented in Table 1 and Table S2 were normalized to those obtained in the presence of the small CD4-mimetic BNM-III-170 (17b binding in presence of BNM$\mathrm{III}-170=1$ and in the absence of CD4mc is <0.05).

\section{Flow cytometry analysis of cell-surface staining}

Cell surface staining was performed as previously described. ${ }^{8}$ Primary CD4 T cells were isolated

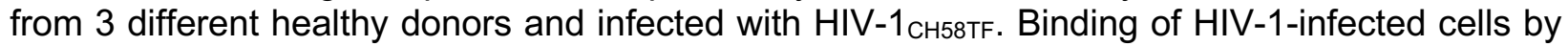
sera $(1: 1,000$ dilution) or antibodies $(5 \mu \mathrm{g} / \mathrm{ml})$ in the presence or absence of $50 \mu \mathrm{M}$ compounds was performed 48 hours after infection. Cells were then incubated at $37^{\circ} \mathrm{C}$ for 1 hour followed by adding anti-human Alexa Fluor-647 (Invitrogen) secondary Abs for 20 minute. Primary CD4 T cells infected with HIV-1 $1_{\mathrm{CH} 58 \mathrm{TF}}$ were then stained intracellularly for HIV-1 p24, using the Cytofix/Cytoperm Fixation/ Permeabilization Kit (BD Biosciences, Mississauga, ON, Canada) and the fluorescent anti-p24 mAb (PE-conjugated anti-p24, clone KC57; Beckman Coulter/Immunotech). The percentage of infected or transfected cells (p24+ cells or GFP+, respectively) was determined by gating the living cell population on the basis of the AquaVivid viability dye staining. Samples were analyzed on an LSRII cytometer (BD Biosciences), and data analysis was performed using FlowJo vX.0.7 (Tree Star, Ashland, OR, USA).

\section{ADCC FACS-based assay}

Measurement of ADCC using the FACS-based assay was performed at $48 \mathrm{~h}$ post-infection as previously described. ${ }^{8,9,10}$ Briefly, HIV-1 ${ }_{\mathrm{CH} 58 \mathrm{TF}}$ infected primary CD4+ T cells were stained with viability (AquaVivid; Thermo Fisher Scientific) and cellular (cell proliferation dye eFluor670; eBioscience) markers and used as target cells. Autologous PBMC effectors cells, stained with another cellular marker (cell proliferation dye eFluor450; eBioscience), were added at an effector: target ratio of 10:1 in 96-well V-bottom plates (Corning, Corning, NY). Briefly, infected primary CD4+ T cells were incubated with HIV+ sera (1:1000), in the presence of $50 \mu \mathrm{M}$ of compounds or with equivalent volume of vehicle (DMSO). The plates were subsequently centrifuged for $1 \mathrm{~min}$ at $300 \mathrm{~g}$, and incubated at $37^{\circ} \mathrm{C}, 5 \% \mathrm{CO} 2$ for 4 to $6 \mathrm{~h}$ before being fixed in a $2 \%$ PBS-formaldehyde solution. Samples were analyzed on an LSRII cytometer (BD Biosciences). Data analysis was performed using FlowJo vX.0.7 (Tree Star). The percentage of ADCC was calculated with the following formula: (\% of p24+ cells in Targets plus Effectors) - (\% of p24+ cells in Targets plus Effectors plus sera) / (\% of p24+ cells in Targets) by gating on infected lived target cells.

\section{Statistical analyses}

Statistics were analyzed using GraphPad Prism version 6.01 (GraphPad, San Diego, CA, USA). Every data set was tested for statistical normality and this information was used to apply the appropriate (parametric or nonparametric) statistical test. $P$ values $<0.05$ were considered significant; significance values are indicated as ${ }^{*} p<0.05,{ }^{* *} p<0.01,{ }^{* * *} p<0.001,{ }^{* * * *} p<0.0001$.

\section{Isothermal titration calorimetry}

Isothermal titration calorimetry (ITC) was carried out using a VP- ITC microcalorimeter from MicroCal/Malvern Instruments (Northampton, MA, USA). In all titration experiments, the gp120 and the different inhibitors were equilibrated with PBS, pH 7.4, with $2 \%$ DMSO. The titrations were performed at $25^{\circ} \mathrm{C}$ by injecting $10 \mu \mathrm{L}$ aliquots of inhibitor solution into the calori- metric cell 
(volume $\sim 1.4 \mathrm{~mL}$ ) containing gp120 at a concentration of $2 \mu \mathrm{M}$. The inhibitor concentration was $30-60 \mu \mathrm{M}$. The heat evolved upon each injection of inhibitor was obtained from the integral of the calorimetric signal. The heat associated with binding to gp120 in the cell was obtained by subtracting the heat of dilution from the heat of reaction. The individual heats were plotted against the molar ratio, and the enthalpy change $(\Delta \mathrm{H})$ and association constant $(\mathrm{Ka}=1 / \mathrm{Kd})$ were obtained by nonlinear regression of the data. The change in Gibbs energy $(\Delta G)$ was calculated from the affinity according to the relation $\Delta \mathrm{G}=-\mathrm{RT}$ In $\mathrm{Ka}$, where $\mathrm{Ka}$ is the association constant $(\mathrm{Ka}=$ $1 / \mathrm{Kd}), \mathrm{R}$ is the gas constant $(1.987 \mathrm{cal} /(\mathrm{K} \cdot \mathrm{mol}))$, and $\mathrm{T}$ is the ab- solute temperature in kelvin. $\mathrm{T} \Delta \mathrm{S}$ was calculated from the relation $\Delta \mathrm{G}=\Delta \mathrm{H}-\mathrm{T} \Delta \mathrm{S}$.

\section{Protein Purification and X-ray Crystallography}

\section{CRF01_AE core e expression and purification}

Plasmids encoding the layers mutant gp120 extended core (core e $_{\text {) }}$ protein, LM/HT gp120 CRF01_AE $_{\text {A }}$ core $_{e}$, were transfected into $\mathrm{GnT}^{-}$cells using Xtremegene (SigmaAldrich) transfection reagent as per manufacturer's instruction. Following seven days of culture growth at $37^{\circ} \mathrm{C}$ and $8 \% \mathrm{CO} 2$, cell supernatant was filtered and passed over a $17 \mathrm{~b}$ affinity column to isolate expressed gp 120. gp120 was eluted with $0.1 \mathrm{M}$ glycine $\mathrm{pH} 3.0$ into tubes containing $1 \mathrm{M}$ Tris- $\mathrm{HCl} \mathrm{pH} 8.5$ to immediately raise the $\mathrm{pH}$. The protein was then deglycosylated with 10 units/ $\mu \mathrm{g}$ of Endo $\mathrm{H}_{\mathrm{f}}(\mathrm{NE}$ Biolabs) overnight at $37^{\circ} \mathrm{C}$. Endo $\mathrm{H}_{\mathrm{f}}$ was removed by passage over an amylose resin column followed by gel filtration chromatography on a Superdex 200 16/60 column (GE Healthcare, Piscataway, $\mathrm{NJ}$ ) equilibrated with $5 \mathrm{mM}$ Tris- $\mathrm{HCl} \mathrm{pH} 7.2$ and $150 \mathrm{mM}$ sodium chloride. The protein was concentrated to approximately $5 \mathrm{mg} / \mathrm{ml}$ for use in crystallization trials.

\section{Crystallization of gp120 LM-HT cores complex with CD4mc}

Deglycosylated LM/HT gp120 ${ }_{\text {CRF01_AE }}$ core $(5 \mathrm{mg} / \mathrm{ml})$ was crystalized by the hanging drop method in 5-10\% PEG 1500, 6\% PEG 400 and $0.1 \mathrm{M}$ HEPES pH7.5. Crystals were allowed to grow fully prior to soaking with CD4 mimetic. All mimetics were solubilized with DMSO at a concentration of $10 \mathrm{mM}$ and diluted with crystallization buffer to $100 \mathrm{nM}$ prior to use in crystal soaks. Briefly, $0.4 \mu \mathrm{l}$ of $100 \mathrm{nM}$ mimetic was added to the $0.4 \mu \mathrm{l}$ hanging drop containing the gp120 crystals prior to incubation for 4 hours. Crystals were then flash frozen in liquid nitrogen following a brief soak in crystallization buffer containing 15\% MPD for cryoprotection and $50 \mathrm{nM}$ of the CD4 mimetic.

\section{Small Molecule Synthesis}

\section{General Information}

All reactions were conducted in oven-dried glassware under an inert atmosphere of nitrogen, unless otherwise stated. All solvents were reagent or high-performance liquid chromatography (HPLC) grade. Anhydrous $\mathrm{CH}_{2} \mathrm{Cl}_{2}$, toluene, ether and THF were obtained from the Pure Solve ${ }^{\mathrm{TM}}$ PS-400 system under an argon atmosphere. All reagents were purchased from commercially available sources and used as received. Reactions were magnetically stirred under a nitrogen atmosphere, unless otherwise noted and reactions were monitored by either thin layer chromatography (TLC) with $250 \mu \mathrm{m}$ SiliaPlate ${ }^{\mathrm{TM}}$ pre-coated TLC plates or analytical ultraperformance liquid chromatography (UPLC). Yields refer to chromatographically or spectroscopically pure compounds. Optical rotations were measured on a JASCO P-2000 polarimeter. Proton $\left({ }^{1} \mathrm{H}\right)$ and carbon $\left({ }^{13} \mathrm{C}\right)$ NMR spectra were recorded on a Bruker Avance III $500-\mathrm{MHz}$ spectrometer. Chemical shifts $(\delta)$ are reported in parts per million (ppm) relative to chloroform $(\delta 7.26)$, dimethyl sulfoxide $(\delta 2.50)$, acetone $(\delta 2.05)$, methanol $(\delta 3.31)$, or acetonitrile $\left(\delta\right.$ 1.94) for ${ }^{1} \mathrm{H} N M R$, and chloroform $(\delta 77.0)$, dimethyl sulfoxide $(\delta 39.4)$, acetone $(\delta 29.8)$ or 
methanol ( $\delta 49.0)$ for ${ }^{13} \mathrm{C}$ NMR. Accurate mass measurements (AMM) were recorded at the University of Pennsylvania Mass Spectroscopy Service Center on either a Waters LCT Premier XE LC/MS or a Waters GC-TOF Premier system. Preparative scale UPLC was performed with a Waters AutoPurification system equipped with: a Sunfire C18 OBD column (10 $\mu \mathrm{m}$ packing material, 30 x $150 \mathrm{~mm}$ column dimensions); a 2767 sample manager; a 2545 binary gradient module; a system fluidics organizer; a 2489 UV-Vis dual wavelength (210 and $254 \mathrm{~nm}$ ) detector; and MassLynx software with the FractionLynx application manager. Solvent systems were comprised of $\mathrm{H}_{2} \mathrm{O}$ and acetonitrile containing $0.1 \%$ trifluoroacetic acid. Evaporation was performed using a Genevac EZ-2 Plus Evaporating System. SFC analyses were performed with a JASCO system equipped with a PU-280- $\mathrm{CO}_{2}$ plus $\mathrm{CO}_{2}$ Delivery System, a $\mathrm{CO}-2060$ plus Intelligent Column Thermostat/Selector, an HC-2068-01 Heater Controller, a BP-2080 plus Automatic Back Pressure Regulator, an MD-2018 plus Photodiode Array Detector (200-648 nm), and PU 2080 plus Intelligent HPLC Pumps. The purity of new compounds was judged by NMR and LCMS (>95\%). 


\section{Experimental Procedures}

Synthesis of (S)-MCG-II-153 (2)

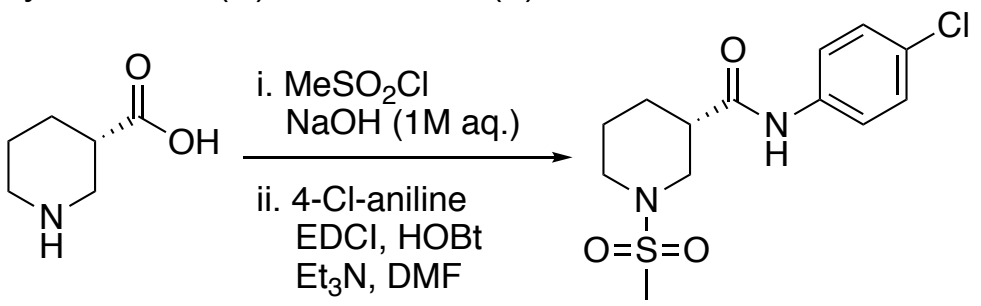

i. To a precooled $\left(0^{\circ} \mathrm{C}\right)$ solution of $(\mathrm{S})$-3-piperidinecarboxylic acid (100. $\mathrm{mg}, 0.774$ $\mathrm{mmol})$ in $1 \mathrm{M}$ aq. $\mathrm{NaOH}(3.8 \mathrm{~mL})$ under $\mathrm{N} 2$ atmosphere was added dropwise methanesulfonyl chloride $(0.07 \mathrm{~mL}, 0.9 \mathrm{mmol})$. The resulting mixture was stirred at 0 ${ }^{\circ} \mathrm{C}$ for $2 \mathrm{~h}$, then allowed to warm to room temperature and stirred for $2 \mathrm{~h}$. The aqueous solution was washed with ether then acidified with $1 \mathrm{~N}$ aq. $\mathrm{HCl}$ to $\mathrm{pH} 3$ and diluted with EtOAc. The layers were separated, and the aqueous phase was extracted with EtOAc (3x) then iPrOH: $\mathrm{CHCl} 3(30: 70,3 x)$. The combined organic layers were dried over MgSO4, and concentrated in vacuo to afford the desired product, which was carried forward without additional purification (30 mg, crude 14\% yield).

ii. To a precooled $\left(0^{\circ} \mathrm{C}\right)$ solution of $(S)$-mesylated piperidine intermediate $(16 \mathrm{mg}$, $0.077 \mathrm{mmol})$, 4-chloroaniline (9.8 $\mathrm{mg}, 0.077 \mathrm{mmol})$, 1-ethyl-3-(3dimethylaminopropyl)carbodiimide hydrochloride $(22 \mathrm{mg}, 0.12 \mathrm{mmol}$ ) and 1hydroxybenzotriazole hydrate $(10 . \mathrm{mg}, 0.077 \mathrm{mmol})$ in DMF $(0.8 \mathrm{~mL})$ under $\mathrm{N}_{2}$ atmosphere was added triethylamine $(0.01 \mathrm{~mL}, 0.08 \mathrm{mmol})$. The resulting solution was allowed to warm to room temperature and stirred for $18 \mathrm{~h}$, then concentrated in vacuo. The resulting residue was taken up in EtOAc and $\mathrm{H}_{2} \mathrm{O}$. The layers were separated, and the aqueous phase was extracted with EtOAc (3x). The combined organic layers were washed with brine, dried over $\mathrm{MgSO}_{4}$, and concentrated in vacuo. Flash chromatography $\left(\mathrm{SiO}_{2}, 50: 50\right.$ hexanes: EtOAc) afforded the product as a white solid (15 mg, $70 \%$ yield, $89.5 \%$ ee). [ $[\alpha]_{\mathrm{D}}{ }^{22}+6.75$ (c. $0.14, \mathrm{CH}_{3} \mathrm{OH}$ ); ${ }^{1} \mathrm{H}$ NMR (500 MHz, Methanol- $\left.d_{4}\right) \delta 7.56(\mathrm{~d}, J=8.8 \mathrm{~Hz}, 1 \mathrm{H}), 7.29(\mathrm{~d}, J=8.7 \mathrm{~Hz}, 1 \mathrm{H}), 3.83$ (dd, $J=11.5,3.5 \mathrm{~Hz}, 1 \mathrm{H}), 3.70(\mathrm{~d}, J=12.0 \mathrm{~Hz}, 1 \mathrm{H}), 2.91(\mathrm{t}, J=11.3 \mathrm{~Hz}, 1 \mathrm{H}), 2.86(\mathrm{~s}$, $2 \mathrm{H}), 2.81-2.71(\mathrm{~m}, 1 \mathrm{H}), 2.71-2.59(\mathrm{~m}, 1 \mathrm{H}), 2.10-1.98(\mathrm{~m}, 1 \mathrm{H}), 1.97-1.83(\mathrm{~m}$, $1 \mathrm{H}), 1.68(\mathrm{t}, J=10.3 \mathrm{~Hz}, 2 \mathrm{H}) ;{ }^{13} \mathrm{C}$ NMR $\left(126 \mathrm{MHz} \mathrm{CDCl}_{3}\right) \delta 171.07,136.47,129.12$, 121.21, 100.12, 48.03, 46.40, 43.51, 34.87, 27.38, 24.01; IR (ATR) $v_{\max } 3296,1651$, $1525,1322,1156,826,506 \mathrm{~cm}^{-1}$; AMM (ESI) $\mathrm{m} / \mathrm{z} 339.0552$ [calc for $\left.\mathrm{C}_{13} \mathrm{H}_{17} \mathrm{CIN}_{2} \mathrm{O}_{3} \mathrm{SNa}(\mathrm{M}+\mathrm{Na})^{+} 339.0546\right]$.

Synthesis of (R)-MCG-II-156 (3)

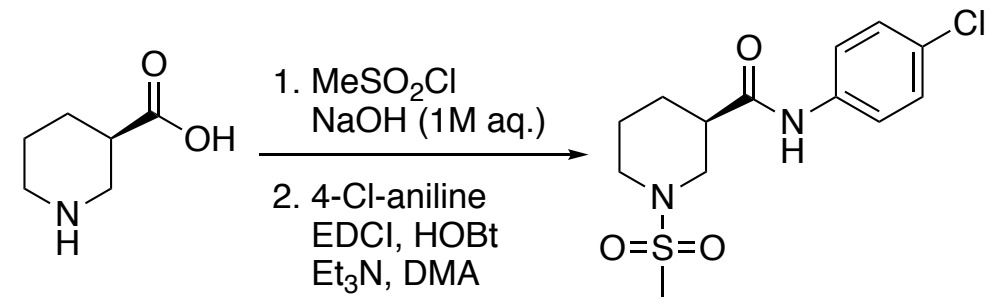

i. $\quad$ To a precooled $\left(0{ }^{\circ} \mathrm{C}\right)$ solution of $(R)$-3-piperidinecarboxylic acid (100. $\mathrm{mg}, 0.774$ $\mathrm{mmol})$ in $1 \mathrm{M}$ aq. $\mathrm{NaOH}(3 \mathrm{~mL})$ under $\mathrm{N}_{2}$ atmosphere was added dropwise methanesulfonyl chloride $(0.07 \mathrm{~mL}, 0.9 \mathrm{mmol})$. The resulting mixture was allowed to 
warm to room temperature and stirred for $3 \mathrm{~h}$. The aqueous solution was then acidified with $1 \mathrm{~N}$ aq. $\mathrm{HCl}$ to $\mathrm{pH} 3$ and diluted with iPrOH: $\mathrm{CHCl}_{3}(30: 70)$. The layers were separated, and the aqueous phase was extracted with $\mathrm{iPrOH}: \mathrm{CHCl}_{3}(30: 70,3 x)$. The combined organic layers were dried over $\mathrm{MgSO}_{4}$, and concentrated in vacuo to afford the desired product, which was carried forward without additional purification (62 $\mathrm{mg}$, $30 \%$ crude yield).

ii. To a precooled $\left(0^{\circ} \mathrm{C}\right)$ solution of $(R)$-mesylated piperidine intermediate $(40 . \mathrm{mg}, 0.19$ $\mathrm{mmol})$, 4-chloroaniline $\quad(25 \mathrm{mg}, \quad 0.19 \quad \mathrm{mmol}), \quad$ 1-ethyl-3-(3dimethylaminopropyl)carbodiimide hydrochloride (56 $\mathrm{mg}, 0.29 \mathrm{mmol}$ ) and 1hydroxybenzotriazole hydrate $(26 \mathrm{mg}, 0.19 \mathrm{mmol})$ in dimethylacetamide $(1.9 \mathrm{~mL})$ under $\mathrm{N}_{2}$ atmosphere was added triethylamine $(0.03 \mathrm{~mL}, 0.2 \mathrm{mmol})$. The resulting solution was allowed to warm to room temperature and stirred for $16 \mathrm{~h}$, then quenched with $\mathrm{H}_{2} \mathrm{O}$ and diluted with EtOAc. The layers were separated, and the aqueous phase was extracted with EtOAc (3x). The combined organic layers were washed with brine, dried over $\mathrm{MgSO}_{4}$, and concentrated in vacuo. Flash chromatography $\left(\mathrm{SiO}_{2}, 50: 50\right.$ hexanes: EtOAc) afforded the product as a white solid (29 $\mathrm{mg}, 48 \%$ yield, $65.9 \% \mathrm{ee}$ ). $[\alpha]_{\mathrm{D}}{ }^{23}-7.25$ (c. $\left.0.13, \mathrm{CH}_{3} \mathrm{OH}\right) ;{ }^{1} \mathrm{H}$ NMR $\left(500 \mathrm{MHz}\right.$, Methanol- $\left.d_{4}\right) \delta 7.56$ (d, J = $8.4 \mathrm{~Hz}$, $1 \mathrm{H}), 7.29(\mathrm{~d}, J=8.4 \mathrm{~Hz}, 1 \mathrm{H}), 3.88-3.78(\mathrm{~m}, 1 \mathrm{H}), 3.70(\mathrm{~d}, J=11.5 \mathrm{~Hz}, 1 \mathrm{H}), 2.91(\mathrm{t}, J$ $=11.3 \mathrm{~Hz}, 1 \mathrm{H}), 2.86(\mathrm{~s}, 2 \mathrm{H}), 2.80-2.71(\mathrm{~m}, 1 \mathrm{H}), 2.71-2.61(\mathrm{~m}, 1 \mathrm{H}), 2.09-1.98(\mathrm{~m}$, $1 \mathrm{H}), 1.95-1.84(\mathrm{~m}, 1 \mathrm{H}), 1.73-1.58(\mathrm{~m}, 1 \mathrm{H}) ;{ }^{13} \mathrm{C}$ NMR (126 MHz, DMSO) $\delta 171.33$, 137.93, 128.57, 126.78, 120.72, 47.72, 45.42, 42.77, 39.52, 34.36, 26.56, 23.83; IR (ATR) $v_{\max } 3297,1656,1524,1321,1141,984,826,499 \mathrm{~cm}^{-1} ;$ AMM (ESI) $\mathrm{m} / \mathrm{z}$ 339.0563 [calc for $\mathrm{C}_{13} \mathrm{H}_{17} \mathrm{CIN}_{2} \mathrm{O}_{3} \mathrm{SNa}(\mathrm{M}+\mathrm{Na})^{+} 339.0546$ ].

Enantiomeric excess determined by SFC (see figure below):

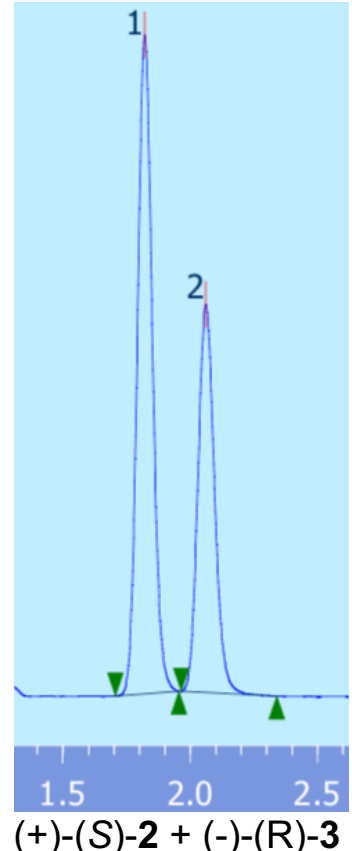

Method: column: ChiralPak AS-H; eluent: $15 \% \mathrm{MeOH}$ in supercritical $\mathrm{CO}_{2}$; flow rate: $4 \mathrm{~mL} / \mathrm{min}$; pressure: $12 \mathrm{MPa}$. Retention times: (+)-(S)-2: $1.8 \mathrm{~min},(-)-(R)-3: 2.1 \mathrm{~min}$.
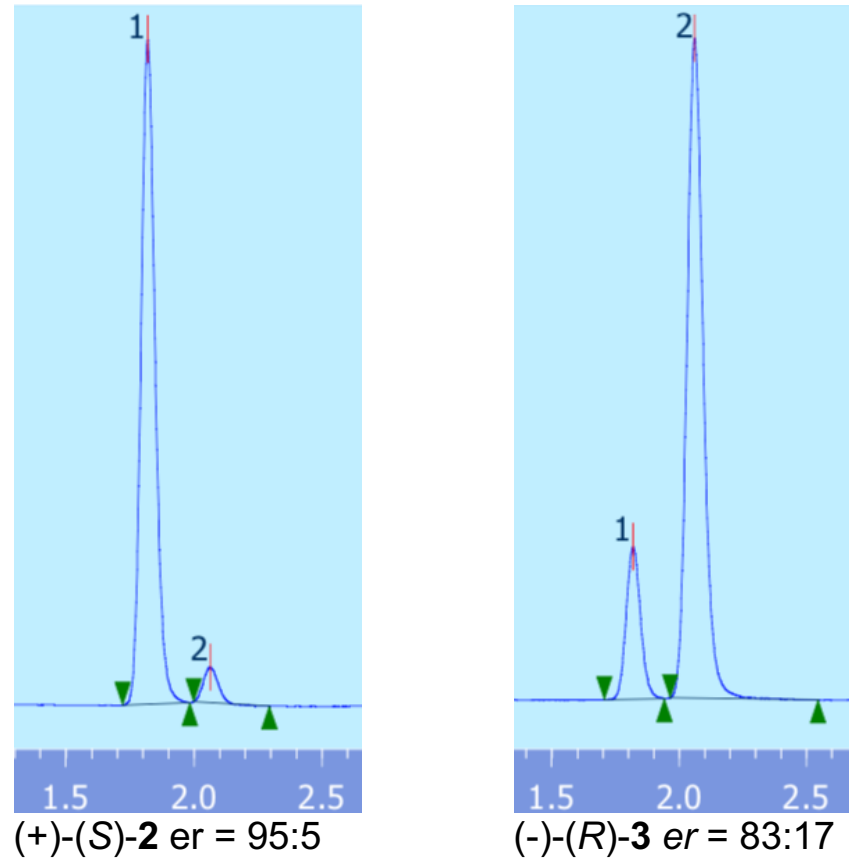
General Synthesis of Analogs 6

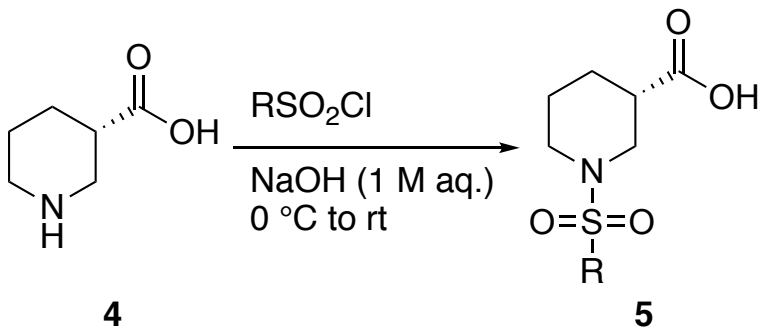

To a precooled $\left(0{ }^{\circ} \mathrm{C}\right)$ solution of $(S)$-3-piperidinecarboxylic acid (1 eq) in $1 \mathrm{M}$ aq. $\mathrm{NaOH}(0.2-0.5 \mathrm{M})$ under $\mathrm{N}_{2}$ atmosphere was added dropwise $\mathrm{R}$-sulfonyl chloride (1.2 eq). The resulting mixture was allowed to warm to room temperature and stirred for 14-23 h, then diluted with ether. The aqueous layer was washed with ether (1x) then acidified to $\mathrm{pH} 1$ with $1 \mathrm{M}$ aq. $\mathrm{HCl}$. The layers were separated, and the aqueous phase was extracted with $\mathrm{CH}_{2} \mathrm{Cl}_{2}(3 \mathrm{x})$. The combined organic layers were washed with brine, dried over $\mathrm{Na}_{2} \mathrm{SO}_{4}$ and concentrated in vacuo to afford the product as a white solid (21-96\% yield).

$5 a, R=\operatorname{Me}(21 \%$ yield $)$

$[\alpha]_{D}{ }^{22}+20.24$ (c. 0.13, $\left.\mathrm{CH}_{3} \mathrm{OH}\right) ;{ }^{1} \mathrm{H}$ NMR $\left(500 \mathrm{MHz}\right.$, Methanol- $\left.d_{4}\right) \delta 3.40(\mathrm{dd}, J=13.0,3.9 \mathrm{~Hz}, 1 \mathrm{H}), 3.31(\mathrm{~s}$, $5 \mathrm{H}), 3.28-3.15(\mathrm{~m}, 2 \mathrm{H}), 3.10-3.00(\mathrm{~m}, 1 \mathrm{H}), 2.87-2.76(\mathrm{~m}, 1 \mathrm{H}), 2.17-2.07(\mathrm{~m}, 1 \mathrm{H}), 2.00-1.87(\mathrm{~m}$, 1H), 1.87 - $1.72(\mathrm{~m}, 2 \mathrm{H}) ;{ }^{13} \mathrm{C} \mathrm{NMR}\left(126 \mathrm{MHz}, \mathrm{CDCl}_{3}\right) \delta$ 178.03, 77.16, 47.29, 46.11, 40.92, 35.39, 26.55, 24.23; IR (ATR) $v_{\max } 3245,2960,2942,2860,1732,1694,1317,1153,1140,780,519 \mathrm{~cm}^{-1}$; AMM (ESI) $\mathrm{m} / \mathrm{z} 208.0650$ [calc for $\mathrm{C}_{7} \mathrm{H}_{14} \mathrm{NO}_{4} \mathrm{~S}(\mathrm{M}+\mathrm{H})^{+} 208.0644$ ].

$5 \mathbf{b}, \mathrm{R}=\mathrm{Et}(34 \%$ yield $)$

$[\alpha]_{D}{ }^{22}+21.69$ (c. $\left.0.24, \mathrm{CH}_{3} \mathrm{OH}\right) ;{ }^{1} \mathrm{H}$ NMR $(500 \mathrm{MHz}$, Chloroform- $d) \delta 3.86(\mathrm{dd}, J=12.4,3.8 \mathrm{~Hz}, 1 \mathrm{H}), 3.66-$ $3.58(\mathrm{~m}, 1 \mathrm{H}), 3.06(\mathrm{dd}, J=12.5,9.7 \mathrm{~Hz}, 1 \mathrm{H}), 2.98(\mathrm{q}, J=7.4 \mathrm{~Hz}, 2 \mathrm{H}), 2.89$ (ddd, $J=12.4,10.3,3.2 \mathrm{~Hz}$, 1H), $2.72-2.60(\mathrm{~m}, 1 \mathrm{H}), 2.15-2.05(\mathrm{~m}, 1 \mathrm{H}), 1.89-1.78(\mathrm{~m}, 1 \mathrm{H}), 1.72-1.58(\mathrm{~m}, 2 \mathrm{H}), 1.35(\mathrm{t}, \mathrm{J}=7.4 \mathrm{~Hz}$, $3 \mathrm{H}) ;{ }^{13} \mathrm{C}$ NMR $\left(126 \mathrm{MHz}, \mathrm{CDCl}_{3}\right) \delta 178.53,77.16,47.24,46.12,44.67,41.18,26.66,24.56,8.00$; IR (ATR) $v_{\max } 2945,2863,1708,1452,1130,967,750,573,509 \mathrm{~cm}^{-1} ;$ AMM (ESI) $\mathrm{m} / \mathrm{z} 222.0810$ [calc for $\mathrm{C}_{8} \mathrm{H}_{16} \mathrm{NO}_{4} \mathrm{~S}$ $\left.(\mathrm{M}+\mathrm{H})^{+} 222.0800\right]$.

5c, $\mathrm{R}=\mathrm{Ph}(96 \%$ yield $)$

$[\alpha]^{22}-11.7$ (c. 0.13, $\left.\mathrm{CH}_{3} \mathrm{OH}\right) ;{ }^{1} \mathrm{H}$ NMR $(500 \mathrm{MHz}$, Chloroform- $d) \delta 7.81-7.74(\mathrm{~m}, 2 \mathrm{H}), 7.65-7.58(\mathrm{~m}$, $1 \mathrm{H}), 7.58-7.50(\mathrm{~m}, 2 \mathrm{H}), 3.81(\mathrm{dd}, J=11.6,3.7 \mathrm{~Hz}, 1 \mathrm{H}), 3.64-3.52(\mathrm{~m}, 1 \mathrm{H}), 2.73-2.62(\mathrm{~m}, 1 \mathrm{H}), 2.57(\mathrm{t}$, $J=10.8 \mathrm{~Hz}, 1 \mathrm{H}), 2.41(\mathrm{td}, J=11.3,3.0 \mathrm{~Hz}, 1 \mathrm{H}), 2.05-1.94(\mathrm{~m}, 1 \mathrm{H}), 1.86-1.75(\mathrm{~m}, 1 \mathrm{H}), 1.73-1.58(\mathrm{~m}$, 1H), $1.49-1.33(\mathrm{~m}, 1 \mathrm{H}) ;{ }^{13} \mathrm{C}$ NMR $\left(126 \mathrm{MHz}, \mathrm{CDCl}_{3}\right) \delta 178.51,136.00,132.98,129.19,127.59,77.16$, 47.38, 46.28, 40.76, 26.17, 23.86; IR (ATR) $v_{\max } 2950,1733,1197,1167,737,571 \mathrm{~cm}^{-1}$;

AMM (ESI) $m / z 270.0805$ [calc for $\mathrm{C}_{12} \mathrm{H}_{16} \mathrm{NO}_{4} \mathrm{~S}(\mathrm{M}+\mathrm{H})^{+} 270.0800$ ].<smiles>[R]S(=O)(=O)N1CCC[C@H](C(=O)O)C1</smiles> 
i. To a precooled $\left({ }^{\circ} \mathrm{C}\right)$ solution of common intermediate $5\left(1.0\right.$ eq) in $\mathrm{CH}_{2} \mathrm{Cl}_{2}(0.2 \mathrm{M})$ under $\mathrm{N}_{2}$ atmosphere was added dropwise oxalyl chloride (1.05 eq) then DMF (0.04 eq). The resulting mixture was stirred at $0{ }^{\circ} \mathrm{C}$ for $25-35 \mathrm{~min}$. then concentrated in vacuo and used directly.

ii. To a precooled $\left(0{ }^{\circ} \mathrm{C}\right)$ solution of acid chloride intermediate $(1 \mathrm{eq})$ in $\mathrm{CH}_{2} \mathrm{Cl}_{2}(0.05 \mathrm{M})$ was added triethylamine (1 eq) then a solution of acid chloride (1.1 eq.) in $\mathrm{CH}_{2} \mathrm{Cl}_{2}(0.05 \mathrm{M})$. The resulting mixture were allowed to warm to room temperature and stirred for $16 \mathrm{~h}$ then quenched with DMSO $(0.5 \mathrm{~mL})$, filtered through celite and purified by mass-directed isolation using ultra-performance liquid chromatography.

(S)-MCG-III-027-A02 (6a)

$\mathrm{R}=\mathrm{Me}, \mathrm{R}^{\prime}=4-\mathrm{Br}(20 \%$ yield $)$

${ }^{1} \mathrm{H}$ NMR $(500 \mathrm{MHz}$, Chloroform- $d$ ) $\delta 8.06(\mathrm{~s}, 1 \mathrm{H}), 7.71(\mathrm{t}, J=2.0 \mathrm{~Hz}, 1 \mathrm{H}), 7.39-7.34(\mathrm{~m}, 1 \mathrm{H}), 7.23(\mathrm{t}, J=$ $8.1 \mathrm{~Hz}, 1 \mathrm{H}), 7.11-7.04(\mathrm{~m}, 1 \mathrm{H}), 3.75(\mathrm{dd}, J=12.1,3.7 \mathrm{~Hz}, 1 \mathrm{H}), 3.58(\mathrm{~d}, J=11.1 \mathrm{~Hz}, 1 \mathrm{H}), 3.16(\mathrm{dd}, J=$ $12.1,9.1 \mathrm{~Hz}, 1 \mathrm{H}), 3.00-2.89(\mathrm{~m}, 2 \mathrm{H}), 2.84(\mathrm{~s}, 3 \mathrm{H}), 2.71-2.61(\mathrm{~m}, 1 \mathrm{H}), 2.01-1.95(\mathrm{~m}, 1 \mathrm{H}), 1.92-1.81$ $(\mathrm{m}, 2 \mathrm{H}) ; \mathbf{A M M}(\mathrm{ESI}) \mathrm{m} / \mathrm{z} 383.0070$ [calc for $\mathrm{C}_{13} \mathrm{H}_{17} \mathrm{BrN}_{2} \mathrm{O}_{3} \mathrm{SNa}(\mathrm{M}+\mathrm{Na})^{+} 383.0041$ ].

(S)-MCG-III-027-A03 (6b)

$\mathrm{R}=\mathrm{Me}, \mathrm{R}^{\prime}=4-\mathrm{F}(29 \%$ yield $)$

${ }^{1} \mathrm{H}$ NMR $(500 \mathrm{MHz}$, Chloroform-d) $\delta 7.99(\mathrm{~s}, 1 \mathrm{H}), 7.55-7.44(\mathrm{~m}, 2 \mathrm{H}), 7.00(\mathrm{t}, J=8.6 \mathrm{~Hz}, 2 \mathrm{H}), 3.86-3.67$ $(\mathrm{m}, 1 \mathrm{H}), 3.57(\mathrm{~d}, J=11.8 \mathrm{~Hz}, 1 \mathrm{H}), 3.17(\mathrm{dd}, J=12.0,9.0 \mathrm{~Hz}, 1 \mathrm{H}), 2.97-2.89(\mathrm{~m}, 1 \mathrm{H}), 2.83(\mathrm{~s}, 3 \mathrm{H}), 2.71-$ $2.60(\mathrm{~m}, 1 \mathrm{H}), 2.00-1.95(\mathrm{~m}, 1 \mathrm{H}), 1.77-1.57(\mathrm{~m}, 2 \mathrm{H}) ; \mathrm{AMM}(\mathrm{ESI}) \mathrm{m} / z 323.0839$ [calc for $\mathrm{C}_{13} \mathrm{H}_{17} \mathrm{FN}_{2} \mathrm{O}_{3} \mathrm{SNa}$ $(\mathrm{M}+\mathrm{Na})^{+}$323.0842].

(S)-MCG-III-027-A04 (6c)

$\mathrm{R}=\mathrm{Me}, \mathrm{R}^{\prime}=4-\mathrm{CF}_{3}(15 \%$ yield $)$

${ }^{1} \mathrm{H}$ NMR $(500 \mathrm{MHz}$, Chloroform- $d) \delta 8.24(\mathrm{~s}, 1 \mathrm{H}), 7.69(\mathrm{~d}, J=8.3 \mathrm{~Hz}, 2 \mathrm{H}), 7.57(\mathrm{~d}, J=8.4 \mathrm{~Hz}, 2 \mathrm{H}), 3.74$ (dd, $J=11.9,3.7 \mathrm{~Hz}, 1 \mathrm{H}), 3.61-3.52(\mathrm{~m}, 1 \mathrm{H}), 3.21(\mathrm{dd}, J=12.1,8.8 \mathrm{~Hz}, 1 \mathrm{H}), 3.03-2.94(\mathrm{~m}, 1 \mathrm{H}), 2.85$ (s, 3H), $2.76-2.67(\mathrm{~m}, 1 \mathrm{H}), 2.06-1.97(\mathrm{~m}, 1 \mathrm{H}), 1.94-1.84(\mathrm{~m}, 2 \mathrm{H})$; AMM (ESI) m/z 373.0825 [calc for $\left.\mathrm{C}_{14} \mathrm{H}_{17} \mathrm{~F}_{3} \mathrm{~N}_{2} \mathrm{O}_{3} \mathrm{SNa}(\mathrm{M}+\mathrm{Na})+373.0810\right]$.

(S)-MCG-III-027-B01 (6d)

$\mathrm{R}=\mathrm{Me}, \mathrm{R}^{\prime}=3-\mathrm{Cl}(26 \%$ yield $)$

${ }^{1} \mathrm{H}$ NMR $(500 \mathrm{MHz}$, Chloroform- $d) \delta 8.06(\mathrm{~s}, 1 \mathrm{H}), 7.71(\mathrm{t}, J=2.0 \mathrm{~Hz}, 1 \mathrm{H}), 7.39-7.34(\mathrm{~m}, 1 \mathrm{H}), 7.23(\mathrm{t}, J=$ $8.1 \mathrm{~Hz}, 1 \mathrm{H}), 7.11-7.05(\mathrm{~m}, 1 \mathrm{H}), 3.75(\mathrm{dd}, J=12.0,3.7 \mathrm{~Hz}, 1 \mathrm{H}), 3.63-3.53(\mathrm{~m}, 1 \mathrm{H}), 3.16(\mathrm{dd}, J=12.1$, $9.1 \mathrm{~Hz}, 1 \mathrm{H}), 2.99-2.89(\mathrm{~m}, 2 \mathrm{H}), 2.84(\mathrm{~s}, 3 \mathrm{H}), 2.71-2.63(\mathrm{~m}, 1 \mathrm{H}), 2.01-1.95(\mathrm{~m}, 1 \mathrm{H}), 1.93-1.81(\mathrm{~m}$, $2 \mathrm{H}$ ); $\mathbf{A M M}(\mathrm{ESI}) \mathrm{m} / \mathrm{z} 339.0552$ [calc for $\mathrm{C}_{13} \mathrm{H}_{17} \mathrm{CIN}_{2} \mathrm{O}_{3} \mathrm{SNa}(\mathrm{M}+\mathrm{Na})^{+} 339.0546$ ].

(S)-MCG-III-027-B02 (6e)

$\mathrm{R}=\mathrm{Me}, \mathrm{R}^{\prime}=3-\mathrm{Br}(24 \%$ yield $)$

${ }^{1} \mathrm{H}$ NMR $(500 \mathrm{MHz}$, Chloroform- $d) \delta 8.00(\mathrm{~s}, 1 \mathrm{H}), 7.86(\mathrm{t}, J=2.0 \mathrm{~Hz}, 1 \mathrm{H}), 7.42(\mathrm{~d}, J=7.9 \mathrm{~Hz}, 1 \mathrm{H}), 7.24(\mathrm{~d}$, $J=8.1 \mathrm{~Hz}, 1 \mathrm{H}), 7.17(\mathrm{t}, J=8.0 \mathrm{~Hz}, 1 \mathrm{H}), 3.74(\mathrm{dd}, J=12.1,3.7 \mathrm{~Hz}, 1 \mathrm{H}), 3.57(\mathrm{~d}, J=11.6 \mathrm{~Hz}, 1 \mathrm{H}), 3.17(\mathrm{dd}$, $J=12.1,8.9 \mathrm{~Hz}, 1 \mathrm{H}), 3.00-2.90(\mathrm{~m}, 2 \mathrm{H}), 2.84(\mathrm{~s}, 3 \mathrm{H}), 2.71-2.61(\mathrm{~m}, 1 \mathrm{H}), 2.01-1.95(\mathrm{~m}, 1 \mathrm{H}), 1.93-$ $1.81(\mathrm{~m}, 3 \mathrm{H}) ; \mathbf{A M M}(\mathrm{ESI}) \mathrm{m} / \mathrm{z} 383.0041$ [calc for $\mathrm{C}_{13} \mathrm{H}_{17} \mathrm{BrN}_{2} \mathrm{O}_{3} \mathrm{SNa}(\mathrm{M}+\mathrm{Na})^{+} 383.0041$ ].

(S)-MCG-III-027-B03 (6f)

$\mathrm{R}=\mathrm{Me}, \mathrm{R}^{\prime}=3-\mathrm{F}(32 \%$ yield $)$

${ }^{1} \mathrm{H}$ NMR (500 MHz, Chloroform-d) $\delta 8.13(\mathrm{~s}, 1 \mathrm{H}), 7.53(\mathrm{dt}, J=10.9,2.3 \mathrm{~Hz}, 1 \mathrm{H}), 7.26-7.21(\mathrm{~m}, 1 \mathrm{H}), 7.19$ $(\mathrm{d}, J=8.1 \mathrm{~Hz}, 1 \mathrm{H}), 6.80(\mathrm{td}, J=8.2,2.5 \mathrm{~Hz}, 1 \mathrm{H}), 3.76(\mathrm{dd}, J=12.1,3.8 \mathrm{~Hz}, 1 \mathrm{H}), 3.65-3.55(\mathrm{~m}, 1 \mathrm{H}), 3.15$ (dd, $J=12.0,9.2 \mathrm{~Hz}, 1 \mathrm{H}), 2.99-2.88(\mathrm{~m}, 2 \mathrm{H}), 2.84(\mathrm{~s}, 3 \mathrm{H}), 2.74-2.63(\mathrm{~m}, 1 \mathrm{H}), 2.06-1.97(\mathrm{~m}, 1 \mathrm{H}), 1.95$ $-1.83(\mathrm{~m}, 2 \mathrm{H})$; $\mathbf{A M M}(\mathrm{ESI}) \mathrm{m} / \mathrm{z} 323.0850$ [calc for $\mathrm{C}_{13} \mathrm{H}_{17} \mathrm{FN}_{2} \mathrm{O}_{3} \mathrm{SNa}(\mathrm{M}+\mathrm{Na})^{+} 323.0842$ ].

(S)-MCG-III-027-B04 (6g)

$\mathrm{R}=\mathrm{Me}, \mathrm{R}^{\prime}=3-\mathrm{CF}_{3}(30 \%$ yield $)$

${ }^{1} \mathrm{H}$ NMR $(500 \mathrm{MHz}$, Chloroform-d) $\delta 8.15(\mathrm{~s}, 1 \mathrm{H}), 7.95(\mathrm{~s}, 1 \mathrm{H}), 7.68(\mathrm{~d}, J=8.0 \mathrm{~Hz}, 1 \mathrm{H}), 7.43(\mathrm{t}, J=8.0 \mathrm{~Hz}$, $1 \mathrm{H}), 7.36(\mathrm{~d}, J=7.7 \mathrm{~Hz}, 1 \mathrm{H}), 3.75(\mathrm{~d}, J=12.6 \mathrm{~Hz}, 1 \mathrm{H}), 3.57(\mathrm{~d}, J=11.9 \mathrm{~Hz}, 1 \mathrm{H}), 3.20(\mathrm{dd}, J=12.1,8.8$ 
$\mathrm{Hz}, 1 \mathrm{H}), 2.97(\mathrm{~m}, 1 \mathrm{H}), 2.84(\mathrm{~s}, 3 \mathrm{H}), 2.70(\mathrm{~m}, 1 \mathrm{H}), 2.00(\mathrm{~m}, 1 \mathrm{H}), 1.95-1.82(\mathrm{~m}, 2 \mathrm{H}) ;$ AMM $(\mathrm{ESI}) \mathrm{m} / \mathrm{z}$ 373.0835 [calc for $\mathrm{C}_{14} \mathrm{H}_{17} \mathrm{~F}_{3} \mathrm{~N}_{2} \mathrm{O}_{3} \mathrm{SNa}(\mathrm{M}+\mathrm{Na})^{+} 373.0810$ ].

(S)-MCG-III-027-B05 (6h)

$\mathrm{R}=\mathrm{Me}, \mathrm{R}^{\prime}=3-\mathrm{OMe}(42 \%$ yield $)$

${ }^{1} \mathrm{H}$ NMR $(500 \mathrm{MHz}$, Chloroform-d) $\delta 7.92(\mathrm{~s}, 1 \mathrm{H}), 7.32(\mathrm{~s}, 1 \mathrm{H}), 7.20(\mathrm{t}, J=8.1 \mathrm{~Hz}, 1 \mathrm{H}), 7.05-6.97(\mathrm{~m}, 1 \mathrm{H})$, $6.66(\mathrm{dd}, J=8.2,2.5 \mathrm{~Hz}, 1 \mathrm{H}), 3.91-3.72(\mathrm{~m}, 4 \mathrm{H}), 3.65-3.56(\mathrm{~m}, 1 \mathrm{H}), 3.10(\mathrm{dd}, J=12.1,9.4 \mathrm{~Hz}, 1 \mathrm{H})$, $2.90-2.83(\mathrm{~m}, 2 \mathrm{H}), 2.82(\mathrm{~s}, 3 \mathrm{H}), 2.69-2.58(\mathrm{~m}, 1 \mathrm{H}), 2.06-1.96(\mathrm{~m}, 2 \mathrm{H}), 1.77-1.65(\mathrm{~m}, 1 \mathrm{H}) ;$ AMM (ESI) $\mathrm{m} / \mathrm{z} 335.1048$ [calc for $\mathrm{C}_{14} \mathrm{H}_{20} \mathrm{~N}_{2} \mathrm{O}_{4} \mathrm{SNa}(\mathrm{M}+\mathrm{Na})^{+} 335.1041$ ].

(S)-MCG-III-027-C01 (6i)

$\mathrm{R}=\mathrm{Me}, \mathrm{R}^{\prime}=2-\mathrm{Cl}(29 \%$ yield $)$

${ }^{1} \mathrm{H}$ NMR $(500 \mathrm{MHz}$, Chloroform- $d) \delta 8.28(\mathrm{~d}, J=8.3 \mathrm{~Hz}, 1 \mathrm{H}), 7.88(\mathrm{~s}, 1 \mathrm{H}), 7.38(\mathrm{~d}, J=7.9 \mathrm{~Hz}, 1 \mathrm{H}), 7.28(\mathrm{~d}$, $J=8.6 \mathrm{~Hz}, 1 \mathrm{H}), 7.07(\mathrm{t}, J=7.6 \mathrm{~Hz}, 1 \mathrm{H}), 3.93-3.82(\mathrm{~m}, 1 \mathrm{H}), 3.68(\mathrm{~d}, J=11.8 \mathrm{~Hz}, 1 \mathrm{H}), 3.08(\mathrm{dd}, J=12.0$, $9.6 \mathrm{~Hz}, 1 \mathrm{H}), 2.98-2.88(\mathrm{~m}, 1 \mathrm{H}), 2.83(\mathrm{~s}, 3 \mathrm{H}), 2.74-2.64(\mathrm{~m}, 1 \mathrm{H}), 2.15-2.05(\mathrm{~m}, 1 \mathrm{H}), 1.93(\mathrm{~d}, J=12.0$ $\mathrm{Hz}, 2 \mathrm{H}$ ); AMM (ESI) $\mathrm{m} / \mathrm{z} 339.0571$ [calc for $\mathrm{C}_{13} \mathrm{H}_{17} \mathrm{ClN}_{2} \mathrm{O}_{3} \mathrm{SNa}(\mathrm{M}+\mathrm{Na})^{+} 339.0546$ ].

(S)-MCG-III-027-C02 (6j)

$\mathrm{R}=\mathrm{Me}, \mathrm{R}^{\prime}=2-\mathrm{OMe}(13 \%$ yield $)$

${ }^{1} \mathrm{H}$ NMR $(500 \mathrm{MHz}$, Chloroform-d) $\delta 8.31$ (dd, $J=8.1,1.6 \mathrm{~Hz}, 1 \mathrm{H}), 8.11(\mathrm{~s}, 1 \mathrm{H}), 7.09-7.03(\mathrm{~m}, 1 \mathrm{H}), 6.98$ $-6.92(\mathrm{~m}, 1 \mathrm{H}), 6.91-6.85(\mathrm{~m}, 1 \mathrm{H}), 3.90(\mathrm{~s}, 3 \mathrm{H}), 3.82(\mathrm{~d}, J=11.6 \mathrm{~Hz}, 1 \mathrm{H}), 3.64(\mathrm{~d}, J=12.0 \mathrm{~Hz}, 1 \mathrm{H}), 3.14$ - $3.04(\mathrm{~m}, 1 \mathrm{H}), 2.90-2.82(\mathrm{~m}, 1 \mathrm{H}), 2.81(\mathrm{~s}, 3 \mathrm{H}), 2.71-2.62(\mathrm{~m}, 1 \mathrm{H}), 2.04-1.98(\mathrm{~m}, 1 \mathrm{H}), 1.95-1.86(\mathrm{~m}$, $1 \mathrm{H}), 1.86-1.79(\mathrm{~m}, 1 \mathrm{H}), 1.77-1.67(\mathrm{~m}, 1 \mathrm{H}) ; \mathbf{A M M}(\mathrm{ESI}) \mathrm{m} / \mathrm{z} 335.1039$ [calc for $\mathrm{C}_{14} \mathrm{H}_{20} \mathrm{~N}_{2} \mathrm{O}_{4} \mathrm{SNa}(\mathrm{M}+\mathrm{Na})^{+}$ 335.1041].

(S)-MCG-III-027-D04 (6k)

$\mathrm{R}=\mathrm{Me}, \mathrm{R}^{\prime}=2,4-\mathrm{diF}(14 \%$ yield $)$

${ }^{1} \mathrm{H}$ NMR $(500 \mathrm{MHz}$, Chloroform-d) $\delta 8.22-8.12(\mathrm{~m}, 1 \mathrm{H}), 7.60(\mathrm{~s}, 1 \mathrm{H}), 6.92-6.83(\mathrm{~m}, 2 \mathrm{H}), 3.81(\mathrm{~d}, J=12.1$ $\mathrm{Hz}, 1 \mathrm{H}), 3.64(\mathrm{~d}, J=11.7 \mathrm{~Hz}, 1 \mathrm{H}), 3.16-3.06(\mathrm{~m}, 1 \mathrm{H}), 2.88(\mathrm{t}, J=10.8 \mathrm{~Hz}, 1 \mathrm{H}), 2.82(\mathrm{~s}, 3 \mathrm{H}), 2.73-2.61$ $(\mathrm{m}, 1 \mathrm{H}), 2.09-1.99(\mathrm{~m}, 1 \mathrm{H}), 1.96-1.87(\mathrm{~m}, 1 \mathrm{H}), 1.86-1.79(\mathrm{~m}, 1 \mathrm{H}), 1.79-1.69(\mathrm{~m}, 1 \mathrm{H}) ; \mathbf{A M M}(\mathrm{ESI}) \mathrm{m} / \mathrm{z}$ 341.0762 [calc for $\mathrm{C}_{13} \mathrm{H}_{16} \mathrm{~F}_{2} \mathrm{~N}_{2} \mathrm{O}_{3} \mathrm{SNa}(\mathrm{M}+\mathrm{Na})^{+} 341.0747$ ].

(S)-MCG-III-027-D05 (6I)

$\mathrm{R}=\mathrm{Me}, \mathrm{R}^{\prime}=4-\mathrm{Cl}-3-\mathrm{F}(11 \%$ yield $)$

$[\alpha]_{0}{ }^{23}+4.31$ (c. $\left.0.083, \mathrm{CH}_{3} \mathrm{OH}\right) ;{ }^{1} \mathrm{H}$ NMR $\left(500 \mathrm{MHz}\right.$, Acetonitrile-d $\left.d_{3}\right) \delta 8.70(\mathrm{~s}, 1 \mathrm{H}), 7.72$ (dd, $J=11.8,2.4$ $\mathrm{Hz}, 1 \mathrm{H}$ ), 7.37 (t, $J=8.6 \mathrm{~Hz}, 1 \mathrm{H}$ ), 7.24 (ddd, $J=8.8,2.4,1.1 \mathrm{~Hz}, 1 \mathrm{H}$ ), 3.79 (ddt, $J=11.8,3.6,1.6 \mathrm{~Hz}, 1 \mathrm{H}$ ), $3.61(\mathrm{~d}, J=11.7 \mathrm{~Hz}, 1 \mathrm{H}), 2.87(\mathrm{dd}, J=11.8,10.7 \mathrm{~Hz}, 1 \mathrm{H}), 2.78(\mathrm{~s}, 3 \mathrm{H}), 2.72(\mathrm{td}, J=11.5,2.9 \mathrm{~Hz}, 1 \mathrm{H}), 2.58$ (tt, $J=10.7,3.9 \mathrm{~Hz}, 1 \mathrm{H}), 2.00(\mathrm{~d}, J=7.6 \mathrm{~Hz}, 1 \mathrm{H}), 1.89-1.80(\mathrm{~m}, 1 \mathrm{H}), 1.66-1.55(\mathrm{~m}, 2 \mathrm{H}) ;{ }^{13} \mathrm{C}$ NMR $(126$ $\mathrm{MHz}, \mathrm{MeOD}) \delta 174.03,160.08,158.13,140.39,140.31,131.53,117.34,117.31,116.09,115.94,109.33$, 109.12, 47.09, 45.02, 40.40, 34.89, 28.45, 25.53; IR (ATR) $v_{\max } 2990,1665,1529,1422,1322,1201,1166$, $815,491 \mathrm{~cm}^{-1} ;$ AMM (ESI) $\mathrm{m} / \mathrm{z} 357.0457$ [calc for $\mathrm{C}_{13} \mathrm{H}_{16} \mathrm{ClFN}_{2} \mathrm{O}_{3} \mathrm{SNa}(\mathrm{M}+\mathrm{Na})^{+} 357.0452$ ].

(S)-MCG-III-085-A02 (6m)

$\mathrm{R}=\mathrm{Me}, \mathrm{R}^{\prime}=3-\mathrm{Cl}-4-\mathrm{F}(16 \%$ yield $)$

${ }^{1} \mathrm{H}$ NMR $\left(500 \mathrm{MHz}\right.$, Acetonitrile- $\left.d_{3}\right) \delta 8.58(\mathrm{~s}, 1 \mathrm{H}), 7.85-7.79(\mathrm{~m}, 1 \mathrm{H}), 7.45-7.38(\mathrm{~m}, 1 \mathrm{H}), 7.18(\mathrm{td}, \mathrm{J}=$ $9.1,1.0 \mathrm{~Hz}, 1 \mathrm{H}), 3.84-3.75(\mathrm{~m}, 1 \mathrm{H}), 3.62(\mathrm{~d}, J=11.8 \mathrm{~Hz}, 1 \mathrm{H}), 2.87(\mathrm{t}, J=11.2 \mathrm{~Hz}, 1 \mathrm{H}), 2.79(\mathrm{~s}, 3 \mathrm{H}), 2.72$ $(\mathrm{td}, J=11.6,3.1 \mathrm{~Hz}, 1 \mathrm{H}), 2.57(\mathrm{tt}, J=10.8,4.0 \mathrm{~Hz}, 2 \mathrm{H}), 2.04-1.98(\mathrm{~m}, 1 \mathrm{H}), 1.89-1.80(\mathrm{~m}, 1 \mathrm{H}), 1.67-$ $1.56(\mathrm{~m}, 2 \mathrm{H})$; AMM (ESI) $\mathrm{m} / \mathrm{z} 357.0447$ [calc for $\mathrm{C}_{13} \mathrm{H}_{16} \mathrm{ClFN}_{2} \mathrm{O}_{3} \mathrm{SNa}(\mathrm{M}+\mathrm{Na})^{+} 357.0452$ ].

(S)-MCG-III-085-A03 (6n)

$\mathrm{R}=\mathrm{Me}, \mathrm{R}^{\prime}=3,4-\mathrm{diCl}(15 \%$ yield $)$

${ }^{1} \mathrm{H}$ NMR $(500 \mathrm{MHz}$, Acetonitrile-d3) $\delta 8.67(\mathrm{~s}, 1 \mathrm{H}), 7.89(\mathrm{dd}, J=2.0,0.9 \mathrm{~Hz}, 1 \mathrm{H}), 7.47-7.39(\mathrm{~m}, 2 \mathrm{H}), 3.83$ $-3.74(\mathrm{~m}, 1 \mathrm{H}), 3.66-3.57(\mathrm{~m}, 1 \mathrm{H}), 2.87(\mathrm{dd}, J=11.8,10.6 \mathrm{~Hz}, 1 \mathrm{H}), 2.79(\mathrm{~s}, 3 \mathrm{H}), 2.72(\mathrm{td}, J=11.6,2.9$ 
$\mathrm{Hz}, 1 \mathrm{H}), 2.59(\mathrm{tt}, J=10.8,3.9 \mathrm{~Hz}, 1 \mathrm{H}), 2.05-1.98(\mathrm{~m}, 1 \mathrm{H}), 1.90-1.82(\mathrm{~m}, 1 \mathrm{H}), 1.67-1.56(\mathrm{~m}, 2 \mathrm{H}) ;$ AMM (ESI) $\mathrm{m} / \mathrm{z} 373.0159$ [calc for $\mathrm{C}_{13} \mathrm{H}_{16} \mathrm{Cl}_{2} \mathrm{~N}_{2} \mathrm{O}_{3} \mathrm{SNa}(\mathrm{M}+\mathrm{Na})^{+} 373.0156$ ].

(S)-MCG-III-085-A04 (60)

$R=M e, R^{\prime}=3,4-d i F(15 \%$ yield $)$

${ }^{1} \mathrm{H}$ NMR $\left(500 \mathrm{MHz}\right.$, Acetonitrile- $\left.d_{3}\right) \delta 8.60(\mathrm{~s}, 1 \mathrm{H}), 7.77-7.66(\mathrm{~m}, 1 \mathrm{H}), 7.25-7.14(\mathrm{~m}, 2 \mathrm{H}), 3.83-3.75(\mathrm{~m}$, 1H), $3.66-3.58(\mathrm{~m}, 1 \mathrm{H}), 2.87(\mathrm{dd}, J=11.8,10.6 \mathrm{~Hz}, 1 \mathrm{H}), 2.78(\mathrm{~s}, 3 \mathrm{H}), 2.72(\mathrm{td}, J=11.6,2.9 \mathrm{~Hz}, 1 \mathrm{H}), 2.57$ (tt, $J=10.8,3.9 \mathrm{~Hz}, 1 \mathrm{H}), 2.04-1.97(\mathrm{~m}, 1 \mathrm{H}), 1.90-1.82(\mathrm{~m}, 1 \mathrm{H}), 1.67-1.55(\mathrm{~m}, 2 \mathrm{H}) ;$ AMM $(\mathrm{ESI}) \mathrm{m} / \mathrm{z}$ 341.0736 [calc for $\mathrm{C}_{13} \mathrm{H}_{16} \mathrm{~F}_{2} \mathrm{~N}_{2} \mathrm{O}_{3} \mathrm{SNa}(\mathrm{M}+\mathrm{Na})^{+} 341.0747$ ].

(S)-MCG-III-085-A05 (6p)

$\mathrm{R}=\mathrm{Me}, \mathrm{R}^{\prime}=3-\mathrm{Br}-4-\mathrm{Cl}(9 \%$ yield $)$

${ }^{1} \mathrm{H}$ NMR $\left(500 \mathrm{MHz}\right.$, Acetonitrile-d $\left.d_{3}\right) \delta 8.65(\mathrm{~s}, 1 \mathrm{H}), 8.03(\mathrm{~d}, J=2.4 \mathrm{~Hz}, 1 \mathrm{H}), 7.48(\mathrm{dd}, J=8.8,2.4 \mathrm{~Hz}, 1 \mathrm{H})$, $7.43(\mathrm{~d}, J=8.7 \mathrm{~Hz}, 1 \mathrm{H}), 3.83-3.76(\mathrm{~m}, 1 \mathrm{H}), 3.61(\mathrm{~d}, J=11.9 \mathrm{~Hz}, 1 \mathrm{H}), 2.87(\mathrm{dd}, J=11.8,10.6 \mathrm{~Hz}, 1 \mathrm{H})$, $2.79(\mathrm{~s}, 3 \mathrm{H}), 2.72(\mathrm{td}, J=11.6,2.9 \mathrm{~Hz}, 1 \mathrm{H}), 2.58(\mathrm{tt}, J=10.7,3.8 \mathrm{~Hz}, 1 \mathrm{H}), 2.03-1.98(\mathrm{~m}, 1 \mathrm{H}), 1.90-1.82$ $(\mathrm{m}, 1 \mathrm{H}), 1.67-1.55(\mathrm{~m}, 2 \mathrm{H})$; AMM (ESI) $\mathrm{m} / \mathrm{z} 416.9674$ [calc for $\mathrm{C}_{13} \mathrm{H}_{16} \mathrm{BrClN}_{2} \mathrm{O}_{3} \mathrm{SNa}(\mathrm{M}+\mathrm{Na})^{+} 416.9651$ ].

(S)-MCG-III-085-A06 (6q)

$\mathrm{R}=\mathrm{Me}, \mathrm{R}^{\prime}=4-\mathrm{Br}-3-\mathrm{Cl}(24 \%$ yield $)$

${ }^{1} \mathrm{H}$ NMR $\left(500 \mathrm{MHz}\right.$, Acetonitrile- $\left.d_{3}\right) \delta 8.66(\mathrm{~s}, 1 \mathrm{H}), 7.90(\mathrm{~d}, J=2.5 \mathrm{~Hz}, 1 \mathrm{H}), 7.58(\mathrm{~d}, J=8.7 \mathrm{~Hz}, 1 \mathrm{H}), 7.35$ (dd, $J=8.8,2.5 \mathrm{~Hz}, 1 \mathrm{H}$ ), 3.79 (ddt, $J=11.7,3.7,1.7 \mathrm{~Hz}, 1 \mathrm{H}), 3.65-3.57(\mathrm{~m}, 1 \mathrm{H}), 2.87$ (dd, $J=11.8,10.6$ $\mathrm{Hz}, 1 \mathrm{H}), 2.79(\mathrm{~s}, 3 \mathrm{H}), 2.77-2.68(\mathrm{~m}, 1 \mathrm{H}), 2.58(\mathrm{tt}, J=10.8,3.9 \mathrm{~Hz}, 1 \mathrm{H}), 2.05-1.98(\mathrm{~m}, 1 \mathrm{H}), 1.90-1.81$ $(\mathrm{m}, 1 \mathrm{H}), 1.67-1.53(\mathrm{~m}, 2 \mathrm{H})$; AMM $(\mathrm{ESI}) \mathrm{m} / \mathrm{z} 416.9650$ [calc for $\mathrm{C}_{13} \mathrm{H}_{16} \mathrm{BrClN}_{2} \mathrm{O}_{3} \mathrm{SNa}(\mathrm{M}+\mathrm{Na})^{+} 416.9651$ ].

(S)-MCG-III-085-C01 (6r)

$\mathrm{R}=\mathrm{Et}, \mathrm{R}^{\prime}=4-\mathrm{Cl}-3-\mathrm{F}(18 \%$ yield $)$

${ }^{1} \mathrm{H}$ NMR $\left(500 \mathrm{MHz}\right.$, Acetonitrile- $\left.d_{3}\right) \delta 8.69(\mathrm{~s}, 1 \mathrm{H}), 7.72(\mathrm{dd}, J=11.9,2.4 \mathrm{~Hz}, 1 \mathrm{H}), 7.37(\mathrm{t}, J=8.6 \mathrm{~Hz}, 1 \mathrm{H})$, $7.28-7.20(\mathrm{~m}, 1 \mathrm{H}), 3.86-3.74(\mathrm{~m}, 1 \mathrm{H}), 3.64(\mathrm{dd}, J=12.6,4.2 \mathrm{~Hz}, 1 \mathrm{H}), 3.06-2.93(\mathrm{~m}, 3 \mathrm{H}), 2.83(\mathrm{td}, J=$ 11.8, $2.9 \mathrm{~Hz}, 1 \mathrm{H}), 2.61-2.49(\mathrm{~m}, 2 \mathrm{H}), 2.04-1.97(\mathrm{~m}, 1 \mathrm{H}), 1.86-1.77(\mathrm{~m}, 1 \mathrm{H}), 1.71-1.50(\mathrm{~m}, 2 \mathrm{H}), 1.27$ (t, $J=7.4 \mathrm{~Hz}, 3 \mathrm{H})$; AMM (ESI) $\mathrm{m} / \mathrm{z} 371.0599$ [calc for $\mathrm{C}_{14} \mathrm{H}_{18} \mathrm{CIFN}_{2} \mathrm{O}_{3} \mathrm{SNa}(\mathrm{M}+\mathrm{Na})^{+} 371.0608$ ].

(S)-MCG-III-085-C02 (6s)

$\mathrm{R}=\mathrm{Et}, \mathrm{R}^{\prime}=3-\mathrm{Cl}-4-\mathrm{F}$ (21\% yield)

${ }^{1} \mathrm{H}$ NMR $\left(500 \mathrm{MHz}\right.$, Acetonitrile- $\left.d_{3}\right) \delta 8.57(\mathrm{~s}, 1 \mathrm{H}), 7.81(\mathrm{dd}, J=6.8,2.6 \mathrm{~Hz}, 1 \mathrm{H}), 7.45-7.36(\mathrm{~m}, 1 \mathrm{H}), 7.17$ $(\mathrm{t}, J=9.0 \mathrm{~Hz}, 1 \mathrm{H}), 3.81(\mathrm{ddt}, J=12.2,3.7,1.7 \mathrm{~Hz}, 1 \mathrm{H}), 3.68-3.58(\mathrm{~m}, 1 \mathrm{H}), 3.04-2.92(\mathrm{~m}, 3 \mathrm{H}), 2.83(\mathrm{td}$, $J=11.7,2.8 \mathrm{~Hz}, 1 \mathrm{H}), 2.59-2.49(\mathrm{~m}, 1 \mathrm{H}), 2.03-1.96(\mathrm{~m}, 1 \mathrm{H}), 1.87-1.76(\mathrm{~m}, 1 \mathrm{H}), 1.70-1.50(\mathrm{~m}, 2 \mathrm{H})$, 1.27 (t, $J=7.4 \mathrm{~Hz}, 3 \mathrm{H})$; AMM (ESI) $\mathrm{m} / \mathrm{z} 371.0618$ [calc for $\mathrm{C}_{14} \mathrm{H}_{18} \mathrm{ClFN}_{2} \mathrm{O}_{3} \mathrm{SNa}(\mathrm{M}+\mathrm{Na})^{+} 371.0608$ ].

(S)-MCG-III-085-C03 (6t)

$\mathrm{R}=\mathrm{Et}, \mathrm{R}^{\prime}=3,4-\mathrm{diCl}$ (20\% yield)

${ }^{1} \mathrm{H}$ NMR $\left(500 \mathrm{MHz}\right.$, Acetonitrile- $\left.d_{3}\right) \delta 8.65(\mathrm{~s}, 1 \mathrm{H}), 7.89(\mathrm{dd}, J=1.8,0.9 \mathrm{~Hz}, 1 \mathrm{H}), 7.47-7.38(\mathrm{~m}, 2 \mathrm{H}), 3.81$ (ddt, $J=12.2,3.7,1.7 \mathrm{~Hz}, 1 \mathrm{H}), 3.68-3.59(\mathrm{~m}, 1 \mathrm{H}), 3.05-2.92(\mathrm{~m}, 3 \mathrm{H}), 2.83(\mathrm{td}, J=11.7,2.9 \mathrm{~Hz}, 1 \mathrm{H})$, $2.61-2.49(\mathrm{~m}, 1 \mathrm{H}), 2.04-1.97(\mathrm{~m}, 1 \mathrm{H}), 1.89-1.78(\mathrm{~m}, 1 \mathrm{H}), 1.70-1.50(\mathrm{~m}, 2 \mathrm{H}), 1.27(\mathrm{t}, J=7.4 \mathrm{~Hz}, 3 \mathrm{H})$; AMM (ESI) $\mathrm{m} / \mathrm{z} 387.0302$ [calc for $\mathrm{C}_{14} \mathrm{H}_{18} \mathrm{Cl}_{2} \mathrm{~N}_{2} \mathrm{O}_{3} \mathrm{SNa}(\mathrm{M}+\mathrm{Na})^{+} 387.0313$ ].

(S)-MCG-III-085-C04 (6u)

$R=$ Et, R' = 3,4-diF (23\% yield)

${ }^{1} \mathrm{H}$ NMR $\left(500 \mathrm{MHz}\right.$, Acetonitrile- $\left.d_{3}\right) \delta 8.58(\mathrm{~s}, 1 \mathrm{H}), 7.75-7.66(\mathrm{~m}, 1 \mathrm{H}), 7.24-7.13(\mathrm{~m}, 2 \mathrm{H}), 3.85-3.76(\mathrm{~m}$, 1H), $3.68-3.58(\mathrm{~m}, 1 \mathrm{H}), 3.04-2.93(\mathrm{~m}, 3 \mathrm{H}), 2.83(\mathrm{td}, J=11.7,2.8 \mathrm{~Hz}, 1 \mathrm{H}), 2.59-2.47(\mathrm{~m}, 1 \mathrm{H}), 2.04-$ $1.96(\mathrm{~m}, 1 \mathrm{H}), 1.87-1.78(\mathrm{~m}, 1 \mathrm{H}), 1.70-1.51(\mathrm{~m}, 2 \mathrm{H}), 1.27(\mathrm{t}, \mathrm{J}=7.4 \mathrm{~Hz}, 3 \mathrm{H}) ;$ AMM (ESI) m/z 355.0882 [calc for $\mathrm{C}_{14} \mathrm{H}_{18} \mathrm{~F}_{2} \mathrm{~N}_{2} \mathrm{O}_{3} \mathrm{SNa}(\mathrm{M}+\mathrm{Na})^{+} 355.0904$ ].

(S)-MCG-III-085-C05 (6v)

$\mathrm{R}=\mathrm{Et}, \mathrm{R}^{\prime}=3-\mathrm{Br}-4-\mathrm{Cl}(11 \%$ yield $)$

${ }^{1} \mathrm{H}$ NMR $\left(500 \mathrm{MHz}\right.$, Acetonitrile- $\left.d_{3}\right) \delta 8.66(\mathrm{~s}, 1 \mathrm{H}), 8.03(\mathrm{~d}, J=2.4 \mathrm{~Hz}, 1 \mathrm{H}), 7.48(\mathrm{dd}, J=8.8,2.4 \mathrm{~Hz}, 1 \mathrm{H})$, $7.43(\mathrm{~d}, J=8.7 \mathrm{~Hz}, 1 \mathrm{H}), 3.85-3.75(\mathrm{~m}, 1 \mathrm{H}), 3.63(\mathrm{~d}, J=12.4 \mathrm{~Hz}, 1 \mathrm{H}), 3.05-2.93(\mathrm{~m}, 3 \mathrm{H}), 2.83(\mathrm{td}, J=$ 
11.7, $2.8 \mathrm{~Hz}, 1 \mathrm{H}), 2.60-2.52(\mathrm{~m}, 1 \mathrm{H}), 2.04-1.97(\mathrm{~m}, 1 \mathrm{H}), 1.88-1.78(\mathrm{~m}, 2 \mathrm{H}), 1.70-1.50(\mathrm{~m}, 3 \mathrm{H}), 1.27$ (t, $J=7.4 \mathrm{~Hz}, 3 \mathrm{H}) ; \mathbf{A M M}(\mathrm{ESI}) \mathrm{m} / \mathrm{z} 430.9807$ [calc for $\mathrm{C}_{14} \mathrm{H}_{18} \mathrm{BrClN}_{2} \mathrm{O}_{3} \mathrm{SNa}(\mathrm{M}+\mathrm{Na})^{+} 430.9808$ ].

(S)-MCG-III-085-C06 (6w)

$\mathrm{R}=\mathrm{Et}, \mathrm{R}^{\prime}=4-\mathrm{Br}-3-\mathrm{Cl}(24 \%$ yield $)$

${ }^{1} \mathrm{H}$ NMR $\left(500 \mathrm{MHz}\right.$, Acetonitrile-d $\left.d_{3}\right) \delta 8.67(\mathrm{~s}, 1 \mathrm{H}), 7.90(\mathrm{~d}, J=2.5 \mathrm{~Hz}, 1 \mathrm{H}), 7.58(\mathrm{~d}, J=8.7 \mathrm{~Hz}, 1 \mathrm{H}), 7.35$ $(\mathrm{dd}, J=8.7,2.5 \mathrm{~Hz}, 1 \mathrm{H}), 3.85-3.76(\mathrm{~m}, 1 \mathrm{H}), 3.67-3.58(\mathrm{~m}, 1 \mathrm{H}), 3.04-2.93(\mathrm{~m}, 3 \mathrm{H}), 2.83(\mathrm{td}, J=11.7$, $2.8 \mathrm{~Hz}, 1 \mathrm{H}), 2.61-2.50(\mathrm{~m}, 1 \mathrm{H}), 2.04-1.97(\mathrm{~m}, 1 \mathrm{H}), 1.86-1.78(\mathrm{~m}, 1 \mathrm{H}), 1.71-1.49(\mathrm{~m}, 2 \mathrm{H}), 1.27(\mathrm{t}, J=$ $7.4 \mathrm{~Hz}, 3 \mathrm{H})$; AMM (ESI) $\mathrm{m} / \mathrm{z} 430.9834$ [calc for $\mathrm{C}_{14} \mathrm{H}_{18} \mathrm{BrClN}_{2} \mathrm{O}_{3} \mathrm{SNa}(\mathrm{M}+\mathrm{Na})^{+} 430.9808$ ].

(S)-MCG-III-085-D01 (6x)

$\mathrm{R}=\mathrm{Ph}, \mathrm{R}^{\prime}=4-\mathrm{Cl}-3-\mathrm{F}(16 \%$ yield $)$

${ }^{1} \mathrm{H}$ NMR $\left(500 \mathrm{MHz}\right.$, Acetonitrile- $\left.d_{3}\right) \delta 8.61(\mathrm{~s}, 1 \mathrm{H}), 7.77-7.71(\mathrm{~m}, 2 \mathrm{H}), 7.71-7.63(\mathrm{~m}, 2 \mathrm{H}), 7.63-7.56(\mathrm{~m}$, $2 \mathrm{H}), 7.35(\mathrm{t}, J=8.6 \mathrm{~Hz}, 1 \mathrm{H}), 7.23-7.15(\mathrm{~m}, 1 \mathrm{H}), 3.85-3.76(\mathrm{~m}, 1 \mathrm{H}), 3.62(\mathrm{~d}, J=11.7 \mathrm{~Hz}, 1 \mathrm{H}), 2.60-$ $2.52(\mathrm{~m}, 2 \mathrm{H}), 2.38(\mathrm{t}, J=11.1 \mathrm{~Hz}, 2 \mathrm{H}), 2.26(\mathrm{td}, J=11.7,2.9 \mathrm{~Hz}, 1 \mathrm{H}), 1.88(\mathrm{dd}, J=13.3,3.6 \mathrm{~Hz}, 1 \mathrm{H}), 1.81$ - $1.73(\mathrm{~m}, 1 \mathrm{H}), 1.65-1.50(\mathrm{~m}, 1 \mathrm{H}), 1.46-1.32(\mathrm{~m}, 1 \mathrm{H})$; AMM (ESI) $\mathrm{m} / \mathrm{z} 419.0588$ [calc for $\left.\mathrm{C}_{18} \mathrm{H}_{18} \mathrm{ClFN}_{2} \mathrm{O}_{3} \mathrm{SNa}(\mathrm{M}+\mathrm{Na})^{+} 419.0608\right]$.

(S)-MCG-III-085-D02 (6y)

$\mathrm{R}=\mathrm{Ph}, \mathrm{R}^{\prime}=3-\mathrm{Cl}-4-\mathrm{F}(21 \%$ yield $)$

${ }^{1} \mathrm{H}$ NMR $\left(500 \mathrm{MHz}\right.$, Acetonitrile- $\left.d_{3}\right) \delta 8.49(\mathrm{~s}, 1 \mathrm{H}), 7.80-7.70(\mathrm{~m}, 3 \mathrm{H}), 7.70-7.62(\mathrm{~m}, 1 \mathrm{H}), 7.62-7.55(\mathrm{~m}$, $2 \mathrm{H}), 7.41-7.32(\mathrm{~m}, 1 \mathrm{H}), 7.15(\mathrm{t}, J=9.1 \mathrm{~Hz}, 1 \mathrm{H}), 3.85-3.77(\mathrm{~m}, 1 \mathrm{H}), 3.67-3.58(\mathrm{~m}, 1 \mathrm{H}), 2.54(\mathrm{tt}, J=$ $11.1,3.8 \mathrm{~Hz}, 1 \mathrm{H}), 2.38(\mathrm{t}, J=11.1 \mathrm{~Hz}, 1 \mathrm{H}), 2.25(\mathrm{td}, J=11.7,2.9 \mathrm{~Hz}, 1 \mathrm{H}), 1.90-1.82(\mathrm{~m}, 1 \mathrm{H}), 1.82-1.72$ $(\mathrm{m}, 1 \mathrm{H}), 1.63-1.50(\mathrm{~m}, 1 \mathrm{H}), 1.45-1.34(\mathrm{~m}, 1 \mathrm{H}) ; \mathrm{AMM}(\mathrm{ESI}) \mathrm{m} / \mathrm{z} 419.0610$ [calc for $\mathrm{C}_{18} \mathrm{H}_{18} \mathrm{ClFN}_{2} \mathrm{O}_{3} \mathrm{SNa}$ $\left.(\mathrm{M}+\mathrm{Na})^{+} 419.0608\right]$.

(S)-MCG-III-085-D03 (6z)

$\mathrm{R}=\mathrm{Ph}, \mathrm{R}^{\prime}=3,4-\mathrm{diCl}(16 \%$ yield $)$

${ }^{1} \mathrm{H}$ NMR $\left(500 \mathrm{MHz}\right.$, Acetonitrile- $\left.d_{3}\right) \delta 8.53(\mathrm{~s}, 1 \mathrm{H}), 7.80-7.72(\mathrm{~m}, 2 \mathrm{H}), 7.68(\mathrm{q}, J=6.9 \mathrm{~Hz}, 2 \mathrm{H}), 7.61(\mathrm{t}, J=$ $7.6 \mathrm{~Hz}, 2 \mathrm{H}), 7.24-7.10(\mathrm{~m}, 2 \mathrm{H}), 3.83(\mathrm{dd}, J=11.8,4.2 \mathrm{~Hz}, 1 \mathrm{H}), 3.64(\mathrm{~d}, J=11.5 \mathrm{~Hz}, 1 \mathrm{H}), 2.65-2.51(\mathrm{~m}$, $1 \mathrm{H}), 2.40(\mathrm{t}, J=11.1 \mathrm{~Hz}, 1 \mathrm{H}), 2.28(\mathrm{td}, J=11.7,3.0 \mathrm{~Hz}, 1 \mathrm{H}), 1.92-1.84(\mathrm{~m}, 1 \mathrm{H}), 1.84-1.75(\mathrm{~m}, 1 \mathrm{H}), 1.66$ - $1.52(\mathrm{~m}, 1 \mathrm{H}), 1.42$ (qd, $J=12.5,3.9 \mathrm{~Hz}, 1 \mathrm{H}$ ); AMM (ESI) $\mathrm{m} / \mathrm{z} 435.0310$ [calc for $\mathrm{C}_{18} \mathrm{H}_{18} \mathrm{Cl}_{2} \mathrm{~N}_{2} \mathrm{O}_{3} \mathrm{SNa}$ $\left.(\mathrm{M}+\mathrm{Na})^{+} 435.0313\right]$.

(S)-MCG-III-085-D04 (6aa)

$\mathrm{R}=\mathrm{Ph}, \mathrm{R}^{\prime}=3,4-\mathrm{diF}(19 \%$ yield $)$

${ }^{1} \mathrm{H}$ NMR $\left(500 \mathrm{MHz}\right.$, Acetonitrile- $\left.d_{3}\right) \delta 8.53(\mathrm{~s}, 1 \mathrm{H}), 7.81-7.72(\mathrm{~m}, 2 \mathrm{H}), 7.68(\mathrm{q}, J=6.9 \mathrm{~Hz}, 2 \mathrm{H}), 7.61(\mathrm{t}, J=$ $7.6 \mathrm{~Hz}, 2 \mathrm{H}), 7.24-7.12(\mathrm{~m}, 2 \mathrm{H}), 3.83(\mathrm{dd}, J=11.8,4.2 \mathrm{~Hz}, 1 \mathrm{H}), 3.64(\mathrm{~d}, J=11.5 \mathrm{~Hz}, 1 \mathrm{H}), 2.63-2.50(\mathrm{~m}$, $1 \mathrm{H}), 2.40(\mathrm{t}, J=11.1 \mathrm{~Hz}, 1 \mathrm{H}), 2.28(\mathrm{td}, J=11.7,3.0 \mathrm{~Hz}, 1 \mathrm{H}), 1.92-1.86(\mathrm{~m}, 1 \mathrm{H}), 1.84-1.74(\mathrm{~m}, 1 \mathrm{H}), 1.59$ (qt, $J=12.3,4.1 \mathrm{~Hz}, 1 \mathrm{H}$ ), 1.42 (qd, $J=12.5,3.9 \mathrm{~Hz}, 1 \mathrm{H}$ ); AMM (ESI) $\mathrm{m} / \mathrm{z} 403.0910$ [calc for $\left.\mathrm{C}_{18} \mathrm{H}_{18} \mathrm{~F}_{2} \mathrm{~N}_{2} \mathrm{O}_{3} \mathrm{SNa}(\mathrm{M}+\mathrm{Na})^{+} 403.0904\right]$.

(S)-MCG-III-085-D05 (6ab)

$\mathrm{R}=\mathrm{Ph}, \mathrm{R}^{\prime}=3-\mathrm{Br}-4-\mathrm{Cl}(7 \%$ yield $)$

${ }^{1} \mathrm{H}$ NMR $\left(500 \mathrm{MHz}\right.$, Acetonitrile- $\left.d_{3}\right) \delta 8.64(\mathrm{~s}, 1 \mathrm{H}), 8.01(\mathrm{~d}, J=2.4 \mathrm{~Hz}, 1 \mathrm{H}), 7.81-7.74(\mathrm{~m}, 2 \mathrm{H}), 7.73-7.67$ $(\mathrm{m}, 1 \mathrm{H}), 7.62(\mathrm{t}, J=7.6 \mathrm{~Hz}, 2 \mathrm{H}), 7.51-7.40(\mathrm{~m}, 2 \mathrm{H}), 3.83(\mathrm{dd}, J=11.6,3.9 \mathrm{~Hz}, 1 \mathrm{H}), 3.64(\mathrm{~d}, J=12.0 \mathrm{~Hz}$, $1 \mathrm{H}), 2.64-2.54(\mathrm{~m}, 1 \mathrm{H}), 2.40(\mathrm{t}, J=11.1 \mathrm{~Hz}, 1 \mathrm{H}), 2.28(\mathrm{td}, J=11.8,3.0 \mathrm{~Hz}, 1 \mathrm{H}), 1.93-1.87(\mathrm{~m}, 1 \mathrm{H}), 1.83$ $-1.76(\mathrm{~m}, 1 \mathrm{H}), 1.59$ (tdd, $J=12.7,8.3,4.1 \mathrm{~Hz}, 1 \mathrm{H}), 1.41$ (qd, $J=12.6,3.9 \mathrm{~Hz}, 1 \mathrm{H}) ;$ AMM $(\mathrm{ESI}) \mathrm{m} / \mathrm{z}$ 478.9834 [calc for $\mathrm{C}_{18} \mathrm{H}_{18} \mathrm{BrClN}_{2} \mathrm{O}_{3} \mathrm{SNa}(\mathrm{M}+\mathrm{Na})^{+} 478.9808$ ].

(S)-MCG-III-085-D06 (6ac)

$\mathrm{R}=\mathrm{Ph}, \mathrm{R}^{\prime}=4-\mathrm{Br}-3-\mathrm{Cl}(10 \%$ yield $)$

${ }^{1} \mathrm{H}$ NMR $\left(500 \mathrm{MHz}\right.$, Acetonitrile- $\left.d_{3}\right) \delta 8.60(\mathrm{~s}, 1 \mathrm{H}), 7.88(\mathrm{~d}, J=2.5 \mathrm{~Hz}, 1 \mathrm{H}), 7.80-7.74(\mathrm{~m}, 2 \mathrm{H}), 7.69(\mathrm{t}, J=$ $7.4 \mathrm{~Hz}, 1 \mathrm{H}), 7.62(\mathrm{t}, J=7.7 \mathrm{~Hz}, 2 \mathrm{H}), 7.58(\mathrm{~d}, J=8.7 \mathrm{~Hz}, 1 \mathrm{H}), 7.34(\mathrm{dd}, J=8.7,2.5 \mathrm{~Hz}, 1 \mathrm{H}), 3.88-3.79(\mathrm{~m}$, $1 \mathrm{H}), 3.64(\mathrm{~d}, J=11.5 \mathrm{~Hz}, 1 \mathrm{H}), 2.58(\mathrm{tt}, J=11.0,3.8 \mathrm{~Hz}, 1 \mathrm{H}), 2.40(\mathrm{t}, J=11.1 \mathrm{~Hz}, 1 \mathrm{H}), 2.28(\mathrm{td}, J=11.8$, 
3.0 Hz, 1H), $1.92-1.85(\mathrm{~m}, 1 \mathrm{H}), 1.83-1.75(\mathrm{~m}, 1 \mathrm{H}), 1.66-1.53(\mathrm{~m}, 1 \mathrm{H}), 1.47-1.34(\mathrm{~m}, 1 \mathrm{H})$; AMM (ESI) $\mathrm{m} / \mathrm{z} 478.9834$ [calc for $\mathrm{C}_{18} \mathrm{H}_{18} \mathrm{BrClN}_{2} \mathrm{O}_{3} \mathrm{SNa}(\mathrm{M}+\mathrm{Na})^{+} 478.9808$ ].

*Analogs 6ad-6ak prepared from intermediate 14 Synthesis of Common Intermediate 14 (MCG-III-115)

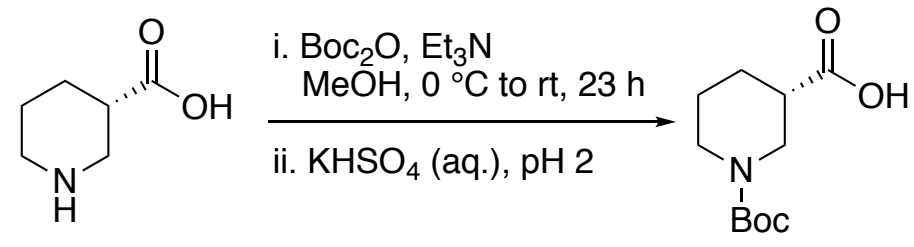

S2

To a precooled $\left(0^{\circ} \mathrm{C}\right)$ solution of $(S)$-3-piperidinecarboxylic acid $(1.00 \mathrm{~g}, 7.74 \mathrm{mmol})$ in $\mathrm{MeOH}(38 \mathrm{~mL})$ under $\mathrm{N}_{2}$ atmosphere was added triethylamine $(2.2 \mathrm{~mL}, 15 \mathrm{mmol})$ then dropwise Boc anhydride $(2.1 \mathrm{~mL}$, $9.3 \mathrm{mmol}$ ). The resulting mixture was allowed to warm to room temperature and stirred for $23 \mathrm{~h}$, then concentrated in vacuo. The crude residue was taken up in $\mathrm{H}_{2} \mathrm{O}$, cooled to $0{ }^{\circ} \mathrm{C}$ and acidified with aq. $\mathrm{KHSO}_{4}$ to $\mathrm{pH}$ 2. The aqueous solution was diluted with EtOAc and the biphasic solution was stirred for $10 \mathrm{~min}$. The layers were separated, and the aqueous phase was extracted with EtOAc (3x). The combined organic layers were washed with $1 \mathrm{M}$ aq. $\mathrm{HCl}$ then brine, dried over $\mathrm{Na}_{2} \mathrm{SO}_{4}$, and concentrated in vacuo to afford the product as a white solid $(1.63 \mathrm{~g}, 92 \% \text { yield). [ } \alpha]_{\mathrm{D}}{ }^{23}-17.8$ (c. $\left.0.64, \mathrm{CH}_{3} \mathrm{OH}\right) ;{ }^{1} \mathrm{H}$ NMR $(500 \mathrm{MHz}$, Chloroform-d) $\delta 4.11(\mathrm{~s}, 1 \mathrm{H}), 3.88(\mathrm{~d}, J=13.4 \mathrm{~Hz}, 1 \mathrm{H}), 3.05(\mathrm{~s}, 1 \mathrm{H}), 2.93-2.81(\mathrm{~m}, 1 \mathrm{H}), 2.56-2.42(\mathrm{~m}$, 1H), $2.13-1.99(\mathrm{~m}, 1 \mathrm{H}), 1.72(\mathrm{dt}, J=13.1,3.9 \mathrm{~Hz}, 1 \mathrm{H}), 1.63-1.68(\mathrm{~m}, 1 \mathrm{H}), 1.46(\mathrm{~s}, 9 \mathrm{H}) ;{ }^{13} \mathrm{C}$ NMR $(126$ $\left.\mathrm{MHz}_{2} \mathrm{CDCl}_{3}\right) \delta 179.09,154.87,80.08,45.68,43.87,41.24,28.51,27.30,24.24$; IR (ATR) $v_{\max } 3150,1731$, $1657,1474,1144,849 \mathrm{~cm}^{-1}$; AMM (ESI) $\mathrm{m} / \mathrm{z} 230.1413$ [calc for $\mathrm{C}_{11} \mathrm{H}_{20} \mathrm{NO}_{4}(\mathrm{M}+\mathrm{H})^{+} 230.1392$ ].

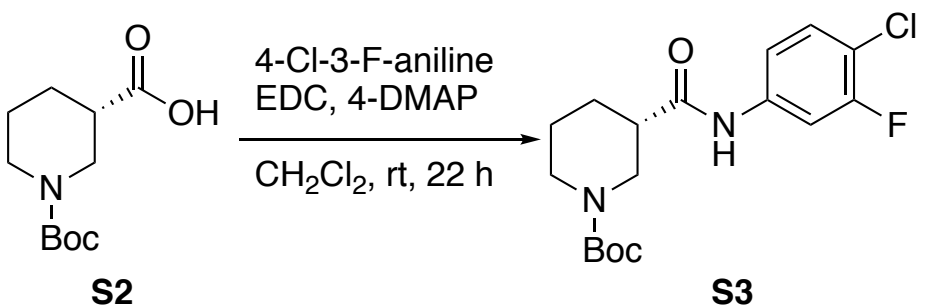

To a flask charged with intermediate $\mathbf{S 2}(2.00,8.72 \mathrm{mmol})$, 4-chloro-3-fluoroaniline $(1.52 \mathrm{~g}, 8.72 \mathrm{mmol}), 1$ ethyl-3-(3-dimethylaminopropyl)carbodiimide $(1.84 \mathrm{~g}, 9.60 \mathrm{mmol})$ and 4-dimethylaminopyridine $(1.17 \mathrm{~g}$, $9.60 \mathrm{mmol}$ ) at room temperature under $\mathrm{N}_{2}$ atmosphere was added $\mathrm{CH}_{2} \mathrm{Cl}_{2}(43 \mathrm{~mL})$. The resulting mixture was stirred at room temperature for $22 \mathrm{~h}$, then quenched with $\mathrm{H}_{2} \mathrm{O}$. The biphasic solution was stirred for 30 min, then the layers were separated, and the aqueous phase was extracted with $\mathrm{CH}_{2} \mathrm{Cl}_{2}$ (3x). The combined organic layers were washed sequentially with sat. aq. $\mathrm{NH}_{4} \mathrm{Cl}$, sat. aq. $\mathrm{NaHCO}_{3}$, and brine, dried over $\mathrm{Na}_{2} \mathrm{SO}_{4}$, and concentrated in vacuo. Flash chromatography $\left(\mathrm{SiO}_{2}, 95: 5 \mathrm{CHCl}_{3}: \mathrm{MeOH}\right)$ afforded the product as a white solid $(2.50 \mathrm{~g}, 80 \% \text { yield). [ } \alpha]_{\mathrm{D}}{ }^{23}+51.0$ (c. $\left.0.42, \mathrm{CH}_{3} \mathrm{OH}\right) ;{ }^{1} \mathrm{H}$ NMR (500 MHz, Chloroform-d) $\delta$ $8.91(\mathrm{~s}, 1 \mathrm{H}), 7.70(\mathrm{dd}, J=11.3,2.3 \mathrm{~Hz}, 1 \mathrm{H}), 7.30-7.26(\mathrm{~m}, 1 \mathrm{H}), 7.21(\mathrm{~d}, J=8.9 \mathrm{~Hz}, 1 \mathrm{H}), 3.85-3.67(\mathrm{~m}$, $1 \mathrm{H}), 3.58(\mathrm{~d}, J=41.0 \mathrm{~Hz}, 2 \mathrm{H}), 3.43-3.21(\mathrm{~m}, 1 \mathrm{H}), 2.58-2.44(\mathrm{~m}, 1 \mathrm{H}), 2.21-2.03(\mathrm{~m}, 1 \mathrm{H}), 1.93-1.80$ $(\mathrm{m}, 1 \mathrm{H}), 1.69-1.54(\mathrm{~m}, 1 \mathrm{H}), 1.46(\mathrm{~s}, 10 \mathrm{H}) ;{ }^{13} \mathrm{C} \mathrm{NMR}\left(126 \mathrm{MHz}, \mathrm{CDCl}_{3}\right) \delta 171.67,159.06,157.10,155.48$, 138.54, 130.43, 115.85, 115.82, 115.54, 108.55, 108.35, 80.71, 77.16, 45.50, 44.92, 43.73, 28.57, 27.73, 24.10; IR (ATR) $v_{\max } 3095,2943,1656,1605,1493,1147,857 \mathrm{~cm}^{-1}$; AMM (ESI) $\mathrm{m} / \mathrm{z} 357.1396$ (ESI) $\mathrm{m} / \mathrm{z}$ [calc for $\mathrm{C}_{17} \mathrm{H}_{23} \mathrm{ClFN}_{2} \mathrm{O}_{3}(\mathrm{M}+\mathrm{H})^{+} 357.1381$ ]. 


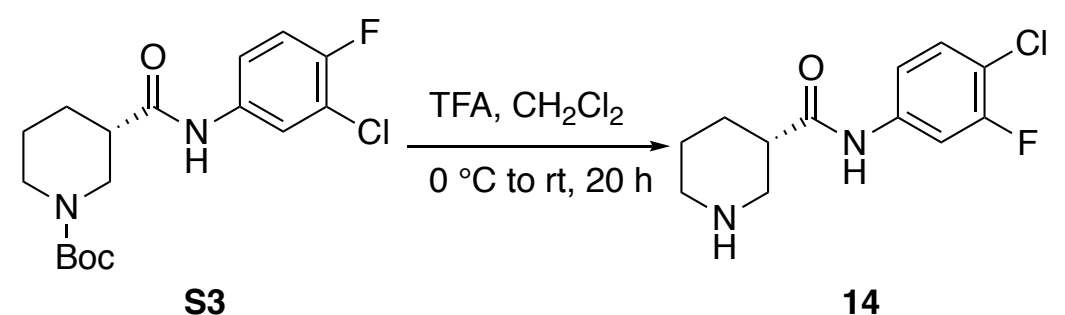

To a precooled $\left(0{ }^{\circ} \mathrm{C}\right)$ solution of intermediate $\mathbf{S 3}(1.07 \mathrm{~g}, 3.00 \mathrm{mmol})$ in $\mathrm{CH}_{2} \mathrm{Cl}_{2}$ under $\mathrm{N}_{2}$ atmosphere was added dropwise trifluoroacetic acid $(1.2 \mathrm{~mL}, 15 \mathrm{mmol})$. The resulting mixture was allowed to warm to room temperature and stirred for $20 \mathrm{~h}$, then concentrated in vacuo. The crude residue was taken up in $\mathrm{H}_{2} \mathrm{O}$ and the resulting mixture was cooled to $0{ }^{\circ} \mathrm{C}$ then slowly neutralized with powdered $\mathrm{NaHCO}_{3}$. The aqueous layer was diluted with $\mathrm{CH}_{2} \mathrm{Cl}_{2}$, the layers were separated, and the aqueous phase was extracted with $\mathrm{CH}_{2} \mathrm{Cl}_{2}$ (3x). The combined organic layers were dried over $\mathrm{Na}_{2} \mathrm{SO}_{4}$ and concentrated in vacuo to afford the product as a white solid $(722 \mathrm{mg}, 94 \% \text { yield). [ } \alpha]_{\mathrm{D}}{ }^{23}+2.6$ (c. $\left.0.72, \mathrm{CH}_{3} \mathrm{OH}\right) ;{ }^{1} \mathrm{H}$ NMR $(500 \mathrm{MHz}$, Chloroform- $d$ ) $\delta$ $10.87(\mathrm{~s}, 1 \mathrm{H}), 7.67(\mathrm{dd}, J=11.2,2.4 \mathrm{~Hz}, 1 \mathrm{H}), 7.32-7.27(\mathrm{~m}, 1 \mathrm{H}), 7.17(\mathrm{dd}, J=8.7,2.3 \mathrm{~Hz}, 1 \mathrm{H}), 3.28(\mathrm{~d}$, $J=12.2 \mathrm{~Hz}, 1 \mathrm{H}), 3.11(\mathrm{~d}, J=11.3 \mathrm{~Hz}, 1 \mathrm{H}), 2.96(\mathrm{~d}, J=12.1 \mathrm{~Hz}, 1 \mathrm{H}), 2.83-2.73(\mathrm{~m}, 1 \mathrm{H}), 2.63-2.56(\mathrm{~m}$, 1H), $2.10-2.01(\mathrm{~m}, 1 \mathrm{H}), 1.83-1.71(\mathrm{~m}, 2 \mathrm{H}), 1.66-1.54(\mathrm{~m}, 1 \mathrm{H}) ;{ }^{13} \mathrm{C}$ NMR $\left(126 \mathrm{MHz}, \mathrm{CDCl}_{3}\right) \delta 174.00$, 159.07, 157.11, 138.67, 138.59, 130.35, 115.92, 115.89, 115.08, 114.94, 108.52, 108.31, 47.79, 46.47, 41.78, 27.52, 22.60; IR (ATR) vmax 3275, 2425, 1670, 1604, 1490, 1201, 857, $719 \mathrm{~cm}^{-1}$; AMM (ESI) m/z 257.0842 [calc for $\mathrm{C}_{12} \mathrm{H}_{15} \mathrm{CIFN} \mathrm{N}_{2} \mathrm{O}(\mathrm{M}+\mathrm{H})^{+} 256.0857$ ].

General Synthesis of Analogs 15a-15h

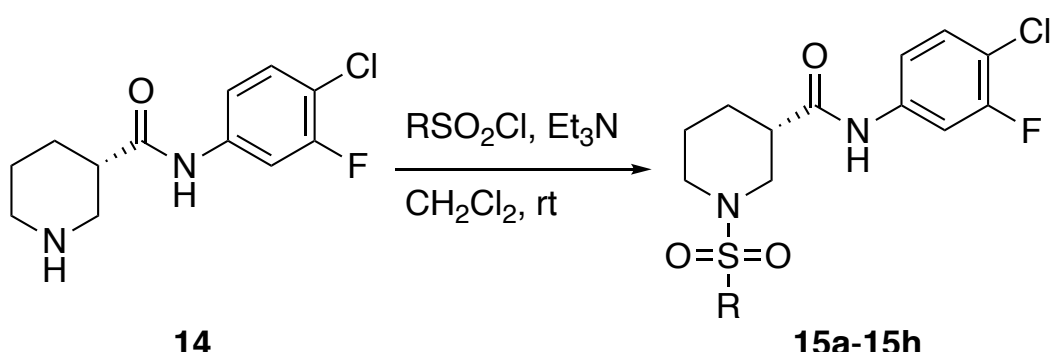

To separate solutions of common intermediate $14(20 . \mathrm{mg}, 0.078 \mathrm{mmol})$ and triethylamine $(30 \mu \mathrm{L}, 0.2 \mathrm{mmol})$ in $\mathrm{CH}_{2} \mathrm{Cl}_{2}(0.5 \mathrm{~mL})$ at ambient temperature was added R-sulfonyl chloride $(0.12 \mathrm{mmol})$. The resulting mixtures were stirred for 18-72 $\mathrm{h}$, then diluted with wet dimethyl sulfoxide $(0.5 \mathrm{~mL})$, filtered through celite and purified via mass-directed isolation using ultra-performance liquid chromatography $(7-91 \%$ yield).

(S)-MCG-III-116-A01 (15a)

$\mathrm{R}=3$-pyridine, $\mathrm{R}^{\prime}=4-\mathrm{Cl}-3-\mathrm{F}(91 \%$ yield $)$

${ }^{1} \mathrm{H}$ NMR $\left(500 \mathrm{MHz}\right.$, Acetonitrile- $\left.d_{3}\right) \delta 8.98(\mathrm{~s}, 1 \mathrm{H}), 8.90-8.79(\mathrm{~m}, 1 \mathrm{H}), 8.61(\mathrm{~s}, 1 \mathrm{H}), 8.20(\mathrm{~d}, J=8.4 \mathrm{~Hz}$, $1 \mathrm{H}), 7.72-7.61(\mathrm{~m}, 2 \mathrm{H}), 7.37(\mathrm{t}, J=8.7 \mathrm{~Hz}, 1 \mathrm{H}), 7.25-7.15(\mathrm{~m}, 1 \mathrm{H}), 3.89(\mathrm{~d}, J=10.7 \mathrm{~Hz}, 1 \mathrm{H}), 3.70(\mathrm{~d}, J$ $=11.5 \mathrm{~Hz}, 1 \mathrm{H}), 2.67-2.48(\mathrm{~m}, 2 \mathrm{H}), 2.42(\mathrm{td}, J=11.8,2.9 \mathrm{~Hz}, 1 \mathrm{H}), 1.86-1.72(\mathrm{~m}, 1 \mathrm{H}), 1.68-1.52(\mathrm{~m}$, $1 \mathrm{H}), 1.52-1.34(\mathrm{~m}, 1 \mathrm{H}) ; \mathbf{A M M}(\mathrm{ESI}) \mathrm{m} / \mathrm{z} 398.0728$ [calc for $\mathrm{C}_{17} \mathrm{H}_{18} \mathrm{ClFN}_{3} \mathrm{O}_{3} \mathrm{~S}(\mathrm{M}+\mathrm{H})^{+} 398.0741$ ].

(S)-MCG-III-116-A02 (15b)

$\mathrm{R}=\mathrm{N}-\mathrm{Me}$ imidazole, $\mathrm{R}^{\prime}=4-\mathrm{Cl}-3-\mathrm{F}(68 \%$ yield $)$

${ }^{1} \mathrm{H}$ NMR $\left(500 \mathrm{MHz}\right.$, Acetonitrile- $\left.d_{3}\right) \delta 8.64(\mathrm{~s}, 1 \mathrm{H}), 7.70(\mathrm{dd}, J=11.8,2.4 \mathrm{~Hz}, 1 \mathrm{H}), 7.62(\mathrm{~d}, J=1.4 \mathrm{~Hz}, 1 \mathrm{H})$, $7.54(\mathrm{~d}, J=1.4 \mathrm{~Hz}, 1 \mathrm{H}$ ), 7.37 (t, $J=8.6 \mathrm{~Hz}, 1 \mathrm{H}$ ), 7.22 (ddd, $J=8.8,2.4,1.2 \mathrm{~Hz}, 1 \mathrm{H}$ ), 3.80 (ddd, $J=11.7$, 3.7, $1.9 \mathrm{~Hz}, 1 \mathrm{H}), 3.71(\mathrm{~s}, 3 \mathrm{H}), 3.63(\mathrm{~d}, J=12.1 \mathrm{~Hz}, 1 \mathrm{H}), 2.65(\mathrm{t}, J=11.1 \mathrm{~Hz}, 1 \mathrm{H}), 2.58(\mathrm{ddt}, J=10.8,7.2$, $3.5 \mathrm{~Hz}, 1 \mathrm{H}), 2.52(\mathrm{td}, J=11.9,3.0 \mathrm{~Hz}, 1 \mathrm{H}), 1.93-1.89(\mathrm{~m}, 1 \mathrm{H}), 1.85-1.74(\mathrm{~m}, 1 \mathrm{H}), 1.65-1.52(\mathrm{~m}, 1 \mathrm{H})$, $1.52-1.39(\mathrm{~m}, 1 \mathrm{H}) ; \mathrm{AMM}(\mathrm{ESI}) \mathrm{m} / \mathrm{z} 401.0858$ [calc for $\mathrm{C}_{16} \mathrm{H}_{19} \mathrm{ClFN}_{4} \mathrm{O}_{3} \mathrm{~S}(\mathrm{M}+\mathrm{H})^{+} 401.0850$ ].

(S)-MCG-III-116-A03 (15c)

$\mathrm{R}=$ cyclohexyl, $\mathrm{R}^{\prime}=4-\mathrm{Cl}-3-\mathrm{F}(19 \%$ yield $)$ 
${ }^{1} \mathrm{H}$ NMR $\left(500 \mathrm{MHz}\right.$, Acetonitrile- $\left.d_{3}\right) \delta 8.71(\mathrm{~s}, 1 \mathrm{H}), 7.72(\mathrm{dd}, J=11.8,2.4 \mathrm{~Hz}, 1 \mathrm{H}), 7.37(\mathrm{t}, J=8.6 \mathrm{~Hz}, 1 \mathrm{H})$, $7.28-7.20(\mathrm{~m}, 1 \mathrm{H}), 3.86-3.76(\mathrm{~m}, 1 \mathrm{H}), 3.63(\mathrm{dt}, J=12.6,3.9 \mathrm{~Hz}, 1 \mathrm{H}), 3.09(\mathrm{dd}, J=12.6,10.3 \mathrm{~Hz}, 1 \mathrm{H})$, $3.02(\mathrm{tt}, J=12.0,3.5 \mathrm{~Hz}, 1 \mathrm{H}), 2.98-2.89(\mathrm{~m}, 1 \mathrm{H}), 2.52(\mathrm{tt}, J=10.6,3.9 \mathrm{~Hz}, 1 \mathrm{H}), 2.09-1.97(\mathrm{~m}, 3 \mathrm{H}), 1.87$ $-1.74(\mathrm{~m}, 3 \mathrm{H}), 1.73-1.61(\mathrm{~m}, 2 \mathrm{H}), 1.60-1.48(\mathrm{~m}, 1 \mathrm{H}), 1.42(\mathrm{qd}, J=12.4,3.5 \mathrm{~Hz}, 2 \mathrm{H}), 1.29$ (qt, $J=12.7$, $3.3 \mathrm{~Hz}, 2 \mathrm{H}$ ), 1.18 (qt, $\mathrm{J}=12.7,3.2 \mathrm{~Hz}, 1 \mathrm{H}$ ); AMM (ESI) $\mathrm{m} / \mathrm{z} 403.1252$ [calc for $\mathrm{C}_{18} \mathrm{H}_{25} \mathrm{ClFN}_{2} \mathrm{O}_{3} \mathrm{~S}(\mathrm{M}+\mathrm{H})^{+}$ 403.1258].

(S)-MCG-III-116-A05 (15d)

$\mathrm{R}=4-\mathrm{OMe}-\mathrm{Ph}, \mathrm{R}^{\prime}=4-\mathrm{Cl}-3-\mathrm{F}(38 \%$ yield $)$

${ }^{1} \mathrm{H}$ NMR $\left(500 \mathrm{MHz}\right.$, Acetonitrile- $\left.d_{3}\right) \delta 8.69(\mathrm{~s}, 1 \mathrm{H}), 7.75-7.65(\mathrm{~m}, 3 \mathrm{H}), 7.37(\mathrm{t}, J=8.6 \mathrm{~Hz}, 1 \mathrm{H}), 7.26-7.19$ $(\mathrm{m}, 1 \mathrm{H}), 7.13-7.04(\mathrm{~m}, 2 \mathrm{H}), 3.87(\mathrm{~s}, 3 \mathrm{H}), 3.84-3.76(\mathrm{~m}, 1 \mathrm{H}), 3.61(\mathrm{~d}, J=11.7 \mathrm{~Hz}, 1 \mathrm{H}), 2.58(\mathrm{tt}, J=11.0$, $3.8 \mathrm{~Hz}, 1 \mathrm{H}), 2.37(\mathrm{t}, J=11.1 \mathrm{~Hz}, 1 \mathrm{H}), 2.25(\mathrm{td}, J=11.7,2.9 \mathrm{~Hz}, 2 \mathrm{H}), 1.90(\mathrm{dd}, J=13.2,3.7 \mathrm{~Hz}, 1 \mathrm{H}), 1.84$ - $1.75(\mathrm{~m}, 1 \mathrm{H}$ ), 1.59 (qt, $J=12.4,4.0 \mathrm{~Hz}, 1 \mathrm{H}), 1.40$ (qd, $J=12.5,3.9 \mathrm{~Hz}, 1 \mathrm{H}$ ); AMM (ESI) m/z 427.0902 [calc for $\mathrm{C}_{19} \mathrm{H}_{21} \mathrm{ClFN}_{2} \mathrm{O}_{4} \mathrm{~S}(\mathrm{M}+\mathrm{H})^{+} 427.0895$ ].

(S)-MCG-III-116-A06 (15e)

$\mathrm{R}=4-\mathrm{CN}-\mathrm{Ph}, \mathrm{R}^{\prime}=4-\mathrm{Cl}-3-\mathrm{F}(7 \%$ yield $)$

${ }^{1} \mathrm{H}$ NMR $(500 \mathrm{MHz}$, Chloroform- $d$ ) $\delta 7.88(\mathrm{q}, J=5.4,3.0 \mathrm{~Hz}, 3 \mathrm{H}), 7.84(\mathrm{~d}, J=18.1 \mathrm{~Hz}, 1 \mathrm{H}), 7.65(\mathrm{~d}, J=$ $10.8 \mathrm{~Hz}, 1 \mathrm{H}), 7.32(\mathrm{t}, J=8.4 \mathrm{~Hz}, 1 \mathrm{H}), 7.13(\mathrm{~d}, J=8.9 \mathrm{~Hz}, 1 \mathrm{H}), 3.67(\mathrm{~d}, J=12.3 \mathrm{~Hz}, 1 \mathrm{H}), 3.52(\mathrm{~d}, J=11.5$ $\mathrm{Hz}, 1 \mathrm{H}), 2.96-2.84(\mathrm{~m}, 1 \mathrm{H}), 2.78-2.56(\mathrm{~m}, 2 \mathrm{H}), 2.01-1.82(\mathrm{~m}, 2 \mathrm{H}), 1.82-1.69(\mathrm{~m}, 2 \mathrm{H})$; AMM (ESI) $\mathrm{m} / \mathrm{z} 422.0743$ [calc for $\mathrm{C}_{19} \mathrm{H}_{18} \mathrm{ClFN}_{3} \mathrm{O}_{3} \mathrm{~S}(\mathrm{M}+\mathrm{H})^{+} 422.0741$ ].

(S)-MCG-III-117 (15f)

$\mathrm{R}=4-(\mathrm{NHC}(\mathrm{O}) \mathrm{Me})-\mathrm{Ph}, \mathrm{R}^{\prime}=4-\mathrm{Cl}-3-\mathrm{F}(42 \%$ yield $)$

${ }^{1} \mathrm{H}$ NMR $\left(500 \mathrm{MHz}\right.$, Acetonitrile- $\left.d_{3}\right) \delta 8.66(\mathrm{~s}, 1 \mathrm{H}), 8.60(\mathrm{~s}, 1 \mathrm{H}), 7.80-7.74(\mathrm{~m}, 2 \mathrm{H}), 7.73-7.64(\mathrm{~m}, 2 \mathrm{H})$, $7.37(\mathrm{t}, J=8.6 \mathrm{~Hz}, 1 \mathrm{H}), 7.25-7.17(\mathrm{~m}, 1 \mathrm{H}), 3.83-3.76(\mathrm{~m}, 1 \mathrm{H}), 3.60(\mathrm{~d}, J=11.5 \mathrm{~Hz}, 1 \mathrm{H}), 2.63-2.51(\mathrm{~m}$, $1 \mathrm{H}), 2.40(\mathrm{t}, J=11.1 \mathrm{~Hz}, 1 \mathrm{H}), 2.29(\mathrm{td}, J=11.6,2.9 \mathrm{~Hz}, 1 \mathrm{H}), 2.10(\mathrm{~s}, 3 \mathrm{H}), 1.92-1.84(\mathrm{~m}, 1 \mathrm{H}), 1.83-1.75$ $(\mathrm{m}, 1 \mathrm{H}), 1.65-1.52(\mathrm{~m}, 1 \mathrm{H}), 1.48-1.36(\mathrm{~m}, 1 \mathrm{H}) ; \mathrm{AMM}(\mathrm{ESI}) \mathrm{m} / \mathrm{z} 454.1022$ [calc for $\mathrm{C}_{20} \mathrm{H}_{22} \mathrm{CIFN}_{3} \mathrm{O}_{4} \mathrm{~S}$ $\left.(\mathrm{M}+\mathrm{H})^{+} 454.1004\right]$.

(S)-MCG-III-132 (15g)

$\mathrm{R}=\mathrm{CF}_{3}, \mathrm{R}^{\prime}=4-\mathrm{Cl}-3-\mathrm{F}(13 \%$ yield $)$

${ }^{1} \mathrm{H}$ NMR $\left(500 \mathrm{MHz}\right.$, Acetonitrile- $\left.d_{3}\right) \delta 8.67(\mathrm{~s}, 1 \mathrm{H}), 7.69(\mathrm{dd}, J=11.8,2.4 \mathrm{~Hz}, 1 \mathrm{H}), 7.38(\mathrm{t}, J=8.6 \mathrm{~Hz}, 1 \mathrm{H})$, $7.29-7.19(\mathrm{~m}, 1 \mathrm{H}), 3.99(\mathrm{~d}, J=13.5 \mathrm{~Hz}, 1 \mathrm{H}), 3.83(\mathrm{~d}, J=13.1 \mathrm{~Hz}, 1 \mathrm{H}), 3.38-3.22(\mathrm{~m}, 1 \mathrm{H}), 3.21-3.07$ $(\mathrm{m}, 1 \mathrm{H}), 2.61(\mathrm{tt}, J=11.1,3.9 \mathrm{~Hz}, 1 \mathrm{H}), 2.40-2.22(\mathrm{~m}, 2 \mathrm{H}), 2.08(\mathrm{~d}, J=12.6 \mathrm{~Hz}, 1 \mathrm{H}), 1.92-1.83(\mathrm{~m}, 1 \mathrm{H})$, $1.79-1.54(\mathrm{~m}, 3 \mathrm{H})$; AMM $411.0157(\mathrm{ESI}) \mathrm{m} / \mathrm{z}$ [calc for $\mathrm{C}_{13} \mathrm{H}_{13} \mathrm{ClF}_{4} \mathrm{~N}_{2} \mathrm{O}_{3} \mathrm{SNa}(\mathrm{M}+\mathrm{Na})^{+} 411.0169$ ].

(S)-MCG-III-128 (15h)

$\mathrm{R}=4-\mathrm{Br}-\mathrm{Ph}, \mathrm{R}^{\prime}=4-\mathrm{Cl}-3-\mathrm{F}(49 \%$ yield $)$

${ }^{1} \mathrm{H}$ NMR $\left(500 \mathrm{MHz}\right.$, Acetonitrile- $\left.d_{3}\right) \delta 8.64(\mathrm{~s}, 1 \mathrm{H}), 7.81-7.75(\mathrm{~m}, 2 \mathrm{H}), 7.72-7.62(\mathrm{~m}, 3 \mathrm{H}), 7.37(\mathrm{t}, J=8.6$ $\mathrm{Hz}, 1 \mathrm{H}), 7.23(\mathrm{dd}, J=9.2,2.4 \mathrm{~Hz}, 1 \mathrm{H}), 3.86-3.77(\mathrm{~m}, 1 \mathrm{H}), 3.63(\mathrm{~d}, J=11.8 \mathrm{~Hz}, 1 \mathrm{H}), 2.58(\mathrm{tt}, J=11.1,3.8$ $\mathrm{Hz}, 1 \mathrm{H}), 2.53-2.42(\mathrm{~m}, 1 \mathrm{H}), 2.34(\mathrm{td}, J=11.8,2.9 \mathrm{~Hz}, 1 \mathrm{H}), 1.92-1.87(\mathrm{~m}, 1 \mathrm{H}), 1.81(\mathrm{dt}, J=13.6,3.5 \mathrm{~Hz}$, $1 \mathrm{H}), 1.66-1.52(\mathrm{~m}, 1 \mathrm{H}), 1.50-1.37(\mathrm{~m}, 1 \mathrm{H}) ; \mathrm{AMM} 496.9738$ (ESI) $\mathrm{m} / \mathrm{z}$ [calc for $\mathrm{C}_{18} \mathrm{H}_{17} \mathrm{BrClFN}_{2} \mathrm{O}_{3} \mathrm{SNa}$ $(\mathrm{M}+\mathrm{Na})^{+}$496.9714].

\section{Synthesis of Analogs 7}

Synthesis of Common Intermediate (S1)

$$
\text { i. } \mathrm{Boc}_{2} \mathrm{O}, \mathrm{Et}_{3} \mathrm{~N}
$$<smiles>NC1CCCNC1</smiles>
$\mathrm{MeOH}, 0{ }^{\circ} \mathrm{C}$ to rt, $17 \mathrm{~h}$ ii. 4-Cl-3-F-benzoic acid

HATU, DIPEA, DMF $0{ }^{\circ} \mathrm{C}$ to rt, $42 \mathrm{~h}$ iii. TFA, $\mathrm{CH}_{2} \mathrm{Cl}_{2}, \mathrm{rt}, 14 \mathrm{~h}$<smiles>O=C(NC1CCCNC1)c1ccc(Cl)c(F)c1</smiles>

S4 
i. To a precooled $\left(0^{\circ} \mathrm{C}\right)$ solution of 3-aminopiperidine $(300 . \mathrm{mg}, 3.00 \mathrm{mmol})$ in $\mathrm{MeOH}(15 \mathrm{~mL})$ under $\mathrm{N}_{2}$ atmosphere was added triethylamine $(0.83 \mathrm{~mL}, 6.0 \mathrm{mmol})$ then Boc anhydride $(0.68$ $\mathrm{mL}, 3.0 \mathrm{mmol}$ ). The resulting mixture was allowed to warm to room temperature and stirred for $17 \mathrm{~h}$, then concentrated in vacuo. The resulting residue was taken up in $\mathrm{CH}_{2} \mathrm{Cl}_{2}$ and quenched with sat. aq. $\mathrm{NaHCO}_{3}$. The layers were separated, and the aqueous phase was extracted with $\mathrm{CH}_{2} \mathrm{Cl}_{2}(3 \mathrm{x})$. The combined organic layers were washed with brine, dried over $\mathrm{Na}_{2} \mathrm{SO}_{4}$, and concentrated in vacuo to afford the product as a white solid $(573 \mathrm{mg})$, which was carried forward without additional purification.

ii. To a precooled $\left(0^{\circ} \mathrm{C}\right)$ solution of intermediate $(350 . \mathrm{mg}, 1.75 \mathrm{mmol})$, 4-chloro-3-fluorobenzoic acid $(366 \mathrm{mg}, 2.10 \mathrm{mmol})$ and HATU $(731 \mathrm{mg}, 1.92 \mathrm{mmol})$ in DMF $(5.8 \mathrm{~mL})$ under $\mathrm{N}_{2}$ atmosphere was added diisopropylethylamine $(0.9 \mathrm{~mL}, 5 \mathrm{mmol})$. The resulting mixture was allowed to warm to room temperature and stirred for $42 \mathrm{~h}$, then concentrated in vacuo. The resulting residue was taken up in $\mathrm{CH}_{2} \mathrm{Cl}_{2}$ and the organic layer was washed with sat. aq. $\mathrm{NaHCO}_{3}$. The aqueous phase was then extracted with $\mathrm{CH}_{2} \mathrm{Cl}_{2}(1 \mathrm{x})$. The combined organic layers were washed with $\mathrm{H}_{2} \mathrm{O}$ and brine, dried over $\mathrm{Na}_{2} \mathrm{SO}_{4}$, and concentrated in vacuo to afford the product as a white solid $(528 \mathrm{mg})$, which was carried forward without additional purification.

iii. To a solution of intermediate $(526 \mathrm{mg}, 1.47 \mathrm{mmol})$ in $\mathrm{CH}_{2} \mathrm{Cl}_{2}(7.4 \mathrm{~mL})$ at room temperature under $\mathrm{N}_{2}$ atmosphere was added trifluoroacetic acid $(0.34 \mathrm{~mL}, 4.4 \mathrm{mmol})$. The resulting mixture was stirred at room temperature for $14 \mathrm{~h}$, followed by addition of trifluoroacetic acid $(0.1 \mathrm{~mL}$, $1.3 \mathrm{mmol}$ ). The resulting mixture was stirred for an additional $24 \mathrm{~h}$, then concentrated in vacuo. The resulting residue was taken up in $\mathrm{CH}_{2} \mathrm{Cl}_{2}$ and diluted with $\mathrm{H}_{2} \mathrm{O}$. The layers were separated, and the organic layer was extracted with $\mathrm{H}_{2} \mathrm{O}(3 \mathrm{x})$. The combined aqueous layers were basified with powdered $\mathrm{NaHCO}_{3}$ to $\mathrm{pH} 8$ then diluted with $\mathrm{CH}_{2} \mathrm{Cl}_{2}$. The layers were separated, and the aqueous phase was extracted with $\mathrm{CH}_{2} \mathrm{Cl}_{2}(3 \mathrm{x})$. The combined organic layers were dried over $\mathrm{Na}_{2} \mathrm{SO}_{4}$ and concentrated in vacuo to afford the product as a white solid (122 mg, 64\% yield over 3 steps). ${ }^{13} \mathrm{C}$ NMR $\left(126 \mathrm{MHz}, \mathrm{CDCl}_{3}\right) \delta$ 165.28, 159.24, 159.10, 157.25, 157.10, 131.23, 131.12, 124.03, 123.23, 123.20, 115.90, 115.72, 49.29, 47.55, 42.96, 28.90, 23.28; IR (ATR) $v_{\max } 3209,1674,1440,1190,1133,801,724 \mathrm{~cm}^{-1}$; AMM 257.0861 (ESI) $\mathrm{m} / \mathrm{z}$ [calc for $\left.\mathrm{C}_{12} \mathrm{H}_{15} \mathrm{CIFN}_{2} \mathrm{O}(\mathrm{M}+\mathrm{H})^{+} 257.0857\right]$.

General Synthesis of Analogs 7

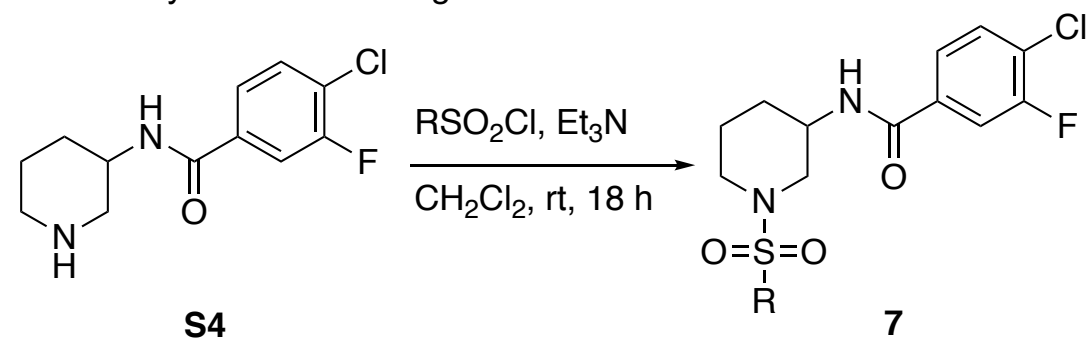

To separate solutions of common intermediate $\mathbf{S} 4(24 \mathrm{mg}, 0.093 \mathrm{mmol})$ and triethylamine $(40 \mu \mathrm{L}, 0.3 \mathrm{mmol})$ in dichloromethane $(0.6 \mathrm{~mL})$ at $0{ }^{\circ} \mathrm{C}$ was added R-sulfonyl chloride $(0.14 \mathrm{mmol})$. The resulting mixtures were stirred for $18 \mathrm{~h}$, then diluted with wet DMSO $(1 \mathrm{~mL})$, filtered through celite and purified via massdirected isolation using ultra-performance liquid chromatography (45-57\% yield).

( \pm )-MCG-III-157-C01 (7a)

$\mathrm{R}=\mathrm{Me}(45 \%$ yield $)$

${ }^{1} \mathrm{H}$ NMR $\left(500 \mathrm{MHz}\right.$, Acetonitrile- $\left.d_{3}\right) \delta 7.67(\mathrm{dd}, J=10.0,1.9 \mathrm{~Hz}, 1 \mathrm{H}), 7.62-7.53(\mathrm{~m}, 2 \mathrm{H}), 7.02(\mathrm{~s}, 1 \mathrm{H}), 4.10$ $-3.97(\mathrm{~m}, 1 \mathrm{H}), 3.66(\mathrm{dd}, J=11.7,3.8 \mathrm{~Hz}, 1 \mathrm{H}), 3.50-3.34(\mathrm{~m}, 1 \mathrm{H}), 2.98-2.86(\mathrm{~m}, 1 \mathrm{H}), 2.78(\mathrm{~s}, 3 \mathrm{H}), 1.92$ - $1.82(\mathrm{~m}, 1 \mathrm{H}), 1.75-1.63(\mathrm{~m}, 1 \mathrm{H}), 1.63-1.53(\mathrm{~m}, 1 \mathrm{H}) ; \mathbf{A M M} 357.0455(\mathrm{ESI}) \mathrm{m} / \mathrm{z}$ [calc for $\left.\mathrm{C}_{13} \mathrm{H}_{16} \mathrm{ClFN}_{2} \mathrm{O}_{3} \mathrm{SNa}(\mathrm{M}+\mathrm{Na})^{+} 357.0452\right]$.

( \pm )-MCG-III-157-C02 (7b)

$\mathrm{R}=\mathrm{Et}(43 \%$ yield $)$ 
${ }^{1} \mathrm{H}$ NMR $(500 \mathrm{MHz}$, Acetonitrile-d3) $\delta 7.67(\mathrm{dd}, J=10.1,1.9 \mathrm{~Hz}, 1 \mathrm{H}), 7.62-7.52(\mathrm{~m}, 2 \mathrm{H}), 7.01(\mathrm{~s}, 1 \mathrm{H}), 4.07$ $-3.92(\mathrm{~m}, 1 \mathrm{H}), 3.70(\mathrm{dd}, J=12.0,3.9 \mathrm{~Hz}, 1 \mathrm{H}), 3.53-3.40(\mathrm{~m}, 1 \mathrm{H}), 3.07-2.94(\mathrm{~m}, 3 \mathrm{H}), 2.90(\mathrm{dd}, J=11.9$, $8.5 \mathrm{~Hz}, 1 \mathrm{H}), 1.90-1.79(\mathrm{~m}, 1 \mathrm{H}), 1.72-1.53(\mathrm{~m}, 2 \mathrm{H}), 1.27(\mathrm{t}, J=7.4 \mathrm{~Hz}, 3 \mathrm{H}) ;$ AMM $371.0603(\mathrm{ESI}) \mathrm{m} / \mathrm{z}$ [calc for C14H18CIFN2O3SNa $(\mathrm{M}+\mathrm{Na})+371.0608$ ].

( \pm )-MCG-III-157-C04 (7c)

$\mathrm{R}=\mathrm{N}-\mathrm{Me}$ Imidazole $(55 \%$ yield $)$

${ }^{1} \mathrm{H}$ NMR $\left(500 \mathrm{MHz}\right.$, Acetonitrile- $\left.d_{3}\right) \delta 7.70(\mathrm{dd}, J=10.1,1.9 \mathrm{~Hz}, 1 \mathrm{H}), 7.65-7.60(\mathrm{~m}, 2 \mathrm{H}), 7.60-7.53(\mathrm{~m}$, $2 \mathrm{H}), 7.40(\mathrm{~s}, 1 \mathrm{H}), 4.07(\mathrm{tt}, J=7.9,4.1 \mathrm{~Hz}, 1 \mathrm{H}), 3.70(\mathrm{~s}, 3 \mathrm{H}), 3.59(\mathrm{dd}, J=12.2,3.7 \mathrm{~Hz}, 1 \mathrm{H}), 3.40-3.30(\mathrm{~m}$, $1 \mathrm{H}), 2.96-2.85(\mathrm{~m}, 2 \mathrm{H}), 1.88-1.80(\mathrm{~m}, 1 \mathrm{H}), 1.80-1.71(\mathrm{~m}, 1 \mathrm{H}), 1.67-1.47(\mathrm{~m}, 2 \mathrm{H})$; AMM 423.0685 (ESI) $\mathrm{m} / \mathrm{z}$ [calc for $\left.\mathrm{C}_{16} \mathrm{H}_{18} \mathrm{ClFN}_{4} \mathrm{O}_{3} \mathrm{SNa}(\mathrm{M}+\mathrm{Na})^{+} 423.0670\right]$.

\section{Synthesis of Analogs 8}

Synthesis of Common Intermediate $\mathbf{S 6}$

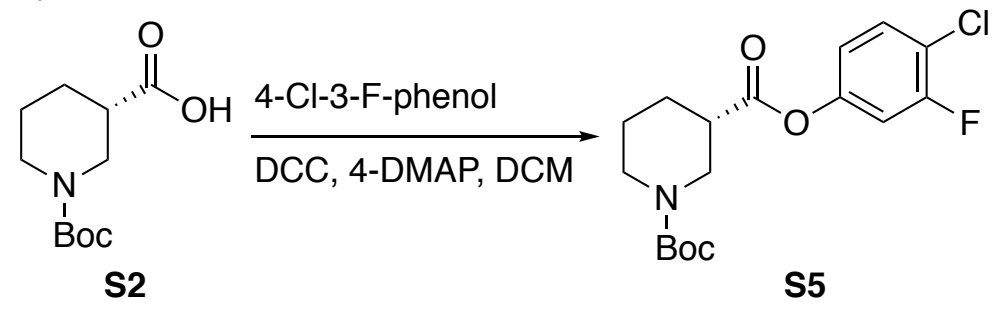

To a solution of intermediate 2.38 (877 $\mathrm{mg}, 3.83 \mathrm{mmol})$, 4-chloro-3-fluorophenol (510 $\mathrm{mg}, 3.48 \mathrm{mmol})$, and 4-dimethylaminopyridine (128 mg, $1.04 \mathrm{mmol})$ in $\mathrm{CH}_{2} \mathrm{Cl}_{2}(24 \mathrm{~mL})$ at room temperature under $\mathrm{N}_{2}$ atmosphere was added dropwise a solution of N,N'-dicyclohexylcarbodiimide (DCC, $1.2 \mathrm{~g}, 5.7 \mathrm{mmol}$ ) in $\mathrm{CH}_{2} \mathrm{Cl}_{2}(14 \mathrm{~mL}$ ). The resulting mixture was stirred for $14 \mathrm{~h}$, then filtered and rinsed with minimal $\mathrm{CH}_{2} \mathrm{Cl}_{2}$. The filtrate was concentrated in vacuo. Flash column chromatography $\left(\mathrm{SiO}_{2}, 90: 10\right.$ hexanes:ethyl acetate, dry loaded on celite) afforded the desired product as a white solid (1.08 g, 87\% yield). [ $\alpha]_{D}{ }^{22}-22.1$ (c. $\left.0.22, \mathrm{CH}_{3} \mathrm{OH}\right) ;{ }^{1} \mathrm{H}$ NMR $(500 \mathrm{MHz}$, Chloroform- $d) \delta 7.38(\mathrm{t}, J=8.5 \mathrm{~Hz}, 1 \mathrm{H}), 6.97$ (dd, $J=9.4,2.6 \mathrm{~Hz}, 1 \mathrm{H}), 6.89-6.82(\mathrm{~m}$, 1H), $4.12(\mathrm{~s}, 1 \mathrm{H}), 3.81(\mathrm{~s}, 1 \mathrm{H}), 3.29(\mathrm{dd}, J=13.3,9.3 \mathrm{~Hz}, 1 \mathrm{H}), 3.10-2.92(\mathrm{~m}, 1 \mathrm{H}), 2.71(\mathrm{~s}, 1 \mathrm{H}), 2.12(\mathrm{~d}, J$ $=12.4 \mathrm{~Hz}, 1 \mathrm{H}), 1.87-1.73(\mathrm{~m}, 2 \mathrm{H}), 1.60-1.49(\mathrm{~m}, 1 \mathrm{H}), 1.46(\mathrm{~s}, 9 \mathrm{H}) ;{ }^{13} \mathrm{C}$ NMR $\left(126 \mathrm{MHz}, \mathrm{CDCl}_{3}\right) \delta 171.45$, 159.07, 157.08, 154.75, 149.84, 149.77, 130.75, 118.49, 118.31, 118.28, 111.12, 110.93, 80.10, 45.64, 41.34, 34.11, 28.55, 27.18, 24.04; IR (ATR) $v_{\max } 2948,1759,1673,1426,1175,1144,1127,997 \mathrm{~cm}^{-1}$; AMM $358.1240(\mathrm{ESI}) \mathrm{m} / \mathrm{z}$ [calc for $\mathrm{C}_{17} \mathrm{H}_{22} \mathrm{CIFNO}_{4}(\mathrm{M}+\mathrm{H})^{+} 358.1221$ ].<smiles>O=C(Oc1ccc(Cl)c(F)c1)C1CNCC(C(=O)Oc2ccc(Cl)c(F)c2)C1</smiles>

To a precooled $\left(0{ }^{\circ} \mathrm{C}\right)$ solution of intermediate $2.54(1.04 \mathrm{~g}, 2.91 \mathrm{mmol})$ in $\mathrm{CH}_{2} \mathrm{Cl}_{2}(15 \mathrm{~mL})$ under $\mathrm{N}_{2}$ atmosphere was added dropwise trifluoroacetic acid $(0.66 \mathrm{~mL}, 8.7 \mathrm{mmol})$. The resulting mixture was allowed to warm to room temperature and stirred for $24 \mathrm{~h}$, then concentrated in vacuo. The resulting residue was taken up in $\mathrm{CH}_{2} \mathrm{Cl}_{2}$ and diluted with $\mathrm{H}_{2} \mathrm{O}$. The layers were separated, and the organic layer was extracted with $\mathrm{H}_{2} \mathrm{O}(3 \mathrm{x})$. The combined aqueous layers were basified with powdered $\mathrm{NaHCO}_{3}$ to $\mathrm{pH} 8$ then diluted with $\mathrm{CH}_{2} \mathrm{Cl}_{2}$. The layers were separated, and the aqueous phase was extracted with $\mathrm{CH}_{2} \mathrm{Cl}_{2}(3 x)$. The combined organic layers were washed with brine, dried over $\mathrm{Na}_{2} \mathrm{SO}_{4}$, and concentrated in vacuo to afford the product as a colorless oil $\left(418 \mathrm{mg}, 84 \%\right.$ yield). ${ }^{1} \mathrm{H}$ NMR $\left(500 \mathrm{MHz}\right.$, Acetonitrile- $\left.d_{3}\right) \delta 8.71(\mathrm{~s}, 1 \mathrm{H})$, $7.97(\mathrm{~s}, 1 \mathrm{H}), 7.53(\mathrm{t}, J=8.6 \mathrm{~Hz}, 1 \mathrm{H}), 7.15(\mathrm{dd}, J=9.9,2.6 \mathrm{~Hz}, 1 \mathrm{H}), 7.05-6.95(\mathrm{~m}, 1 \mathrm{H}), 3.55(\mathrm{dd}, J=12.5$, $3.3 \mathrm{~Hz}, 1 \mathrm{H}), 3.36-3.23(\mathrm{~m}, 2 \mathrm{H}), 3.23-3.12(\mathrm{~m}, 2 \mathrm{H}), 3.08-2.94(\mathrm{~m}, 1 \mathrm{H}), 2.26-2.14(\mathrm{~m}, 1 \mathrm{H}), 1.92-1.81$ (m, 2H); ${ }^{13} \mathrm{C}$ NMR (126 MHz, MeOD) $\delta 171.25,160.08,158.10,151.17,151.09,131.88,119.76,119.73$, 119.32, 119.18, 112.12, 111.93, 49.00, 45.26, 45.02, 44.92, 39.60, 34.68, 26.01, 25.92, 22.29; IR (ATR) 
$v_{\max } 1753,1661,1492,1427,1196,1173,1149,1068,1048,835,795,722 \mathrm{~cm}^{-1} ;$ AMM 258.0695 (ESI) m/z [calc for $\mathrm{C}_{12} \mathrm{H}_{14} \mathrm{CIFNO}_{2}(\mathrm{M}+\mathrm{H})^{+} 258.0697$ ].

General Synthesis of Analogs 8

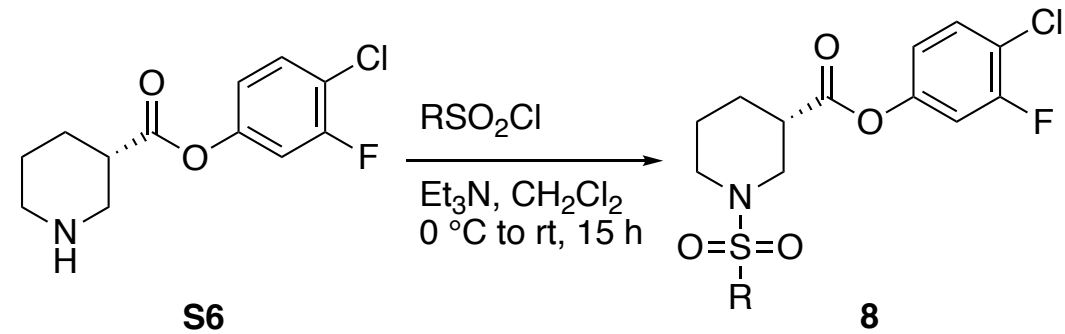

To separate precooled $\left(0{ }^{\circ} \mathrm{C}\right)$ solutions of common intermediate $\mathbf{S 6}(20 . \mathrm{mg}, 0.078 \mathrm{mmol})$ in dichloromethane $(0.5 \mathrm{~mL})$ was added triethylamine $(30 \mu \mathrm{L}, 0.2 \mathrm{mmol})$ and R-sulfonyl chloride $(0.12 \mathrm{mmol})$. The resulting mixtures were allowed to warm to room temperature and stirred for $15 \mathrm{~h}$, then diluted with wet DMSO $(0.5 \mathrm{~mL})$, filtered through celite and purified via mass-directed isolation using ultra-performance liquid chromatography ( $9-45 \%$ yield).

(S)-MCG-III-213-A01 (8a)

$\mathrm{R}=\mathrm{Me}(9 \%$ yield $)$

${ }^{1} \mathrm{H}$ NMR $\left(500 \mathrm{MHz}\right.$, Acetonitrile- $\left.d_{3}\right) \delta 7.52(\mathrm{t}, J=8.6 \mathrm{~Hz}, 1 \mathrm{H}), 7.11(\mathrm{dd}, J=9.9,2.6 \mathrm{~Hz}, 1 \mathrm{H}), 7.02-6.95(\mathrm{~m}$, $1 \mathrm{H}), 3.72(\mathrm{dd}, J=12.0,3.9 \mathrm{~Hz}, 1 \mathrm{H}), 3.41(\mathrm{dt}, J=10.7,4.7 \mathrm{~Hz}, 1 \mathrm{H}), 3.25(\mathrm{dd}, J=11.9,8.7 \mathrm{~Hz}, 1 \mathrm{H}), 3.00-$ $2.96(\mathrm{~m}, 1 \mathrm{H}), 2.96-2.88(\mathrm{~m}, 1 \mathrm{H}), 2.80(\mathrm{~s}, 3 \mathrm{H}), 2.11-2.02(\mathrm{~m}, 1 \mathrm{H}), 1.91-1.83(\mathrm{~m}, 1 \mathrm{H}), 1.83-1.72(\mathrm{~m}$, $1 \mathrm{H}), 1.72-1.62(\mathrm{~m}, 1 \mathrm{H})$; AMM $336.0464(\mathrm{ESI}) \mathrm{m} / \mathrm{z}$ [calc for $\mathrm{C}_{13} \mathrm{H}_{16} \mathrm{CIFNO}_{4} \mathrm{~S}(\mathrm{M}+\mathrm{H})^{+} 336.0473$ ].

(S)-MCG-III-213-A02 (8b)

$\mathrm{R}=\mathrm{Et}(10 \%$ yield $)$

${ }^{1} \mathrm{H}$ NMR $(500 \mathrm{MHz}$, Acetonitrile-d3) $\delta 7.51(\mathrm{t}, J=8.6 \mathrm{~Hz}, 1 \mathrm{H}), 7.11(\mathrm{dd}, J=9.9,2.6 \mathrm{~Hz}, 1 \mathrm{H}), 7.01-6.96$ $(\mathrm{m}, 1 \mathrm{H}), 3.76(\mathrm{dd}, J=12.4,3.9 \mathrm{~Hz}, 1 \mathrm{H}), 3.49-3.41(\mathrm{~m}, 1 \mathrm{H}), 3.33(\mathrm{dd}, J=12.4,8.6 \mathrm{~Hz}, 1 \mathrm{H}), 3.10-3.03$ $(\mathrm{m}, 1 \mathrm{H}), 3.00(\mathrm{q}, J=7.4 \mathrm{~Hz}, 2 \mathrm{H}), 2.89(\mathrm{tt}, J=8.3,3.9 \mathrm{~Hz}, 1 \mathrm{H}), 2.10-2.03(\mathrm{~m}, 1 \mathrm{H}), 1.89-1.75(\mathrm{~m}, 2 \mathrm{H})$, $1.70-1.58(\mathrm{~m}, 1 \mathrm{H}), 1.28(\mathrm{t}, J=7.4 \mathrm{~Hz}, 3 \mathrm{H})$; AMM $350.0648(\mathrm{ESI}) \mathrm{m} / \mathrm{z}$ [calc for C14H18CIFNO4S (M+H)+ 350.0629].

(S)-MCG-III-213-A03 (8c)

$\mathrm{R}=\mathrm{Ph}(9 \%$ yield $)$

${ }^{1} \mathrm{H}$ NMR $\left(500 \mathrm{MHz}\right.$, Acetonitrile- $\left.d_{3}\right) \delta 7.82-7.76(\mathrm{~m}, 2 \mathrm{H}), 7.72-7.66(\mathrm{~m}, 1 \mathrm{H}), 7.65-7.58(\mathrm{~m}, 2 \mathrm{H}), 7.52(\mathrm{t}$, $J=8.6 \mathrm{~Hz}, 1 \mathrm{H}), 7.10(\mathrm{dd}, J=9.9,2.6 \mathrm{~Hz}, 1 \mathrm{H}), 7.01-6.95(\mathrm{~m}, 1 \mathrm{H}), 3.60(\mathrm{~d}, J=11.2 \mathrm{~Hz}, 1 \mathrm{H}), 3.35-3.26$ (m, 1H), $3.01-2.94(\mathrm{~m}, 1 \mathrm{H}), 2.91(\mathrm{tt}, J=8.7,3.9 \mathrm{~Hz}, 1 \mathrm{H}), 2.74-2.65(\mathrm{~m}, 1 \mathrm{H}), 1.89-1.77(\mathrm{~m}, 1 \mathrm{H}), 1.70-$ $1.57(\mathrm{~m}, 2 \mathrm{H})$; AMM $398.0639(\mathrm{ESI}) \mathrm{m} / \mathrm{z}$ [calc for $\left.\mathrm{C}_{18} \mathrm{H}_{18} \mathrm{ClFNO}_{4} \mathrm{~S}(\mathrm{M}+\mathrm{H})^{+} 398.0629\right]$.

(S)-MCG-III-213-A04 (8d)

$\mathrm{R}=\mathrm{N}-\mathrm{Me}$ Imidazole $(45 \%$ yield $)$

${ }^{1} \mathrm{H}$ NMR $(500 \mathrm{MHz}$, Acetonitrile-d3) $\delta 7.63(\mathrm{~d}, J=1.4 \mathrm{~Hz}, 1 \mathrm{H}), 7.56(\mathrm{~d}, J=1.4 \mathrm{~Hz}, 1 \mathrm{H}), 7.51(\mathrm{t}, J=8.6 \mathrm{~Hz}$, 1H), $7.11(\mathrm{dd}, J=9.9,2.6 \mathrm{~Hz}, 1 \mathrm{H}), 7.01-6.95(\mathrm{~m}, 1 \mathrm{H}), 3.75-3.72(\mathrm{~m}, 1 \mathrm{H}), 3.71(\mathrm{~s}, 3 \mathrm{H}), 3.40(\mathrm{dd}, J=$ $12.3,5.1 \mathrm{~Hz}, 1 \mathrm{H}), 3.10(\mathrm{dd}, J=12.1,9.1 \mathrm{~Hz}, 1 \mathrm{H}), 2.92(\mathrm{tt}, J=9.0,4.0 \mathrm{~Hz}, 1 \mathrm{H}), 2.81$ (ddd, $J=12.9,9.6,3.4$ $\mathrm{Hz}, 1 \mathrm{H}), 2.05-1.97(\mathrm{~m}, 1 \mathrm{H}), 1.87-1.78(\mathrm{~m}, 1 \mathrm{H}), 1.70-1.56(\mathrm{~m}, 2 \mathrm{H}) ;$ AMM $402.0697(\mathrm{ESI}) \mathrm{m} / \mathrm{z}$ [calc for C16H18CIFN3O4S $(\mathrm{M}+\mathrm{H})+402.0691]$.

\section{Synthesis of Analog 9}




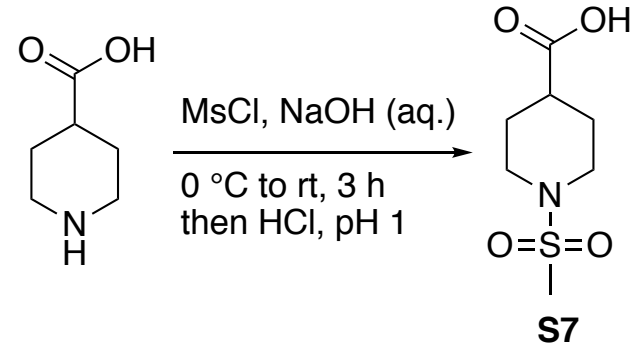

To a precooled $\left(0^{\circ} \mathrm{C}\right)$ solution of 4-piperidine carboxylic acid $(1.0 \mathrm{~g}, 7.7 \mathrm{mmol})$ in $1 \mathrm{M}$ aq. $\mathrm{NaOH}(15 \mathrm{~mL})$ was added methanesulfonyl chloride $(0.72 \mathrm{~mL}, 9.3 \mathrm{mmol})$. The resulting mixture was stirred at $0{ }^{\circ} \mathrm{C}$ to room temperature for $3 \mathrm{~h}$, then quenched slowly with $6 \mathrm{M}$ aq. $\mathrm{HCl}$ and diluted with EtOAc. The layers were separated, and the aqueous phase was extracted with EtOAc (3x). The combined organic layers were dried over $\mathrm{Na}_{2} \mathrm{SO}_{4}$ and concentrated in vacuo to afford the product as a white solid ( $264 \mathrm{mg}, 16 \%$ yield). ${ }^{1} \mathrm{H}$ NMR (500 MHz, Chloroform-d) ठ $3.73-3.62(\mathrm{~m}, 2 \mathrm{H}), 2.94-2.83(\mathrm{~m}, 2 \mathrm{H}), 2.79(\mathrm{~s}, 3 \mathrm{H}), 2.11-2.01(\mathrm{~m}, 2 \mathrm{H}), 1.94$ -1.77 (m, 3H); ${ }^{13} \mathrm{C}$ NMR (126 MHz, CDCl 3 ) $\delta 179.40,45.14,39.85,35.23,27.51$; IR (ATR) $v_{\max } 2936,1697$, 1320, 1141, 920, 776, $518 \mathrm{~cm}^{-1}$; AMM (ESI) $\mathrm{m} / \mathrm{z} 208.0641$ [calc for $\mathrm{C}_{7} \mathrm{H}_{14} \mathrm{NO}_{4} \mathrm{~S}(\mathrm{M}+\mathrm{H})^{+}$208.0644].

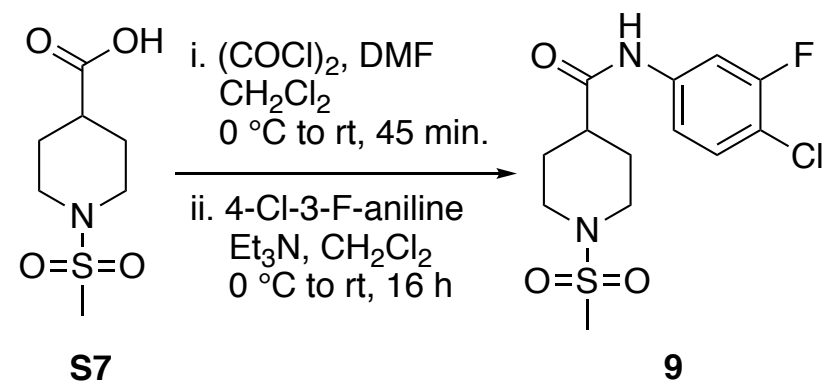

i. To a precooled $\left(0^{\circ} \mathrm{C}\right)$ solution of intermediate $\mathbf{S 7}$ (100. $\left.\mathrm{mg}, 0.41 \mathrm{mmol}\right)$ in $\mathrm{CH}_{2} \mathrm{Cl}_{2}(2 \mathrm{~mL})$ under $\mathrm{N}_{2}$ atmosphere was added dropwise oxalyl chloride $(0.04 \mathrm{~mL}, 0.4 \mathrm{mmol})$ then DMF (1 drop). The resulting mixture was allowed to warm to room temperature and stirred for $45 \mathrm{~min}$. then concentrated in vacuo and carried forward without additional purification.

ii. To a precooled $\left(0^{\circ} \mathrm{C}\right)$ solution of 4-chloro-3-fluoroaniline $(60 . \mathrm{mg}, 0.41 \mathrm{mmol})$ and triethylamine $(0.1 \mathrm{~mL}, 0.8 \mathrm{mmol})$ in $\mathrm{CH}_{2} \mathrm{Cl}_{2}(1 \mathrm{~mL})$ was added a precooled $\left(0{ }^{\circ} \mathrm{C}\right)$ solution of acid chloride intermediate (93 mg, $0.41 \mathrm{mmol})$ in $\mathrm{CH}_{2} \mathrm{Cl}_{2}(3 \mathrm{~mL})$. The resulting mixture was allowed to warm to room temperature and stirred for $16 \mathrm{~h}$, then quenched with $\mathrm{H}_{2} \mathrm{O}$. The layers were separated, and the aqueous phase was extracted with $\mathrm{CH}_{2} \mathrm{Cl}_{2}(3 \mathrm{x})$. The combined organic layers were washed with brine, dried over $\mathrm{Na}_{2} \mathrm{SO}_{4}$, and concentrated in vacuo. Flash chromatography $\left(\mathrm{SiO}_{2}, 50: 50\right.$ ethyl acetate: hexanes) afforded the product as a white solid (91 mg, 66\% yield). ${ }^{1} \mathrm{H}$ NMR $\left(500 \mathrm{MHz}\right.$, Acetonitrile- $\left.d_{3}\right) \delta 8.52(\mathrm{~s}, 1 \mathrm{H}), 7.73(\mathrm{dd}, J=11.9,2.7 \mathrm{~Hz}, 1 \mathrm{H}), 7.37$ (dd, $J$ $=10.1,7.3 \mathrm{~Hz}, 1 \mathrm{H}), 7.24(\mathrm{~d}, J=8.6 \mathrm{~Hz}, 1 \mathrm{H}), 3.75-3.63(\mathrm{~m}, 2 \mathrm{H}), 2.84-2.68(\mathrm{~m}, 5 \mathrm{H}), 2.50-$ $2.36(\mathrm{~m}, 1 \mathrm{H}), 1.83-1.68(\mathrm{~m}, 2 \mathrm{H})$; AMM (ESI) $\mathrm{m} / \mathrm{z} 335.0640$ [calc for $\mathrm{C}_{13} \mathrm{H}_{17} \mathrm{CIFN}_{2} \mathrm{O}_{3} \mathrm{~S}(\mathrm{M}+\mathrm{H})^{+}$ 335.0632].

\section{Syntheses of Common Intermediates 10}

Synthesis of Common Intermediate 10a (MCG-III-196)

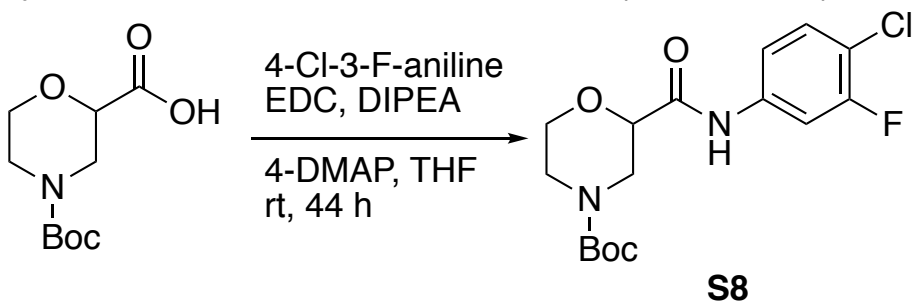

To a precooled $\left(0^{\circ} \mathrm{C}\right)$ solution of 4-Boc-morpholine-2-carboxylic acid (400. $\left.\mathrm{mg}, 1.73 \mathrm{mmol}\right)$, 4-chloro-3fluoroaniline (378 mg, $2.60 \mathrm{mmol}$ ), 1-ethyl-3-(3-dimethylaminopropyl)-carbodiimide hydrochloride (EDCl, $269 \mathrm{mg}, 1.73 \mathrm{mmol}$ ) and 4-dimethylaminopyridine (42 mg, $0.35 \mathrm{mmol})$ in tetrahydrofuran (17 mL) under $\mathrm{N}_{2}$ 
atmosphere was added diisopropylethylamine $(0.75 \mathrm{~mL}, 4.3 \mathrm{mmol})$. The resulting mixture was allowed to warm to room temperature and stirred for $44 \mathrm{~h}$ then quenched with sat. aq. $\mathrm{NaHCO}_{3}$ and diluted with $\mathrm{EtOAc}$. The layers were separated, and the aqueous phase was extracted with ethyl acetate $(3 \mathrm{x})$. The combined organic layers were washed with brine, dried over $\mathrm{Na}_{2} \mathrm{SO}_{4}$, and concentrated in vacuo. Flash column chromatography $\left(\mathrm{SiO}_{2}, 70: 30\right.$ hexanes:ethyl acetate) afforded the product as a white solid $(330 \mathrm{mg}, 53 \%$ yield). ${ }^{1} \mathrm{H}$ NMR $(500 \mathrm{MHz}$, Chloroform- $d$ ) $\delta 8.34(\mathrm{~s}, 1 \mathrm{H}), 7.66(\mathrm{dd}, J=10.9,2.4 \mathrm{~Hz}, 1 \mathrm{H}), 7.32(\mathrm{t}, J=8.3 \mathrm{~Hz}$, $1 \mathrm{H}), 7.21-7.13(\mathrm{~m}, 1 \mathrm{H}), 4.41(\mathrm{~s}, 1 \mathrm{H}), 4.11-3.92(\mathrm{~m}, 3 \mathrm{H}), 3.64(\mathrm{td}, J=11.8,2.8 \mathrm{~Hz}, 1 \mathrm{H}), 3.02-2.74(\mathrm{~m}$, 2H), 1.48 (s, 9H); ${ }^{13} \mathrm{C}$ NMR (126 MHz, CDCl $) \delta 167.04,159.18,157.21,154.61,137.10,137.02,130.70$, 116.40, 116.26, 115.88, 115.85, 108.64, 108.44, 80.88, 75.12, 66.88, 46.17, 28.50; IR (ATR) vmax 3398, 2925, 1691, 1527, 1416, 1127, 868, 809, $605 \mathrm{~cm}^{-1}$; AMM 359.1197 (ESI) $\mathrm{m} / \mathrm{z}$ [calc for $\mathrm{C}_{16} \mathrm{H}_{21} \mathrm{CIFN}_{2} \mathrm{O}_{4}$ $(\mathrm{M}+\mathrm{H})^{+}$359.1174].<smiles>O=C(Nc1ccc(Cl)c(F)c1)C1CNCC(C(=O)Nc2ccc(Cl)c(F)c2)O1</smiles>

To a precooled $\left(0{ }^{\circ} \mathrm{C}\right)$ solution of intermediate 2.72 (300. $\left.\mathrm{mg}, 0.836 \mathrm{mmol}\right)$ in $\mathrm{CH}_{2} \mathrm{Cl}_{2}(8.4 \mathrm{~mL})$ under $\mathrm{N}_{2}$ atmosphere was added dropwise trifluoroacetic acid $(0.2 \mathrm{~mL}, 3 \mathrm{mmol})$. The resulting mixture was allowed to warm to room temperature and stirred for $22 \mathrm{~h}$, then cooled to $0{ }^{\circ} \mathrm{C}$ before addition of trifluoroacetic acid $(0.2 \mathrm{~mL}, 3 \mathrm{mmol})$. The resulting mixture was allowed to warm to room temperature and stirred for $36 \mathrm{~h}$, then concentrated in vacuo. The resulting residue was taken up in $\mathrm{CH}_{2} \mathrm{Cl}_{2}$ and the solution was quenched with sat. aq. $\mathrm{NaHCO}_{3}$. The layers were separated, and the aqueous phase was extracted with $\mathrm{CH}_{2} \mathrm{Cl}_{2}(3 \mathrm{x})$. The combined organic layers were dried over $\mathrm{Na}_{2} \mathrm{SO}_{4}$ and concentrated in vacuo to afford the product as a white solid (233 mg, 98\% yield). ${ }^{1} \mathrm{H}$ NMR $\left(500 \mathrm{MHz}\right.$, Acetonitrile- $\left.d_{3}\right) \delta 8.92(\mathrm{~s}, 1 \mathrm{H}), 7.70$ (dd, $J=11.6,2.4$ $\mathrm{Hz}, 1 \mathrm{H}), 7.41(\mathrm{t}, J=8.5 \mathrm{~Hz}, 1 \mathrm{H}), 7.37-7.31(\mathrm{~m}, 1 \mathrm{H}), 4.53(\mathrm{dd}, J=10.7,2.8 \mathrm{~Hz}, 1 \mathrm{H}), 4.19-4.10(\mathrm{~m}, 1 \mathrm{H})$, 3.99 (ddd, $J=13.1,11.4,2.6 \mathrm{~Hz}, 1 \mathrm{H}), 3.67-3.59(\mathrm{~m}, 1 \mathrm{H}), 3.31(\mathrm{~d}, J=13.1 \mathrm{~Hz}, 1 \mathrm{H}), 3.20-3.09(\mathrm{~m}, 2 \mathrm{H})$; ${ }^{13} \mathrm{C}$ NMR $\left(126 \mathrm{MHz}, \mathrm{CDCl}_{3}\right) \delta 159.16,157.19,137.30,137.23,130.65,116.19,116.05,115.86,115.83$, 108.59, 108.39, 100.12, 34.26; IR (ATR) vmax 3380, 2500, 1708, 1663, 1522, 1426, 1196, 1171, 1130, 1066, 836, 792, 725, $473 \mathrm{~cm}^{-1}$; AMM 259.0669 (ESI) $\mathrm{m} / \mathrm{z}$ [calc for $\mathrm{C}_{11} \mathrm{H}_{13} \mathrm{ClFN}_{2} \mathrm{O}_{2}(\mathrm{M}+\mathrm{H})^{+} 259.0650$ ].

Synthesis of Common Intermediate 10b (MCG-III-210)

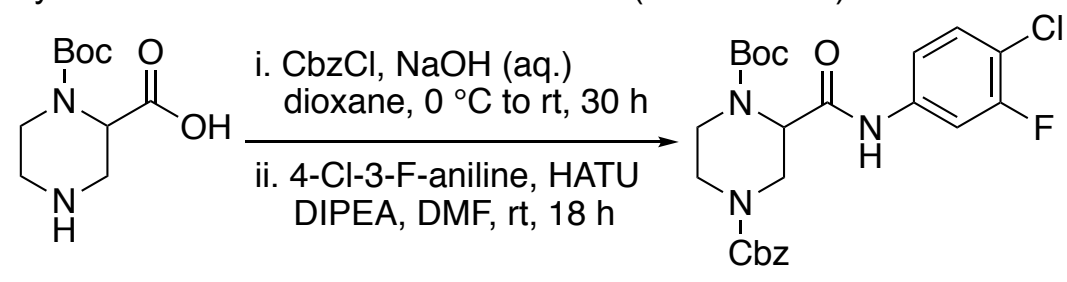

S9

i. To a precooled $\left(0^{\circ} \mathrm{C}\right)$ solution of 1-Boc-piperazine-2-carboxylic acid $(500 . \mathrm{mg}, 2.17 \mathrm{mmol})$ in 1,4-dioxane $(11 \mathrm{~mL})$ under $\mathrm{N}_{2}$ atmosphere was added $1 \mathrm{M}$ aq. $\mathrm{NaOH}$ until $\mathrm{pH} 11$ achieved. To the resulting mixture was then added dropwise benzyl chloroformate $(0.31 \mathrm{~mL}, 2.17 \mathrm{mmol})$ followed by additional $1 \mathrm{M}$ aq. $\mathrm{NaOH}$ to maintain $\mathrm{pH} 11$. The resulting mixture was allowed to warm to room temperature and stirred for $3 \mathrm{~h}$, then cooled to $0{ }^{\circ} \mathrm{C}$ before addition of benzyl chloroformate $(0.31 \mathrm{~mL}, 2.17 \mathrm{mmol})$ and $1 \mathrm{M}$ aq. $\mathrm{NaOH}$ to maintain $\mathrm{pH} 11$. The resulting mixture was allowed to warm to room temperature and stirred for $28 \mathrm{~h}$, then cooled to $0{ }^{\circ} \mathrm{C}$ and acidified slowly with $1 \mathrm{M}$ aq. $\mathrm{HCl}$ to $\mathrm{pH} 2$. The aqueous layer was diluted with EtOAc and the layers were separated then the aqueous phase was extracted with EtOAc (3x). The combined organic layers were washed with brine, dried over $\mathrm{Na}_{2} \mathrm{SO}_{4}$, and concentrated in vacuo to afford the product, which was carried forward.

ii. $\quad$ To a solution of intermediate $(586 \mathrm{mg}, 1.61 \mathrm{mmol}), 4$-chloro-3-fluoroaniline $(281 \mathrm{mg}, 1.93$ $\mathrm{mmol})$, and HATU $(673 \mathrm{mg}, 1.77 \mathrm{mmol})$ in DMF $(8.0 \mathrm{~mL})$ at room temperature under $\mathrm{N}_{2}$ 
atmosphere was added diisopropylethylamine $(0.84 \mathrm{~mL}, 4.8 \mathrm{mmol})$. The resulting mixture was stirred at room temperature for $18 \mathrm{~h}$ then concentrated in vacuo. The resulting residue was taken up in EtOAc and quenched with $\mathrm{H}_{2} \mathrm{O}$. The layers were separated, and the aqueous phase was extracted with EtOAc (3x). The combined organic layers were washed with brine, dried over $\mathrm{Na}_{2} \mathrm{SO}_{4}$ and concentrated in vacuo. Flash chromatography $\left(\mathrm{SiO}_{2}, 50: 50\right.$ hexanes:EtOAc) afforded the product as a white solid $\left(216 \mathrm{mg}, 20 \%\right.$ yield over 2 steps). ${ }^{1} \mathbf{H}$ NMR $(500 \mathrm{MHz}$, Chloroform- $d$ ) $\delta 8.76(\mathrm{~s}, 1 \mathrm{H}), 7.61(\mathrm{~d}, J=10.5 \mathrm{~Hz}, 1 \mathrm{H}), 7.30(\mathrm{t}, J=8.4 \mathrm{~Hz}, 1 \mathrm{H}), 7.11-7.04(\mathrm{~m}$, $1 \mathrm{H}), 4.59(\mathrm{~d}, J=4.2 \mathrm{~Hz}, 1 \mathrm{H}), 3.91(\mathrm{~s}, 1 \mathrm{H}), 3.56(\mathrm{~d}, J=13.2 \mathrm{~Hz}, 1 \mathrm{H}), 3.05-2.92(\mathrm{~m}, 2 \mathrm{H}), 2.88$ $(\mathrm{dd}, J=13.4,4.3 \mathrm{~Hz}, 1 \mathrm{H}), 2.78(\mathrm{td}, J=12.4,3.5 \mathrm{~Hz}, 1 \mathrm{H}), 1.52(\mathrm{~s}, 9 \mathrm{H}) ;{ }^{13} \mathrm{C}$ NMR $(126 \mathrm{MHz}$, $\left.\mathrm{CDCl}_{3}\right) \delta 174.33,147.70,143.90,139.16,129.72,127.25,125.47,119.69,117.66,114.46$, 52.08, 43.73, 38.55, 29.84; IR (ATR) $v_{\max } 3285,2925,2850,1653,1525,1321,1154,983,948$, $826,790,506 \mathrm{~cm}^{-1}$; AMM $492.1708(\mathrm{ESI}) \mathrm{m} / \mathrm{z}$ [calc for $\mathrm{C}_{24} \mathrm{H}_{28} \mathrm{ClFN}_{3} \mathrm{O}_{5}(\mathrm{M}+\mathrm{H})^{+} 492.1702$ ].

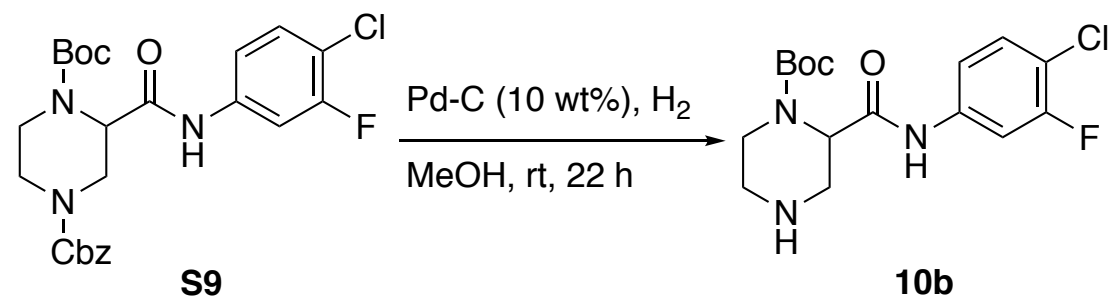

To a solution of palladium on carbon (10 wt. \%, $17 \mathrm{mg}, 0.16 \mathrm{mmol})$ in $\mathrm{MeOH}(3 \mathrm{~mL})$ at room temperature under $\mathrm{N}_{2}$ atmosphere was added a solution of intermediate 2.79 (389 mg, $\left.0.791 \mathrm{mmol}\right)$ in $\mathrm{MeOH}(5 \mathrm{~mL})$. The resulting mixture was then backfilled with $\mathrm{H}_{2}(3 \mathrm{x})$ then stirred at room temperature under $\mathrm{H}_{2}$ atmosphere for $22 \mathrm{~h}$. The resulting mixture was filtered through a bed of celite and rinsed with $\mathrm{MeOH}$. The filtrate was concentrated in vacuo. Flash chromatography $\left(\mathrm{SiO}_{2}, 95: 5 \mathrm{CH}_{2} \mathrm{Cl}_{2}: \mathrm{MeOH}\right)$ afforded the product as a white solid (152 mg, 53\% yield). ${ }^{1} \mathrm{H}$ NMR (500 MHz, Acetonitrile-d3) $\delta 9.47(\mathrm{~s}, 1 \mathrm{H}), 7.74$ (dd, J = 11.6, $2.4 \mathrm{~Hz}$, $1 \mathrm{H}), 7.45(\mathrm{t}, J=8.5 \mathrm{~Hz}, 1 \mathrm{H}), 7.35(\mathrm{~d}, J=8.8 \mathrm{~Hz}, 1 \mathrm{H}), 4.01(\mathrm{~s}, 1 \mathrm{H}), 3.51-3.43(\mathrm{~m}, 1 \mathrm{H}), 3.37(\mathrm{dd}, J=12.9$, $7.5 \mathrm{~Hz}, 1 \mathrm{H}), 3.24-3.09(\mathrm{~m}, 3 \mathrm{H}), 2.54(\mathrm{~s}, 1 \mathrm{H}), 1.95$ (s, 9H); IR (ATR) v $v_{\max } 2456,1660,1607,1533,1429$, 1182, 1137, 867, 797, 724, $596 \mathrm{~cm}^{-1}$; AMM 358.1334 (ESI) $\mathrm{m} / z$ [calc for $\mathrm{C}_{16} \mathrm{H}_{22} \mathrm{ClFN}_{3} \mathrm{O}_{3}(\mathrm{M}+\mathrm{H})^{+} 358.1334$ ].

Synthesis of Compound 10c (MCG-III-216-A01)<smiles>O=C(Nc1ccc(Cl)c(F)c1)C1CNCC(C(=O)Nc2ccc(Cl)c(F)c2)N1</smiles>

$10 \mathrm{~b}$

$10 \mathrm{c}$

To a precooled $\left(0{ }^{\circ} \mathrm{C}\right)$ solution of $10 \mathrm{~b}(10 . \mathrm{mg}, 0.028 \mathrm{mmol})$ in dichloromethane $(0.5 \mathrm{~mL})$ was added trifluoroacetic acid $(10 \mu \mathrm{L}, 0.1 \mathrm{mmol})$. The resulting mixtures were allowed to warm to room temperature and stirred for $18 \mathrm{~h}$, then diluted with wet DMSO $(0.5 \mathrm{~mL})$, filtered through celite and purified via massdirected isolation using ultra-performance liquid chromatography $(13.2 \mathrm{mg}, 85 \%$ yield).

${ }^{1} \mathrm{H}$ NMR $\left(500 \mathrm{MHz}\right.$, Acetonitrile-d $\left.d_{3}\right) \delta 9.73(\mathrm{~s}, 1 \mathrm{H}), 7.67(\mathrm{dd}, J=11.3,2.6 \mathrm{~Hz}, 1 \mathrm{H}), 7.44(\mathrm{t}, J=8.4 \mathrm{~Hz}, 1 \mathrm{H})$, $7.35-7.24(\mathrm{~m}, 1 \mathrm{H}), 4.34(\mathrm{~s}, 1 \mathrm{H}), 3.67(\mathrm{~s}, 1 \mathrm{H}), 3.47(\mathrm{dd}, J=13.4,9.1 \mathrm{~Hz}, 1 \mathrm{H}), 3.43-3.22(\mathrm{~m}, 4 \mathrm{H}), 2.10-$ $2.03(\mathrm{~m}, 1 \mathrm{H})$; AMM $258.0818(\mathrm{ESI}) \mathrm{m} / \mathrm{z}$ [calc for $\mathrm{C}_{11} \mathrm{H}_{14} \mathrm{CIFN}_{3} \mathrm{O}(\mathrm{M}+\mathrm{H})^{+} 258.0809$ ].

Synthesis of Common Intermediate 10d (MCG-III-209)<smiles>COC(=O)c1cnc2ccc(-c3ccccc3)cc2c1</smiles> 
To a precooled $\left(0^{\circ} \mathrm{C}\right)$ solution of quinoline-3-carboxylic acid $(1.50 \mathrm{~g}, 8.66 \mathrm{mmol})$ in $\mathrm{MeOH}(43 \mathrm{~mL})$ under $\mathrm{N}_{2}$ atmosphere was added dropwise thionyl chloride $(1.3 \mathrm{~mL}, 17 \mathrm{mmol})$. The resulting mixture was heated to reflux and stirred for $24 \mathrm{~h}$, then allowed to cool to room temperature and concentrated in vacuo. The resulting residue was taken up in $\mathrm{CH}_{2} \mathrm{Cl}_{2}$ and quenched with sat. aq. $\mathrm{NaHCO}_{3}$. The layers were separated, and the aqueous phase was extracted with $\mathrm{CH}_{2} \mathrm{Cl}_{2}(3 \mathrm{x})$. The combined organic layers were washed with brine, dried over $\mathrm{Na}_{2} \mathrm{SO}_{4}$ and concentrated in vacuo to afford the product as an off-white solid $(1.58 \mathrm{~g}, 97 \%$ yield). ${ }^{11}{ }^{1} \mathrm{H}$ NMR $(500 \mathrm{MHz}$, Chloroform-d) $\delta 9.43(\mathrm{~s}, 1 \mathrm{H}), 8.82(\mathrm{~d}, J=2.0 \mathrm{~Hz}, 1 \mathrm{H}), 8.16(\mathrm{~d}, J=8.5 \mathrm{~Hz}, 1 \mathrm{H})$, $7.94-7.86(\mathrm{~m}, 1 \mathrm{H}), 7.81$ (ddd, $J=8.4,6.9,1.4 \mathrm{~Hz}, 1 \mathrm{H}), 7.60$ (t, $J=7.5 \mathrm{~Hz}, 1 \mathrm{H}), 3.99(\mathrm{~s}, 3 \mathrm{H}) ;{ }^{13} \mathrm{C}$ NMR $\left(126 \mathrm{MHz}, \mathrm{CDCl}_{3}\right) \delta 165.78,149.83,149.57,139.07,132.08,129.33,129.20,127.64,126.95,123.12$, 77.16, 52.59; IR (ATR) $v_{\max } 3509,2994,1714,1618,1572,1497,1434,1367,1290,1241,1192,1100$, $791,769 \mathrm{~cm}^{-1}$; AMM $188.0704(\mathrm{ESI}) \mathrm{m} / \mathrm{z}$ [calc for $\mathrm{C}_{11} \mathrm{H}_{10} \mathrm{NO}_{2}(\mathrm{M}+\mathrm{H})^{+} 188.0712$ ].

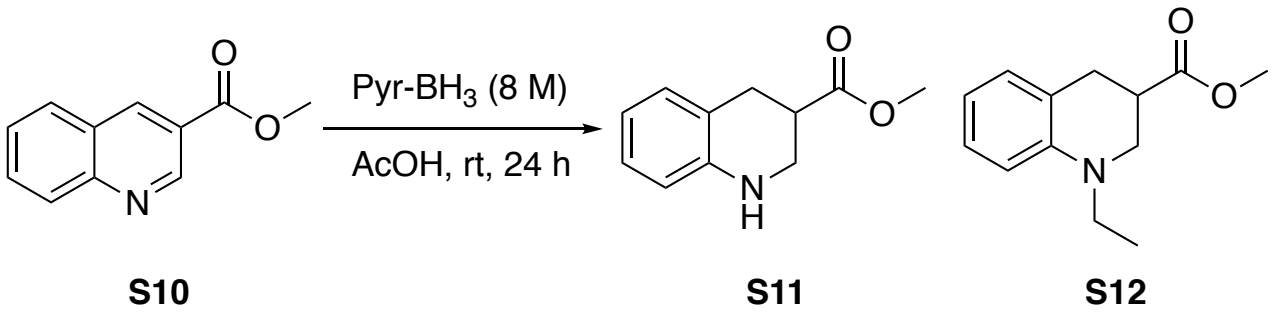

To a precooled $\left(0{ }^{\circ} \mathrm{C}\right)$ solution of intermediate $\mathbf{S 1 0}(1.50 \mathrm{~g}, 8.01 \mathrm{mmol})$ in glacial acetic acid $(40 \mathrm{~mL})$ under $\mathrm{N}_{2}$ atmosphere was added $8 \mathrm{M}$ borane pyridine complex $(2.0 \mathrm{~mL}, 16 \mathrm{mmol})$. The resulting mixture was allowed to warm to room temperature and stirred for $24 \mathrm{~h}$, then concentrated in vacuo. The resulting residue was taken up in EtOAc and the solution was cooled to $0{ }^{\circ} \mathrm{C}$ and neutralized with sat. aq. $\mathrm{NaHCO}_{3}$. The layers were separated, and the aqueous phase was extracted with EtOAc (3x). The combined organic layers were washed with brined, dried over $\mathrm{Na}_{2} \mathrm{SO}_{4}$, and concentrated in vacuo. Flash chromatography $\left(\mathrm{SiO}_{2}, 80: 20\right.$ hexanes:EtOAc) afforded the product $\mathbf{S 1 1}(874 \mathrm{mg}, 57 \%$ yield) and side product $\mathbf{S} 12$ (464 $\mathrm{mg}$, $26 \%$ yield).

S11: ${ }^{1} \mathrm{H}$ NMR $(500 \mathrm{MHz}$, Chloroform- $d) \delta 6.99(\mathrm{t}, J=7.3 \mathrm{~Hz}, 2 \mathrm{H}), 6.65(\mathrm{td}, J=7.4,1.2 \mathrm{~Hz}, 1 \mathrm{H}), 6.51$ (dd, $J$ $=8.4,1.5 \mathrm{~Hz}, 1 \mathrm{H}), 3.74(\mathrm{~s}, 3 \mathrm{H}), 3.55$ (ddd, $J=11.6,3.4,1.3 \mathrm{~Hz}, 1 \mathrm{H}), 3.37(\mathrm{dd}, J=11.4,9.4 \mathrm{~Hz}, 1 \mathrm{H}), 3.06$ $-2.99(\mathrm{~m}, 2 \mathrm{H}), 2.98-2.87(\mathrm{~m}, 1 \mathrm{H})$; AMM $192.1023(\mathrm{ESI}) \mathrm{m} / \mathrm{z}$ [calc for $\mathrm{C}_{11} \mathrm{H}_{14} \mathrm{NO}_{2}(\mathrm{M}+\mathrm{H})^{+}$192.1025]. The experimental data agreed with literature precedent. ${ }^{1}$

S12: ${ }^{1} \mathrm{H}$ NMR $(500 \mathrm{MHz}$, Chloroform-d) $\delta 7.12-7.04(\mathrm{~m}, 1 \mathrm{H}), 7.00(\mathrm{~d}, J=7.1 \mathrm{~Hz}, 1 \mathrm{H}), 6.67-6.56(\mathrm{~m}, 2 \mathrm{H})$, $3.74(\mathrm{~s}, 3 \mathrm{H}), 3.53-3.42(\mathrm{~m}, 2 \mathrm{H}), 3.42-3.35(\mathrm{~m}, 1 \mathrm{H}), 3.34-3.24(\mathrm{~m}, 1 \mathrm{H}), 3.04-2.89(\mathrm{~m}, 3 \mathrm{H}), 1.15(\mathrm{t}, J$ $=7.0 \mathrm{~Hz}, 3 \mathrm{H}) ;{ }^{13} \mathrm{C}$ NMR $\left(126 \mathrm{MHz}, \mathrm{CDCl}_{3}\right) \delta$ 173.92, 144.09, 129.30, 127.31, 120.43, 115.99, 110.76, 51.76, 49.61, 45.30, 38.29, 30.63, 10.79; AMM 220.1351 (ESI) $\mathrm{m} / \mathrm{z}$ [calc for $\mathrm{C}_{13} \mathrm{H}_{18} \mathrm{NO}_{2}(\mathrm{M}+\mathrm{H})^{+} 220.1338$ ].

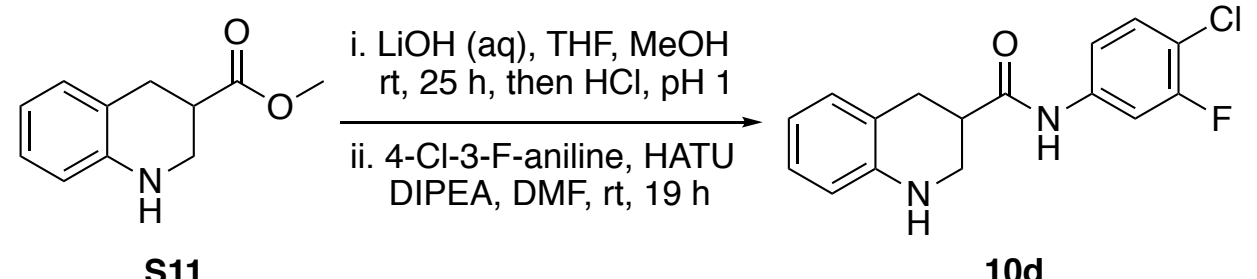

i. $\quad$ To a flask charged with intermediate $\mathbf{S} 11(786 \mathrm{mg}, 4.11 \mathrm{mmol})$ at room temperature under $\mathrm{N}_{2}$ atmosphere was added $1 \mathrm{M}$ aq. $\mathrm{LiOH}(8 \mathrm{~mL})$, THF $(24 \mathrm{~mL})$ and $\mathrm{MeOH}(8 \mathrm{~mL})$. The resulting mixture was stirred at room temperature for $25 \mathrm{~h}$, then concentrated in vacuo to remove volatiles. The remaining mixture was quenched with $1 \mathrm{M}$ aq. $\mathrm{NaOH}$ and the aqueous phase was washed with $\mathrm{Et}_{2} \mathrm{O}$ then cooled to $0{ }^{\circ} \mathrm{C}$ and acidified with $1 \mathrm{M}$ aq. $\mathrm{HCl}$ to $\mathrm{pH} 2$ and diluted with $\mathrm{CH}_{2} \mathrm{Cl}_{2}$. The layers were separated, and the aqueous phase was extracted with $\mathrm{CH}_{2} \mathrm{Cl}_{2}$ (3x). The combined organic layers were washed with brine, dried over $\mathrm{Na}_{2} \mathrm{SO}_{4}$, and concentrated in vacuo to afford the product, which was carried forward without additional purification.

ii. To a solution of intermediate $(129 \mathrm{mg}, 0.727 \mathrm{mmol})$, 4-chloro-3-fluoroaniline (128 $\mathrm{mg}, 0.872$ $\mathrm{mmol})$, and HATU $(304 \mathrm{mg}, 0.800 \mathrm{mmol})$ in DMF $(3.6 \mathrm{~mL})$ at room temperature under $\mathrm{N}_{2}$ 
atmosphere was added diisopropylethylamine $(0.38 \mathrm{~mL}, 2.18 \mathrm{mmol})$. The resulting mixture was stirred at room temperature for $19 \mathrm{~h}$, then concentrated in vacuo. The resulting residue was taken up in EtOAc and quenched with $\mathrm{H}_{2} \mathrm{O}$. The layers were separated, and the aqueous phase was extracted with EtOAc $(3 x)$. The combined organic layers were washed with brine, dried over $\mathrm{Na}_{2} \mathrm{SO}_{4}$ and concentrated in vacuo. Flash chromatography $\left(\mathrm{SiO}_{2}, 80: 20\right.$ hexanes:EtOAc) afforded the product as a white solid ( $195 \mathrm{mg}, 17 \%$ yield over 2 steps).

${ }^{1} \mathrm{H}$ NMR $\left(500 \mathrm{MHz}\right.$, Acetonitrile- $\left.d_{3}\right) \delta 9.01(\mathrm{~s}, 1 \mathrm{H}), 7.69(\mathrm{dd}, J=11.7,2.4 \mathrm{~Hz}, 1 \mathrm{H}), 7.40(\mathrm{t}, J=$ $8.5 \mathrm{~Hz}, 1 \mathrm{H}), 7.30-7.19(\mathrm{~m}, 3 \mathrm{H}), 7.17-7.10(\mathrm{~m}, 1 \mathrm{H}), 7.07(\mathrm{~d}, \mathrm{~J}=8.0 \mathrm{~Hz}, 1 \mathrm{H}), 3.65-3.52(\mathrm{~m}$, $2 \mathrm{H}), 3.21-3.05(\mathrm{~m}, 3 \mathrm{H}) ;{ }^{13} \mathrm{C} \mathrm{NMR}\left(126 \mathrm{MHz}, \mathrm{CDCl}_{3}\right) \delta 172.78,159.06,157.10,143.11,138.18$, 138.10, 130.46, 129.98, 127.50, 119.74, 118.99, 116.08, 115.16, 108.84, 108.63, 77.16, 43.51, 40.19, 38.75, 30.11; IR (ATR) $v_{\max } 3400,2928,1667,1604,1531,1493,1423,1385,840,747$, $556 \mathrm{~cm}^{-1}$; AMM 305.0869 (ESI) $\mathrm{m} / z$ [calc for $\mathrm{C}_{16} \mathrm{H}_{15} \mathrm{CIFN}_{2} \mathrm{O}(\mathrm{M}+\mathrm{H})^{+} 305.0857$ ].

\section{Synthesis of Common Intermediate S1}

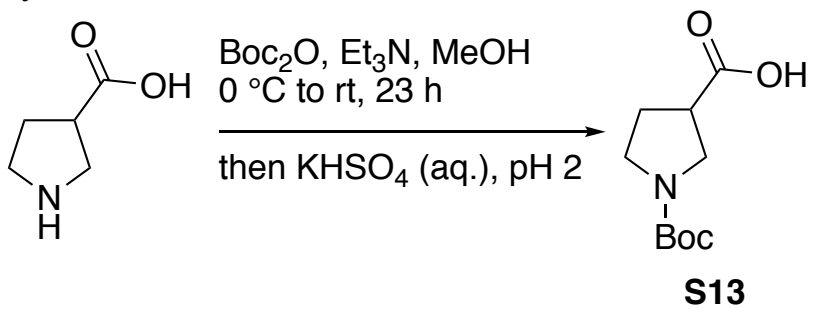

To a precooled $\left(0^{\circ} \mathrm{C}\right)$ solution of pyrrolidine-3-carboxylic acid $(300 . \mathrm{mg}, 2.61 \mathrm{mmol})$ in $\mathrm{MeOH}(13 \mathrm{~mL})$ under $\mathrm{N}_{2}$ atmosphere was added triethylamine $(0.7 \mathrm{~mL}, 3 \mathrm{mmol})$ then Boc anhydride $(0.7 \mathrm{~mL}, 3 \mathrm{mmol})$. The resulting mixture was allowed to warm to room temperature and stirred for $23 \mathrm{~h}$ then concentrated in vacuo. The resulting residue was taken up in $\mathrm{CH}_{2} \mathrm{Cl}_{2}$ and the solution acidified with sat. aq. $\mathrm{KHSO}_{4}$ to $\mathrm{pH}$ 2. The layers were separated, and the aqueous phase was extracted with $\mathrm{CH}_{2} \mathrm{Cl}_{2}(3 \mathrm{x})$. The combined organic layers were dried over $\mathrm{Na}_{2} \mathrm{SO}_{4}$ and concentrated in vacuo to afford the product as a white solid (556 mg, 99\% yield). ${ }^{1} \mathrm{H}$ NMR $(500 \mathrm{MHz}$, Chloroform- $d$ ) $\delta 3.87$ (dt, $J=13.4,4.1 \mathrm{~Hz}, 1 \mathrm{H}), 3.21-2.94(\mathrm{~m}, 1 \mathrm{H}), 2.85$ $(\mathrm{t}, J=12.5 \mathrm{~Hz}, 1 \mathrm{H}), 2.53-2.39(\mathrm{~m}, 1 \mathrm{H}), 2.12-2.00(\mathrm{~m}, 1 \mathrm{H}), 1.77-1.67(\mathrm{~m}, 1 \mathrm{H}), 1.67-1.55(\mathrm{~m}, 1 \mathrm{H})$, 1.45 (d, $J=2.0 \mathrm{~Hz}, 9 \mathrm{H}) ;{ }^{13} \mathrm{C}$ NMR $(126 \mathrm{MHz}, \mathrm{DMSO}) \delta 174.32,153.75,78.65,40.54,39.52,28.13,28.03$, 26.59, 23.80; IR (ATR) $v_{\max } 2975,1732,1660,1435,1271,1144,849,767,640 \mathrm{~cm}^{-1}$; AMM (ESI) $\mathrm{m} / \mathrm{z}$ 216.1224 [calc for $\mathrm{C}_{10} \mathrm{H}_{18} \mathrm{NO}_{4}(\mathrm{M}+\mathrm{H})^{+} 216.1236$ ].

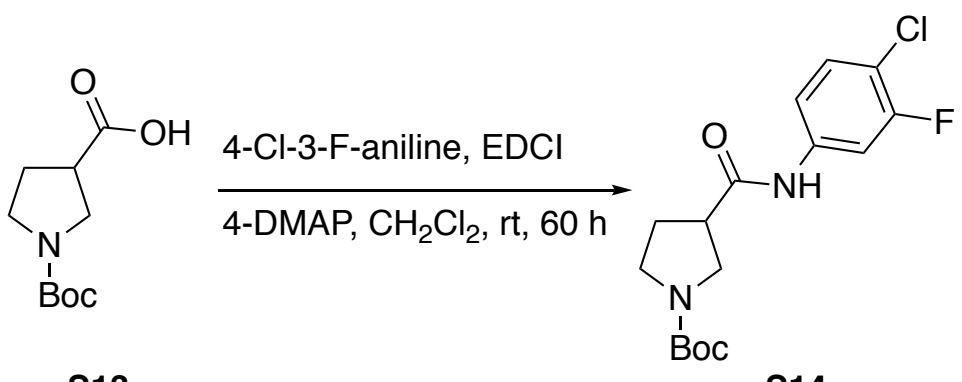

\section{S13}

S14

To a precooled $\left(0{ }^{\circ} \mathrm{C}\right.$ ) solution of 4-chloro-3-fluoroaniline (262 mg, $\left.1.50 \mathrm{mmol}\right)$, 1-ethyl-3-(3dimethylaminopropyl)-carbodiimide hydrochloride $(316 \mathrm{mg}, 1.65 \mathrm{mmol})$ and 4-dimethylaminopyridine (202 $\mathrm{mg}, 1.65 \mathrm{mmol}$ ) in $\mathrm{CH}_{2} \mathrm{Cl}_{2}(7.5 \mathrm{~mL})$ under $\mathrm{N}_{2}$ atmosphere was added a solution of intermediate $\mathbf{S} 13$ (323 $\mathrm{mg}, 1.50 \mathrm{mmol})$ in $\mathrm{CH}_{2} \mathrm{Cl}_{2}(7.5 \mathrm{~mL})$. The resulting mixture was allowed to warm to room temperature and stirred for $60 \mathrm{~h}$, then quenched with $\mathrm{H}_{2} \mathrm{O}$. The layers were separated, and the aqueous phase was extracted with $\mathrm{CH}_{2} \mathrm{Cl}_{2}(3 \mathrm{x})$. The combined organic layers were washed with brine, dried over $\mathrm{Na}_{2} \mathrm{SO}_{4}$ and concentrated in vacuo. Flash chromatography $\left(\mathrm{SiO}_{2}, 60: 40\right.$ hexanes:EtOAc) afforded the product as a white solid (417 mg, 81\% yield). ${ }^{1} \mathrm{H}$ NMR $(500 \mathrm{MHz}$, Chloroform-d) $\delta 9.22$ (d, $J=8.9 \mathrm{~Hz}, 1 \mathrm{H}), 7.58$ (dd, $J=11.2$, $2.4 \mathrm{~Hz}, 1 \mathrm{H}), 7.24-7.06(\mathrm{~m}, 2 \mathrm{H}), 3.65-3.45(\mathrm{~m}, 3 \mathrm{H}), 3.38-3.19(\mathrm{~m}, 1 \mathrm{H}), 3.15-2.96(\mathrm{~m}, 1 \mathrm{H}), 2.26-2.00$ $(\mathrm{m}, 2 \mathrm{H}), 1.41(\mathrm{~s}, 9 \mathrm{H}) ;{ }^{13} \mathrm{C}$ NMR $\left(126 \mathrm{MHz}, \mathrm{CDCl}_{3}\right) \delta 171.52,158.74,156.78,154.64,138.28,138.20$, 130.29, 116.12, 116.09, 115.53, 115.39, 108.68, 108.47, 79.97, 77.16, 48.79, 48.64, 45.76, 45.47, 45.11, 44.31, 29.53, 29.04, 28.43; AMM (ESI) $m / z 343.1228$ [calc for $\mathrm{C}_{16} \mathrm{H}_{21} \mathrm{CIFN}_{2} \mathrm{O}_{3}(\mathrm{M}+\mathrm{H})^{+} 343.1225$ ]. 
<smiles>CC(C)(C)OC(=O)N1CCC(C(=O)Nc2ccc(Cl)c(F)c2)C1</smiles>

S14<smiles>O=C(Nc1ccc(Cl)c(F)c1)C1CCNC1</smiles>

S15

To a precooled $\left(0^{\circ} \mathrm{C}\right)$ solution of intermediate $\mathbf{S 1 4}(139 \mathrm{mg}, 0.405 \mathrm{mmol})$ in $\mathrm{CH}_{2} \mathrm{Cl}_{2}(2 \mathrm{~mL})$ under $\mathrm{N}_{2}$ atmosphere was added dropwise trifluoroacetic acid $(0.2 \mathrm{~mL}, 2 \mathrm{mmol})$. The resulting mixture was allowed to warm to room temperature and stirred for $39 \mathrm{~h}$ then concentrated in vacuo. The resulting residue was taken up in $\mathrm{H}_{2} \mathrm{O}$ and the aqueous solution was neutralized with powdered $\mathrm{NaHCO}_{3}$ then diluted with $\mathrm{CHCl}_{3}$. The layers were separated, and the aqueous phase was extracted with $\mathrm{CHCl}_{3}(3 \mathrm{x})$. The combined organic layers were dried over $\mathrm{Na}_{2} \mathrm{SO}_{4}$ and concentrated in vacuo to afford the product as a white solid (35 mg, $36 \%$ yield). ${ }^{1} \mathrm{H}$ NMR $(500 \mathrm{MHz}$, Chloroform-d) $\delta 9.17$ (s, 1H), 7.61 (dd, $J=11.2,2.5 \mathrm{~Hz}, 1 \mathrm{H}), 7.31-7.22$ $(\mathrm{m}, 1 \mathrm{H}), 7.10(\mathrm{dd}, J=8.9,2.4 \mathrm{~Hz}, 1 \mathrm{H}), 3.28(\mathrm{dd}, J=10.3,2.3 \mathrm{~Hz}, 1 \mathrm{H}), 3.19$ (ddd, $J=10.0,8.5,4.2 \mathrm{~Hz}, 1 \mathrm{H}$ ), $2.99-2.82(\mathrm{~m}, 3 \mathrm{H}), 2.39(\mathrm{~s}, 1 \mathrm{H}), 2.25-2.11(\mathrm{~m}, 1 \mathrm{H}), 2.09-1.95(\mathrm{~m}, 1 \mathrm{H}) ;{ }^{13} \mathrm{C} \mathrm{NMR}\left(126 \mathrm{MHz}, \mathrm{CDCl}_{3}\right) \delta$ 174.59, 130.49, 115.76, 108.50, 108.29, 53.57, 50.81, 45.73, 45.66, 29.86, 29.74; IR (ATR) vmax 3243, 3187, 3111, 2926, 1674, 1604, 1538, 1492, 1422, 1213, 1061, 863, $814 \mathrm{~cm}^{-1} ;$ AMM (ESI) $\mathrm{m} / \mathrm{z} 243.0692$ [calc for $\mathrm{C}_{11} \mathrm{H}_{13} \mathrm{ClFN}_{2} \mathrm{O}(\mathrm{M}+\mathrm{H})^{+} 243.0700$ ].

Synthesis of Common Intermediate S18

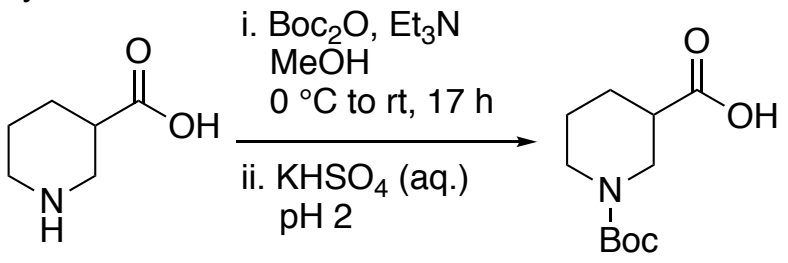

S16

To a precooled $\left(0^{\circ} \mathrm{C}\right)$ solution of piperidine-3-carboxylic acid (300. $\mathrm{mg}, 2.32 \mathrm{mmol}$ ) in $\mathrm{MeOH}(12 \mathrm{~mL})$ under $\mathrm{N}_{2}$ atmosphere was added triethylamine $(0.65 \mathrm{~mL}, 4.6 \mathrm{mmol})$ then dropwise Boc anhydride $(0.64 \mathrm{~mL}, 2.8$ $\mathrm{mmol}$ ). The resulting mixture was allowed to warm to room temperature and stirred for $17 \mathrm{~h}$, then concentrated in vacuo. The crude residue was taken up in $\mathrm{CH}_{2} \mathrm{Cl}_{2}$ and acidified with aq. $\mathrm{KHSO}_{4}$ to $\mathrm{pH} 2$. The layers were separated, and the aqueous phase was extracted with $\mathrm{CH}_{2} \mathrm{Cl}_{2}(3 \mathrm{x})$. The combined organic layers were washed with $1 \mathrm{M}$ aq. $\mathrm{HCl}$ then brine, dried over $\mathrm{Na}_{2} \mathrm{SO}_{4}$, and concentrated in vacuo to afford the product as a white solid (357 mg, 67\% yield). ${ }^{1} \mathrm{H}$ NMR $(500 \mathrm{MHz}$, Chloroform-d) $\delta 4.10(\mathrm{~s}, 1 \mathrm{H}), 3.88(\mathrm{dt}$, $J=13.4,4.1 \mathrm{~Hz}, 1 \mathrm{H}), 3.23-2.93(\mathrm{~m}, 1 \mathrm{H}), 2.93-2.80(\mathrm{~m}, 1 \mathrm{H}), 2.56-2.42(\mathrm{~m}, 1 \mathrm{H}), 2.14-2.01(\mathrm{~m}, 1 \mathrm{H})$, $1.80-1.56(\mathrm{~m}, 2 \mathrm{H}), 1.46(\mathrm{~d}, J=6.8 \mathrm{~Hz}, 9 \mathrm{H}) ;{ }^{13} \mathrm{C}$ NMR $\left(126 \mathrm{MHz}, \mathrm{CDCl}_{3}\right) \delta 177.93,154.65,79.98,48.08$, 45.48, 45.20, 43.21, 42.39, 31.11, 28.58; IR (ATR) $v_{\max } 3177,2972,1741,1665,1424,1165,1131,868$, $831,765,648,581 \mathrm{~cm}^{-1}$; AMM $230.1406(\mathrm{ESI}) \mathrm{m} / \mathrm{z}$ [calc for $\mathrm{C}_{11} \mathrm{H}_{20} \mathrm{NO}_{4}(\mathrm{M}+\mathrm{H})^{+} 230.1392$ ].

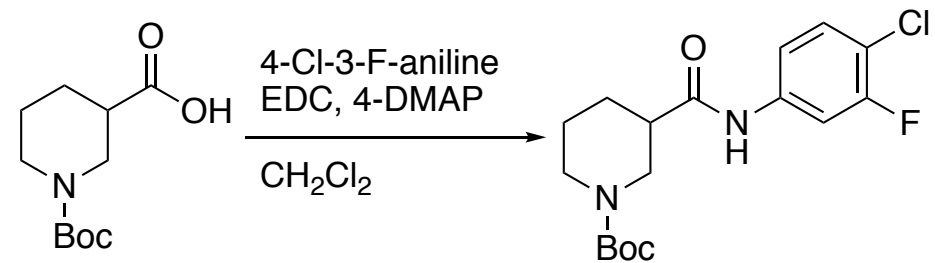

S16

S17

To a precooled $\left(0{ }^{\circ} \mathrm{C}\right)$ solution of intermediate $\mathbf{S} 16(357 \mathrm{mg}, 1.56 \mathrm{mmol})$, hexafluorophosphate azabenzotriazole tetramethyl uranium (HATU, $652 \mathrm{mg}, 1.71 \mathrm{mmol}$ ), and 4-chloro-3-fluoroaniline (327 mg, $1.87 \mathrm{mmol})$ in dimethylformamide $(5.2 \mathrm{~mL})$ under $\mathrm{N}_{2}$ atmosphere was added diisopropylethylamine $(0.81$ 
$\mathrm{mL}, 4.7 \mathrm{mmol}$ ). The resulting mixture was stirred at room temperature for $45 \mathrm{~h}$, then concentrated in vacuo. The crude residue was taken up in $\mathrm{CH}_{2} \mathrm{Cl}_{2}$. The organic layer was washed sequentially with sat. aq. $\mathrm{NaHCO}_{3}$, and brine, dried over $\mathrm{Na}_{2} \mathrm{SO}_{4}$, and concentrated in vacuo. Flash chromatography $\left(\mathrm{SiO}_{2}, 60: 40\right.$ hexanes:EtOAc) afforded the product as a white solid $\left(247 \mathrm{mg}, 44 \%\right.$ yield). ${ }^{1} \mathrm{H}$ NMR $(500 \mathrm{MHz}$, Chloroformd) $\delta 9.19(\mathrm{~s}, 1 \mathrm{H}), 7.81-7.58(\mathrm{~m}, 1 \mathrm{H}), 7.37-7.05(\mathrm{~m}, 2 \mathrm{H}), 4.00-3.79(\mathrm{~m}, 1 \mathrm{H}), 3.68(\mathrm{~s}, 1 \mathrm{H}), 3.45(\mathrm{~s}, 1 \mathrm{H})$, $3.19(\mathrm{~s}, 1 \mathrm{H}), 2.62-2.42(\mathrm{~m}, 1 \mathrm{H}), 2.16-1.98(\mathrm{~m}, 1 \mathrm{H}), 1.98-1.82(\mathrm{~m}, 1 \mathrm{H}), 1.74-1.58(\mathrm{~m}, 1 \mathrm{H}), 1.47(\mathrm{~s}$, $10 \mathrm{H}) ;{ }^{13} \mathrm{C}$ NMR $\left(126 \mathrm{MHz}, \mathrm{CDCl}_{3}\right) \delta 171.79,158.98,157.02,155.41,138.61,130.38,115.84,115.81$, 115.44, 115.30, 108.50, 108.29, 80.64, 45.60, 44.85, 43.78, 28.52, 24.15; IR (ATR) vmax 3150, 1731, 1657, $1474,1144,849 \mathrm{~cm}^{-1}$; AMM (ESI) $\mathrm{m} / \mathrm{z} 357.1393$ [calc for $\mathrm{C}_{17} \mathrm{H}_{23} \mathrm{ClFN}_{2} \mathrm{O}_{3}(\mathrm{M}+\mathrm{H})^{+} 357.1381$ ].<smiles>O=C(Nc1ccc(Cl)c(F)c1)C1CCCN(C(=O)c2ccc(Cl)c(F)c2)C1</smiles>

To a solution of intermediate $2.102(247 \mathrm{mg}, 0.692 \mathrm{mmol})$ in $\mathrm{CH}_{2} \mathrm{Cl}_{2}(3.5 \mathrm{~mL})$ at room temperature under $\mathrm{N}_{2}$ atmosphere was added trifluoroacetic acid $(0.16 \mathrm{~mL}, 2.1 \mathrm{mmol})$. The resulting mixture was stirred for 38 $\mathrm{h}$, then concentrated in vacuo. The crude residue was taken up in $\mathrm{CH}_{2} \mathrm{Cl}_{2}$ and diluted with water. The layers were separated, and the organic phase was washed with water (3x). The combined aqueous layers were basified to $\mathrm{pH} 8$ with powdered $\mathrm{NaHCO}_{3}$. The aqueous phase was then extracted with $\mathrm{CH}_{2} \mathrm{Cl}_{2}(3 \mathrm{x})$, then the combined organic layers were dried over $\mathrm{Na}_{2} \mathrm{SO}_{4}$, and concentrated in vacuo to afford the product as a white solid (66 mg, 37\% yield). ${ }^{1} \mathrm{H}$ NMR $(500 \mathrm{MHz}$, Chloroform-d) $\delta 11.01$ (s, 1H), 7.69 (dd, $J=11.3,2.3$ $\mathrm{Hz}, 1 \mathrm{H}), 7.32-7.23(\mathrm{~m}, 1 \mathrm{H}), 7.17(\mathrm{dd}, J=8.9,2.3 \mathrm{~Hz}, 1 \mathrm{H}), 3.26(\mathrm{dd}, J=12.1,3.2 \mathrm{~Hz}, 1 \mathrm{H}), 3.16-3.02(\mathrm{~m}$, $1 \mathrm{H}), 2.93(\mathrm{dd}, J=12.0,3.1 \mathrm{~Hz}, 1 \mathrm{H}), 2.75(\mathrm{td}, J=10.9,3.2 \mathrm{~Hz}, 1 \mathrm{H}), 2.60-2.51(\mathrm{~m}, 1 \mathrm{H}), 2.35-2.17(\mathrm{~m}$, 1H), $2.11-1.99(\mathrm{~m}, 1 \mathrm{H}), 1.85-1.66(\mathrm{~m}, 2 \mathrm{H}), 1.65-1.51(\mathrm{~m}, 1 \mathrm{H}) ;{ }^{13} \mathrm{C}$ NMR $\left(126 \mathrm{MHz}, \mathrm{CDCl}_{3}\right) \delta 174.27$, 159.08, 157.12, 138.66, 138.58, 130.35, 115.89, 115.86, 115.03, 114.88, 108.50, 108.30, 47.92, 46.67, 41.79, 29.82, 27.62, 22.61; IR (ATR) v $v_{\max } 3075,2920,2850,1673,1604,1545,1490,1420,1337,1202$, $857,805,717 \mathrm{~cm}^{-1}$; AMM (ESI) $\mathrm{m} / \mathrm{z} 257.0877$ [calc for $\mathrm{C}_{12} \mathrm{H}_{15} \mathrm{ClFN}_{2} \mathrm{O}(\mathrm{M}+\mathrm{H})^{+} 257.0857$ ].

\section{Synthesis of Analogs 11}

General Synthesis of Analogs 11a-11d<smiles>O=C(Nc1ccc(Cl)c(F)c1)C1CCNC1</smiles>

S15<smiles>CCO[Mg]O[Mg]</smiles>
$0{ }^{\circ} \mathrm{C}$ to rt, $18 \mathrm{~h}$

$$
\mathrm{O}=\stackrel{\substack{1 \\ \mathrm{~S}}}{\mathrm{R}}=\mathrm{O}
$$

11a-11d

To separate precooled $\left(0^{\circ} \mathrm{C}\right)$ solutions of common intermediate $\mathbf{S 1 5}(18 \mathrm{mg}, 0.074 \mathrm{mmol})$ and triethylamine $(30 \mu \mathrm{L}, 0.2 \mathrm{mmol})$ in dichloromethane $(0.5 \mathrm{~mL})$ was added R-sulfonyl chloride $(0.11 \mathrm{mmol})$. The resulting mixtures were allowed to warm to room temperature and stirred for $18 \mathrm{~h}$, then diluted with wet DMSO ( 1 $\mathrm{mL}$ ), filtered through celite and purified via mass-directed isolation using ultra-performance liquid chromatography (22-29\% yield).

( \pm )-MCG-III-157-A01 (11a)

$\mathrm{R}=\mathrm{Me}(29 \%$ yield $)$

${ }^{1} \mathrm{H}$ NMR $\left(500 \mathrm{MHz}\right.$, Acetonitrile- $\left.d_{3}\right) \delta 8.71(\mathrm{~s}, 1 \mathrm{H}), 7.71(\mathrm{dd}, J=11.8,2.4 \mathrm{~Hz}, 1 \mathrm{H}), 7.39(\mathrm{t}, J=8.6 \mathrm{~Hz}, 1 \mathrm{H})$, 7.26 (ddd, $J=8.8,2.5,1.2 \mathrm{~Hz}, 1 \mathrm{H}$ ), 3.55 (dd, $J=10.4,7.8 \mathrm{~Hz}, 1 \mathrm{H}$ ), 3.49 (dd, $J=10.4,6.2 \mathrm{~Hz}, 1 \mathrm{H}$ ), $3.44-$ 
$3.30(\mathrm{~m}, 2 \mathrm{H}), 3.17$ (p, J = 7.2 Hz, 1H), $2.84(\mathrm{~s}, 3 \mathrm{H}), 2.31-2.12(\mathrm{~m}, 2 \mathrm{H})$; AMM 343.0306 (ESI) $\mathrm{m} / \mathrm{z}$ [calc for $\left.\mathrm{C}_{12} \mathrm{H}_{14} \mathrm{ClFN}_{2} \mathrm{O}_{3} \mathrm{SNa}(\mathrm{M}+\mathrm{Na})^{+}\right]$343.0295].

(土)-MCG-III-157-A02 (11b)

$\mathrm{R}=\mathrm{Et}(23 \%$ yield $)$

${ }^{1} \mathrm{H}$ NMR $(500 \mathrm{MHz}$, Acetonitrile-d3) $\delta 8.68(\mathrm{~s}, 1 \mathrm{H}), 7.71$ (dd, $J=11.8,2.4 \mathrm{~Hz}, 1 \mathrm{H}), 7.39(\mathrm{t}, J=8.6 \mathrm{~Hz}, 1 \mathrm{H})$, $7.31-7.21(\mathrm{~m}, 1 \mathrm{H}), 3.59(\mathrm{dd}, J=10.1,7.8 \mathrm{~Hz}, 1 \mathrm{H}), 3.51(\mathrm{dd}, J=10.1,6.4 \mathrm{~Hz}, 1 \mathrm{H}), 3.48-3.34(\mathrm{~m}, 2 \mathrm{H})$, $3.16(\mathrm{p}, J=7.3 \mathrm{~Hz}, 1 \mathrm{H}), 3.05(\mathrm{qd}, J=7.3,2.4 \mathrm{~Hz}, 2 \mathrm{H}), 2.30-2.11(\mathrm{~m}, 2 \mathrm{H}), 1.30(\mathrm{t}, J=7.4 \mathrm{~Hz}, 3 \mathrm{H}) ;$ AMM 357.0447 (ESI) $\mathrm{m} / \mathrm{z}$ [calc for C13H16CIFN2O3SNa (M+Na)+] 357.0452].

( \pm )-MCG-III-157-A03 (11c)

$\mathrm{R}=\mathrm{Ph}(26 \%$ yield $)$

${ }^{1} \mathrm{H}$ NMR $(500 \mathrm{MHz}$, Acetonitrile-d3) $\delta 8.58(\mathrm{~s}, 1 \mathrm{H}), 7.88-7.80(\mathrm{~m}, 2 \mathrm{H}), 7.71-7.64(\mathrm{~m}, 1 \mathrm{H}), 7.64-7.56$ $(\mathrm{m}, 3 \mathrm{H}), 7.36(\mathrm{t}, J=8.6 \mathrm{~Hz}, 1 \mathrm{H}), 7.21-7.13(\mathrm{~m}, 1 \mathrm{H}), 3.54(\mathrm{dd}, J=10.3,8.0 \mathrm{~Hz}, 1 \mathrm{H}), 3.39-3.24(\mathrm{~m}, 3 \mathrm{H})$, $2.97(\mathrm{p}, J=7.5 \mathrm{~Hz}, 1 \mathrm{H}), 2.10-2.00(\mathrm{~m}, 1 \mathrm{H}) ; \mathrm{AMM} 405.0446(\mathrm{ESI}) \mathrm{m} / \mathrm{z}$ [calc for $\mathrm{C}_{17} \mathrm{H}_{16} \mathrm{ClFN}_{2} \mathrm{O}_{3} \mathrm{SNa}$ $\left.(\mathrm{M}+\mathrm{Na})^{+}\right]$405.0452].

( \pm )-MCG-III-157-A04 (11d)

$\mathrm{R}=\mathrm{N}-\mathrm{Me}$ Imidazole $(22 \%$ yield $)$

${ }^{1} \mathrm{H}$ NMR $\left(500 \mathrm{MHz}\right.$, Acetonitrile- $\left.d_{3}\right) \delta 8.56(\mathrm{~s}, 1 \mathrm{H}), 7.69(\mathrm{~s}, 1 \mathrm{H}), 7.66(\mathrm{dd}, J=11.8,2.4 \mathrm{~Hz}, 1 \mathrm{H}), 7.59(\mathrm{~d}, J=$ $1.4 \mathrm{~Hz}, 1 \mathrm{H}), 7.37(\mathrm{t}, J=8.6 \mathrm{~Hz}, 1 \mathrm{H}), 7.21(\mathrm{dd}, J=8.7,2.1 \mathrm{~Hz}, 1 \mathrm{H}), 3.72(\mathrm{~s}, 3 \mathrm{H}), 3.63(\mathrm{dd}, J=10.4,7.9 \mathrm{~Hz}$, $1 \mathrm{H}), 3.50-3.40(\mathrm{~m}, 2 \mathrm{H}), 3.40-3.32(\mathrm{~m}, 1 \mathrm{H}), 3.00(\mathrm{p}, \mathrm{J}=7.6 \mathrm{~Hz}, 1 \mathrm{H}), 2.14-1.96(\mathrm{~m}, 2 \mathrm{H})$; AMM 409.0521 (ESI) $\mathrm{m} / \mathrm{z}$ [calc for $\mathrm{C}_{15} \mathrm{H}_{16} \mathrm{ClFN}_{4} \mathrm{O}_{3} \mathrm{SNa}(\mathrm{M}+\mathrm{Na})^{+} 409.0513$ ].

General Synthesis of Analogs 11e-11h<smiles>O=C(Nc1ccc(Cl)c(F)c1)C1CN(S(=O)(=O)c2ccc(F)cc2)CCO1</smiles>

$10 a$

$11 \mathrm{e}-11 \mathrm{~h}$

To separate precooled $\left(0{ }^{\circ} \mathrm{C}\right)$ solutions of common intermediate 10a $(20 . \mathrm{mg}, 0.077 \mathrm{mmol})$ in dichloromethane $(0.5 \mathrm{~mL})$ was added triethylamine $(30 \mu \mathrm{L}, 0.2 \mathrm{mmol})$ and R-sulfonyl chloride $(0.12 \mathrm{mmol})$. The resulting mixtures were allowed to warm to room temperature and stirred for $15 \mathrm{~h}$, then diluted with wet DMSO $(0.5 \mathrm{~mL})$, filtered through celite and purified via mass-directed isolation using ultra-performance liquid chromatography (41-91\% yield).

( \pm )-MCG-III-211-A01 (11e)

$\mathrm{R}=\mathrm{Me}(41 \%$ yield $)$

${ }^{1} \mathrm{H}$ NMR $\left(500 \mathrm{MHz}\right.$, Acetonitrile- $\left.d_{3}\right) \delta 8.84(\mathrm{~s}, 1 \mathrm{H}), 7.72(\mathrm{dd}, J=11.6,2.3 \mathrm{~Hz}, 1 \mathrm{H}), 7.41(\mathrm{t}, J=8.4 \mathrm{~Hz}, 1 \mathrm{H})$, $7.39-7.33(\mathrm{~m}, 1 \mathrm{H}), 4.19(\mathrm{dd}, J=10.0,3.1 \mathrm{~Hz}, 1 \mathrm{H}), 4.15-4.07(\mathrm{~m}, 1 \mathrm{H}), 3.84-3.78(\mathrm{~m}, 1 \mathrm{H}), 3.74(\mathrm{td}, J=$ 11.3, $2.8 \mathrm{~Hz}, 1 \mathrm{H}), 3.48(\mathrm{dq}, J=12.1,2.2 \mathrm{~Hz}, 1 \mathrm{H}), 2.98-2.85(\mathrm{~m}, 2 \mathrm{H}), 2.82(\mathrm{~s}, 3 \mathrm{H})$; AMM $337.0448(\mathrm{ESI})$ $\mathrm{m} / \mathrm{z}$ [calc for $\mathrm{C}_{12} \mathrm{H}_{15} \mathrm{ClFN}_{2} \mathrm{O}_{4} \mathrm{~S}(\mathrm{M}+\mathrm{H})^{+} 337.0425$ ].

(土)-MCG-III-211-A02 (11f)

$\mathrm{R}=\mathrm{Et}(51 \%$ yield $)$

${ }^{1} \mathrm{H}$ NMR $\left(500 \mathrm{MHz}\right.$, Acetonitrile- $\left.d_{3}\right) \delta 8.83(\mathrm{~s}, 1 \mathrm{H}), 7.72(\mathrm{dd}, J=11.7,2.4 \mathrm{~Hz}, 1 \mathrm{H}), 7.41(\mathrm{t}, J=8.4 \mathrm{~Hz}, 1 \mathrm{H})$, $7.39-7.33(\mathrm{~m}, 1 \mathrm{H}), 4.16(\mathrm{dd}, J=10.0,3.1 \mathrm{~Hz}, 1 \mathrm{H}), 4.07(\mathrm{ddd}, J=11.6,3.3,2.1 \mathrm{~Hz}, 1 \mathrm{H}), 3.83(\mathrm{ddd}, J=$ 12.3, 3.1, $1.8 \mathrm{~Hz}, 1 \mathrm{H}$ ), 3.71 (ddd, $J=11.7,10.9,2.8 \mathrm{~Hz}, 1 \mathrm{H}$ ), $3.51(\mathrm{dq}, J=12.4,2.2 \mathrm{~Hz}, 1 \mathrm{H}$ ), $3.09-2.93$ $(\mathrm{m}, 4 \mathrm{H}), 1.29(\mathrm{t}, \mathrm{J}=7.4 \mathrm{~Hz}, 3 \mathrm{H})$; AMM 351.0597 (ESI) $\mathrm{m} / \mathrm{z}$ [calc for $\mathrm{C}_{13} \mathrm{H}_{17} \mathrm{ClFN}_{2} \mathrm{O}_{4} \mathrm{~S}(\mathrm{M}+\mathrm{H})^{+} 351.0582$ ].

( \pm )-MCG-III-211-A03 (11g)

$\mathrm{R}=\mathrm{Ph}(55 \%$ yield $)$ 
${ }^{1} \mathrm{H}$ NMR $\left(500 \mathrm{MHz}\right.$, Acetonitrile- $\left.d_{3}\right) \delta 8.73(\mathrm{~s}, 1 \mathrm{H}), 7.82-7.76(\mathrm{~m}, 2 \mathrm{H}), 7.73-7.65(\mathrm{~m}, 2 \mathrm{H}), 7.65-7.59(\mathrm{~m}$, $2 \mathrm{H}), 7.39(\mathrm{t}, J=8.5 \mathrm{~Hz}, 1 \mathrm{H}), 7.34-7.28(\mathrm{~m}, 1 \mathrm{H}), 4.19(\mathrm{dd}, J=10.1,3.0 \mathrm{~Hz}, 1 \mathrm{H}), 4.03$ (ddd, $J=11.7,3.4$, $2.1 \mathrm{~Hz}, 1 \mathrm{H}$ ), 3.81 (ddd, $J=11.8,3.1,1.8 \mathrm{~Hz}, 1 \mathrm{H}), 3.74(\mathrm{td}, J=11.3,2.8 \mathrm{~Hz}, 1 \mathrm{H}), 3.50(\mathrm{dq}, J=12.0,2.2 \mathrm{~Hz}$, $1 \mathrm{H}), 2.53-2.40(\mathrm{~m}, 3 \mathrm{H})$; AMM $399.0594(\mathrm{ESI}) \mathrm{m} / z$ [calc for $\mathrm{C}_{17} \mathrm{H}_{17} \mathrm{CIFN}_{2} \mathrm{O}_{4} \mathrm{~S}(\mathrm{M}+\mathrm{H})^{+}$399.0582].

( \pm )-MCG-III-211-A04 (11h)

$\mathrm{R}=\mathrm{N}-\mathrm{Me}$ Imidazole $(91 \%$ yield $)$

${ }^{1} \mathrm{H}$ NMR $\left(500 \mathrm{MHz}\right.$, Acetonitrile- $\left.d_{3}\right) \delta 8.77(\mathrm{~s}, 1 \mathrm{H}), 7.76(\mathrm{~d}, J=1.4 \mathrm{~Hz}, 1 \mathrm{H}), 7.69(\mathrm{dd}, J=11.6,2.4 \mathrm{~Hz}, 1 \mathrm{H})$, $7.63(\mathrm{~d}, J=1.4 \mathrm{~Hz}, 1 \mathrm{H}), 7.39(\mathrm{t}, J=8.5 \mathrm{~Hz}, 1 \mathrm{H}), 7.35-7.29(\mathrm{~m}, 1 \mathrm{H}), 4.19(\mathrm{dd}, J=10.3,3.1 \mathrm{~Hz}, 1 \mathrm{H}), 4.05$ (ddd, $J=11.7,3.5,2.0 \mathrm{~Hz}, 1 \mathrm{H}$ ), 3.81 (ddd, $J=12.1,3.1,1.8 \mathrm{~Hz}, 1 \mathrm{H}$ ), $3.72(\mathrm{~s}, 5 \mathrm{H}$ ), 3.52 (dt, $J=12.4,2.2$ $\mathrm{Hz}, 1 \mathrm{H}$ ), 2.75 (ddd, $J=12.3,11.1,3.4 \mathrm{~Hz}, 1 \mathrm{H}), 2.69-2.59(\mathrm{~m}, 1 \mathrm{H})$; AMM 403.0655 (ESI) $\mathrm{m} / \mathrm{z}$ [calc for $\mathrm{C}_{15} \mathrm{H}_{17} \mathrm{ClFN}_{4} \mathrm{O}_{4} \mathrm{~S}(\mathrm{M}+\mathrm{H})^{+}$403.0643].

General Synthesis of Analogs 11i-11k<smiles>[R]OS(=O)(=O)N1CCN(C(=O)C(=O)Nc2ccc(Cl)c(F)c2)C(C(=O)Nc2ccc(Cl)c(F)c2)C1</smiles>

To separate precooled $\left(0{ }^{\circ} \mathrm{C}\right)$ solutions of common intermediate $10 \mathrm{~b}(20 . \mathrm{mg}, 0.056 \mathrm{mmol})$ in dichloromethane $(0.5 \mathrm{~mL})$ was added triethylamine $(20 \mu \mathrm{L}, 0.1 \mathrm{mmol})$ and R-sulfonyl chloride $(0.084 \mathrm{mmol})$. The resulting mixtures were allowed to warm to room temperature and stirred for $15 \mathrm{~h}$, then diluted with wet DMSO $(0.5 \mathrm{~mL})$, filtered through celite and purified via mass-directed isolation using ultra-performance liquid chromatography $(40-78 \%$ yield).

( \pm )-MCG-III-212-A01 (11i)

$\mathrm{R}=\mathrm{Me}(40 \%$ yield $)$

${ }^{1} \mathrm{H}$ NMR $\left(500 \mathrm{MHz}\right.$, Acetonitrile- $\left.d_{3}\right) \delta 8.81(\mathrm{~s}, 1 \mathrm{H}), 7.69(\mathrm{dd}, J=11.7,2.4 \mathrm{~Hz}, 1 \mathrm{H}), 7.40(\mathrm{t}, J=8.5 \mathrm{~Hz}, 1 \mathrm{H})$, $7.32(\mathrm{~d}, J=8.9 \mathrm{~Hz}, 1 \mathrm{H}), 4.83(\mathrm{~s}, 1 \mathrm{H}), 4.13(\mathrm{~d}, J=12.6 \mathrm{~Hz}, 1 \mathrm{H}), 4.02(\mathrm{~d}, J=13.6 \mathrm{~Hz}, 1 \mathrm{H}), 3.55(\mathrm{~d}, J=11.8$ $\mathrm{Hz}, 1 \mathrm{H}$ ), 3.30 (s, 1H), 3.03 (dd, $J=12.6,4.3 \mathrm{~Hz}, 1 \mathrm{H}), 2.83$ (dd, $J=14.9,3.1 \mathrm{~Hz}, 1 \mathrm{H}), 2.79(\mathrm{~s}, 3 \mathrm{H}), 1.45$ (s, $9 \mathrm{H}$ ); AMM 436.1121 (ESI) $\mathrm{m} / \mathrm{z}$ [calc for $\mathrm{C}_{17} \mathrm{H}_{24} \mathrm{ClFN}_{3} \mathrm{O}_{5} \mathrm{~S}(\mathrm{M}+\mathrm{H})^{+} 436.1109$ ].

( \pm )-MCG-III-212-A03 (11j)

$\mathrm{R}=\mathrm{Ph}(65 \%$ yield $)$

${ }^{1} \mathrm{H}$ NMR $\left(500 \mathrm{MHz}\right.$, Acetonitrile- $\left.d_{3}\right) \delta 8.82(\mathrm{~s}, 1 \mathrm{H}), 7.77-7.73(\mathrm{~m}, 2 \mathrm{H}), 7.72-7.65(\mathrm{~m}, 2 \mathrm{H}), 7.59(\mathrm{dd}, J=$ 8.4, 7.0 Hz, 2H), $7.41(\mathrm{t}, J=8.5 \mathrm{~Hz}, 1 \mathrm{H}), 7.32(\mathrm{~d}, J=8.1 \mathrm{~Hz}, 1 \mathrm{H}), 4.76(\mathrm{~s}, 1 \mathrm{H}), 4.17(\mathrm{~d}, J=12.4 \mathrm{~Hz}, 1 \mathrm{H})$, $3.96(\mathrm{~d}, J=13.9 \mathrm{~Hz}, 1 \mathrm{H}), 3.60(\mathrm{~d}, J=11.8 \mathrm{~Hz}, 1 \mathrm{H}), 2.60(\mathrm{dd}, J=12.4,4.4 \mathrm{~Hz}, 1 \mathrm{H}), 2.39(\mathrm{~d}, J=11.7 \mathrm{~Hz}$, $2 \mathrm{H}$ ), 1.39 (s, 9H); AMM 498.1280 (ESI) $\mathrm{m} / z$ [calc for $\mathrm{C}_{22} \mathrm{H}_{26} \mathrm{CIFN}_{3} \mathrm{O}_{5} \mathrm{~S}(\mathrm{M}+\mathrm{H})^{+} 498.1266$ ].

( \pm )-MCG-III-212-A04 (11k)

$\mathrm{R}=\mathrm{N}-\mathrm{Me}$ Imidazole $(42 \%$ yield $)$

${ }^{1} \mathrm{H}$ NMR $\left(500 \mathrm{MHz}\right.$, Acetonitrile- $\left.d_{3}\right) \delta 8.69(\mathrm{~s}, 1 \mathrm{H}), 7.69$ (dd, $\left.J=11.7,2.4 \mathrm{~Hz}, 1 \mathrm{H}\right), 7.54(\mathrm{~s}, 2 \mathrm{H}), 7.41(\mathrm{t}, J=$ $8.6 \mathrm{~Hz}, 1 \mathrm{H}), 7.36-7.28(\mathrm{~m}, 1 \mathrm{H}), 4.76(\mathrm{~s}, 1 \mathrm{H}), 4.15(\mathrm{~d}, J=12.7 \mathrm{~Hz}, 1 \mathrm{H}), 3.96(\mathrm{~d}, J=13.6 \mathrm{~Hz}, 1 \mathrm{H}), 3.67(\mathrm{~s}$, $3 \mathrm{H}), 3.61-3.53(\mathrm{~m}, 1 \mathrm{H}), 2.85(\mathrm{~d}, J=12.7 \mathrm{~Hz}, 1 \mathrm{H}), 2.58(\mathrm{td}, J=11.9,3.6 \mathrm{~Hz}, 1 \mathrm{H}), 1.41(\mathrm{~s}, 9 \mathrm{H})$; AMM $502.1324(\mathrm{ESI}) \mathrm{m} / \mathrm{z}$ [calc for $\mathrm{C}_{20} \mathrm{H}_{26} \mathrm{CIFN}_{5} \mathrm{O}_{5} \mathrm{~S}(\mathrm{M}+\mathrm{H})^{+}$502.1327].

\section{Synthesis of Analog $11 \mathrm{~m}$}

To a precooled $\left(0{ }^{\circ} \mathrm{C}\right)$ solution of common intermediate $10 \mathrm{~b}(20 . \mathrm{mg}, 0.056 \mathrm{mmol})$ in dichloromethane $(0.5$ $\mathrm{mL}$ ) was added triethylamine $(20 \mu \mathrm{L}, 0.1 \mathrm{mmol})$ and ethanesulfonyl chloride $(7.9 \mu \mathrm{L}, 0.084 \mathrm{mmol})$. The resulting mixtures were allowed to warm to room temperature and stirred for $15 \mathrm{~h}$, then diluted with wet DMSO $(0.5 \mathrm{~mL})$, filtered through celite and purified via mass-directed isolation using ultra-performance 
liquid chromatography (15 mg, 78\% yield). ${ }^{*}$ Note: Boc deprotection ${ }^{1} \mathrm{H}$ NMR $\left(500 \mathrm{MHz}\right.$, Acetonitrile- $\left.d_{3}\right) \delta$ $8.82(\mathrm{~s}, 1 \mathrm{H}), 7.72(\mathrm{dd}, J=11.6,2.4 \mathrm{~Hz}, 1 \mathrm{H}), 7.41(\mathrm{t}, J=8.4 \mathrm{~Hz}, 1 \mathrm{H}), 7.36$ (ddd, $J=8.8,2.4,0.9 \mathrm{~Hz}, 1 \mathrm{H}$ ), 4.16 (dd, $J=10.0,3.1 \mathrm{~Hz}, 1 \mathrm{H}$ ), 4.07 (ddd, $J=11.7,3.3,2.1 \mathrm{~Hz}, 1 \mathrm{H}$ ), 3.83 (ddd, $J=12.3,3.2,1.8 \mathrm{~Hz}, 1 \mathrm{H}$ ), $3.72(\mathrm{td}, J=11.3,2.8 \mathrm{~Hz}, 1 \mathrm{H}), 3.51(\mathrm{dq}, J=12.5,2.2 \mathrm{~Hz}, 1 \mathrm{H}), 3.07-2.94(\mathrm{~m}, 4 \mathrm{H}), 1.29(\mathrm{t}, J=7.4 \mathrm{~Hz}, 3 \mathrm{H})$; AMM $350.0765(\mathrm{ESI}) \mathrm{m} / \mathrm{z}$ [calc for $\mathrm{C}_{13} \mathrm{H}_{18} \mathrm{ClFN}_{3} \mathrm{O}_{3} \mathrm{~S}(\mathrm{M}+\mathrm{H})^{+} 350.0741$ ].

General Synthesis of Analogs 11 and 11n-110<smiles>[R]PS(=O)(=O)N1CCN(C(=O)OC(C)(C)C)C(C(=O)Nc2ccc(Cl)c(F)c2)C1</smiles>

11i-11k

11I, 11n and 110

To separate precooled $\left(0^{\circ} \mathrm{C}\right)$ solutions of $11 \mathrm{i}-11 \mathrm{k}(10 . \mathrm{mg})$ in dichloromethane $(0.5 \mathrm{~mL})$ was added trifluoroacetic acid $(10 \mu \mathrm{L}, 0.1 \mathrm{mmol})$. The resulting mixtures were allowed to warm to room temperature and stirred for $18 \mathrm{~h}$, then diluted with wet DMSO $(0.5 \mathrm{~mL})$, filtered through celite and purified via massdirected isolation using ultra-performance liquid chromatography $(60-92 \%$ yield).

( \pm )-MCG-III-216-A02 (11I)

$\mathrm{R}=\mathrm{Me}(60 \%$ yield $)$

${ }^{1} \mathrm{H}$ NMR $\left(500 \mathrm{MHz}\right.$, Acetonitrile-d $\left.d_{3}\right) \delta 9.50(\mathrm{~s}, 1 \mathrm{H}), 7.62(\mathrm{dd}, J=11.3,2.5 \mathrm{~Hz}, 1 \mathrm{H}), 7.43(\mathrm{t}, J=8.5 \mathrm{~Hz}, 1 \mathrm{H})$, $7.33-7.24(\mathrm{~m}, 1 \mathrm{H}), 4.26(\mathrm{dd}, J=10.4,3.9 \mathrm{~Hz}, 1 \mathrm{H}), 4.19-4.11(\mathrm{~m}, 1 \mathrm{H}), 3.81-3.71(\mathrm{~m}, 1 \mathrm{H}), 3.63-3.53$ (m, 1H), $3.40-3.22(\mathrm{~m}, 3 \mathrm{H}), 2.91(\mathrm{~s}, 3 \mathrm{H})$; AMM $336.0599(\mathrm{ESI}) \mathrm{m} / \mathrm{z}$ [calc for $\mathrm{C}_{12} \mathrm{H}_{16} \mathrm{ClFN}_{3} \mathrm{O}_{3} \mathrm{~S}(\mathrm{M}+\mathrm{H})^{+}$ 336.0585].

(士)-MCG-III-216-A03 (11n)

$\mathrm{R}=\mathrm{Ph}(83 \%$ yield $)$

${ }^{1} \mathrm{H}$ NMR $\left(500 \mathrm{MHz}\right.$, Acetonitrile- $\left.\mathrm{d}_{3}\right) \delta 9.54(\mathrm{~d}, J=7.5 \mathrm{~Hz}, 1 \mathrm{H}), 7.83-7.76(\mathrm{~m}, 2 \mathrm{H}), 7.76-7.69(\mathrm{~m}, 1 \mathrm{H})$, $7.67-7.56(\mathrm{~m}, 3 \mathrm{H}), 7.42(\mathrm{t}, J=8.5 \mathrm{~Hz}, 1 \mathrm{H}), 7.29-7.23(\mathrm{~m}, 1 \mathrm{H}), 4.28-4.22(\mathrm{~m}, 1 \mathrm{H}), 4.13-4.05(\mathrm{~m}, 1 \mathrm{H})$, $3.68(\mathrm{~d}, J=13.1 \mathrm{~Hz}, 1 \mathrm{H}), 3.51(\mathrm{dt}, J=13.2,3.3 \mathrm{~Hz}, 1 \mathrm{H}), 3.33-3.22(\mathrm{~m}, 1 \mathrm{H}), 2.91-2.75(\mathrm{~m}, 2 \mathrm{H})$; AMM 398.0737 (ESI) $\mathrm{m} / \mathrm{z}$ [calc for $\mathrm{C}_{17} \mathrm{H}_{18} \mathrm{ClFN}_{3} \mathrm{O}_{3} \mathrm{~S}(\mathrm{M}+\mathrm{H})^{+} 398.0741$ ].

( \pm )-MCG-III-216-A04 (110)

$\mathrm{R}=\mathrm{N}-\mathrm{Me}$ Imidazole $(92 \%$ yield $)$

${ }^{1} \mathrm{H}$ NMR (500 MHz, Acetonitrile-d $\left.d_{3}\right) \delta 9.38(\mathrm{~s}, 1 \mathrm{H}), 7.64$ (dd, $\left.J=14.0,1.3 \mathrm{~Hz}, 2 \mathrm{H}\right), 7.60$ (dd, $J=11.3,2.4$ $\mathrm{Hz}, 1 \mathrm{H}), 7.43(\mathrm{t}, J=8.5 \mathrm{~Hz}, 1 \mathrm{H}), 7.29-7.24(\mathrm{~m}, 1 \mathrm{H}), 4.27(\mathrm{dd}, J=10.6,3.8 \mathrm{~Hz}, 1 \mathrm{H}), 4.25-4.20(\mathrm{~m}, 1 \mathrm{H})$, $3.76(\mathrm{~d}, J=13.6 \mathrm{~Hz}, 1 \mathrm{H}), 3.72(\mathrm{~s}, 3 \mathrm{H}), 3.53(\mathrm{dt}, J=13.1,3.1 \mathrm{~Hz}, 1 \mathrm{H}), 3.27(\mathrm{td}, J=12.9,12.3,3.8 \mathrm{~Hz}, 1 \mathrm{H})$, $3.16-3.03(\mathrm{~m}, 2 \mathrm{H})$; AMM $402.0795(\mathrm{ESI}) \mathrm{m} / \mathrm{z}$ [calc for $\mathrm{C}_{15} \mathrm{H}_{18} \mathrm{CIFN}_{5} \mathrm{O}_{3} \mathrm{~S}(\mathrm{M}+\mathrm{H})^{+} 402.0803$ ].

General Synthesis of 11p-11r

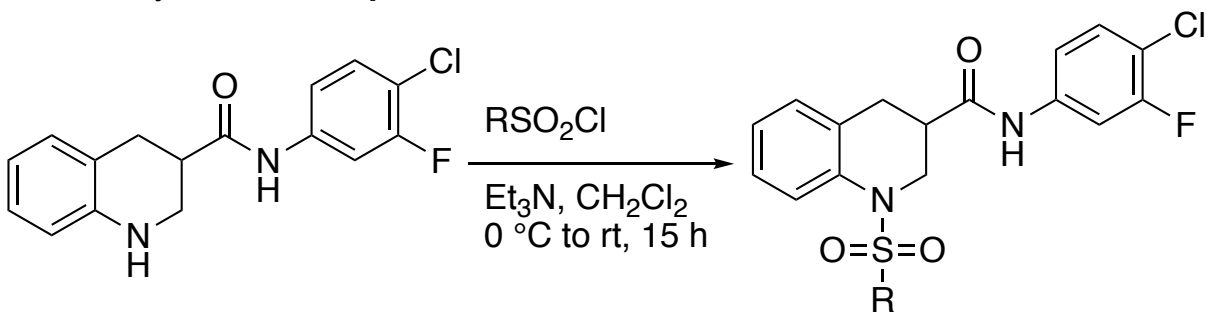

10d

$11 p-11 r$ 
To separate precooled $\left(0{ }^{\circ} \mathrm{C}\right)$ solutions of common intermediate $10 \mathrm{~d}(20 . \mathrm{mg}, 0.066 \mathrm{mmol})$ in dichloromethane $(0.5 \mathrm{~mL})$ was added triethylamine $(30 \mu \mathrm{L}, 0.2 \mathrm{mmol})$ and R-sulfonyl chloride $(0.098 \mathrm{mmol})$. The resulting mixtures were allowed to warm to room temperature and stirred for $15 \mathrm{~h}$, then diluted with wet DMSO $(0.5 \mathrm{~mL})$, filtered through celite and purified via mass-directed isolation using ultra-performance liquid chromatography $(4-52 \%$ yield).

( \pm )-MCG-III-214-A01 (11p)

$\mathrm{R}=\mathrm{Me}(28 \%$ yield $)$

${ }^{1} \mathrm{H}$ NMR $\left(500 \mathrm{MHz}\right.$, Acetonitrile- $\left.d_{3}\right) \delta 8.81(\mathrm{~s}, 1 \mathrm{H}), 7.76-7.69(\mathrm{~m}, 1 \mathrm{H}), 7.62(\mathrm{dd}, J=8.2,1.2 \mathrm{~Hz}, 1 \mathrm{H}), 7.40$ $(\mathrm{t}, J=8.6 \mathrm{~Hz}, 1 \mathrm{H}), 7.31-7.26(\mathrm{~m}, 1 \mathrm{H}), 7.26-7.18(\mathrm{~m}, 2 \mathrm{H}), 7.12(\mathrm{td}, J=7.4,1.2 \mathrm{~Hz}, 1 \mathrm{H}), 4.19(\mathrm{dd}, J=$ 13.4, $4.3 \mathrm{~Hz}, 1 \mathrm{H}), 3.65(\mathrm{dd}, J=13.3,9.5 \mathrm{~Hz}, 1 \mathrm{H}), 3.10(\mathrm{~d}, J=7.8 \mathrm{~Hz}, 2 \mathrm{H}), 3.06-3.00(\mathrm{~m}, 1 \mathrm{H}), 3.00(\mathrm{~s}$, $3 \mathrm{H}$ ); AMM 383.0619 (ESI) $\mathrm{m} / z$ [calc for $\mathrm{C}_{17} \mathrm{H}_{17} \mathrm{ClFN}_{2} \mathrm{O}_{3} \mathrm{~S}(\mathrm{M}+\mathrm{H})^{+} 383.0632$ ].

(士)-MCG-III-214-A02 (11q)

$\mathrm{R}=\mathrm{Et}(4 \%$ yield $)$

${ }^{1} \mathrm{H}$ NMR $\left(500 \mathrm{MHz}\right.$, Acetonitrile- $\left.d_{3}\right) \delta 8.80(\mathrm{~s}, 1 \mathrm{H}), 7.74(\mathrm{dd}, J=11.8,2.4 \mathrm{~Hz}, 1 \mathrm{H}), 7.38(\mathrm{t}, J=8.6 \mathrm{~Hz}, 1 \mathrm{H})$, $7.25(\mathrm{~d}, J=9.0 \mathrm{~Hz}, 1 \mathrm{H}), 7.03-6.94(\mathrm{~m}, 2 \mathrm{H}), 6.68-6.57(\mathrm{~m}, 2 \mathrm{H}), 3.54-3.46(\mathrm{~m}, 2 \mathrm{H}), 3.31$ (dd, $J=11.6$, $9.3 \mathrm{~Hz}, 2 \mathrm{H}), 3.02-2.91(\mathrm{~m}, 3 \mathrm{H}), 2.86-2.77(\mathrm{~m}, 3 \mathrm{H})$.

( \pm )-MCG-III-214-A03 (11q)

$\mathrm{R}=\mathrm{Ph}(43 \%$ yield $)$

${ }^{1} \mathrm{H}$ NMR $\left(500 \mathrm{MHz}\right.$, Acetonitrile- $\left.d_{3}\right) \delta 8.62(\mathrm{~s}, 1 \mathrm{H}), 7.72-7.58(\mathrm{~m}, 5 \mathrm{H}), 7.53-7.44(\mathrm{~m}, 2 \mathrm{H}), 7.36(\mathrm{t}, J=8.6$ $\mathrm{Hz}, 1 \mathrm{H}), 7.26-7.15(\mathrm{~m}, 2 \mathrm{H}), 7.12-7.05(\mathrm{~m}, 2 \mathrm{H}), 4.28$ (ddd, $J=13.4,4.8,1.6 \mathrm{~Hz}, 1 \mathrm{H}), 3.69$ (ddd, $J=11.6$, 8.2, $1.9 \mathrm{~Hz}, 1 \mathrm{H}), 2.79-2.65(\mathrm{~m}, 2 \mathrm{H}), 2.64-2.52(\mathrm{~m}, 1 \mathrm{H}) ;$ AMM 445.0809 (ESI) $\mathrm{m} / \mathrm{z}$ [calc for $\left.\mathrm{C}_{22} \mathrm{H}_{19} \mathrm{ClFN}_{2} \mathrm{O}_{3} \mathrm{~S}(\mathrm{M}+\mathrm{H})^{+} 445.0789\right]$.

( \pm )-MCG-III-214-A04 (11r)

$\mathrm{R}=\mathrm{N}-\mathrm{Me}$ Imidazole $(52 \%$ yield $)$

${ }^{1} \mathrm{H}$ NMR $\left(500 \mathrm{MHz}\right.$, Acetonitrile- $\left.d_{3}\right) \delta 8.85(\mathrm{~s}, 1 \mathrm{H}), 7.77-7.65(\mathrm{~m}, 2 \mathrm{H}), 7.53(\mathrm{dd}, J=12.3,1.5 \mathrm{~Hz}, 2 \mathrm{H}), 7.39$ $(\mathrm{t}, J=8.5 \mathrm{~Hz}, 1 \mathrm{H}), 7.32-7.24(\mathrm{~m}, 1 \mathrm{H}), 7.21-7.10(\mathrm{~m}, 2 \mathrm{H}), 7.10-7.02(\mathrm{~m}, 1 \mathrm{H}), 4.36(\mathrm{dd}, J=13.3,4.3$ $\mathrm{Hz}, 1 \mathrm{H}), 3.68-3.58(\mathrm{~m}, 4 \mathrm{H}), 3.06-2.94(\mathrm{~m}, 1 \mathrm{H}), 2.94-2.86(\mathrm{~m}, 2 \mathrm{H})$; AMM 449.0869 (ESI) $\mathrm{m} / \mathrm{z}$ [calc for $\left.\mathrm{C}_{20} \mathrm{H}_{19} \mathrm{ClFN}_{4} \mathrm{O}_{3} \mathrm{~S}(\mathrm{M}+\mathrm{H})^{+} 449.0850\right]$.

General Synthesis of 11s-11v

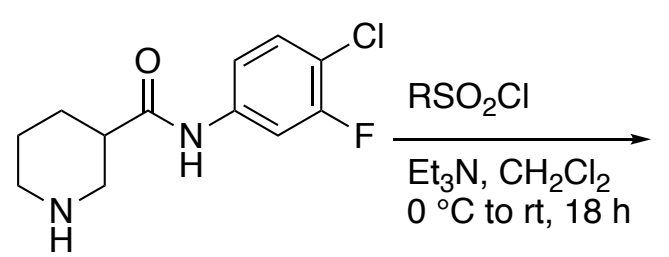

S18<smiles>[R]PS(=O)(=O)N1CCCC(C(=O)Nc2ccc(Cl)c(F)c2)C1</smiles>

To separate precooled $\left(0{ }^{\circ} \mathrm{C}\right)$ solutions of common intermediate $\mathbf{S 1 8}(20 . \mathrm{mg}, 0.078 \mathrm{mmol})$ and triethylamine $(30 \mu \mathrm{L}, 0.2 \mathrm{mmol})$ in dichloromethane $(0.5 \mathrm{~mL})$ was added R-sulfonyl chloride $(0.12 \mathrm{mmol})$. The resulting mixtures were allowed to warm to room temperature and stirred for $18 \mathrm{~h}$, then diluted with wet DMSO $(0.5 \mathrm{~mL})$, filtered through celite and purified via mass-directed isolation using ultra-performance liquid chromatography (43-57\% yield).

( \pm )-MCG-III-157-B01 (11s)

$\mathrm{R}=\mathrm{Me}(45 \%$ yield $)$

${ }^{1} \mathrm{H}$ NMR $\left(500 \mathrm{MHz}\right.$, Acetonitrile- $\left.d_{3}\right) \delta 8.65(\mathrm{~s}, 1 \mathrm{H}), 7.71$ (dd, $\left.J=11.8,2.4 \mathrm{~Hz}, 1 \mathrm{H}\right), 7.37(\mathrm{t}, J=8.6 \mathrm{~Hz}, 1 \mathrm{H})$, $7.28-7.19(\mathrm{~m}, 1 \mathrm{H}), 3.84-3.74(\mathrm{~m}, 1 \mathrm{H}), 3.65-3.56(\mathrm{~m}, 1 \mathrm{H}), 2.88(\mathrm{dd}, J=11.8,10.6 \mathrm{~Hz}, 1 \mathrm{H}), 2.79(\mathrm{~s}$, $3 \mathrm{H}), 2.77-2.68(\mathrm{~m}, 1 \mathrm{H}), 2.63-2.53(\mathrm{~m}, 1 \mathrm{H}), 2.05-1.97(\mathrm{~m}, 1 \mathrm{H}), 1.90-1.80(\mathrm{~m}, 1 \mathrm{H}), 1.68-1.51(\mathrm{~m}$, $2 \mathrm{H}$ ); AMM 357.0471 (ESI) $\mathrm{m} / \mathrm{z}$ [calc for $\mathrm{C}_{13} \mathrm{H}_{16} \mathrm{ClFN}_{2} \mathrm{O}_{3} \mathrm{SNa}(\mathrm{M}+\mathrm{Na})^{+} 357.0452$ ]. 
( \pm )-MCG-III-157-B02 (11t)

$\mathrm{R}=\mathrm{Et}(43 \%$ yield $)$

${ }^{1} \mathrm{H}$ NMR $\left(500 \mathrm{MHz}\right.$, Acetonitrile- $\left.d_{3}\right) \delta 8.65(\mathrm{~s}, 1 \mathrm{H}), 7.71(\mathrm{dd}, J=11.8,2.4 \mathrm{~Hz}, 1 \mathrm{H}), 7.37(\mathrm{t}, J=8.6 \mathrm{~Hz}, 1 \mathrm{H})$, $7.27-7.19(\mathrm{~m}, 1 \mathrm{H}), 3.86-3.75(\mathrm{~m}, 1 \mathrm{H}), 3.68-3.57(\mathrm{~m}, 1 \mathrm{H}), 3.04-2.91(\mathrm{~m}, 3 \mathrm{H}), 2.84(\mathrm{td}, J=11.7,2.9$ $\mathrm{Hz}, 1 \mathrm{H}), 2.61-2.49(\mathrm{~m}, 1 \mathrm{H}), 2.05-1.96(\mathrm{~m}, 1 \mathrm{H}), 1.87-1.77(\mathrm{~m}, 1 \mathrm{H}), 1.71-1.50(\mathrm{~m}, 2 \mathrm{H}), 1.27(\mathrm{t}, J=7.4$ $\mathrm{Hz}, 3 \mathrm{H})$; AMM 349.0814 (ESI) $\mathrm{m} / \mathrm{z}$ [calc for $\mathrm{C}_{14} \mathrm{H}_{19} \mathrm{ClFN}_{2} \mathrm{O}_{3} \mathrm{~S}(\mathrm{M}+\mathrm{H})^{+} 349.0789$ ].

( \pm )-MCG-III-157-B03 (11u)

$\mathrm{R}=\mathrm{Ph}(45 \%$ yield $)$

${ }^{1} \mathrm{H}$ NMR $\left(500 \mathrm{MHz}\right.$, Acetonitrile- $\left.d_{3}\right) \delta 8.59(\mathrm{~s}, 1 \mathrm{H}), 7.80-7.73(\mathrm{~m}, 2 \mathrm{H}), 7.72-7.65(\mathrm{~m}, 2 \mathrm{H}), 7.65-7.58(\mathrm{~m}$, $2 \mathrm{H}), 7.37(\mathrm{t}, J=8.6 \mathrm{~Hz}, 1 \mathrm{H}), 7.26-7.17(\mathrm{~m}, 1 \mathrm{H}), 3.87-3.78(\mathrm{~m}, 1 \mathrm{H}), 3.64(\mathrm{~d}, J=11.7 \mathrm{~Hz}, 1 \mathrm{H}), 2.63-$ $2.54(\mathrm{~m}, 1 \mathrm{H}), 2.42(\mathrm{t}, J=11.1 \mathrm{~Hz}, 1 \mathrm{H}), 2.30(\mathrm{td}, J=11.7,2.9 \mathrm{~Hz}, 1 \mathrm{H}), 1.92-1.86(\mathrm{~m}, 1 \mathrm{H}), 1.84-1.74(\mathrm{~m}$, $1 \mathrm{H}), 1.67-1.52(\mathrm{~m}, 1 \mathrm{H}), 1.42(\mathrm{qd}, J=12.6,3.9 \mathrm{~Hz}, 1 \mathrm{H}) ;$ AMM 419.0621 (ESI) $\mathrm{m} / \mathrm{z}$ [calc for $\left.\mathrm{C}_{18} \mathrm{H}_{18} \mathrm{ClFN}_{2} \mathrm{O}_{3} \mathrm{SNa}(\mathrm{M}+\mathrm{Na})^{+} 419.0608\right]$.

( \pm )-MCG-III-157-B04 (11v)

$\mathrm{R}=\mathrm{N}-\mathrm{Me}$ Imidazole (57\% yield)

${ }^{1} \mathrm{H}$ NMR $\left(500 \mathrm{MHz}\right.$, Acetonitrile- $\left.d_{3}\right) \delta 8.61(\mathrm{~s}, 1 \mathrm{H}), 7.73(\mathrm{~s}, 1 \mathrm{H}), 7.69(\mathrm{dd}, J=11.8,2.4 \mathrm{~Hz}, 1 \mathrm{H}), 7.57(\mathrm{~d}, J=$ $1.4 \mathrm{~Hz}, 1 \mathrm{H}), 7.37(\mathrm{t}, J=8.6 \mathrm{~Hz}, 1 \mathrm{H}), 7.26-7.18(\mathrm{~m}, 1 \mathrm{H}), 3.85-3.77(\mathrm{~m}, 1 \mathrm{H}), 3.73(\mathrm{~s}, 3 \mathrm{H}), 3.64(\mathrm{~d}, J=$ $12.0 \mathrm{~Hz}, 1 \mathrm{H}), 2.67(\mathrm{t}, J=11.2 \mathrm{~Hz}, 1 \mathrm{H}), 2.62-2.47(\mathrm{~m}, 2 \mathrm{H}), 1.85-1.76(\mathrm{~m}, 1 \mathrm{H}), 1.59(\mathrm{qt}, J=12.5,4.0 \mathrm{~Hz}$, $1 \mathrm{H}), 1.53-1.41(\mathrm{~m}, 1 \mathrm{H})$; AMM $423.0678(\mathrm{ESI}) \mathrm{m} / \mathrm{z}$ [calc for $\mathrm{C}_{16} \mathrm{H}_{18} \mathrm{ClFN}_{4} \mathrm{O}_{3} \mathrm{SNa}(\mathrm{M}+\mathrm{Na})^{+} 423.0670$ ].

Synthesis of Analog 13 (MCG-III-207)<smiles>O=C(O)C1CCCOC1</smiles>

13

To a precooled $\left(0^{\circ} \mathrm{C}\right)$ solution of 4-chloro-3-fluoroaniline $(336 \mathrm{mg}, 2.31 \mathrm{mmol})$ and HATU (584 $\mathrm{mg}, 1.54$ $\mathrm{mmol}$ ) in DMF $(8 \mathrm{~mL})$ under $\mathrm{N}_{2}$ atmosphere was added tetrahydro-2H-pyran-3-carboxylic acid (200. $\mathrm{mg}$, $1.54 \mathrm{mmol})$ then diisopropylethylamine $(0.80 \mathrm{~mL}, 4.61 \mathrm{mmol})$. The resulting mixture was allowed to warm to room temperature and stirred for $19 \mathrm{~h}$, then concentrated in vacuo. The resulting residue was taken up in EtOAc and quenched with $\mathrm{H}_{2} \mathrm{O}$. The layers were separated, and the aqueous phase was extracted with EtOAc (3x). The combined organic layers were washed with brine, dried over $\mathrm{Na}_{2} \mathrm{SO}_{4}$, and concentrated in vacuo. Flash chromatography $\left(\mathrm{SiO}_{2}, 80: 30\right.$ hexanes:EtOAc) afforded the product as a white solid (345 mg, $87 \%$ yield).

${ }^{1} \mathrm{H}$ NMR $\left(500 \mathrm{MHz}\right.$, Acetonitrile- $\left.d_{3}\right) \delta 8.56(\mathrm{~s}, 1 \mathrm{H}), 7.72(\mathrm{dd}, J=11.9,2.4 \mathrm{~Hz}, 1 \mathrm{H}), 7.37(\mathrm{t}, J=8.6 \mathrm{~Hz}, 1 \mathrm{H})$, $7.27-7.19(\mathrm{~m}, 1 \mathrm{H}), 4.00-3.91(\mathrm{~m}, 1 \mathrm{H}), 3.82(\mathrm{dt}, J=11.1,3.6 \mathrm{~Hz}, 1 \mathrm{H}), 3.49(\mathrm{dd}, J=11.3,9.8 \mathrm{~Hz}, 1 \mathrm{H})$, $3.40(\mathrm{td}, J=11.1,3.0 \mathrm{~Hz}, 1 \mathrm{H}), 2.62-2.51(\mathrm{~m}, 1 \mathrm{H}), 2.03-1.96(\mathrm{~m}, 1 \mathrm{H}), 1.84-1.71(\mathrm{~m}, 1 \mathrm{H}), 1.71-1.53$ $(\mathrm{m}, 2 \mathrm{H}) ;{ }^{13} \mathrm{C}$ NMR $\left(126 \mathrm{MHz}, \mathrm{CDCl}_{3}\right) \delta 172.36,159.14,157.17,137.94,137.87,130.56,116.01,115.98$, $108.83,108.62,68.98,68.67,43.60,38.79,26.45,23.77$; AMM 258.0711 (ESI) $\mathrm{m} / \mathrm{z}$ [calc for $\mathrm{C}_{12} \mathrm{H}_{14} \mathrm{CIFNO}_{2}$ $(\mathrm{M}+\mathrm{H})^{+}$258.0697].

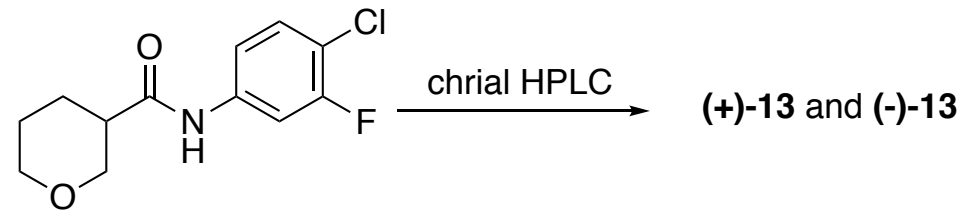

\section{$( \pm)-13$}

Chiral HPLC purification was performed using a Shimadzu HPLC (5 to $30 \%$ reagent alcohol in hexanes, 30 min.) with a chiral normal phase column (ChiralPak AD-H, $5 \mu \mathrm{M}$ pore size, column dimensions $21 \mathrm{~mm} \mathrm{x}$ $250 \mathrm{~mm}$ ). 


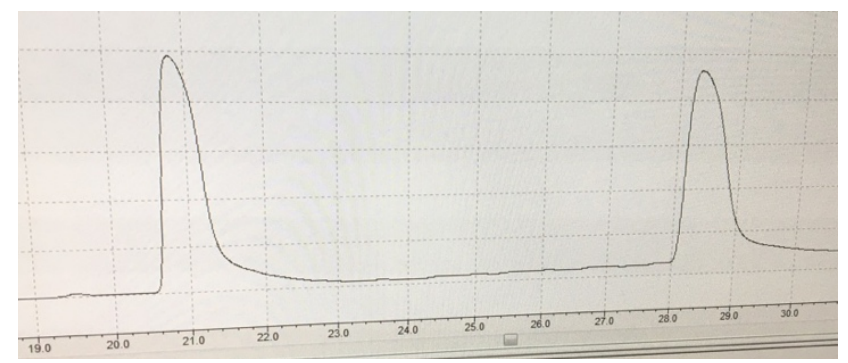

(-)-2.109 (MCG-III-207-P1)

Retention time $=21 \mathrm{~min}$.

$[\alpha]_{0}{ }^{22}-36.12$ (c. $0.083, \mathrm{CH}_{3} \mathrm{OH}$ )

(+)-2.109 (MCG-III-207-P2)

Retention time $=28 \mathrm{~min}$.

$[\alpha]_{D^{22}}+27.80$ (c. $0.11, \mathrm{CH}_{3} \mathrm{OH}$ )

\section{Synthesis of Analogs 16}

General Synthesis of Analogs 16a-16e<smiles>CCN(CC)C(=O)OC(=O)N1CCC[C@H](C(=O)Nc2ccc(Cl)c(F)c2)C1</smiles>

14

16a-16e

To separate precooled $\left(0{ }^{\circ} \mathrm{C}\right)$ solutions of common intermediate $14(20 . \mathrm{mg}, 0.078 \mathrm{mmol})$ in dichloromethane $(0.5 \mathrm{~mL})$ was added triethylamine $(30 \mu \mathrm{L}, 0.2 \mathrm{mmol})$ and R-chloroformate $(0.12 \mathrm{mmol})$. The resulting mixtures were allowed to warm to room temperature and stirred for 20-60 $\mathrm{h}$, then diluted with wet DMSO $(0.5 \mathrm{~mL})$, filtered through celite and purified via mass-directed isolation using ultra-performance liquid chromatography $(23-61 \%$ yield).

(S)-MCG-III-188-A01 (16a)

$\mathrm{R}=\mathrm{Me}(23 \%$ yield $)$

$[\alpha]_{\mathrm{D}}{ }^{22}+45.6$ (c. 0.045, $\left.\mathrm{CH}_{3} \mathrm{OH}\right) ;{ }^{1} \mathrm{H}$ NMR $\left(500 \mathrm{MHz}\right.$, Acetonitrile- $\left.d_{3}\right) \delta 8.61(\mathrm{~s}, 1 \mathrm{H}), 7.71$ (dd, $\mathrm{J}=11.9,2.4$ $\mathrm{Hz}, 1 \mathrm{H}), 7.37(\mathrm{t}, J=8.6 \mathrm{~Hz}, 1 \mathrm{H}), 7.28-7.20(\mathrm{~m}, 1 \mathrm{H}), 4.11(\mathrm{~d}, J=13.2 \mathrm{~Hz}, 1 \mathrm{H}), 4.00-3.85(\mathrm{~m}, 1 \mathrm{H}), 3.63$ $(\mathrm{s}, 3 \mathrm{H}), 3.02(\mathrm{t}, J=12.0 \mathrm{~Hz}, 1 \mathrm{H}), 2.86(\mathrm{~s}, 1 \mathrm{H}), 2.49-2.38(\mathrm{~m}, 1 \mathrm{H}), 1.99(\mathrm{~d}, J=12.5 \mathrm{~Hz}, 1 \mathrm{H}), 1.78-1.62$ (m, 2H), $1.53-1.37(\mathrm{~m}, 1 \mathrm{H}) ;{ }^{13} \mathrm{C}$ NMR (126 MHz, MeOD) $\delta 174.42,160.08,158.13,140.41,140.33,131.52$, 117.33, 117.30, 116.05, 115.91, 109.32, 109.11, 53.38, 47.34, 45.28, 44.95, 40.40, 28.92, 25.41; IR (ATR) $v_{\max } 3260,1714,1695,1660,1597,1532,1469,1235,1207,1165 \mathrm{~cm}^{-1}$; AMM 315.0932 (ESI) $\mathrm{m} / \mathrm{z}$ [calc for $\left.\mathrm{C}_{14} \mathrm{H}_{17} \mathrm{CIFN}_{2} \mathrm{O}_{3}(\mathrm{M}+\mathrm{H})^{+} 315.0912\right]$.

(S)-MCG-III-188-A02 (16b)

$\mathrm{R}=\mathrm{Et}(37 \%$ yield $)$

$[\alpha]_{\mathrm{D}}{ }^{22}+36.24$ (c. $\left.0.057, \mathrm{CH}_{3} \mathrm{OH}\right) ;{ }^{1} \mathrm{H}$ NMR $\left(500 \mathrm{MHz}\right.$, Acetonitrile- $\left.d_{3}\right) \delta 8.59$ (s, 1H), 7.68 (dd, $J=11.9,2.4$ $\mathrm{Hz}, 1 \mathrm{H}), 7.33(\mathrm{t}, J=8.6 \mathrm{~Hz}, 1 \mathrm{H}), 7.24-7.16(\mathrm{~m}, 1 \mathrm{H}), 4.11-3.98(\mathrm{~m}, 3 \mathrm{H}), 3.89(\mathrm{~d}, J=13.3 \mathrm{~Hz}, 1 \mathrm{H}), 2.99$ $(\mathrm{t}, J=12.0 \mathrm{~Hz}, 1 \mathrm{H}), 2.83(\mathrm{~s}, 1 \mathrm{H}), 2.44-2.33(\mathrm{~m}, 1 \mathrm{H}), 1.99-1.92(\mathrm{~m}, 1 \mathrm{H}), 1.74-1.59(\mathrm{~m}, 2 \mathrm{H}), 1.48-1.33$ (m, 1H), 1.17 (t, $J=7.1 \mathrm{~Hz}, 3 \mathrm{H}) ;{ }^{13} \mathrm{C}$ NMR (126 MHz, MeOD) $\delta 174.44,160.09,158.14,157.20,140.43$, 140.35, 131.53, 117.31, 117.29, 116.03, 115.89, 109.30, 109.10, 62.82, 47.25, 44.94, 40.40, 28.95, 25.41, 14.93; IR (ATR) $v_{\max } 3313,1669,1536,1496,1437,1198,1136,852 \mathrm{~cm}^{-1}$; AMM 329.1082 (ESI) $\mathrm{m} / \mathrm{z}$ [calc for $\left.\mathrm{C}_{15} \mathrm{H}_{19} \mathrm{ClFN}_{2} \mathrm{O}_{3}(\mathrm{M}+\mathrm{H})^{+} 329.1068\right]$.

(S)-MCG-III-188-A03 (16c)

$\mathrm{R}=\mathrm{Ph}(61 \%$ yield $)$ 
${ }^{1} \mathrm{H}$ NMR $\left(500 \mathrm{MHz}\right.$, Acetonitrile- $\left.d_{3}\right) \delta 8.58(\mathrm{~s}, 1 \mathrm{H}), 7.68(\mathrm{dd}, J=11.9,2.4 \mathrm{~Hz}, 1 \mathrm{H}), 7.38-7.30(\mathrm{~m}, 3 \mathrm{H}), 7.25$ $-7.14(\mathrm{~m}, 2 \mathrm{H}), 7.07(\mathrm{~d}, J=7.9 \mathrm{~Hz}, 2 \mathrm{H}), 4.29-4.02(\mathrm{~m}, 2 \mathrm{H}), 3.92(\mathrm{~s}, 1 \mathrm{H}), 3.35-3.18(\mathrm{~m}, 1 \mathrm{H}), 3.18-2.90$ $(\mathrm{m}, 2 \mathrm{H}), 2.61-2.42(\mathrm{~m}, 2 \mathrm{H}), 2.06-1.96(\mathrm{~m}, 1 \mathrm{H}), 1.84-1.66(\mathrm{~m}, 2 \mathrm{H}), 1.55(\mathrm{~s}, 1 \mathrm{H})$; AMM 377.1087 (ESI) $\mathrm{m} / \mathrm{z}$ [calc for $\mathrm{C}_{19} \mathrm{H}_{19} \mathrm{ClFN}_{2} \mathrm{O}_{3}(\mathrm{M}+\mathrm{H})^{+} 377.1068$ ].

(S)-MCG-IV-058 (16d)

$\mathrm{R}=n-\operatorname{Pr}(36 \%$ yield $)$

${ }^{1} \mathrm{H}$ NMR (500 MHz, Acetonitrile-d3) $\delta 8.63(\mathrm{~s}, 1 \mathrm{H}), 7.68(\mathrm{dd}, J=11.9,2.5 \mathrm{~Hz}, 1 \mathrm{H}), 7.33(\mathrm{t}, J=8.6 \mathrm{~Hz}, 1 \mathrm{H})$, $7.25-7.17(\mathrm{~m}, 1 \mathrm{H}), 4.07(\mathrm{~d}, J=13.3 \mathrm{~Hz}, 1 \mathrm{H}), 4.01-3.84(\mathrm{~m}, 3 \mathrm{H}), 3.00(\mathrm{~s}, 1 \mathrm{H}), 2.84(\mathrm{~s}, 1 \mathrm{H}), 2.46-2.34$ $(\mathrm{m}, 3 \mathrm{H}), 1.77-1.62(\mathrm{~m}, 2 \mathrm{H}), 1.62-1.50(\mathrm{~m}, 2 \mathrm{H}), 1.50-1.33(\mathrm{~m}, 1 \mathrm{H}), 0.88(\mathrm{t}, J=7.4 \mathrm{~Hz}, 3 \mathrm{H}) ;$ AMM (ESI) $\mathrm{m} / \mathrm{z} 406.1303$ [calc for $\mathrm{C}_{18} \mathrm{H}_{23} \mathrm{ClFN}_{3} \mathrm{O}_{3}(\mathrm{M}+\mathrm{Na})^{+}(\mathrm{ACN})$ 406.1210].

(S)-MCG-IV-061 (16e)

$\mathrm{R}=i-\mathrm{Bu}(46 \%$ yield $)$

${ }^{1} \mathrm{H}$ NMR $\left(500 \mathrm{MHz}\right.$, Acetonitrile- $\left.d_{3}\right) \delta 8.57(\mathrm{~s}, 1 \mathrm{H}), 7.68(\mathrm{dd}, J=11.9,2.5 \mathrm{~Hz}, 1 \mathrm{H}), 7.33(\mathrm{t}, J=8.6 \mathrm{~Hz}, 1 \mathrm{H})$, $7.23-7.16(\mathrm{~m}, 1 \mathrm{H}), 4.12-4.03(\mathrm{~m}, 1 \mathrm{H}), 3.94-3.85(\mathrm{~m}, 1 \mathrm{H}), 3.78(\mathrm{~d}, J=6.6 \mathrm{~Hz}, 2 \mathrm{H}), 3.01(\mathrm{~s}, 1 \mathrm{H}), 2.86$ (s, 1H), $2.45-2.32(\mathrm{~m}, 1 \mathrm{H}), 1.98-1.92(\mathrm{~m}, 1 \mathrm{H}), 1.88-1.80(\mathrm{~m}, 1 \mathrm{H}), 1.77-1.59(\mathrm{~m}, 2 \mathrm{H}), 1.49-1.33(\mathrm{~m}$, $1 \mathrm{H}), 0.87(\mathrm{~d}, \mathrm{~J}=6.8 \mathrm{~Hz}, 6 \mathrm{H})$; AMM $379.1212(\mathrm{ESI}) \mathrm{m} / \mathrm{z}$ [calc for $\mathrm{C}_{17} \mathrm{H}_{22} \mathrm{ClFN}_{2} \mathrm{O}_{3} \mathrm{Na}(\mathrm{M}+\mathrm{Na})^{+} 379.1201$ ].

Synthesis of Analog $16 f$

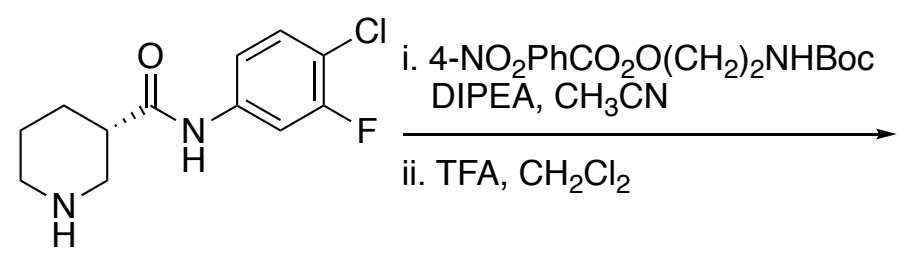

14<smiles>[NH3+]CCOC(=O)N1CCC[C@H](C(=O)Nc2ccc(Cl)c(F)c2)C1</smiles>

i. To a solution of intermediate $14(30 . \mathrm{mg}, 0.12 \mathrm{mmol})$ and tert-butyl (2-((4-nitrophenoxy)carbonyl)oxy)ethyl)carbamate $(76 \mathrm{mg}, 0.23 \mathrm{mmol})$ in acetonitrile $(1.2 \mathrm{~mL})$ at room temperature was added diisopropylethylamine $(60 \mu \mathrm{L}, 0.4 \mathrm{mmol})$. The resulting mixture was heated to $80^{\circ} \mathrm{C}$ in a sealed microwave reaction vessel for $66 \mathrm{~h}$, then concentrated in vacuo. The crude residue was taken up in EtOAc and diluted with $\mathrm{H}_{2} \mathrm{O}$. The layers were separated, and the aqueous phase was extracted with EtOAc (3x). The combined organic layers were dried over $\mathrm{Na}_{2} \mathrm{SO}_{4}$, filtered, and concentrated in vacuo to afford the product, which was carried forward without purification.

ii. To a precooled $\left(0^{\circ} \mathrm{C}\right)$ solution of intermediate $(32 \mathrm{mg}, 0.071 \mathrm{mmol})$ in dichloromethane $(0.7 \mathrm{~mL})$ under $\mathrm{N}_{2}$ atmosphere was added dropwise trifluoroacetic acid $(0.1 \mathrm{~mL}, 1 \mathrm{mmol})$. The resulting mixture was allowed to warm to room temperature and stirred for $18 \mathrm{~h}$, then concentrated in vacuo. The crude residue was diluted with wet DMSO $(0.5 \mathrm{~mL})$ and purified via mass-directed isolation using ultraperformance liquid chromatography to afford the product as a white solid ( $26 \mathrm{mg}, 77 \%$ yield). ${ }^{1} \mathbf{H}$ NMR $\left(500 \mathrm{MHz}\right.$, Methanol- $\left.d_{4}\right) \delta 7.69(\mathrm{dd}, J=11.6,2.3 \mathrm{~Hz}, 1 \mathrm{H}), 7.38(\mathrm{t}, J=8.3 \mathrm{~Hz}, 1 \mathrm{H}), 7.29-7.23(\mathrm{~m}, 1 \mathrm{H})$, $4.42(\mathrm{~s}, 1 \mathrm{H}), 4.23(\mathrm{~s}, 1 \mathrm{H}), 4.16-3.99(\mathrm{~m}, 1 \mathrm{H}), 3.24(\mathrm{~s}, 1 \mathrm{H}), 3.14-2.97(\mathrm{~m}, 1 \mathrm{H}), 2.61-2.48(\mathrm{~m}, 1 \mathrm{H})$, $2.17-1.98(\mathrm{~m}, 2 \mathrm{H}), 1.88-1.73(\mathrm{~m}, 2 \mathrm{H}), 1.54(\mathrm{~d}, \mathrm{~J}=12.4 \mathrm{~Hz}, 1 \mathrm{H})$; AMM 344.1190 (ESI) $\mathrm{m} / \mathrm{z}$ [calc for $\left.\mathrm{C}_{15} \mathrm{H}_{20} \mathrm{ClFN}_{3} \mathrm{O}_{3}(\mathrm{M})^{+} 344.1177\right]$.

\section{Synthesis of Analogs 17}<smiles>O=C(Nc1ccc(Cl)c(F)c1)[C@H]1CCCN(C(=O)Oc2ccc([Se])cc2)C1</smiles> 
To a precooled $\left(0{ }^{\circ} \mathrm{C}\right)$ solution of intermediate $14(300 . \mathrm{mg}, 1.17 \mathrm{mmol})$ and para-nitrophenylchloroformate (236 mg, $1.17 \mathrm{mmol})$ in $\mathrm{CH}_{2} \mathrm{Cl}_{2}(6 \mathrm{~mL})$ under $\mathrm{N}_{2}$ atmosphere was added dropwise triethylamine $(0.33 \mathrm{~mL}$, $2.3 \mathrm{mmol}$ ). The resulting mixture was allowed to warm to room temperature and stirred for $16 \mathrm{~h}$, then quenched with sat. aq. $\mathrm{NaHCO}_{3}$. The layers were separated, and the aqueous phase was extracted with $\mathrm{CH}_{2} \mathrm{Cl}_{2}(3 \mathrm{x})$. The combined organic layers were washed with brine, dried over $\mathrm{Na}_{2} \mathrm{SO}_{4}$, and concentrated in vacuo. Flash chromatography $\left(\mathrm{SiO}_{2}, 50: 50\right.$ hexanes:EtOAc) to afford the product as a white solid (125

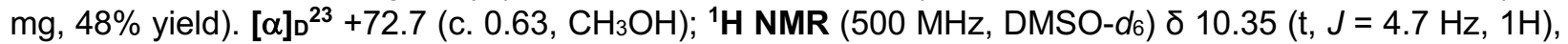
$8.34-8.20(\mathrm{~m}, 2 \mathrm{H}), 7.77(\mathrm{t}, J=9.5 \mathrm{~Hz}, 1 \mathrm{H}), 7.55-7.46(\mathrm{~m}, 1 \mathrm{H}), 7.46-7.37(\mathrm{~m}, 2 \mathrm{H}), 7.33(\mathrm{~d}, J=8.9 \mathrm{~Hz}$, $1 \mathrm{H}), 4.26-4.00(\mathrm{~m}, 2 \mathrm{H}), 3.25-3.01(\mathrm{~m}, 2 \mathrm{H}), 2.73-2.56(\mathrm{~m}, 1 \mathrm{H}), 2.12-1.94(\mathrm{~m}, 1 \mathrm{H}), 1.91-1.79(\mathrm{~m}$, 1H), $1.79-1.63(\mathrm{~m}, 1 \mathrm{H}), 1.63-1.43(\mathrm{~m}, 1 \mathrm{H})$; IR (ATR) $v_{\max } 3075,1715,1656,1606,1519,1423,1344$, $1212,857,748 \mathrm{~cm}^{-1}$; AMM (ESI) $\mathrm{m} / \mathrm{z} 422.0936$ [calc for $\mathrm{C}_{19} \mathrm{H}_{18} \mathrm{CIFN}_{3} \mathrm{O}_{5}(\mathrm{M}+\mathrm{H})^{+} 422.0919$ ].

General Synthesis of Analogs 17a-17e<smiles>CCNC(=O)N1CCC[C@H](C(=O)Nc2ccc(Cl)c(F)c2)C1</smiles>

To separated precooled $\left(0^{\circ} \mathrm{C}\right)$ vials charged with NHRR' $(0.17 \mathrm{mmol})$ was added a solution of common intermediate 2.115 (36 mg, $0.085 \mathrm{mmol})$, triethylamine $(20 \mu \mathrm{L}, 0.2 \mathrm{mmol})$, and 4-dimethylaminopyridine (2 $\mathrm{mg}, 0.002 \mathrm{mmol})$ in dichloromethane $(0.5 \mathrm{~mL})$ and methanol $(0.3 \mathrm{~mL})$. The resulting mixtures were allowed to warm to room temperature and stirred for $60 \mathrm{~h}$, then diluted with wet DMSO $(0.5 \mathrm{~mL})$, filtered through celite, and purified via mass-directed isolation using ultra-performance liquid chromatography (13-98\%).

(S)-MCG-IV-031-A02 (17a)

$\mathrm{R}=\mathrm{Et}, \mathrm{R}^{\prime}=\mathrm{H}(13 \%$ yield $)$

${ }^{1} \mathrm{H}$ NMR $\left(500 \mathrm{MHz}\right.$, Acetonitrile- $\left.d_{3}\right) \delta 8.90(\mathrm{~s}, 1 \mathrm{H}), 7.71$ (dd, $\left.J=11.9,2.4 \mathrm{~Hz}, 1 \mathrm{H}\right), 7.33(\mathrm{t}, J=8.6 \mathrm{~Hz}, 1 \mathrm{H})$, 7.22 (dd, $J=9.3,2.2 \mathrm{~Hz}, 1 \mathrm{H}), 4.02(\mathrm{q}, J=7.1 \mathrm{~Hz}, 1 \mathrm{H}), 3.82(\mathrm{~d}, J=14.5 \mathrm{~Hz}, 1 \mathrm{H}), 3.64(\mathrm{~d}, J=13.9 \mathrm{~Hz}, 1 \mathrm{H})$, $3.17-3.07(\mathrm{~m}, 5 \mathrm{H}), 2.90-2.82(\mathrm{~m}, 2 \mathrm{H}), 2.44-2.33(\mathrm{~m}, 1 \mathrm{H}), 1.80-1.67(\mathrm{~m}, 1 \mathrm{H}), 1.64-1.53(\mathrm{~m}, 1 \mathrm{H})$, $1.47-1.34(\mathrm{~m}, 1 \mathrm{H}), 1.31-1.19(\mathrm{~m}, 2 \mathrm{H}), 1.16(\mathrm{t}, J=7.1 \mathrm{~Hz}, 1 \mathrm{H}), 1.02(\mathrm{t}, J=7.2 \mathrm{~Hz}, 2 \mathrm{H}), 0.89-0.79(\mathrm{~m}$, $2 \mathrm{H})$; $\mathrm{AMM}(\mathrm{ESI}) \mathrm{m} / \mathrm{z} 328.1248$ [calc for $\mathrm{C}_{15} \mathrm{H}_{20} \mathrm{CIFN}_{3} \mathrm{O}_{2}(\mathrm{M}+\mathrm{H})^{+} 328.1228$ ].

(S)-MCG-IV-031-A03 (17b)

$\mathrm{R}=\mathrm{Me}, \mathrm{R}^{\prime}=\mathrm{Me}(32 \%$ yield $)$

${ }^{1} \mathrm{H}$ NMR $\left(500 \mathrm{MHz}\right.$, Acetonitrile- $\left.d_{3}\right) \delta 9.19(\mathrm{~s}, 1 \mathrm{H}), 7.75(\mathrm{~d}, J=12.1 \mathrm{~Hz}, 1 \mathrm{H}), 7.42-7.32(\mathrm{~m}, 1 \mathrm{H}), 7.28(\mathrm{~d}, J$ $=9.1 \mathrm{~Hz}, 1 \mathrm{H}), 3.60(\mathrm{~d}, J=13.6 \mathrm{~Hz}, 1 \mathrm{H}), 3.47(\mathrm{~d}, J=13.1 \mathrm{~Hz}, 1 \mathrm{H}), 3.17(\mathrm{t}, J=11.4 \mathrm{~Hz}, 1 \mathrm{H}), 2.94(\mathrm{t}, J=$ $11.9 \mathrm{~Hz}, 1 \mathrm{H}), 2.79(\mathrm{~d}, J=3.4 \mathrm{~Hz}, 6 \mathrm{H}), 2.57-2.48(\mathrm{~m}, 1 \mathrm{H}), 1.87-1.73(\mathrm{~m}, 1 \mathrm{H}), 1.69-1.58(\mathrm{~m}, 1 \mathrm{H}), 1.58$ $-1.45(\mathrm{~m}, 1 \mathrm{H}), 1.36-1.16(\mathrm{~m}, 1 \mathrm{H})$; AMM (ESI) $\mathrm{m} / \mathrm{z} 328.1239$ [calc for $\mathrm{C}_{15} \mathrm{H}_{20} \mathrm{ClFN}_{3} \mathrm{O}_{2}(\mathrm{M}+\mathrm{H})^{+} 328.1228$ ].

(S)-MCG-IV-031-A04 (17c)

$\mathrm{R}=\mathrm{Et}, \mathrm{R}^{\prime}=\mathrm{Me}(62 \%$ yield $)$

${ }^{1} \mathrm{H}$ NMR (500 MHz, Acetonitrile- $\left.d_{3}\right) \delta 9.13(\mathrm{~s}, 1 \mathrm{H}), 7.70$ (dd, $\left.J=11.9,2.4 \mathrm{~Hz}, 1 \mathrm{H}\right), 7.33(\mathrm{t}, J=8.5 \mathrm{~Hz}, 1 \mathrm{H})$, $7.27-7.20(\mathrm{~m}, 1 \mathrm{H}), 3.54(\mathrm{dd}, J=13.6,3.8 \mathrm{~Hz}, 1 \mathrm{H}), 3.48-3.34(\mathrm{~m}, 1 \mathrm{H}), 3.15(\mathrm{q}, J=7.0 \mathrm{~Hz}, 2 \mathrm{H}), 2.99-$ $2.87(\mathrm{~m}, 1 \mathrm{H}), 2.75(\mathrm{~s}, 3 \mathrm{H}), 2.56-2.46(\mathrm{~m}, 1 \mathrm{H}), 1.82-1.72(\mathrm{~m}, 1 \mathrm{H}), 1.72-1.55(\mathrm{~m}, 2 \mathrm{H}), 1.55-1.43(\mathrm{~m}$, $1 \mathrm{H}), 1.07\left(\mathrm{t}, J=7.1 \mathrm{~Hz}, 3 \mathrm{H}\right.$ ); AMM (ESI) $m / z 342.1380$ [calc for $\mathrm{C}_{16} \mathrm{H}_{22} \mathrm{CIFN}_{3} \mathrm{O}_{2}(\mathrm{M}+\mathrm{H})^{+} 342.1385$ ].

(S)-MCG-IV-031-A05 (17d)

$\mathrm{R}=n-\operatorname{Pr}, \mathrm{R}^{\prime}=\mathrm{H}(98 \%$ yield $)$

${ }^{1} \mathrm{H}$ NMR $\left(500 \mathrm{MHz}\right.$, Acetonitrile- $\left.d_{3}\right) \delta 8.95(\mathrm{~s}, 1 \mathrm{H}), 7.74(\mathrm{dd}, J=11.9,2.4 \mathrm{~Hz}, 1 \mathrm{H}), 7.37$ (t, $\left.J=8.5 \mathrm{~Hz}, 1 \mathrm{H}\right)$, $7.31-7.21(\mathrm{~m}, 1 \mathrm{H}), 3.93-3.84(\mathrm{~m}, 1 \mathrm{H}), 3.70(\mathrm{~d}, J=13.4 \mathrm{~Hz}, 1 \mathrm{H}), 3.25-3.12(\mathrm{~m}, 1 \mathrm{H}), 3.09(\mathrm{t}, J=7.1 \mathrm{~Hz}$, $2 \mathrm{H}), 2.92(\mathrm{ddd}, J=13.7,10.7,3.2 \mathrm{~Hz}, 1 \mathrm{H}), 2.51-2.38(\mathrm{~m}, 1 \mathrm{H}), 1.85-1.71(\mathrm{~m}, 1 \mathrm{H}), 1.71-1.57(\mathrm{~m}, 1 \mathrm{H})$, 
$1.56-1.39(\mathrm{~m}, 3 \mathrm{H}), 0.94-0.79(\mathrm{~m}, 3 \mathrm{H}) ; \mathbf{A M M}(\mathrm{ESI}) \mathrm{m} / \mathrm{z} 342.1392$ [calc for $\mathrm{C}_{16} \mathrm{H}_{22} \mathrm{ClFN}_{3} \mathrm{O}_{2}(\mathrm{M}+\mathrm{H})^{+}$ 342.1385].

(S)-MCG-IV-031-A06 (17e)

$\mathrm{R}=i-\mathrm{Bu}, \mathrm{R}^{\prime}=\mathrm{H}(67 \%$ yield $)$

${ }^{1} \mathrm{H}$ NMR $\left(500 \mathrm{MHz}\right.$, Acetonitrile- $\left.d_{3}\right) \delta 8.97(\mathrm{~d}, J=18.4 \mathrm{~Hz}, 1 \mathrm{H}), 7.74(\mathrm{dd}, J=12.0,2.8 \mathrm{~Hz}, 1 \mathrm{H}), 7.37(\mathrm{t}, J=$ $8.7 \mathrm{~Hz}, 1 \mathrm{H}), 7.26(\mathrm{~d}, J=9.2 \mathrm{~Hz}, 1 \mathrm{H}), 3.94-3.84(\mathrm{~m}, 1 \mathrm{H}), 3.70(\mathrm{~d}, J=13.7 \mathrm{~Hz}, 1 \mathrm{H}), 3.18(\mathrm{dd}, J=13.5,9.7$ $\mathrm{Hz}, 1 \mathrm{H}), 3.04-2.86(\mathrm{~m}, 3 \mathrm{H}), 2.45(\mathrm{dt}, J=13.7,6.2 \mathrm{~Hz}, 1 \mathrm{H}), 1.86-1.56(\mathrm{~m}, 3 \mathrm{H}), 1.46(\mathrm{t}, J=12.4 \mathrm{~Hz}, 1 \mathrm{H})$, $1.36-1.08(\mathrm{~m}, 1 \mathrm{H}), 0.85(\mathrm{~d}, \mathrm{~J}=6.6 \mathrm{~Hz}, 6 \mathrm{H}) ; \mathrm{AMM}(\mathrm{ESI}) \mathrm{m} / \mathrm{z} 356.1551$ [calc for $\mathrm{C}_{17} \mathrm{H}_{24} \mathrm{ClFN}_{3} \mathrm{O}_{2}(\mathrm{M}+\mathrm{H})^{+}$ 356.1541].

General Synthesis of $\mathbf{1 7 f - 1 7 g}$

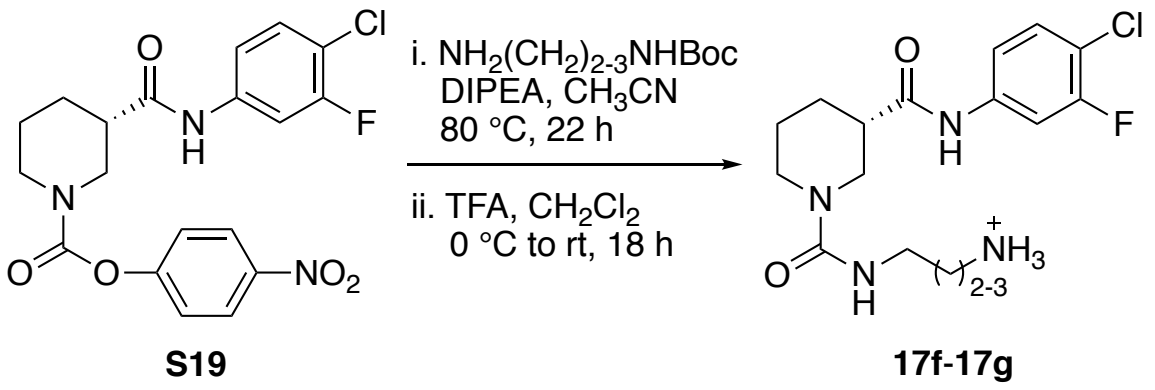

i. To separate microwave reactor vials charged with common intermediate $\mathbf{S 1 9}(50 . \mathrm{mg}, 0.12 \mathrm{mmol})$ and $\mathrm{NH}_{2}\left(\mathrm{CH}_{2}\right)_{2-3} \mathrm{NHBoc}(0.36 \mathrm{mmol})$ was added acetonitrile $(1 \mathrm{~mL})$ then diisopropylethylamine $(40 \mu \mathrm{L}, 0.2$ $\mathrm{mmol}$ ). The vials were sealed and heated to $80^{\circ} \mathrm{C}$ for $22 \mathrm{~h}$, then allowed to cool to room temperature and diluted with $\mathrm{CHCl}_{3}$ and $\mathrm{H}_{2} \mathrm{O}$. The layers were separated, and the aqueous phases were extracted with $\mathrm{CHCl}_{3}(3 \mathrm{x})$. The combined organic layers were washed with sat. aq. $\mathrm{NaHCO}_{3}$ and $\mathrm{H}_{2} \mathrm{O}$, dried over $\mathrm{Na}_{2} \mathrm{SO}_{4}$ and concentrated in vacuo to afford the products, which were carried forward without additional purification.

ii. To separate precooled $\left(0{ }^{\circ} \mathrm{C}\right)$ solutions of intermediate $(0.12 \mathrm{mmol})$ in $\mathrm{CH}_{2} \mathrm{Cl}_{2}(1.2 \mathrm{~mL})$ under $\mathrm{N}_{2}$ atmosphere was added dropwise trifluoroacetic acid $(0.1 \mathrm{~mL}, 1 \mathrm{mmol})$. The resulting mixtures were allowed to warm to room temperature and stirred for $18 \mathrm{~h}$, then concentrated in vacuo. The crude residues were diluted with wet DMSO $(0.5 \mathrm{~mL})$ and purified via mass-directed isolation using ultraperformance liquid chromatography to afford the products as white solids (7-15\% yield).

MCG-IV-210 (17f)

$\mathrm{R}=\left(\mathrm{CH}_{2}\right)_{2} \mathrm{NH}_{3}{ }^{+}, \mathrm{R}^{\prime}=\mathrm{H}(15 \%$ yield $)$

${ }^{1} \mathrm{H}$ NMR $\left(500 \mathrm{MHz}\right.$, Methanol-d $\left.d_{4}\right) \delta 7.71(\mathrm{dd}, J=11.5,2.4 \mathrm{~Hz}, 1 \mathrm{H}), 7.40(\mathrm{t}, J=8.4 \mathrm{~Hz}, 1 \mathrm{H}), 7.31-7.25(\mathrm{~m}$, $1 \mathrm{H}), 4.10-4.02(\mathrm{~m}, 1 \mathrm{H}), 3.86(\mathrm{~d}, J=13.4 \mathrm{~Hz}, 1 \mathrm{H}), 3.44(\mathrm{t}, J=5.8 \mathrm{~Hz}, 2 \mathrm{H}), 3.17(\mathrm{dd}, J=13.4,9.9 \mathrm{~Hz}, 1 \mathrm{H})$, $3.10-2.97(\mathrm{~m}, 3 \mathrm{H}), 2.59-2.49(\mathrm{~m}, 1 \mathrm{H}), 2.11-2.01(\mathrm{~m}, 1 \mathrm{H}), 1.89-1.76(\mathrm{~m}, 2 \mathrm{H}), 1.62-1.49(\mathrm{~m}, 1 \mathrm{H})$; AMM 343.1328 (ESI) $\mathrm{m} / \mathrm{z}$ [calc for $\mathrm{C}_{15} \mathrm{H}_{21} \mathrm{ClFN}_{4} \mathrm{O}_{2}(\mathrm{M})^{+} 343.1337$ ].

MCG-IV-211 (17g)

$\mathrm{R}=\left(\mathrm{CH}_{2}\right)_{3} \mathrm{NH}_{3}{ }^{+}, \mathrm{R}^{\prime}=\mathrm{H}(7 \%$ yield $)$

AMM 357.1518 (ESI) $m / z$ [calc for $\mathrm{C}_{16} \mathrm{H}_{23} \mathrm{ClFN}_{4} \mathrm{O}_{2}(\mathrm{M})^{+}$357.1494].

\section{Synthesis of Analogs 18}

General Synthesis of Analogs 18a-18c 


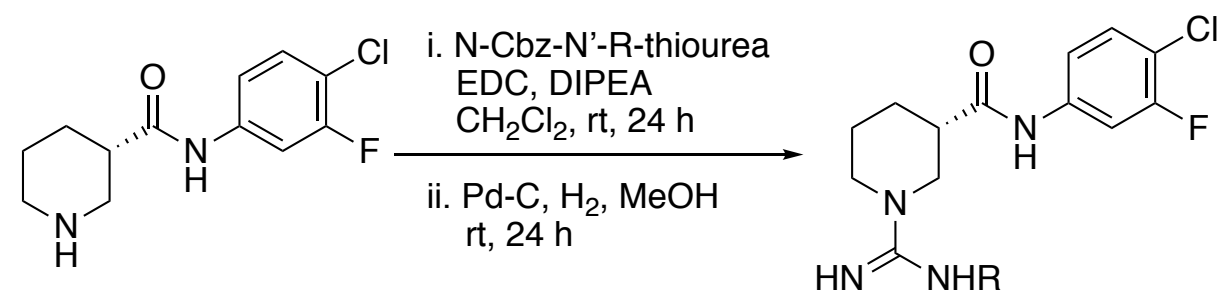

14

18a-18c

To separate vials charged with $\mathrm{N}-\mathrm{Cbz}-\mathrm{N}$ '-R-thiourea $(0.12 \mathrm{mmol})$ was added a solution of common intermediate 14 (30. mg, $0.12 \mathrm{mmol}$ ), 1-ethyl-3-(3-dimethylaminopropyl)-carbodiimide hydrochloride (EDCl, $34 \mathrm{mg}, 0.18 \mathrm{mmol})$ and diisopropylethylamine $(40 \mu \mathrm{L}, 0.3 \mathrm{mmol})$ in $\mathrm{CH}_{2} \mathrm{Cl}_{2}(0.5 \mathrm{~mL})$. The resulting mixtures were stirred at room temperature for $24 \mathrm{~h}$, then diluted with wet DMSO $(0.5 \mathrm{~mL})$, filtered through celite, and purified via mass-directed isolation via ultra-performance liquid chromatography $(24-70 \%$ yield).

MCG-IV-053-A01 (18a)

$\mathrm{R}=\mathrm{Me}, \mathrm{R}^{\prime}=\mathrm{H}(70 \%$ yield $)$

${ }^{1} \mathrm{H}$ NMR $\left(500 \mathrm{MHz}\right.$, Acetonitrile- $\left.d_{3}\right) \delta 10.02(\mathrm{~s}, 1 \mathrm{H}), 7.84-7.74(\mathrm{~m}, 1 \mathrm{H}), 7.43-7.32(\mathrm{~m}, 1 \mathrm{H}), 7.06(\mathrm{~s}, 1 \mathrm{H})$, $6.55(\mathrm{~s}, 1 \mathrm{H}), 3.92(\mathrm{~d}, J=14.0 \mathrm{~Hz}, 1 \mathrm{H}), 3.60(\mathrm{~d}, J=13.5 \mathrm{~Hz}, 1 \mathrm{H}), 3.26(\mathrm{dd}, J=13.9,10.0 \mathrm{~Hz}, 1 \mathrm{H}), 3.11$ (ddd, $J=13.8,11.0,3.4 \mathrm{~Hz}, 1 \mathrm{H}), 2.83(\mathrm{~d}, J=4.7 \mathrm{~Hz}, 3 \mathrm{H}), 2.81-2.71(\mathrm{~m}, 1 \mathrm{H}), 2.04-1.97(\mathrm{~m}, 1 \mathrm{H}), 1.91-$ $1.80(\mathrm{~m}, 1 \mathrm{H}), 1.80-1.71(\mathrm{~m}, 1 \mathrm{H}), 1.63-1.48(\mathrm{~m}, 1 \mathrm{H})$; AMM $313.1245(\mathrm{ESI}) \mathrm{m} / \mathrm{z}$ [calc for $\mathrm{C}_{14} \mathrm{H}_{19} \mathrm{ClFN}_{4} \mathrm{O}$ $\left.(\mathrm{M}+\mathrm{H})^{+} 313.1231\right]$.

MCG-IV-053-A05 (18b)

$\mathrm{R}=n-\operatorname{Pr}, \mathrm{R}^{\prime}=\mathrm{H}(24 \%$ yield $)$

${ }^{1} \mathrm{H}$ NMR $\left(500 \mathrm{MHz}\right.$, Acetonitrile- $\left.d_{3}\right) \delta 9.92(\mathrm{~s}, 1 \mathrm{H}), 7.79(\mathrm{~d}, J=11.2 \mathrm{~Hz}, 1 \mathrm{H}), 7.37(\mathrm{~d}, J=5.9 \mathrm{~Hz}, 1 \mathrm{H}), 6.90$ (s, 1H), $6.55(\mathrm{~s}, 2 \mathrm{H}), 3.88(\mathrm{~d}, J=13.9 \mathrm{~Hz}, 1 \mathrm{H}), 3.57(\mathrm{~d}, J=12.6 \mathrm{~Hz}, 1 \mathrm{H}), 3.32(\mathrm{dd}, J=13.8,9.5 \mathrm{~Hz}, 1 \mathrm{H})$, $3.21-3.09(\mathrm{~m}, 1 \mathrm{H}), 2.83-2.71(\mathrm{~m}, 1 \mathrm{H}), 1.90-1.80(\mathrm{~m}, 2 \mathrm{H}), 1.80-1.68(\mathrm{~m}, 2 \mathrm{H}), 1.66-1.48(\mathrm{~m}, 3 \mathrm{H})$, $0.99-0.87(\mathrm{~m}, 3 \mathrm{H})$; AMM $341.1557(\mathrm{ESI}) \mathrm{m} / \mathrm{z}$ [calc for $\mathrm{C}_{16} \mathrm{H}_{23} \mathrm{ClFN}_{4} \mathrm{O}(\mathrm{M}+\mathrm{H})^{+} 341.1544$ ].

MCG-IV-053-A06 (18c)

$\mathrm{R}=i-\mathrm{Bu}, \mathrm{R}^{\prime}=\mathrm{H}(32 \%$ yield $)$

${ }^{1} \mathrm{H}$ NMR $\left(500 \mathrm{MHz}\right.$, Acetonitrile-d $\left.\mathrm{d}_{3}\right) \delta 9.95(\mathrm{~s}, 1 \mathrm{H}), 7.84-7.72(\mathrm{~m}, 1 \mathrm{H}), 7.42-7.33(\mathrm{~m}, 1 \mathrm{H}), 6.96(\mathrm{~s}, 1 \mathrm{H})$, $6.60(\mathrm{~s}, 1 \mathrm{H}), 3.87(\mathrm{dd}, J=13.7,3.8 \mathrm{~Hz}, 1 \mathrm{H}), 3.64-3.52(\mathrm{~m}, 1 \mathrm{H}), 3.35$ (dd, $J=13.9,9.3 \mathrm{~Hz}, 1 \mathrm{H}), 3.17$ (ddd, $J=13.5,10.4,3.4 \mathrm{~Hz}, 1 \mathrm{H}), 3.01(\mathrm{dd}, J=7.2,5.7 \mathrm{~Hz}, 2 \mathrm{H}), 2.79(\mathrm{tt}, J=9.1,4.1 \mathrm{~Hz}, 2 \mathrm{H}), 2.05-1.97(\mathrm{~m}, 1 \mathrm{H})$, $1.92-1.83(\mathrm{~m}, 2 \mathrm{H}), 1.80-1.70(\mathrm{~m}, 1 \mathrm{H}), 1.62-1.51(\mathrm{~m}, 1 \mathrm{H}), 0.93(\mathrm{~d}, J=6.7 \mathrm{~Hz}, 6 \mathrm{H}) ;$ AMM 355.1712 (ESI) $\mathrm{m} / \mathrm{z}$ [calc for $\mathrm{C}_{17} \mathrm{H}_{25} \mathrm{ClFN} 4 \mathrm{O}(\mathrm{M}+\mathrm{H})^{+} 355.1701$ ].

\section{Synthesis of Analogs 20 and 21}<smiles>COC(=O)c1cncc(C(=O)OC)c1</smiles>

\section{S20}

To a precooled $\left(0^{\circ} \mathrm{C}\right)$ solution of pyridine-3,5-dicarboxylic acid $(10.0 \mathrm{~g}, 59.8 \mathrm{mmol})$ in $\mathrm{MeOH}(100 \mathrm{~mL})$ under $\mathrm{N}_{2}$ atmosphere was slowly added thionyl chloride $(13 \mathrm{~mL}, 180 \mathrm{mmol})$. The resulting mixture was allowed to warm to room temperature then heated to reflux and stirred for $4 \mathrm{~h}$. The mixture was then allowed to cool to room temperature and concentrated in vacuo. The resulting white solid was taken up in $\mathrm{H}_{2} \mathrm{O}$ and the aqueous solution was cooled $\left(0^{\circ} \mathrm{C}\right)$ then neutralized with $10 \mathrm{M}$ aq. $\mathrm{NaOH}$ (white ppt formed). The heterogenous mixture was diluted with EtOAc and the bisphasic solution was stirred for $5 \mathrm{~min}$. The layers were separated, and the aqueous phase was extracted with EtOAc (3x). The combined organic layers were washed with brine, dried over $\mathrm{Na}_{2} \mathrm{SO}_{4}$ and concentrated in vacuo to afford the product as a white solid (10.4 g, $89 \%$ yield). ${ }^{1} \mathrm{H}$ NMR (500 MHz, Chloroform-d) $\delta 9.35$ (d, $\left.J=2.1 \mathrm{~Hz}, 2 \mathrm{H}\right), 8.85(\mathrm{t}, J=2.1 \mathrm{~Hz}, 1 \mathrm{H}), 3.98$ (s, 6H); ${ }^{13} \mathrm{C}$ NMR $\left(126 \mathrm{MHz}, \mathrm{CDCl}_{3}\right) \delta 165.05,154.37,138.19,126.15,52.85$; IR (ATR) V $\max 3074,2966$, 
1713, 1445, 1312, 1256, 1108, 979, $745 \mathrm{~cm}^{-1}$; AMM (ESI) $\mathrm{m} / \mathrm{z} 196.0600$ [calc for $\mathrm{C}_{9} \mathrm{H}_{10} \mathrm{NO}_{4}(\mathrm{M}+\mathrm{H})^{+}$ 196.0610].

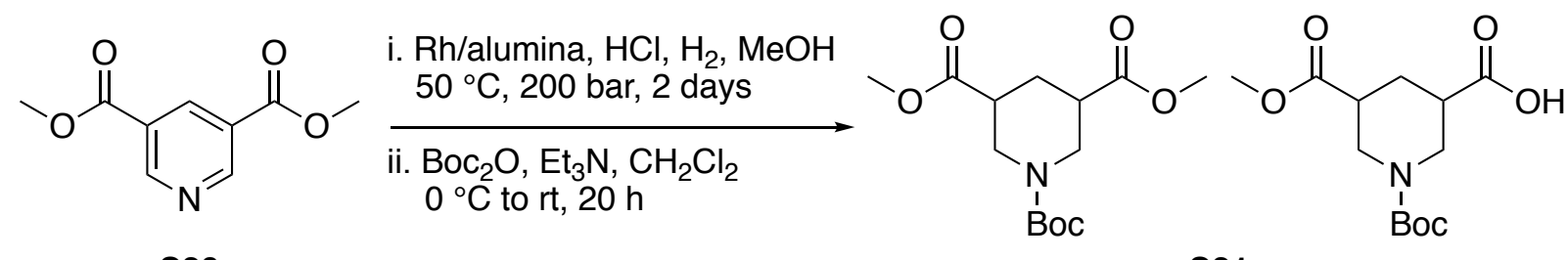

S20

S21

i. To a solution of intermediate $\mathbf{S 2 0}(11.4 \mathrm{~g}, 58.3 \mathrm{mmol})$ in $\mathrm{MeOH}(58 \mathrm{~mL})$ and $6 \mathrm{M}$ aq. $\mathrm{HCl}(15 \mathrm{~mL})$ was added rhodium on alumina $(5 \%, 1.1 \mathrm{~g})$. The resulting mixture was hydrogenated at $50{ }^{\circ} \mathrm{C}$ while stirring under 200 bar pressure in a Parr reactor for 2 days. The reactor was then allowed to cool to room temperature and depressurized to ambient atmosphere. The crude heterogeneous resulting mixture was filtered through a bed of celite and rinsed with $\mathrm{MeOH}$. The filtrate was concentrated in vacuo, and the resulting product was carried forward without additional purification.

ii. To a precooled $\left(0^{\circ} \mathrm{C}\right)$ solution of crude intermediate $(11.7 \mathrm{~g}, 58.3 \mathrm{mmol}$ assumed $)$ in $\mathrm{CH}_{2} \mathrm{Cl}_{2}(60 \mathrm{~mL})$ under $\mathrm{N}_{2}$ atmosphere was added triethylamine $(33 \mathrm{~mL}, 230 \mathrm{mmol})$ then Boc anhydride $(20 \mathrm{~mL}, 87$ $\mathrm{mmol}$ ). The resulting mixture was then allowed to warm to room temperature and stirred for $16 \mathrm{~h}$, then quenched with $\mathrm{H}_{2} \mathrm{O}$. The layers were separated, and the aqueous phase was extracted with $\mathrm{CH}_{2} \mathrm{Cl}_{2}$ (3x). The combined organic layers were washed with brine, dried over $\mathrm{Na}_{2} \mathrm{SO}_{4}$, and concentrated in vacuo. Flash chromatography $\left(\mathrm{SiO}_{2}, 75: 25\right.$ hexanes:EtOAc, dry loaded on celite) afforded the product mixture as a clear colorless oil ( $3.08 \mathrm{~g}, 21 \%$ yield over 2 steps). The experimental data agreed with literature precedent. ${ }^{12}$<smiles>COC(=O)C1CC(C(=O)OCOC(=O)C2CC(C(=O)O)CN(C(=O)OC(C)(C)C)C2)CN(C(=O)OC(C)(C)C)C1</smiles>

S21

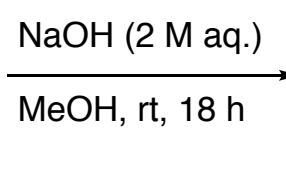<smiles>CC(C)(C)OC(=O)N1CC(C(=O)O)CC(C(=O)O)C1</smiles>

S22

To a solution of intermediate $\mathbf{S} 21(3.00 \mathrm{~g}, 9.96 \mathrm{mmol})$ in $\mathrm{MeOH}(20 \mathrm{~mL})$ at room temperature under $\mathrm{N}_{2}$ atmosphere was added $2 \mathrm{M}$ aq. $\mathrm{NaOH}(10 \mathrm{~mL}, 20 \mathrm{mmol})$. The resulting mixture was stirred at room temperature for $18 \mathrm{~h}$ then concentrated in vacuo. The resulting residue was taken up in sat. aq. $\mathrm{NaHCO}_{3}$ and the aqueous layer was washed with ether $(1 \mathrm{x})$ then cooled to $0^{\circ} \mathrm{C}$ and acidified with $6 \mathrm{M}$ aq. $\mathrm{HCl}$ to $\mathrm{pH}$ 2. The solid precipitate was collected by vacuum filtrated and dried to afford the product as a white solid $\left(1.21 \mathrm{~g}, 45 \%\right.$ yield). The experimental data agreed with literature precedent. $^{2}$

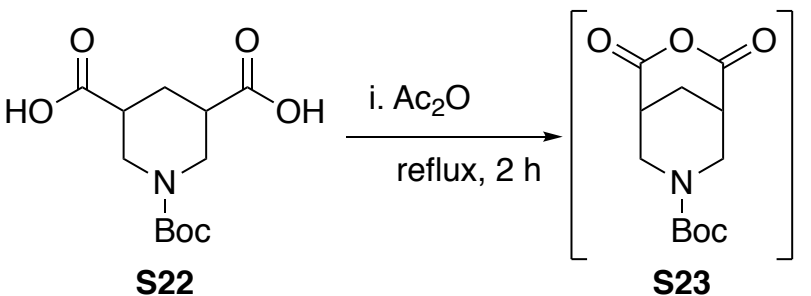

ii. quinine, $\mathrm{MeOH}$ THF, $-40^{\circ} \mathrm{C}, 6 \mathrm{~h}$

then (S)-phenylethylamine recrystallization<smiles>COC(=O)[C@@H]1C[C@@H](C(=O)O)CN(C(=O)OC(C)(C)C)C1</smiles>

$(+)-S 24$

i. To a flask charged with intermediate $\mathbf{S 2 2}(800 . \mathrm{mg}, 2.93 \mathrm{mmol})$ and equipped with a reflux condenser at room temperature under $\mathrm{N}_{2}$ atmosphere was added acetic anhydride $(7 \mathrm{~mL})$. The resulting mixture was heated to reflux for $2 \mathrm{~h}$, then allowed to cool to room temperature and concentrated in vacuo. The crude residue was taken up in toluene and concentrated in vacuo $(3 x)$ then the resulting solid was used directly. 
ii. To a precooled $\left(-40^{\circ} \mathrm{C}\right)$ solution of intermediate $\mathbf{S} 23(1.04 \mathrm{~g}, 2.91 \mathrm{mmol}$ assumed $)$ and quinine $(1.42 \mathrm{~g}, 4.37 \mathrm{mmol})$ in THF $(16 \mathrm{~mL})$ was slowly added dropwise a solution of $\mathrm{MeOH}(1.6 \mathrm{~mL}$, $41 \mathrm{mmol})$ in THF (2 mL). The resulting mixture was stirred at $-40{ }^{\circ} \mathrm{C}$ for $6 \mathrm{~h}$ then allowed to warm to $0{ }^{\circ} \mathrm{C}$ and quenched with $1 \mathrm{M}$ aq. $\mathrm{HCl}$ and diluted with EtOAc. The layers were separated, and the aqueous phase was extracted with EtOAc (3x). The combined organic layers were washed with $1 \mathrm{M}$ aq. $\mathrm{HCl}$ then brine, dried over $\mathrm{Na}_{2} \mathrm{SO}_{4}$, and concentrated in vacuo to afford the crude product $(780 \mathrm{mg}, 66 \%$ ee). The resulting solid was suspended in $\mathrm{EtOH}(3$ $\mathrm{mL}$ ) and warmed to $80{ }^{\circ} \mathrm{C}$ followed by addition of $(S)$-phenylethylamine $(3 \mathrm{mg}, 3 \mathrm{mmol})$. The resulting mixture was allowed to cool to room temperature and stood still for $19 \mathrm{~h}$. The precipitated solid was collected by vacuum filtration, rinsed with hexanes and dried. The obtained solid was taken up in $\mathrm{H}_{2} \mathrm{O}$ and treated with sat. aq. $\mathrm{KHSO}_{4}$ and diluted with EtOAc. The layers were separated, and the aqueous phase was extracted with EtOAc (3x). The combined organic layers were washed with brine, dried over $\mathrm{Na}_{2} \mathrm{SO}_{4}$ and concentrated in vacuo to afford the product as a white solid ( $509 \mathrm{mg}, 43 \%$ yield over 2 steps, $96 \%$ ee). The experimental data agreed with literature precedent. The absolute stereochemistry was determined by comparison of literature. ${ }^{13}[\alpha]_{\mathrm{D}}{ }^{23}+3.25$ (c. $\left.0.09, \mathrm{CH}_{3} \mathrm{OH}\right) ;{ }^{1} \mathrm{H}$ NMR $(500 \mathrm{MHz}$, Methanol- $\left.d_{4}\right) \delta 4.30(\mathrm{~d}, J=13.0 \mathrm{~Hz}, 2 \mathrm{H}), 3.70(\mathrm{~d}, J=2.6 \mathrm{~Hz}, 3 \mathrm{H}), 2.73(\mathrm{~s}, 2 \mathrm{H}), 2.59-2.34(\mathrm{~m}$, $3 \mathrm{H}), 1.75-1.56(\mathrm{~m}, 1 \mathrm{H}), 1.47(\mathrm{~d}, J=2.6 \mathrm{~Hz}, 9 \mathrm{H})$.

Enantiomeric excess determined by SFC (see figure below):

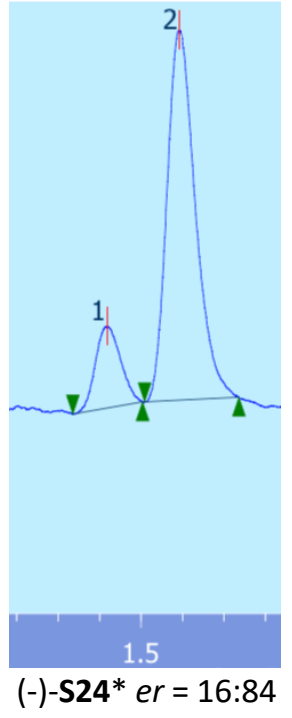

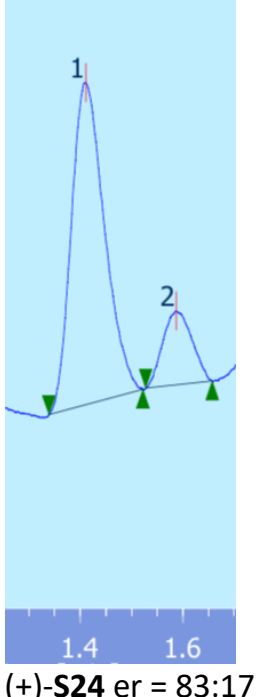

(+)-S24 er $=83: 17$

Pre-recrystallization

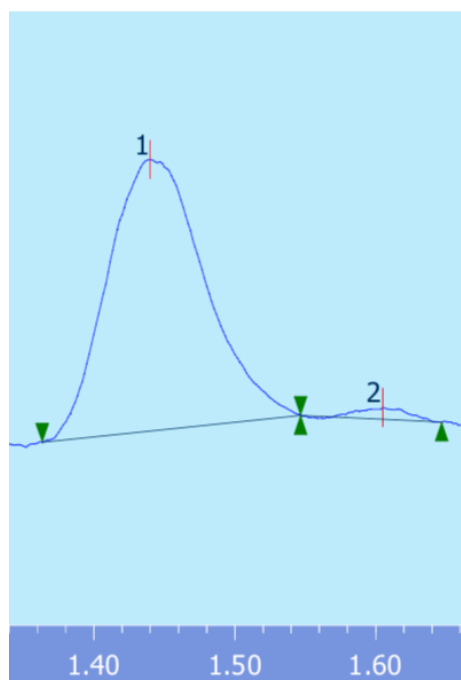

(+)-S24 er $=98: 2$

Post-recrystallization

Method: column: ChiralPak AD-H; eluent: $10 \% \mathrm{MeOH}$ in supercritical $\mathrm{CO}_{2}$; flow rate: $4 \mathrm{~mL} / \mathrm{min}$; pressure: $12 \mathrm{MPa}$. Retention times: (+)-2.151: $1.4 \mathrm{~min},(-)-2.151: 1.6 \mathrm{~min}$.

*Compound (-)-S25 was prepared using the same synthesis employing quinidine instead of quinine.

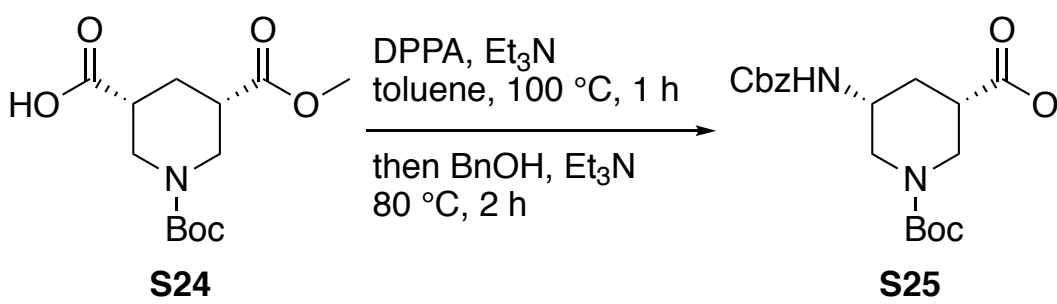

To a solution of intermediate $\mathbf{S 2 4}(550 \mathrm{mg}, 1.91 \mathrm{mmol})$ in toluene $(9.6 \mathrm{~mL})$ at room temperature under $\mathrm{N}_{2}$ atmosphere was added triethylamine $(0.32 \mathrm{~mL}, 2.3 \mathrm{mmol})$ then diphenyl phosphoryl azide $(0.50 \mathrm{~mL}, 2.3$ $\mathrm{mmol}$ ). The resulting mixture was heated to $100{ }^{\circ} \mathrm{C}$ and stirred for $1 \mathrm{~h}$, then allowed to cool to room temperature. To the mixture was then added triethylamine $(0.32 \mathrm{~mL}, 2.3 \mathrm{mmol})$ and benzyl alcohol $(0.5 \mathrm{~mL}$, $4.8 \mathrm{mmol})$. The resulting mixture was heated to $80{ }^{\circ} \mathrm{C}$ and stirred for $2 \mathrm{~h}$, then allowed to cool to room 
temperature and quenched with $\mathrm{H}_{2} \mathrm{O}$. The layers were separated, and the aqueous phase was extracted with toluene (3x). The combined organic layers were washed with sat. aq. citric acid, sat. aq. $\mathrm{NaHCO}_{3}$, then brine, dried over $\mathrm{Na}_{2} \mathrm{SO}_{4}$ and concentrated in vacuo. Flash chromatography $\left(\mathrm{SiO}_{2}, 60: 40\right.$ hexanes:EtOAc) afforded the product as a white solid $(727 \mathrm{mg}, 28 \%$ yield). The experimental data agreed with literature precedent. ${ }^{12}[\alpha]_{D}{ }^{23}-3.15$ (c. $0.10, \mathrm{CH}_{3} \mathrm{OH}$ );

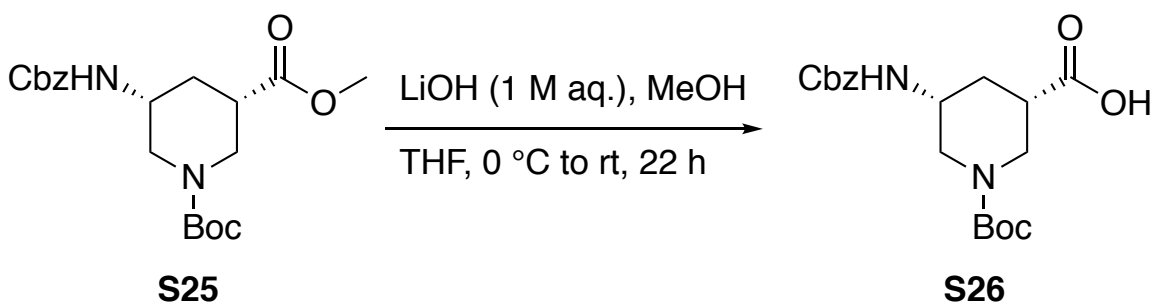

To a precooled $\left(0{ }^{\circ} \mathrm{C}\right)$ solution of intermediate $2.152(727 \mathrm{mg}, 1.85 \mathrm{mmol})$ in $\mathrm{MeOH}(6 \mathrm{~mL})$ under $\mathrm{N}_{2}$ atmosphere was added THF $(3 \mathrm{~mL})$ then $1 \mathrm{M}$ aq. $\mathrm{LiOH}(3 \mathrm{~mL})$. The resulting mixture was allowed to warm to room temperature and stirred vigorously for $22 \mathrm{~h}$, then concentrated in vacuo. The resulting residue was taken up in sat. aq. citric acid (white ppt formed) then diluted with $\mathrm{CH}_{2} \mathrm{Cl}_{2}$. The layers were separated, and the aqueous phase was extracted with $\mathrm{CH}_{2} \mathrm{Cl}_{2}(3 \mathrm{x})$. The combined organic layers were dried over $\mathrm{Na}_{2} \mathrm{SO}_{4}$ and concentrated in vacuo to afford the product as a white solid $(663 \mathrm{mg}, 95 \%$ yield). The experimental data agreed with literature precedent. ${ }^{13}[\alpha]_{D^{23}}+5.91$ (c. $0.05, \mathrm{CH}_{3} \mathrm{OH}$ ); AMM 379.1867 (ESI) $\mathrm{m} / \mathrm{z}$ [calc for $\left.\mathrm{C}_{19} \mathrm{H}_{27} \mathrm{~N}_{2} \mathrm{O}_{6}(\mathrm{M}+\mathrm{H})^{+} 379.1869\right]$.

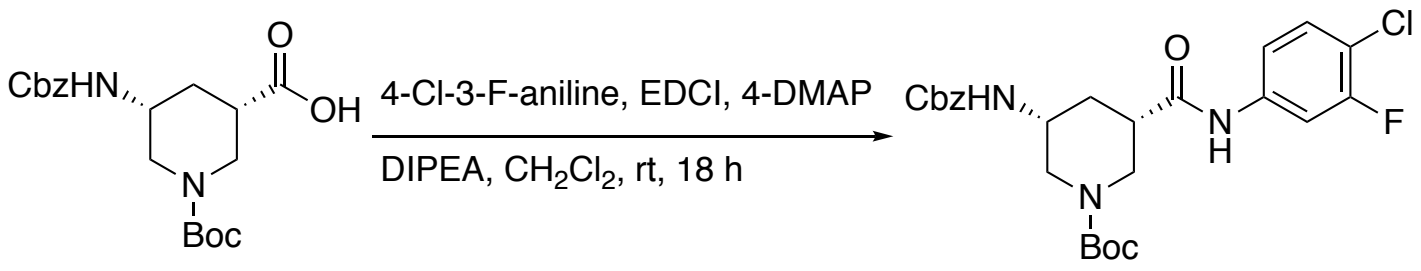

S26

$\mathrm{S} 27$

To a precooled $\left(0{ }^{\circ} \mathrm{C}\right)$ solution of intermediate 2.153 (663 mg, $\left.1.75 \mathrm{mmol}\right)$, 1-ethyl-3-(3dimethylaminopropyl)carbodiimide hydrochloride $(272 \mathrm{mg}, 1.75 \mathrm{mmol})$, and 4-chloro-3-fluoroaniline (383 $\mathrm{mg}, 2.63 \mathrm{mmol}$ ) in $\mathrm{CH}_{2} \mathrm{Cl}_{2}$ under $\mathrm{N}_{2}$ atmosphere was added 4-dimethylaminopyridine (43 $\mathrm{mg}, 0.35 \mathrm{mmol}$ ) then diisopropylethylamine $(0.8 \mathrm{~mL}, 4 \mathrm{mmol})$. The resulting mixture was allowed to warm to room temperature and stirred for $18 \mathrm{~h}$, then quenched with $\mathrm{H}_{2} \mathrm{O}$. The layers were separated, and the aqueous phase was extracted with $\mathrm{CH}_{2} \mathrm{Cl}_{2}(3 \mathrm{x})$. The combined organic layers were washed sequentially with sat. aq. $\mathrm{NH}_{4} \mathrm{Cl}$, sat. aq. $\mathrm{NaHCO}_{3}$, and brine, dried over $\mathrm{Na}_{2} \mathrm{SO}_{4}$, and concentrated in vacuo. Flash chromatography $\left(\mathrm{SiO}_{2}, 50: 50\right.$ hexanes:EtOAc) afforded the product as a white solid $(541 \mathrm{mg}, 61 \%$ yield).

${ }^{1} \mathrm{H}$ NMR $\left(500 \mathrm{MHz}\right.$, Methanol- $\left.d_{4}\right) \delta 7.64(\mathrm{dd}, J=11.5,2.4 \mathrm{~Hz}, 1 \mathrm{H}), 7.38-7.15(\mathrm{~m}, 8 \mathrm{H}), 5.03(\mathrm{~s}, 2 \mathrm{H}), 4.18$ $-3.98(\mathrm{~m}, 2 \mathrm{H}), 3.59-3.45(\mathrm{~m}, 1 \mathrm{H}), 3.05-2.73(\mathrm{~m}, 1 \mathrm{H}), 2.70-2.48(\mathrm{~m}, 2 \mathrm{H}), 2.14(\mathrm{~d}, \mathrm{~J}=12.8 \mathrm{~Hz}, 1 \mathrm{H})$, $1.72-1.53(\mathrm{~m}, 1 \mathrm{H}), 1.41$ (s, 9H); ${ }^{13} \mathrm{C}$ NMR (126 MHz, MeOD) $\delta$ 173.32, 160.02, 158.07, 158.00, 156.19, $140.26,140.18,138.16,131.48,130.44,129.42$, 128.97, 128.79, 127.02, 122.55, 117.27, 117.25, 116.10, 115.96, 109.31, 109.10, 81.67, 67.49, 49.00, 46.63, 44.14, 34.62, 28.58; IR (ATR) $v_{\max } 3315,2935,1662$, $1531,1421,1147,696 \mathrm{~cm}^{-1}$<smiles>CC(C)(C)OC(=O)N[C@H]1CNC[C@H](C(=O)Nc2ccc(Cl)c(F)c2)C1</smiles>

S27

S28

To a precooled $\left(0{ }^{\circ} \mathrm{C}\right)$ solution of intermediate $\mathbf{S} 27(1.14 \mathrm{~g}, 2.25 \mathrm{mmol})$ in $\mathrm{CH}_{2} \mathrm{Cl}_{2}(23 \mathrm{~mL})$ under $\mathrm{N}_{2}$ atmosphere was added dropwise trifluoroacetic acid $(1.04 \mathrm{~mL}, 13.5 \mathrm{mmol})$. The resulting mixture was 
allowed to warm to room temperature and stirred for $18 \mathrm{~h}$, then cooled to $0{ }^{\circ} \mathrm{C}$ before addition of trifluoroacetic acid $(1.0 \mathrm{~mL}, 13 \mathrm{mmol})$. The resulting mixture was allowed to warm to room temperature and stirred for $48 \mathrm{~h}$, then concentrated in vacuo. The resulting residue was suspended in $\mathrm{H}_{2} \mathrm{O}$ and the resulting aqueous solution was cooled to $0{ }^{\circ} \mathrm{C}$ and neutralized with powdered $\mathrm{NaHCO}_{3}$ then diluted with $\mathrm{CH}_{2} \mathrm{Cl}_{2}$. The layers were separated, and the aqueous phase was extracted with $\mathrm{CH}_{2} \mathrm{Cl}_{2}$ (3x). The combined organic layers were dried over $\mathrm{Na}_{2} \mathrm{SO}_{4}$ and concentrated in vacuo to afford the product as a white solid (739 mg, $81 \%$ yield). [ $\alpha]_{\mathrm{D}}{ }^{23}-31.3$ (c. $\left.0.13, \mathrm{CH}_{3} \mathrm{OH}\right) ;{ }^{1} \mathrm{H}$ NMR $(500 \mathrm{MHz}$, Chloroform- $d$ ) $\delta 8.30(\mathrm{~s}, 1 \mathrm{H}), 7.64(\mathrm{~d}, J=$ $10.9 \mathrm{~Hz}, 1 \mathrm{H}), 7.43-7.22(\mathrm{~m}, 6 \mathrm{H}), 7.12(\mathrm{~d}, J=8.9 \mathrm{~Hz}, 1 \mathrm{H}), 5.08(\mathrm{~s}, 1 \mathrm{H}), 5.00(\mathrm{~s}, 1 \mathrm{H}), 3.88-3.60(\mathrm{~m}, 2 \mathrm{H})$, $3.29-3.10(\mathrm{~m}, 2 \mathrm{H}), 3.01(\mathrm{~s}, 1 \mathrm{H}), 2.68(\mathrm{~s}, 1 \mathrm{H}), 2.58(\mathrm{~s}, 1 \mathrm{H}), 1.89(\mathrm{~s}, 1 \mathrm{H}), 1.42-1.17(\mathrm{~m}, 2 \mathrm{H}), 0.86(\mathrm{~s}, 1 \mathrm{H})$; IR (ATR) Vmax 3286, 1679,1654, 1545, 1491, 1284, 1062, 693, $618 \mathrm{~cm}^{-1}$; AMM 406.1307 (ESI) $\mathrm{m} / \mathrm{z}$ [calc for $\left.\mathrm{C}_{20} \mathrm{H}_{22} \mathrm{ClFN}_{3} \mathrm{O}_{3}(\mathrm{M}+\mathrm{H})^{+} 406.1334\right]$.

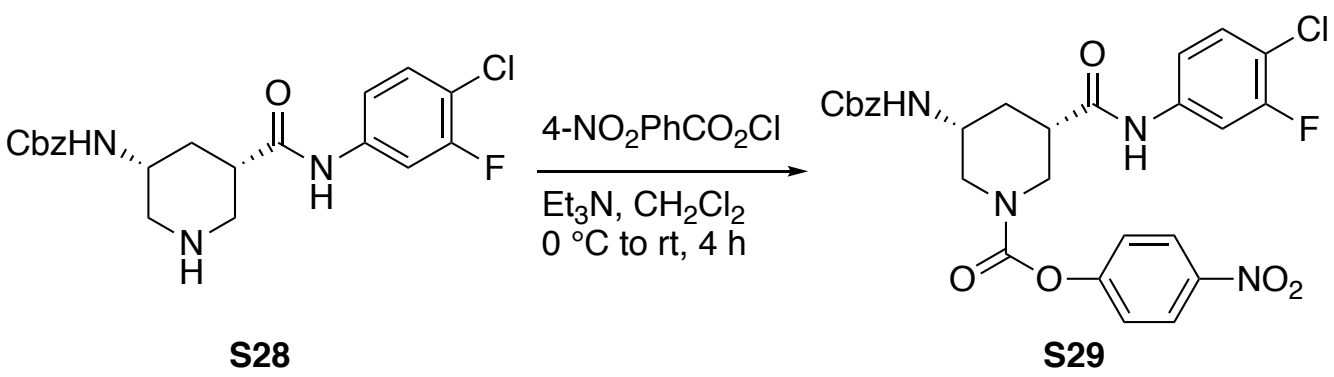

To a precooled $\left(0^{\circ} \mathrm{C}\right)$ solution of intermediate $\mathbf{S} 28(99 \mathrm{mg}, 0.39 \mathrm{mmol})$ and 4-nitrophenyl chloroformate $(79$ $\mathrm{mg}, 0.39 \mathrm{mmol})$ in $\mathrm{CH}_{2} \mathrm{Cl}_{2}$ under $\mathrm{N}_{2}$ atmosphere was added dropwise triethylamine $(0.1 \mathrm{~mL}, 0.8 \mathrm{mmol})$. The resulting mixture was allowed to warm to room temperature and stirred for $4 \mathrm{~h}$, then quenched with sat. aq. $\mathrm{NaHCO}_{3}$. The layers were separated, and the aqueous phase was extracted with $\mathrm{CH}_{2} \mathrm{Cl}_{2}(3 \mathrm{x})$. The combined organic layers were washed with brine, dried over $\mathrm{Na}_{2} \mathrm{SO}_{4}$ and concentrated in vacuo. Flash chromatography 10:90 hexanes:EtOAc) afforded the desired product as a white solid (93 $\mathrm{mg}, 57 \%$ yield). ${ }^{13} \mathrm{C}$ NMR (126 MHz, DMSO) $\delta$ 170.93, 168.77, 157.87, 156.06, 155.93, 155.48, 151.73, 144.48, 139.86, $139.41,136.93,131.49,130.45,130.37,128.62,128.33,127.81,126.11,125.05,122.75,116.16,115.73$, 112.97, 112.44, 107.53, 107.32, 107.08, 106.87, 67.38, 65.49, 51.37, 48.51, 45.77, 42.35, 42.06, 38.10, 29.80, 28.35, 23.98, 23.24, 22.38, 13.83, 10.74; IR (ATR) vmax 3296, 1729, 1677, 1533, 1423, 1344, 1215, 866, $742 \mathrm{~cm}^{-1}$; AMM 593.1230 (ESI) $\mathrm{m} / \mathrm{z}$ [calc for $\mathrm{C}_{27} \mathrm{H}_{24} \mathrm{CIFN}_{4} \mathrm{O}_{7} \mathrm{Na}(\mathrm{M})^{+} 593.1215$ ].

Synthesis of Analog 20

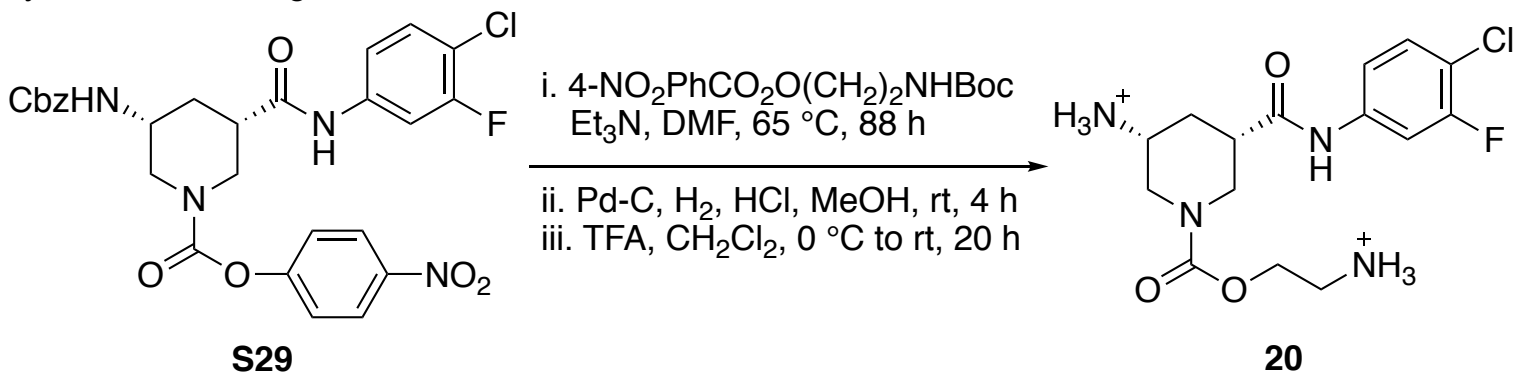

i. To a solution of common intermediate $\mathbf{S 2 9}\left(30 . \mathrm{mg}, 0.074 \mathrm{mmol}\right.$ ) and $4-\mathrm{NO}_{2} \mathrm{PhCO}_{2}$ $\mathrm{O}\left(\mathrm{CH}_{2}\right)_{2} \mathrm{NHBoc}(24 \mathrm{mg}, 0.074 \mathrm{mmol})$ in dimethylformamide $(0.7 \mathrm{~mL})$ at room temperature was added triethylamime $(30 \mu \mathrm{L}, 0.2 \mathrm{mmol})$. The microwave reaction vessel was sealed, and the resulting mixture was heated to $65{ }^{\circ} \mathrm{C}$ and stirred for $88 \mathrm{~h}$, then allowed to cool to room temperature and diluted with EtOAc and $\mathrm{H}_{2} \mathrm{O}$. The layers were separated, and the aqueous phase was extracted with EtOAc (3x). The combined organic layers were dried over $\mathrm{Na}_{2} \mathrm{SO}_{4}$ and concentrated in vacuo to afford the product, which was carried forward without additional purification.

ii. To a solution of intermediate $(32 \mathrm{mg}, 0.074 \mathrm{mmol})$ and palladium on carbon $(10 \mathrm{wt} \%, 8 \mathrm{mg}$, $0.07 \mathrm{mmol}$ ) in methanol $(2 \mathrm{~mL})$ at room temperature under $\mathrm{N}_{2}$ atmosphere was added concentrated $\mathrm{HCl}$ (few drops). The reaction flask was backfilled with $\mathrm{H}_{2}(3 \mathrm{x})$ and the resulting mixture was stirred under $\mathrm{H}_{2}$ atmosphere (balloon) for $4 \mathrm{~h}$, then backfilled with $\mathrm{N}_{2}$, and filtered 
through celite and rinsed with $\mathrm{MeOH}$. The filtrate was concentrated in vacuo and the crude product was carried forward without additional purification.

iii. To a precooled $\left(0^{\circ} \mathrm{C}\right)$ solution of intermediate $(25 \mathrm{mg}, 0.054 \mathrm{mmol})$ in $\mathrm{CH}_{2} \mathrm{Cl}_{2}(0.8 \mathrm{~mL})$ under $\mathrm{N}_{2}$ atmosphere was added trifluoroacetic acid $(30 \mu \mathrm{L}, 0.4 \mathrm{mmol})$. The resulting mixture was allowed to warm to room temperature and stirred for $20 \mathrm{~h}$, then concentrated in vacuo. The crude residue was taken up in wet DMSO $(1 \mathrm{~mL})$, filtered through celite, and purified via massdirected isolation using ultra-performance liquid chromatography to afford the product as a white solid (13 mg, $51 \%$ yield over 3 steps). ${ }^{1} \mathrm{H}$ NMR $\left(500 \mathrm{MHz}\right.$, Methanol- $\left.\mathrm{d}_{4}\right) \delta 7.72(\mathrm{~d}, \mathrm{~J}=$ $11.6 \mathrm{~Hz}, 1 \mathrm{H}), 7.42(\mathrm{t}, J=8.5 \mathrm{~Hz}, 1 \mathrm{H}), 7.22-7.34(\mathrm{~m}, 1 \mathrm{H}), 4.24-4.44(\mathrm{~m}, 2 \mathrm{H}), 4.02-4.22(\mathrm{~m}$, 1H) $3.37-3.57(\mathrm{~m}, 3 \mathrm{H}), 2.89-2.77(\mathrm{~m}, 1 \mathrm{H}), 2.24-2.40(\mathrm{~m}, 1 \mathrm{H}), 1.88-2.04(\mathrm{~m}, 1 \mathrm{H})$; AMM (ESI) $\mathrm{m} / \mathrm{z} 359.1268$ [calc for $\mathrm{C}_{15} \mathrm{H}_{21} \mathrm{ClFN}_{4} \mathrm{O}_{3}(\mathrm{M}+\mathrm{H})^{+} 359.1286$ ].

Synthesis of Analog 21a (MCG-IV-226)<smiles>[Z10]CCNC(=O)N1C[C@@H](C(=O)Nc2ccc(Cl)c(F)c2)C[C@@H]([NH3+])C1</smiles>

i. To a solution of common intermediate $\mathbf{S 2 9}(43 \mathrm{mg}, 0.076 \mathrm{mmol})$ in acetonitrile $(1 \mathrm{~mL})$ at room temperature was added triethylamine $(30 \mu \mathrm{L}, 0.2 \mathrm{mmol})$ and $\mathrm{n}$-propylamine $(20 \mu \mathrm{L}, 0.2 \mathrm{mmol})$. The reaction mixture was heated to reflux and stirred for $15 \mathrm{~h}$, then concentrated in vacuo. The crude residue was taken up in chloroform and diluted with water. The layers were separated, and the aqueous phase was extracted with chloroform (3x). The combined organic layers were washed with brine, dried over $\mathrm{NaSO}_{4}$, and concentrated in vacuo to afford the product, which was carried forward.

ii. To a solution of intermediate $(25 \mathrm{mg}, 0.051 \mathrm{mmol})$ and palladium on carbon $(10 \mathrm{wt} \%, 5 \mathrm{mg}$, $0.05 \mathrm{mmol}$ ) in methanol $(1 \mathrm{~mL})$ at room temperature under $\mathrm{N}_{2}$ atmosphere was added concentrated $\mathrm{HCl}$ (few drops). The reaction flask was backfilled with $\mathrm{H}_{2}(3 \mathrm{x})$ and the resulting mixture was stirred under $\mathrm{H}_{2}$ atmosphere (balloon) for $1 \mathrm{~h}$, then backfilled with $\mathrm{N}_{2}$, and filtered through celite and rinsed with $\mathrm{MeOH}$. The filtrate was concentrated in vacuo and the crude residue was diluted with wet DMSO $(0.5 \mathrm{~mL})$ and purified via mass-directed isolation using ultra-performance liquid chromatography to afford the product as a white solid $(4.7 \mathrm{mg}, 28 \%$ yield). ${ }^{1} \mathrm{H}$ NMR $\left(500 \mathrm{MHz}\right.$, Methanol- $\left.d_{4}\right) \delta 7.72(\mathrm{dd}, J=11.6,2.4 \mathrm{~Hz}, 1 \mathrm{H}), 7.41(\mathrm{t}, J=8.5 \mathrm{~Hz}$, $1 \mathrm{H}), 7.26(\mathrm{~d}, J=8.7 \mathrm{~Hz}, 1 \mathrm{H}), 4.17-4.05(\mathrm{~m}, 1 \mathrm{H}), 3.93(\mathrm{dd}, J=13.8,4.0 \mathrm{~Hz}, 1 \mathrm{H}), 3.21-3.01$ $(\mathrm{m}, 2 \mathrm{H}), 2.80-2.69(\mathrm{~m}, 1 \mathrm{H}), 2.30(\mathrm{~d}, J=14.0 \mathrm{~Hz}, 1 \mathrm{H}), 1.99-1.87(\mathrm{~m}, 1 \mathrm{H}), 1.57-1.39(\mathrm{~m}$, $2 \mathrm{H}), 1.00-0.80(\mathrm{~m}, 3 \mathrm{H})$; AMM 357.1517 (ESI) $\mathrm{m} / \mathrm{z}$ [calc for $\mathrm{C}_{16} \mathrm{H}_{23} \mathrm{ClFN}_{4} \mathrm{O}_{2}(\mathrm{M}+\mathrm{H})^{+} 357.1494$ ].

Synthesis of Analog 21b (MCG-IV-273)

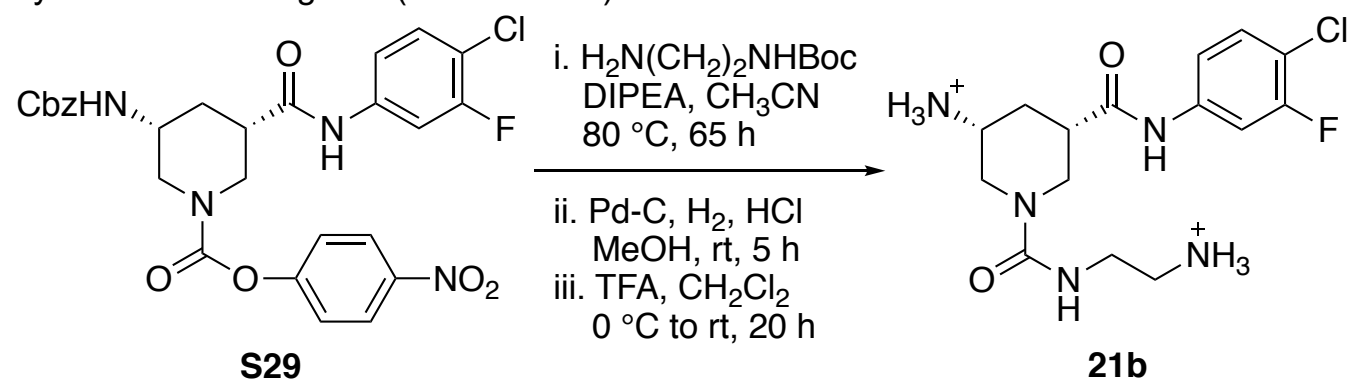

i. $\quad$ To a solution of intermediate $2.156(40 \mathrm{mg}, 0.070 \mathrm{mmol})$ and $\mathrm{H}_{2} \mathrm{~N}\left(\mathrm{CH}_{2}\right)_{2} \mathrm{NHBoc}(22 \mathrm{mg}, 0.14$ $\mathrm{mmol})$ in acetonitrile $(1 \mathrm{~mL})$ at room temperature was added diisopropylethylamine $(20 \mu \mathrm{L}, 0.1$ $\mathrm{mmol}$ ). The reaction mixture was heated to $80^{\circ} \mathrm{C}$ and stirred for $65 \mathrm{~h}$, then concentrated in vacuo. The crude residue was taken up in EtOAc and diluted with water. The layers were 
separated, and the aqueous phase was extracted with EtOAc (3x). The combined organic layers were dried over $\mathrm{NaSO}_{4}$ and concentrated in vacuo to afford the product, which was carried forward.

ii. To a solution of intermediate $(35 \mathrm{mg}, 0.060 \mathrm{mmol})$ and palladium on carbon (10 $\mathrm{wt} \%, 6.4 \mathrm{mg}$, $0.060 \mathrm{mmol})$ in methanol $(1.2 \mathrm{~mL})$ at room temperature under $\mathrm{N}_{2}$ atmosphere was added concentrated $\mathrm{HCl}$ (few drops). The reaction flask was backfilled with $\mathrm{H}_{2}(3 \mathrm{x})$ and the resulting mixture was stirred under $\mathrm{H}_{2}$ atmosphere (balloon) for $5 \mathrm{~h}$, then backfilled with $\mathrm{N}_{2}$, and filtered through celite and rinsed with $\mathrm{MeOH}$. The filtrate was concentrated in vacuo and the crude product was carried forward without additional purification.

iii. To a precooled $\left(0^{\circ} \mathrm{C}\right)$ solution of intermediate $(28 \mathrm{mg}, 0.060 \mathrm{mmol})$ in $\mathrm{CH}_{2} \mathrm{Cl}_{2}(1.2 \mathrm{~mL})$ under $\mathrm{N}_{2}$ atmosphere was added trifluoroacetic acid $(50 \mu \mathrm{L}, 0.6 \mathrm{mmol})$. The resulting mixture was allowed to warm to room temperature and stirred for $20 \mathrm{~h}$, then concentrated in vacuo. The crude residue was taken up in wet DMSO $(0.8 \mathrm{~mL})$, filtered through celite, and purified via mass-directed isolation using ultra-performance liquid chromatography to afford the product as a white solid (12 mg, $29 \%$ yield over 3 steps). ${ }^{1} \mathrm{H}$ NMR $\left(500 \mathrm{MHz}\right.$, Methanol- $\left.d_{4}\right) \delta 7.76-7.68$ $(\mathrm{m}, 1 \mathrm{H}), 7.41(\mathrm{t}, J=8.5 \mathrm{~Hz}, 1 \mathrm{H}), 7.27(\mathrm{~d}, J=8.7 \mathrm{~Hz}, 1 \mathrm{H}), 4.19-4.07(\mathrm{~m}, 1 \mathrm{H}), 3.98-3.89(\mathrm{~m}$, $1 \mathrm{H}), 3.48-3.37(\mathrm{~m}, 1 \mathrm{H}), 3.24-3.13(\mathrm{~m}, 1 \mathrm{H}), 3.03(\mathrm{t}, J=5.8 \mathrm{~Hz}, 1 \mathrm{H}), 2.85-2.75(\mathrm{~m}, 1 \mathrm{H})$, $2.33(\mathrm{~d}, J=13.7 \mathrm{~Hz}, 1 \mathrm{H}), 1.99-1.87(\mathrm{~m}, 1 \mathrm{H})$

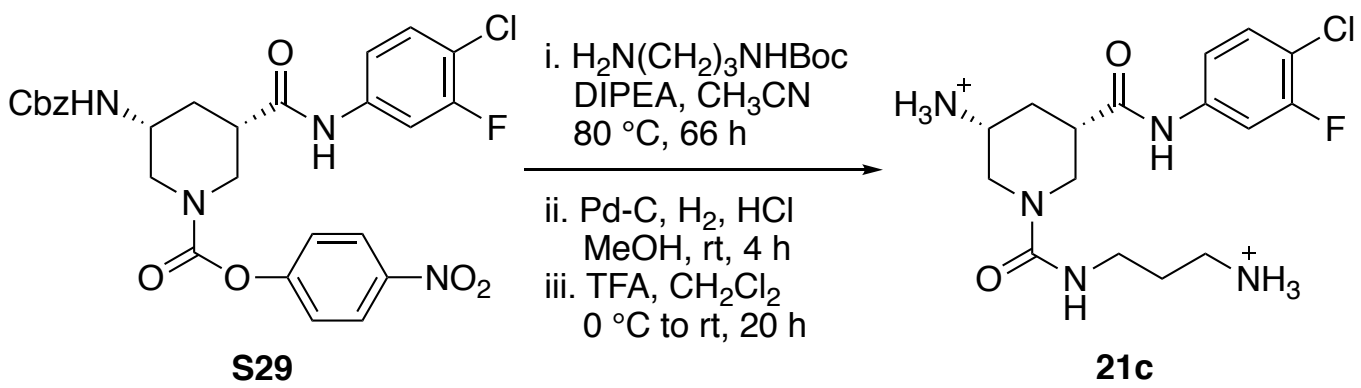

i. To a solution of intermediate $2.156(40 \mathrm{mg}, 0.070 \mathrm{mmol})$ and $\mathrm{H}_{2} \mathrm{~N}\left(\mathrm{CH}_{2}\right)_{3} \mathrm{NHBoc}(24 \mathrm{mg}, 0.14$ $\mathrm{mmol})$ in acetonitrile $(1 \mathrm{~mL})$ at room temperature was added diisopropylethylamine $(20 \mu \mathrm{L}, 0.1$ $\mathrm{mmol})$. The reaction mixture was heated to $80^{\circ} \mathrm{C}$ and stirred for $66 \mathrm{~h}$, then concentrated in vacuo. The crude residue was taken up in EtOAc and diluted with water. The layers were separated, and the aqueous phase was extracted with EtOAc (3x). The combined organic layers were dried over $\mathrm{NaSO}_{4}$ and concentrated in vacuo to afford the product, which was carried forward.

ii. To a solution of intermediate $(23 \mathrm{mg}, 0.037 \mathrm{mmol})$ and palladium on carbon (10 $\mathrm{wt} \%, 4.0 \mathrm{mg}$, $0.037 \mathrm{mmol})$ in methanol $(0.8 \mathrm{~mL})$ at room temperature under $\mathrm{N}_{2}$ atmosphere was added concentrated $\mathrm{HCl}$ (few drops). The reaction flask was backfilled with $\mathrm{H}_{2}(3 \mathrm{x})$ and the resulting mixture was stirred under $\mathrm{H}_{2}$ atmosphere (balloon) for $4 \mathrm{~h}$, then backfilled with $\mathrm{N}_{2}$, and filtered through celite and rinsed with $\mathrm{MeOH}$. The filtrate was concentrated in vacuo and the crude product was carried forward without additional purification.

To a precooled $\left(0{ }^{\circ} \mathrm{C}\right)$ solution of intermediate $(18 \mathrm{mg}, 0.037 \mathrm{mmol})$ in $\mathrm{CH}_{2} \mathrm{Cl}_{2}(0.8 \mathrm{~mL})$ under $\mathrm{N}_{2}$ atmosphere was added trifluoroacetic acid $(30 \mu \mathrm{L}, 0.4 \mathrm{mmol})$. The resulting mixture was allowed to warm to room temperature and stirred for $20 \mathrm{~h}$, then concentrated in vacuo. The crude residue was taken up in wet DMSO $(1 \mathrm{~mL})$, filtered through celite, and purified via massdirected isolation using ultra-performance liquid chromatography to afford the product as a white solid (13 mg, $32 \%$ yield over 3 steps). ${ }^{1} \mathrm{H}$ NMR $\left(500 \mathrm{MHz}\right.$, Methanol- $\left.d_{4}\right) \delta 7.75-7.68(\mathrm{~m}$, $1 \mathrm{H}), 7.41(\mathrm{t}, J=8.6 \mathrm{~Hz}, 1 \mathrm{H}), 7.27(\mathrm{~d}, J=8.6 \mathrm{~Hz}, 1 \mathrm{H}), 4.08(\mathrm{~d}, J=14.0 \mathrm{~Hz}, 1 \mathrm{H}), 3.90(\mathrm{~d}, J=$ $14.3 \mathrm{~Hz}, 1 \mathrm{H}), 3.39(\mathrm{dd}, J=14.0,8.4 \mathrm{~Hz}, 1 \mathrm{H}), 3.26(\mathrm{dd}, J=14.9,7.6 \mathrm{~Hz}, 1 \mathrm{H}), 2.94(\mathrm{~s}, 1 \mathrm{H}), 2.78$ (d, $J=9.9 \mathrm{~Hz}, 1 \mathrm{H}), 2.33(\mathrm{~d}, J=14.2 \mathrm{~Hz}, 1 \mathrm{H}), 1.94(\mathrm{~d}, J=8.6 \mathrm{~Hz}, 1 \mathrm{H}), 1.86-1.72(\mathrm{~m}, 2 \mathrm{H})$; AMM (ESI) $m / z 372.1593$ [calc for $\mathrm{C}_{16} \mathrm{H}_{24} \mathrm{ClFN}_{5} \mathrm{O}_{2}(\mathrm{MH}) 372.1603$ ].

General Synthesis of Analogs S30 


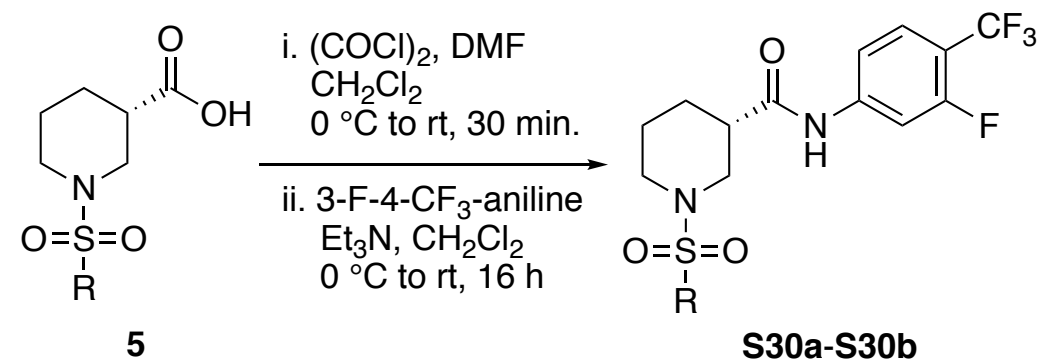

i. To separate precooled $\left(0^{\circ} \mathrm{C}\right)$ solutions of $5(1.0 \mathrm{eq})$ in dichloromethane $(0.2 \mathrm{M})$ was added oxalyl chloride (1.1 eq) and dimethylformamide (1-2 drops). The resulting reaction mixtures were allowed to warm to room temperature and stirred for $30 \mathrm{~min}$. then concentrated in vacuo and used directly.

ii. To separate precooled $\left(0{ }^{\circ} \mathrm{C}\right)$ solutions of 3-fluoro-4-trifluoromethylaniline $(1.0 \mathrm{eq})$ in dichloromethane $(0.05 \mathrm{M})$ was added triethylamine $(1.2 \mathrm{eq})$ then dropwise a solution of intermediate acid chloride $(1.2 \mathrm{eq})$ in dichloromethane $(0.05 \mathrm{M})$. The resulting mixtures were allowed to warm to room temperature and stirred for $16 \mathrm{~h}$, then diluted with wet DMSO $(0.5$ $\mathrm{mL}$ ), filtered through celite, and purified via mass-directed isolation using ultra-performance liquid chromatography to afford the products as white solids (69-73\% yield).

MCG-IV-024-A02 (S30a)

$\mathrm{R}=\mathrm{Me}(69 \%$ yield $)$

${ }^{1} \mathrm{H}$ NMR $\left(500 \mathrm{MHz}\right.$, Acetonitrile- $\left.d_{3}\right) \delta 8.91(\mathrm{~s}, 1 \mathrm{H}), 7.81-7.74(\mathrm{~m}, 1 \mathrm{H}), 7.59(\mathrm{t}, J=8.4 \mathrm{~Hz}, 1 \mathrm{H}), 7.37(\mathrm{~d}, J=$ $8.6 \mathrm{~Hz}, 1 \mathrm{H}), 3.85-3.76(\mathrm{~m}, 1 \mathrm{H}), 3.62(\mathrm{~d}, J=11.7 \mathrm{~Hz}, 1 \mathrm{H}), 2.89(\mathrm{dd}, J=11.8,10.6 \mathrm{~Hz}, 1 \mathrm{H}), 2.79(\mathrm{~s}, 3 \mathrm{H})$, $2.74(\mathrm{td}, J=11.6,2.8 \mathrm{~Hz}, 1 \mathrm{H}), 2.68-2.57(\mathrm{~m}, 1 \mathrm{H}), 2.08-1.98(\mathrm{~m}, 1 \mathrm{H}), 1.90-1.81(\mathrm{~m}, 1 \mathrm{H}), 1.68-1.56$ $(\mathrm{m}, 2 \mathrm{H})$;

MCG-IV-024-B02 (S30b)

$\mathrm{R}=\mathrm{Et}(73 \%$ yield $)$

${ }^{1} \mathrm{H}$ NMR $\left(500 \mathrm{MHz}\right.$, Acetonitrile- $\left.d_{3}\right) \delta 8.93-8.77(\mathrm{~m}, 1 \mathrm{H}), 7.77(\mathrm{dd}, J=13.5,1.9 \mathrm{~Hz}, 1 \mathrm{H}), 7.59(\mathrm{t}, J=8.4$ $\mathrm{Hz}, 1 \mathrm{H}), 7.37(\mathrm{~d}, J=8.6 \mathrm{~Hz}, 1 \mathrm{H}), 3.87-3.78(\mathrm{~m}, 1 \mathrm{H}), 3.67-3.59(\mathrm{~m}, 1 \mathrm{H}), 3.05-2.93(\mathrm{~m}, 3 \mathrm{H}), 2.84(\mathrm{td}, J$ $=11.8,2.9 \mathrm{~Hz}, 1 \mathrm{H}), 2.63-2.54(\mathrm{~m}, 1 \mathrm{H}), 2.07-1.98(\mathrm{~m}, 1 \mathrm{H}), 1.87-1.78(\mathrm{~m}, 1 \mathrm{H}), 1.71-1.51(\mathrm{~m}, 2 \mathrm{H})$, $1.27(\mathrm{t}, J=7.4 \mathrm{~Hz}, 3 \mathrm{H}$ );

\section{Syntheses of Common Intermediate S31}

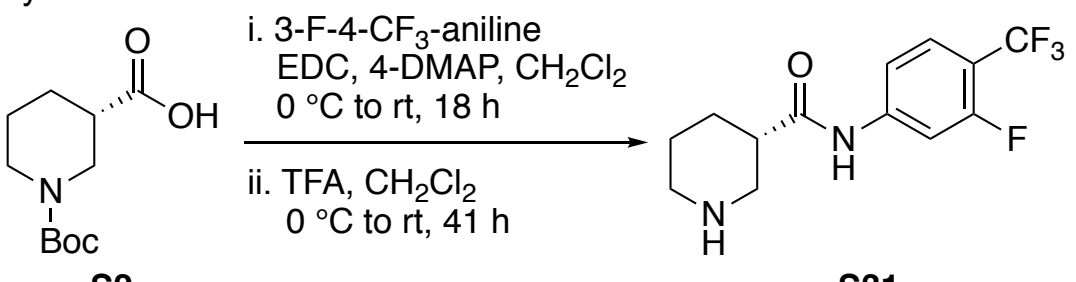

S2

S31

i. $\quad$ To a solution of intermediate $\mathbf{S} 2(591 \mathrm{mg}, 2.58 \mathrm{mmol})$, 3-fluoro-4-trifluoromethylaniline (462 $\mathrm{mg}, 2.58$ $\mathrm{mmol}$ ) and 1-ethyl-3-(3-dimethylaminopropyl)-carbodiimide hydrochloride (EDCl, $544 \mathrm{mg}, 2.84 \mathrm{mmol}$ ) in $\mathrm{CH}_{2} \mathrm{Cl}_{2}(13 \mathrm{~mL})$ at room temperature under $\mathrm{N}_{2}$ atmosphere was added 4-dimethylaminopyridine (346 mg, $2.84 \mathrm{mmol})$. The resulting mixture was stirred for $18 \mathrm{~h}$, then quenched with water. The layers were separated, and the aqueous phase was extracted with $\mathrm{CH}_{2} \mathrm{Cl}_{2}(3 \mathrm{x})$. The combined organic layers were washed sequentially with sat. aq. $\mathrm{NH}_{4} \mathrm{Cl}$, sat. aq. $\mathrm{NaHCO}_{3}$, and brine, dried over $\mathrm{Na}_{2} \mathrm{SO}_{4}$, and concentrated in vacuo. Flash chromatography $\left(\mathrm{SiO}_{2}, 80: 20\right.$ hexanes:ethyl acetate) afforded the product as a white solid $(1.00 \mathrm{~g})$.

ii. To a precooled $\left(0{ }^{\circ} \mathrm{C}\right)$ solution of intermediate $(1.00 \mathrm{~g}, 2.56 \mathrm{mmol})$ in $\mathrm{CH}_{2} \mathrm{Cl}_{2}(12 \mathrm{~mL})$ under $\mathrm{N}_{2}$ atmosphere was added dropwise trifluoroacetic acid $(0.59 \mathrm{~mL}, 7.7 \mathrm{mmol})$. The resulting mixture was 
allowed to warm to room temperature and stirred for $41 \mathrm{~h}$, then concentrated in vacuo. The crude residue was taken up in water, cooled to $0{ }^{\circ} \mathrm{C}$, then slowly neutralized with powdered $\mathrm{NaHCO}_{3}$. The aqueous phase was diluted with $\mathrm{CH}_{2} \mathrm{Cl}_{2}$. The layers were separated, and the aqueous phase was extracted with $\mathrm{CH}_{2} \mathrm{Cl}_{2}(3 \mathrm{x})$. The combined organic layers were dried over $\mathrm{Na}_{2} \mathrm{SO}_{4}$ and concentrated in vacuo to afford the desired product as a white solid $(678 \mathrm{mg}, 68 \% \text { yield). [ } \alpha]_{\mathrm{D}}{ }^{23}-5.0$ (c. $0.31, \mathrm{CH}_{3} \mathrm{OH}$ ); ${ }^{1} \mathrm{H}$ NMR $(500 \mathrm{MHz}$, Chloroform- $d$ ) $\delta 11.21(\mathrm{~s}, 1 \mathrm{H}), 7.71(\mathrm{~d}, J=12.9 \mathrm{~Hz}, 1 \mathrm{H}), 7.53-7.38(\mathrm{~m}, 1 \mathrm{H}), 7.26$ (s, 1H), $3.37(\mathrm{~d}, J=37.4 \mathrm{~Hz}, 1 \mathrm{H}), 3.28-3.18(\mathrm{~m}, 1 \mathrm{H}), 3.14-3.01(\mathrm{~m}, 1 \mathrm{H}), 3.01-2.92(\mathrm{~m}, 1 \mathrm{H}), 2.78$ $(\mathrm{t}, J=11.2 \mathrm{~Hz}, 1 \mathrm{H}), 2.66-2.56(\mathrm{~m}, 1 \mathrm{H}), 2.08-1.95(\mathrm{~m}, 1 \mathrm{H}), 1.86-1.67(\mathrm{~m}, 2 \mathrm{H}), 1.67-1.51(\mathrm{~m}$, 1H), 1.44 (d, $J=3.8 \mathrm{~Hz}, 1 \mathrm{H}) ;{ }^{13} \mathrm{C}$ NMR $\left(126 \mathrm{MHz}, \mathrm{CDCl}_{3}\right) \delta 174.52,161.20,159.18,143.56,143.47$, 127.38, 123.87, 121.72, 114.51, 114.48, 107.93, 107.73, 77.16, 47.58, 46.32, 46.28, 41.72, 28.42, 28.40, 27.41, 22.45; IR (ATR) V $\max 3280,2927,1679,1610,1416,1319,1118,1049,863,637 \mathrm{~cm}^{-1}$; AMM (ESI) $m / z 291.1139$ [calc for $\mathrm{C}_{13} \mathrm{H}_{15} \mathrm{~N}_{2} \mathrm{~F}_{4} \mathrm{O}(\mathrm{M}+\mathrm{H})^{+} 291.1121$ ].

General Synthesis of Analogs S32

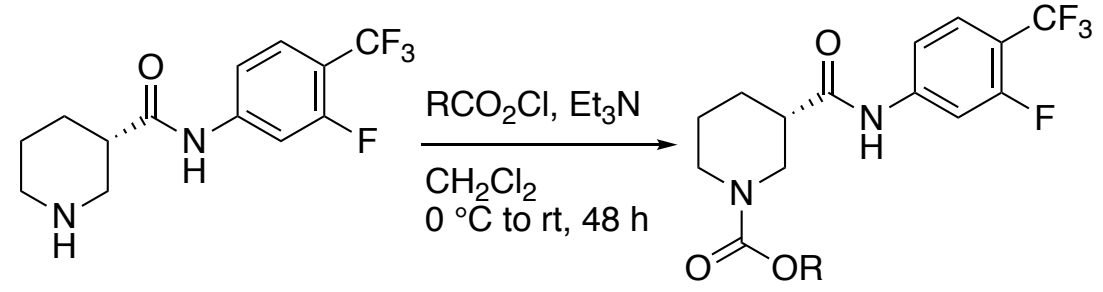

S31

S32a-S32b

To separated precooled $\left(0{ }^{\circ} \mathrm{C}\right)$ solutions of $\mathbf{S} 31(20 . \mathrm{mg}, 0.069 \mathrm{mmol})$ in $\mathrm{CH}_{2} \mathrm{Cl}_{2}(1 \mathrm{~mL})$ was added triethylamine $(30 \mu \mathrm{L}, 0.2 \mathrm{mmol})$ then alkylchloroformate $(0.10 \mathrm{mmol})$. The resulting mixtures were allowed to warm to room temperature and stirred for $48 \mathrm{~h}$, then diluted with wet DMSO $(0.5 \mathrm{~mL})$, filtered through celite, and purified via mass-directed isolation via ultra-performance liquid chromatography (33-36\% yield).

MCG-IV-050-A01 (S32a)

$\mathrm{R}=\mathrm{Me}(36 \%$ yield $)$

${ }^{1} \mathrm{H}$ NMR $\left(500 \mathrm{MHz}\right.$, Acetonitrile-d $\left.d_{3}\right) \delta 8.87(\mathrm{~s}, 1 \mathrm{H}), 7.78(\mathrm{dt}, J=13.3,1.5 \mathrm{~Hz}, 1 \mathrm{H}), 7.59(\mathrm{t}, J=8.5 \mathrm{~Hz}, 1 \mathrm{H})$, $7.42-7.32(\mathrm{~m}, 1 \mathrm{H}), 4.12(\mathrm{~s}, 1 \mathrm{H}), 3.92(\mathrm{~s}, 1 \mathrm{H}), 3.63(\mathrm{~s}, 3 \mathrm{H}), 3.03(\mathrm{t}, J=11.9 \mathrm{~Hz}, 1 \mathrm{H}), 2.87(\mathrm{~s}, 1 \mathrm{H}), 2.54-$ $2.42(\mathrm{~m}, 1 \mathrm{H}), 2.06-1.97(\mathrm{~m}, 1 \mathrm{H}), 1.78-1.62(\mathrm{~m}, 2 \mathrm{H}), 1.54-1.39(\mathrm{~m}, 1 \mathrm{H})$; AMM $371.0986(\mathrm{ESI}) \mathrm{m} / \mathrm{z}$ [calc for $\left.\mathrm{C}_{15} \mathrm{H}_{16} \mathrm{~F}_{4} \mathrm{~N}_{2} \mathrm{O}_{3} \mathrm{Na}(\mathrm{M}+\mathrm{Na})^{+} 371.0995\right]$.

MCG-IV-050-A02 (S32b)

$\mathrm{R}=\mathrm{Et}(33 \%$ yield $)$

${ }^{1} \mathrm{H}$ NMR $\left(500 \mathrm{MHz}\right.$, Acetonitrile- $\left.d_{3}\right) \delta 8.90(\mathrm{~s}, 1 \mathrm{H}), 7.83-7.73(\mathrm{~m}, 1 \mathrm{H}), 7.59(\mathrm{t}, J=8.5 \mathrm{~Hz}, 1 \mathrm{H}), 7.42-7.34$ $(\mathrm{m}, 1 \mathrm{H}), 4.18-4.00(\mathrm{~m}, 3 \mathrm{H}), 3.93(\mathrm{~d}, J=13.5 \mathrm{~Hz}, 1 \mathrm{H}), 3.15-2.96(\mathrm{~m}, 1 \mathrm{H}), 2.88(\mathrm{~s}, 1 \mathrm{H}), 2.54-2.41(\mathrm{~m}$, $1 \mathrm{H}), 2.05-1.97(\mathrm{~m}, 1 \mathrm{H}), 1.80-1.64(\mathrm{~m}, 2 \mathrm{H}), 1.54-1.39(\mathrm{~m}, 1 \mathrm{H}), 1.21(\mathrm{t}, J=7.1 \mathrm{~Hz}, 3 \mathrm{H}) ;$ AMM 385.1149 (ESI) $\mathrm{m} / \mathrm{z}$ [calc for $\mathrm{C}_{16} \mathrm{H}_{18} \mathrm{~F}_{4} \mathrm{~N}_{2} \mathrm{O}_{3} \mathrm{Na}(\mathrm{M}+\mathrm{Na})^{+} 385.1151$ ].

General Synthesis of Analogs S33<smiles>O=C(Nc1ccc(C(F)(F)F)c(F)c1)[C@H]1CCCNC1</smiles>

S31

$$
\begin{aligned}
& \text { i. } 4-\mathrm{NO}_{2} \mathrm{PhCO}_{2} \mathrm{Cl} \\
& \mathrm{Et}_{3} \mathrm{~N}, \mathrm{CH}_{2} \mathrm{Cl}_{2} \\
& { }^{\circ} \mathrm{C} \text { to rt, } 16 \mathrm{~h} \\
& \stackrel{ }{\text { ii. }} \mathrm{NRR}^{\prime}, \mathrm{Et}_{3} \mathrm{~N}, 4-\mathrm{DMAP} \\
& \mathrm{CH}_{2} \mathrm{Cl}_{2}, \mathrm{MeOH} \\
& 0^{\circ} \mathrm{C} \text { to rt, } 36 \mathrm{~h}
\end{aligned}
$$<smiles>[R]N([R])C(=O)N1CCC[C@H](C(=O)Nc2ccc(C(F)(F)F)c(F)c2)C1</smiles>

S33a-S33e

i. To a precooled $\left(0{ }^{\circ} \mathrm{C}\right)$ solution of common intermediate $\mathbf{S} 31(150 \mathrm{mg}, 0.571 \mathrm{mmol})$ and $p$ nitrophenylchloroformate (156 mg, $0.775 \mathrm{mmol})$ in $\mathrm{CH}_{2} \mathrm{Cl}_{2}(4 \mathrm{~mL})$ under $\mathrm{N}_{2}$ atmosphere was added dropwise triethylamine $(22 \mu \mathrm{L}, 1.6 \mathrm{mmol})$. The reaction mixture was allowed to warm to room 
temperature and stirred for $16 \mathrm{~h}$, then quenched with $\mathrm{NaHCO}_{3}$ (sat. aq.). The layers were separated, and the aqueous phase was extracted with $\mathrm{CH}_{2} \mathrm{Cl}_{2}(3 \mathrm{x})$. The combined organic layers were washed with brine, dried over $\mathrm{Na}_{2} \mathrm{SO}_{4}$ and concentrated in vacuo. Flash chromatography $\left(\mathrm{SiO}_{2}, 70: 30\right.$ hexanes:ethyl acetate) afforded the product, which was carried forward.

ii. To separated precooled $\left(0{ }^{\circ} \mathrm{C}\right)$ vials charged with amine $(0.13 \mathrm{mmol})$ was added a solution of intermediate (30. mg, $0.066 \mathrm{mmol})$, triethylamine $(20 \mu \mathrm{L}, 0.1 \mathrm{mmol})$ and 4-dimethylaminopyridine (2 $\mathrm{mg}, 0.002 \mathrm{mmol})$ in $\mathrm{CH}_{2} \mathrm{Cl}_{2}(0.5 \mathrm{~mL})$ and $\mathrm{MeOH}(0.5 \mathrm{~mL})$. The resulting mixtures were allowed to warm to room temperature and stirred for $36 \mathrm{~h}$, then diluted with wet DMSO $(0.5 \mathrm{~mL})$, filtered through celite, and purified via mass-directed isolation using ultra-performance liquid chromatography (16-19\% yield).

MCG-IV-063-A01 (S33a)

$\mathrm{R}=\mathrm{Me}, \mathrm{R}^{\prime}=\mathrm{H}(19 \%$ yield $)$

${ }^{1} \mathrm{H}$ NMR $\left(500 \mathrm{MHz}\right.$, Acetonitrile- $\left.d_{3}\right) \delta 9.28(\mathrm{~s}, 1 \mathrm{H}), 7.81(\mathrm{~d}, J=12.7 \mathrm{~Hz}, 1 \mathrm{H}), 7.59(\mathrm{t}, J=8.5 \mathrm{~Hz}, 1 \mathrm{H}), 7.40$ $(\mathrm{d}, J=9.0 \mathrm{~Hz}, 1 \mathrm{H}), 3.91(\mathrm{~d}, J=14.0 \mathrm{~Hz}, 1 \mathrm{H}), 3.73-3.63(\mathrm{~m}, 1 \mathrm{H}), 3.14(\mathrm{dd}, J=13.6,9.5 \mathrm{~Hz}, 1 \mathrm{H}), 2.90$ (ddd, $J=13.7,10.7,3.2 \mathrm{~Hz}, 2 \mathrm{H}), 2.67(\mathrm{~s}, 3 \mathrm{H}), 1.86-1.72(\mathrm{~m}, 2 \mathrm{H}), 1.69-1.59(\mathrm{~m}, 1 \mathrm{H}), 1.51-1.38(\mathrm{~m}$, $1 \mathrm{H})$; AMM 348.1348 (ESI) $\mathrm{m} / \mathrm{z}$ [calc for $\mathrm{C}_{15} \mathrm{H}_{18} \mathrm{~F}_{4} \mathrm{~N}_{3} \mathrm{O}_{2}(\mathrm{M}+\mathrm{H})^{+} 348.1335$ ].

MCG-IV-063-A02 (S33b)

$\mathrm{R}=\mathrm{Et}, \mathrm{R}^{\prime}=\mathrm{H}(19 \%$ yield $)$

${ }^{1} \mathrm{H}$ NMR $\left(500 \mathrm{MHz}\right.$, Acetonitrile- $\left.d_{3}\right) \delta 9.31(\mathrm{~s}, 1 \mathrm{H}), 7.81(\mathrm{~d}, J=13.8 \mathrm{~Hz}, 1 \mathrm{H}), 7.59(\mathrm{t}, J=8.4 \mathrm{~Hz}, 1 \mathrm{H}), 7.41$ $(\mathrm{d}, J=8.5 \mathrm{~Hz}, 1 \mathrm{H}), 3.89(\mathrm{~d}, J=13.5 \mathrm{~Hz}, 1 \mathrm{H}), 3.71-3.62(\mathrm{~m}, 1 \mathrm{H}), 3.24-3.10(\mathrm{~m}, 3 \mathrm{H}), 2.97-2.86(\mathrm{~m}, 1 \mathrm{H})$, $1.89-1.72(\mathrm{~m}, 2 \mathrm{H}), 1.69-1.57(\mathrm{~m}, 1 \mathrm{H}), 1.51-1.39(\mathrm{~m}, 1 \mathrm{H}), 1.06(\mathrm{t}, J=7.2 \mathrm{~Hz}, 3 \mathrm{H}) ;$ AMM $362.1483(\mathrm{ESI})$ $\mathrm{m} / \mathrm{z}$ [calc for $\mathrm{C}_{16} \mathrm{H}_{20} \mathrm{~F}_{4} \mathrm{~N}_{3} \mathrm{O}_{2}(\mathrm{M}+\mathrm{H})^{+} 362.1492$ ].

MCG-IV-063-A03 (S33c)

$R=M e, R^{\prime}=\operatorname{Me}(16 \%$ yield $)$

${ }^{1} \mathrm{H}$ NMR $\left(500 \mathrm{MHz}\right.$, Acetonitrile- $\left.d_{3}\right) \delta 9.51(\mathrm{~s}, 1 \mathrm{H}), 7.81(\mathrm{dd}, J=13.5,1.9 \mathrm{~Hz}, 1 \mathrm{H}), 7.59(\mathrm{t}, J=8.5 \mathrm{~Hz}, 1 \mathrm{H})$, $7.41(\mathrm{~d}, J=8.3 \mathrm{~Hz}, 1 \mathrm{H}), 3.61(\mathrm{dd}, J=13.4,3.8 \mathrm{~Hz}, 1 \mathrm{H}), 3.52-3.41(\mathrm{~m}, 1 \mathrm{H}), 3.18(\mathrm{dd}, J=13.5,8.9 \mathrm{~Hz}$, $1 \mathrm{H}), 2.79(\mathrm{~s}, 6 \mathrm{H}), 2.61-2.52(\mathrm{~m}, 1 \mathrm{H}), 1.81(\mathrm{dtd}, J=13.6,10.1,3.9 \mathrm{~Hz}, 1 \mathrm{H}), 1.69-1.58(\mathrm{~m}, 1 \mathrm{H}), 1.57-$ $1.45(\mathrm{~m}, 1 \mathrm{H})$; AMM 362.1494 (ESI) $\mathrm{m} / \mathrm{z}$ [calc for $\mathrm{C}_{16} \mathrm{H}_{20} \mathrm{~F}_{4} \mathrm{~N}_{3} \mathrm{O}_{2}(\mathrm{M}+\mathrm{H})^{+} 362.1492$ ].

MCG-IV-063-A05 (S33d)

$\mathrm{R}=n-\operatorname{Pr}, \mathrm{R}^{\prime}=\mathrm{H}(17 \%$ yield $)$

${ }^{1} \mathrm{H}$ NMR $\left(500 \mathrm{MHz}\right.$, Acetonitrile- $\left.d_{3}\right) \delta 9.19(\mathrm{~d}, J=14.1 \mathrm{~Hz}, 1 \mathrm{H}), 7.78(\mathrm{dd}, J=13.4,1.9 \mathrm{~Hz}, 1 \mathrm{H}), 7.56(\mathrm{t}, J=$ $8.4 \mathrm{~Hz}, 1 \mathrm{H}), 7.42-7.32(\mathrm{~m}, 1 \mathrm{H}), 3.88(\mathrm{dd}, J=13.4,4.1 \mathrm{~Hz}, 1 \mathrm{H}), 3.66(\mathrm{~d}, J=13.3 \mathrm{~Hz}, 2 \mathrm{H}), 3.21-3.11(\mathrm{~m}$, $2 \mathrm{H}), 3.07(\mathrm{t}, J=7.1 \mathrm{~Hz}, 3 \mathrm{H}), 2.91(\mathrm{ddd}, J=13.3,10.4,3.1 \mathrm{~Hz}, 1 \mathrm{H}), 2.51-2.39(\mathrm{~m}, 1 \mathrm{H}), 1.77(\mathrm{dtd}, J=13.7$, 10.5, 3.9 Hz, 1H), $1.68-1.55(\mathrm{~m}, 1 \mathrm{H}), 1.51-1.36(\mathrm{~m}, 3 \mathrm{H}), 0.84(\mathrm{t}, J=7.4 \mathrm{~Hz}, 3 \mathrm{H}) ;$ AMM 376.1641 (ESI) $\mathrm{m} / \mathrm{z}$ [calc for $\mathrm{C}_{17} \mathrm{H}_{22} \mathrm{~F}_{4} \mathrm{~N}_{3} \mathrm{O}_{2}(\mathrm{M}+\mathrm{H})^{+} 376.1648$ ].

MCG-IV-063-A06 (S33e)

$\mathrm{R}=i-\mathrm{Bu}, \mathrm{R}^{\prime}=\mathrm{H}(18 \%$ yield $)$

${ }^{1} \mathrm{H}$ NMR $\left(500 \mathrm{MHz}\right.$, Acetonitrile- $\left.d_{3}\right) \delta 9.29(\mathrm{~s}, 1 \mathrm{H}), 7.81(\mathrm{~d}, J=13.5 \mathrm{~Hz}, 1 \mathrm{H}), 7.59(\mathrm{t}, J=8.3 \mathrm{~Hz}, 1 \mathrm{H}), 7.40$ $(\mathrm{d}, J=9.2 \mathrm{~Hz}, 1 \mathrm{H}), 5.37(\mathrm{~s}, 1 \mathrm{H}), 3.85(\mathrm{~d}, J=13.8 \mathrm{~Hz}, 1 \mathrm{H}), 3.71-3.55(\mathrm{~m}, 1 \mathrm{H}), 3.26(\mathrm{dd}, J=13.7,8.9 \mathrm{~Hz}$, $1 \mathrm{H}), 3.03-2.85(\mathrm{~m}, 2 \mathrm{H}), 2.52-2.42(\mathrm{~m}, 2 \mathrm{H}), 1.88-1.76(\mathrm{~m}, 1 \mathrm{H}), 1.76-1.66(\mathrm{~m}, 1 \mathrm{H}), 1.61(\mathrm{t}, J=8.9 \mathrm{~Hz}$, $1 \mathrm{H}), 1.54-1.37(\mathrm{~m}, 1 \mathrm{H}), 0.92-0.74(\mathrm{~m}, 3 \mathrm{H})$; $\mathrm{AMM} 412.1631(\mathrm{ESI}) \mathrm{m} / \mathrm{z}$ [calc for $\mathrm{C}_{18} \mathrm{H}_{23} \mathrm{~F}_{4} \mathrm{~N}_{3} \mathrm{O}{ }_{2} \mathrm{Na}(\mathrm{M}+\mathrm{Na})^{+}$ 412.1624].

\section{References}

1. Brunger, A.T. Free $R$ value: Cross-validation in crystallography. In Methods in Enzymology (Academic Press). 1997, 366-396.

2. Karplus, P.A., and Diederichs, K. Linking crystallographic model and data quality. Science. 2012, 336, 1030-1033.

3. Weiss, M.S. Global indicators of X-ray data quality. J. Appl. Cryst. 2001, 34, 130-135. 
4. Small-Molecule Drug Discovery Suite 2019-1, Schrödinger, LLC, New York, NY, 2019.

5. Morris, G. M., Huey, R., Lindstrom, W., Sanner, M. F., Belew, R. K., Goodsell, D. S. and Olson, A. J. (2009) Autodock4 and AutoDockTools4: automated docking with selective receptor flexibility. J. Computational Chemistry 2009, 16: 2785-91.

6. Ding, S.; Grenier, M. C.; Tolbert, W. D.; Vézina, D.; Sherburn, R.; Richard, J.; Prévost, J.; Chapleau, J.-P.; Gendron-Lepage, G.; Medjahed, H.; Abrams, C.; Sodroski, J.; Pazgier, M.; Smith, A. B.; Finzi, A. A New Family of Small-Molecule CD4-Mimetic Compounds Contact the Highly Conserved Aspartic Acid 368 of HIV-1 Gp120 and Mediates ADCC. J. Virol. 2019, JVI.01325-19.

7. Veillette, M.; Coutu, M.; Richard, J.; Batraville, L.-A.; Désormeaux, A.; Roger, M.; Finzi, A. Conformational Evaluation of HIV-1 Trimeric Envelope Glycoproteins Using a Cell-Based ELISA Assay. J. Vis. Exp. 2014, 91, 51995.

8. Richard, J.; Veillette, M.; Brassard, N.; lyer, S. S.; Roger, M.; Martin, L.; Pazgier, M.; Schön, A.; Freire, E.; Routy, J.-P.; et al. CD4 Mimetics Sensitize HIV-1-Infected Cells to ADCC. Proc. Natl. Acad. Sci. U. S. A. 2015, 112 (20), e2687-94.

9. Richard, J.; Prevost, J.; Baxter, A. E.; Ding, S.; Medjahed, H.; Delgado, G. G.; Brassard, N.; Kaufmann, D. E.; Finzi, A.; Richard, J.; et al. Uninfected Bystander Cells Impact the Measurement of HIV-Specific Antibody-Dependent Cellular Cytotoxicity Responses. MBio. 2018, 9 (2), e00358.

10. Richard, J.; Pacheco, B.; Gohain, N.; Veillette, M.; Ding, S.; Alsahafi, N.; Tolbert, W. D.; Prévost, J.; Chapleau, J.-P.; Coutu, M.; et al. Co-Receptor Binding Site Antibodies Enable CD4-Mimetics to Expose Conserved Anti-Cluster A ADCC Epitopes on HIV-1 Envelope Glycoproteins. EBioMedicine 2016, 12, 208-218.

11. Chen, L.; Wilder, P. T.; Drennen, B.; Tran, J.; Roth, B. M.; Chesko, K.; Shapiro, P.; Fletcher, S. Structure-Based Design of 3-Carboxy-Substituted 1,2,3,4-Tetrahydroquinolines as Inhibitors of Myeloid Cell Leukemia-1 (Mcl-1). Org. Biomol. Chem. 2016, 14 (24), 5505-5510.

12. Imaeda, Y.; Tokuhara, H.; Fukase, Y.; Kanagawa, R.; Kajimoto, Y.; Kusumoto, K.; Kondo, M.; Snell, G.; Behnke, C. A.; Kuroita, T. Discovery of TAK-272: A Novel, Potent, and Orally Active Renin Inhibitor. ACS Med. Chem. Lett. 2016, 7 (10), 933-938.

13. Tokuhara, H.; Imaeda, Y.; Fukase, Y.; Iwanaga, K.; Taya, N.; Watanabe, K.; Kanagawa, R.; Matsuda, K.; Kajimoto, Y.; Kusumoto, K.; Kondo, M.; Snell, G.; Behnke, C. A.; Kuroita, T. Discovery of Benzimidazole Derivatives as Orally Active Renin Inhibitors: Optimization of 3,5-Disubstituted Piperidine to Improve Pharmacokinetic Profile. Bioorg. Med. Chem. 2018, 26 (12), 3261-3286. 